\title{
Effect of flavonoids on fetal programming : implications for cancer susceptibility
}

Citation for published version (APA):

Vanhees, K. (2012). Effect of flavonoids on fetal programming : implications for cancer susceptibility.

[Doctoral Thesis, Maastricht University]. Maastricht University. https://doi.org/10.26481/dis.20120613kv

Document status and date:

Published: 01/01/2012

DOI:

$10.26481 /$ dis.20120613kv

Document Version:

Publisher's PDF, also known as Version of record

\section{Please check the document version of this publication:}

- A submitted manuscript is the version of the article upon submission and before peer-review. There can be important differences between the submitted version and the official published version of record.

People interested in the research are advised to contact the author for the final version of the publication, or visit the DOI to the publisher's website.

- The final author version and the galley proof are versions of the publication after peer review.

- The final published version features the final layout of the paper including the volume, issue and page numbers.

Link to publication

\footnotetext{
General rights rights.

- You may freely distribute the URL identifying the publication in the public portal. please follow below link for the End User Agreement:

www.umlib.nl/taverne-license

Take down policy

If you believe that this document breaches copyright please contact us at:

repository@maastrichtuniversity.nl

providing details and we will investigate your claim.
}

Copyright and moral rights for the publications made accessible in the public portal are retained by the authors and/or other copyright owners and it is a condition of accessing publications that users recognise and abide by the legal requirements associated with these

- Users may download and print one copy of any publication from the public portal for the purpose of private study or research.

- You may not further distribute the material or use it for any profit-making activity or commercial gain

If the publication is distributed under the terms of Article $25 \mathrm{fa}$ of the Dutch Copyright Act, indicated by the "Taverne" license above, 
Effect of Flavonoids on Fetal Programming

Implications for Cancer Susceptibility

Kimberly Vanhees 


\section{Contents}

Chapter 1 General introduction

Chapter 2 Prenatal exposure to flavonoids: implication for cancer risk

Chapter 3 Epigenetics: Prenatal exposure to genistein leaves a permanent signature on the hematopoietic lineage

Chapter $4 \quad$ Intrauterine exposure to flavonoids modifies antioxidant status 67 at adulthood and protects against oxidative stress induced DNA damage

Chapter 5 Maternal quercetin intake during pregnancy results in an adapted iron homeostasis at adulthood

Chapter 6 Maternal intake of quercetin during gestation alters ex vivo benzo[a]pyrene metabolism and DNA-adduct formation in adult offspring

Chapter 7 Summary and General discussion 


\section{Chapter 1}

General introduction 


\section{Environmental and dietary exposures alter disease risk}

Adult chronic illnesses, such as cancer, cardiovascular diseases and respiratory diseases account for the majority of deaths worldwide (1). Since the complete sequencing of the human genome, genes involved in disease susceptibility have been and will be distinguished, resulting in the improvement of predicting an individual's risk on disease (2). Cancer affects millions of people worldwide and represents a major burden of disease. However, only 5-10\% of all cancers are caused by genetic defects, while $90-95 \%$ is caused by environmental factors of which the diet is the most important one (30-35 \%) (3).

Throughout their life humans are constantly exposed to drugs and other foreign compounds. To prevent that these substances cause any damage, they are neutralized and excreted. Environmental genotoxicants and mutagens cause about $80 \%$ of human malignancies (4). One important group of environmental contaminants are the polycyclic aromatic hydrocarbons (PAHs), which we are exposed to through inhalation of smoke from coal, wood, diesel fuel and tobacco; but also through ingestion of roasted, smoked or charbroiled foods. PAH can be metabolically activated to derivates that can damage our DNA, which is an important initiating event in carcinogenesis.

Another important source of DNA damaging compounds are the so-called reactive oxygen species (ROS). Enhanced exposure to ROS is linked to the onset and propagation of different diseases, for instance neurodegenerative diseases (5-9), cardiovascular diseases $(10,11)$, diabetes (12) and cancer (13-15), but are also believed to contribute to aging (16). They are regularly produced by mitochondria as a consequence of the aerobic metabolism. For instance $1-5 \%$ of total oxygen consumed in aerobic metabolism gives rise to superoxide anion radicals $\left(\mathrm{O}_{2}^{-*}\right)(17,18)$. However, ROS are also formed by microsomal CYP450, flavoprotein oxidase and peroxisomal enzymes involved in fatty acid metabolism. Besides, they play a crucial role as signal transducers to regulate cell proliferation and they are also involved in the destruction of invading pathogens (18). The negative outcomes of ROS are thought to be the result of an imbalance between the amount of antioxidants and ROS, termed oxidative stress (17).

\section{How can we protect ourselves against environmental exposure? Role of flavonoid supplementation}

It is well known that a healthy diet contributes to our protection against chronic diseases. One major dietary group of components that receives a lot of attention in the scientific literature, because of their potential protective effects, are the flavonoids. Dietary flavonoids comprise a large group of polyphenolic compounds widely distributed throughout the diet as they play a role in plant's pigmentation and flavor (19). They have a common structure consisting of 3 phenolic rings defined as the $A, B$ and $C$ ring (Figure $1 A$ ). Depending on the oxidation level of the $C$ ring flavonoids can be divided into 6 subclasses, namely flavones (apegenin, luteolin), flavonols (quercetin, kaempferol), flavanones (naringenin, hesperedin), flavanols (epicatechin, gallocatechin), anthocyanidins (malvidin, 
cyanidin) and isoflavones (genistein, daidzein) (19-21). The daily dietary intake of mixed flavonoids in the human population ranges from 65 to $250 \mathrm{mg}$ a day (22).

The most predominant flavonoid in the human diet is the flavonol quercetin (Figure 1B), which is mainly found in onions, apples, tea and red wine $(19,20)$. The average daily dietary intake of quercetin is estimated to be in the range of $10-100 \mathrm{mg}(23)$. This polyphenolic compound is a potent free radical scavenger and iron chelator $(24,25)$.

Another important flavonoid is the isoflavone genistein (Figure 1C), which is mainly found in soybeans. Genistein is also known to be a phytoestrogen due to its structural similarities to $17 \beta$-estradiol and can therefore mimic or antagonize estrogen $(26,27)$. Due to the low soy-containing food consumption in Western countries the daily intake of isoflavones is in the range of several milligrams a day. However, isoflavone intake can increase dramatically when consuming soymilk, for instance by people allergic to cow milk, as soy milk contains between 30 and $175 \mathrm{mg} / \mathrm{L}$ isoflavones. In Asian countries the daily intake of isoflavones is much higher due to the high consumption of soy and reaches levels of 25-40 $\mathrm{mg}$ a day (28). Moreover, the level of isoflavones, mainly genistein, found in soy-based infant formula lies even above the levels found in Asian adults (29).

A

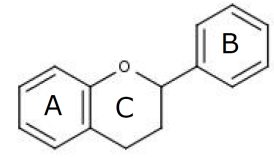

B

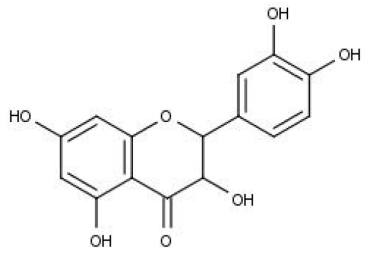

C<smiles>O=C1c2c(O)cc(O)cc2OCC1c1ccc(O)cc1</smiles>

Figure 1. A. Basic flavonoid structure, B. Structure of quercetin, C. Structure of genistein.

In addition, as quercetin and genistein both are flavonoids, they possess besides the above mentioned properties very potent antioxidant capacities. Up till now, this is the best studied property of flavonoids to which several health benefits, like anti-inflammatory (30, $31)$, protection against cardiovascular diseases $(32,33)$, protection against neurodegenerative diseases $(34,35)$, protection against COPD (progression) $(36,37)$, and protection against ocular disease $(38,39)$ are attributed. This is also the main reason why flavonoids are gaining interest as treatment and prevention of adult diseases (19, 40-42). Flavonoids are therefore freely available as high dose supplements, with a daily recommended dose that can be as high as $1-2$ gram per day $(43,44)$.

Moreover, studies concerning the use of dietary supplements during pregnancy are limited, it has been reported for the US that $78 \%$ of the pregnant woman take supplements during pregnancy (45). Although it is know that flavonoids transfer across the placenta to accumulate in the fetus $(46,47)$, there is yet little known about their actions in pregnancy and the effects on the offspring.

\section{Flavonoids during pregnancy: Infant leukemia}

Besides the assumed health benefits, it is suggested that flavonoids can be detrimental when exposed to in utero, as they are thought to be involved in the onset of infant 
leukemia $(48,49)$. Infant leukemia is characterized by an increased white blood cell count within the first twelve months after birth. It is the second most common malignancy within the first year of life $(50,51)$. Infant leukemia is thought to be the result of chromosomal translocations, creating fusion genes; deletions of chromosomal segments or of individual genes; duplication of segments or whole chromosomes $(50,52)$. The chromosomal translocations seen in infant leukemia are thought to be the result of the inhibition of topoisomersase II (topoll), for which fetal cells are more sensitive to as they are rapidly proliferating cells and have high topoll activity (53). This nuclear enzyme is normally involved in the relaxation of supercoiled DNA during replication and transcription. It binds to doublestranded DNA, cuts one of both helical chains, creating a transient double-strand break (DSB) through which the other helical chain passes after which the DNA strand is religated. This decreases the winding of the DNA, making it more available for replication or transcription. However, topoll-inhibitors can inhibit the religation, increasing the risk on translocations (Figure 2) $(52,54)$.

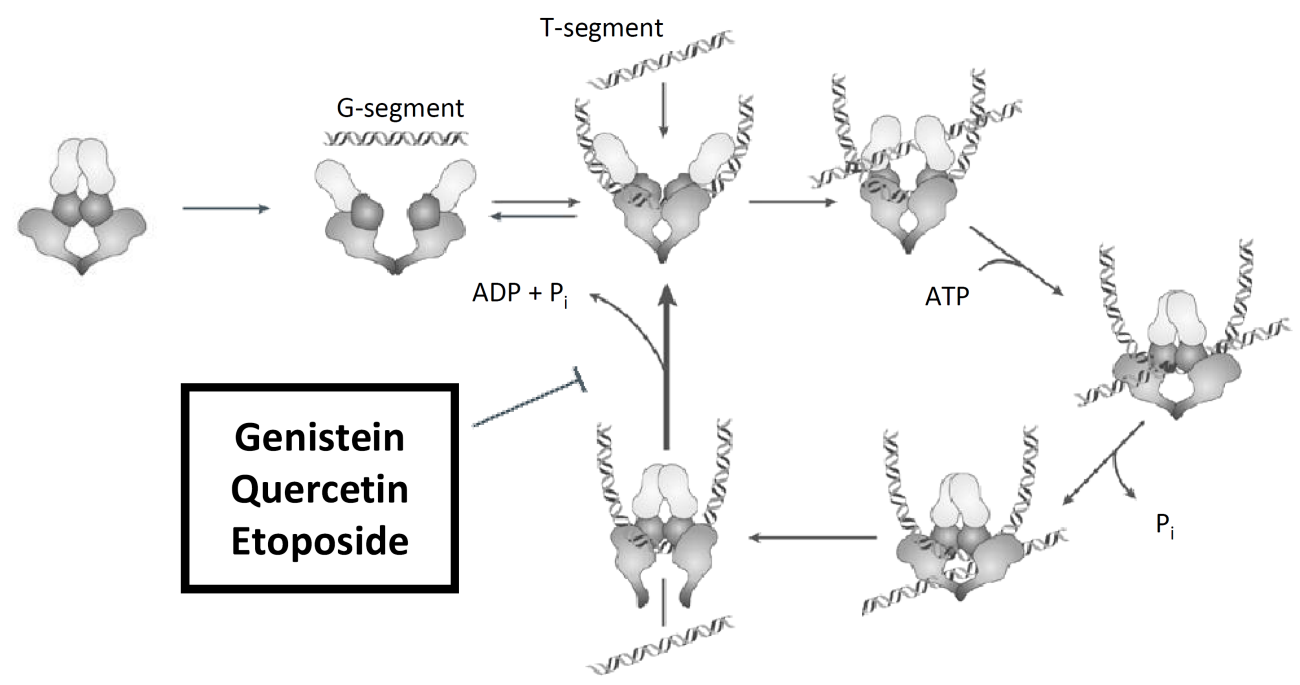

Figure 2. DNA helix relaxation by topoisomerase II.

Topoll relaxes the DNA helix by binding to topoll binding sites on both DNA chains. Next, it generates a transient DSB in one of the helical chains through which the other chain passes, followed by the resealing of the break. Topoll-inhibitors, like genistein, quercetin and etoposide inhibit the resealing of the DNA, increasing the risk on translocations. (The figure was adapted from Nitiss (55))

The most common genetic aberration associated with infant leukemia is a rearrangement in the mixed-lineage leukemia gene (MLL) found in up to $80 \%$ of the children suffering from acute lymphoblastic leukemia (AШ; concerning abnormal expansion of T- or B-cells) and up to $50 \%$ of children with myeloid leukemia (AM L; concerning all other white blood cell types). This gene is involved in normal hematopoiesis and is located at chromosome 11q23. Largely all MLL translocations are located at a $8.3 \mathrm{~kb}$ breakpoint cluster region (BCR) which covers exon 5 to 11 of the gene. However, no specific translocation partners are identified. In addition, MLL rearrangements are also found in $25 \%$ of patients suffering from secondary leukemia resulting from chemotherapy with DNA topoll-inhibitors (e.g. etoposide) (52). Strikingly, it has been 
suggested that several dietary compounds, for instance flavonoids $(48,49,56)$ but also caffeine (57) can inhibit the action of topoll. Still, the complex nature of human diets makes it impossible to elucidate the exact contribution of these dietary compounds to the onset of infant leukemia. It is generally accepted that childhood leukemia originates in utero as leukemia is present in newborns. Moreover, monozygotic twins suffering from leukemia have identical rearrangements of the $M L L$ gene $(49,58)$.

Normally DSB are recognized by the ataxia-telangiectasia mutated (ATM) protein. This protein will activate checkpoints to slow down the cell cycling of cells carrying DNA damage and recruit proteins to repair the damage or if the DNA damage is too severe lead to apoptosis. M utations in this gene result in the disease ataxia-telangiectasia (A-T). Patients suffering from this autosomal recessive disorder have an increased risk on developing cancer. One third of the A-T patients develop cancer of which the majority being lympoid malignancies (e.g. leukemia) (59). About $0.5-1 \%$ of the human population carries at least one mutated ATM gene $(59,60)$.

Different studies suggest that mutations in ATM could play a role in the development of leukemia $(61-63)$. Lavin et al. $(64,65)$ developed a murine model of A-T carrying a common mutation seen in humans with A-T, namely the 7636 del9 deletion. These Atm- $\Delta$ SRI mice have an in-frame deletion of 9 nucleotides, resulting in a non functional Atm protein, lacking its kinase activity. Heterozygous Atm- $\Delta$ SRI mice have a mean age of tumor onset of 18.6 months, while only $30 \%$ of homozygous Atm- $\Delta$ SRI mutant mice are still alive at 16 months of age. Heterozygous and homozygous Atm- $\Delta$ SRI mice suffer from different tumors of which one third is represented by leukemias and lymphomas.

\section{Flavonoids during pregnancy: Fetal programming}

Since the late 1980s the idea that maternal nutrition during pregnancy associates with an increased risk on degenerative diseases later in life gained interest $(66,67)$. A large number of studies on fetal over- or under-nutrition have been performed to investigate the adverse effects at adult age $(66,68-70)$. A clear example is given by the Dutch famine, which occurred during the winter of 1944-1945. Here, reduced nutrient supply during the first trimester of pregnancy resulted in a higher prevalence of obesity and cardiac heart diseases in the adult male progeny $(71,72)$. This study produced evidence for the 'thrifty genotype' also known as the 'Barker Hypothesis', defining the concept of fetal programming, namely an attempt of the fetus to adapt to adverse conditions encountered in utero resulting in adaptations that will be detrimental when these conditions will not prevail later in life (73). A general overview of the concept of fetal programming is given in Figure 3.

Over the years, it turned out that also other diseases at adulthood are linked to in utero malnutrition. For instance, maternal low caloric diets are also thought to increase the risk on diabetes type 2 in offspring at adult age (74-77). These studies on the concept of fetal programming showed that fetal nutritional deprivation (maternal caloric or macronutrient deficiency during pregnancy) is a strong programming stimulus $(66,68,70)$. However, in many Western societies, maternal nutrition is sufficient or even excessive. For instance, maternal high saturated fat diet resulted in insulin resistance, obesity and hypertension in offspring at adult age (78), which indicates that developmental problems may not only be a consequence 
of under-nutrition, but can also be achieved by an unbalanced diet during pregnancy. Thus, maternal over-nutrition can be deleterious to the health of the offspring and results in a phenotype of the offspring that is linked to increased health risks in adulthood.

The use of dietary supplements has tremendously increased over the past decades, and sometimes the manufacturer advices the intake of excessive amounts. Also for flavonoid supplements the recommended intake is high, because up till now no human data on longterm effects of high-dose flavonoid supplementation are available (21). As much as $78 \%$ of woman use natural health products during pregnancy as these micronutrients are essential for a good pregnancy outcome (45), which includes the intake of folate. However, the ideal diet composition for pregnant woman has still to be found, especially in relation to dietary supplements. Although the intake may not be directly toxic to the developing child, the fetal programming hypothesis predicts that physiological alterations may occur that persist into adulthood. To fully understand the safety of supplements during pregnancy, such effects should be taken into account, and more research is needed in understanding the phenomenon of 'fetal programming'.

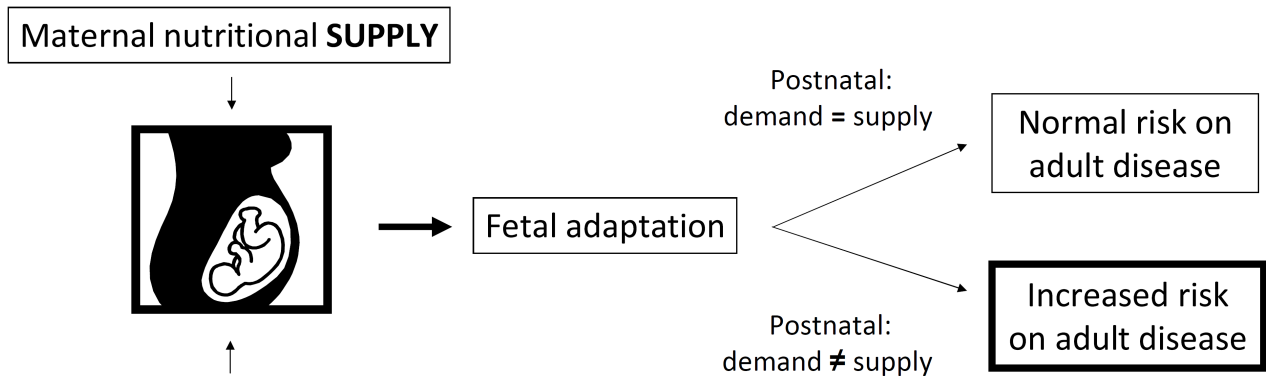

Fetal nutritional DEMAND

Figure 3. Overview of the concept of fetal programming.

During pregnancy the fetus will adapt according to its nutritional demand and its mother's nutritional supply, making the fetus programmed to the in utero nutritional status as it is thought to reflect the nutritional situation it will encounter once born. Indeed, when the postnatal nutritional demand corresponds to the nutritional supply, the adaptations made by the fetus in utero will result in a normal development and disease susceptibility. However, if the postnatal nutritional demand does not correspond to the nutritional supply, the risk on adult diseases increases.

\section{Epigenetics: a tool for fetal programming}

The first theory comprising the responsiveness of the genome to the environment and its modifying capacity was proposed by Jean-Baptiste Lamarck, in the early 19th century (79). However, his ideas were neglected due to lack of evidence and aberrant conceptualization (79, 80). Conrad Waddington was the first to follow in Lamarck's steps, in the first half of the 20th century. He introduced the word 'epigenetics', which stands for 'epi' meaning 'upon' or 'over' and 'genetics' implying the involvement of genes, to define the study of events over or beyond genes. The term 'epigenetics' was derived from the Aristotelian word 'epigenesis' implying that developmental changes are gradual and qualitative, but that there is a link to heredity (81). 
As the phenomena of epigenetic manifestations are gaining increasing appreciation, researchers grow eager, focusing their studies on understanding the control of gene expression and its connection with the underlying processes of human development of diseases. Moreover, they seek the origin of disease in the epigenetic regulation within the placenta (82, 83). Evidently studies regarding the epigenetic alterations within the placenta have provided crucial insights into the fetal origins of the susceptibility to specific diseases later in life. Such epigenetic mechanisms include changes in promoter DNA methylation resulting in hypo- or hyper-methylation of DNA CPG regions; modifications of histone proteins; chromatin conformation as well as micro- and non-coding RNA-mediated control of gene expression within the placenta (82-85). However, considering this thesis, only the epigenetic regulation via DNA methylation will be further elaborated.

DNA methylation can be described as the incorporation of a methyl $\left(\mathrm{CH}_{3}\right)$ group, obtained from the S-adenylmethionine that serves the purpose of a methyl donor, on a cytosine ring located in CG dinucelotides forming methyl-cytosine, which is catalyzed by DNA methyltransferases (DNM Ts) (86). The maintenance and incorporation of these methyl groups is carried out by specific DNMTs, namely DNMT3A, DNMT3B and DNMT1 $(82,86)$. The finding that this DNA modification occurs predominantly on cytosines that come before guanosine in the sequence and that this occurs mostly in non-coding DNA indicates its importance in global genomic maintenance. Methylation of so-called CpG islands in DNA generally leads to silencing of transcription. CpG islands are mainly located in gene promoter regions, which are mostly unmethylated in order to allow normal gene expression. Therefore, aberrant methylation patterns may be detrimental for the well being and can lead to the development or progression of human diseases.

During fetal development, epigenetic alterations are crucially involved in the orchestration of gene expression; the epigenome cycles through several precisely timed methylation changes to ensure proper development (87). Shortly after fertilization the paternal genome is actively demethylated, while the maternal genome is passively demethylated. Some epigenetic marks are maintained to allow proper expression of imprinted genes (parent-of-origin methylation marks) (87) (about 100 identified in mammals) (88). Subsequently, a new pattern of DNA methylation, which is also referred to as de novo methylation, is established predominantly at the blastocyst stage $(82,83,89)$. This de novo methylation can be considered as a reprogramming of the DNA methylation patterns in the zygote, which are normally retained throughout the organism's life, and are crucial for somatic cell viability $(82,83,89)$. The appropriate succession of the resetting and reprogramming phase of methylation is fundamental to post-gestational health and survival. This signifies an important sensitive window within the development of an embryo, where the environment can have profound effects on the expression pattern of certain genes throughout life $(83,90)$. A clear example of fetal programming by diet induced changes in methylation is given by Dolinoy et al. (91). They showed that heterozygous agouti mice exposed to the flavonoid genistein via the maternal diet, at levels comparable with humans consuming a high-soy diet, resulted in an altered coat color, namely towards pseudo-agouti. These mice were also protected against obesity later in life, which is associated with the agouti phenotype. These changes were caused by hypermethylation of transposable repetitive elements, namely intracisternal A particles (IAP), upstream of the transcription start site of the Agouti gene which remained unaltered throughout life. 


\section{Aims and outlines of this thesis}

Many studies on human diseases, including many types of cancers, suggest that the in utero period plays a role in the occurrence of adult diseases (92-94). Therefore, in this thesis we aimed to provide more insight in how dietary flavonoids could alter cancer susceptibility of the individual through direct effects on genomic stability (Chapter 2) and via fetal programming (Chapter 3-6).

\section{Effects on genetic stability and formation of translocations}

In Chapter $\mathbf{2}$ the effect of in utero exposure to the flavonoids genistein and quercetin on the onset of MII translocations, is assessed using a mouse model with an impaired DNA repair for double-strand breaks. As translocations in MLL may not directly result in the onset of infant leukemia, they do increase the risk on developing leukemia later in life (Figure 4).

\section{Maternal nutritional SUPPLY}

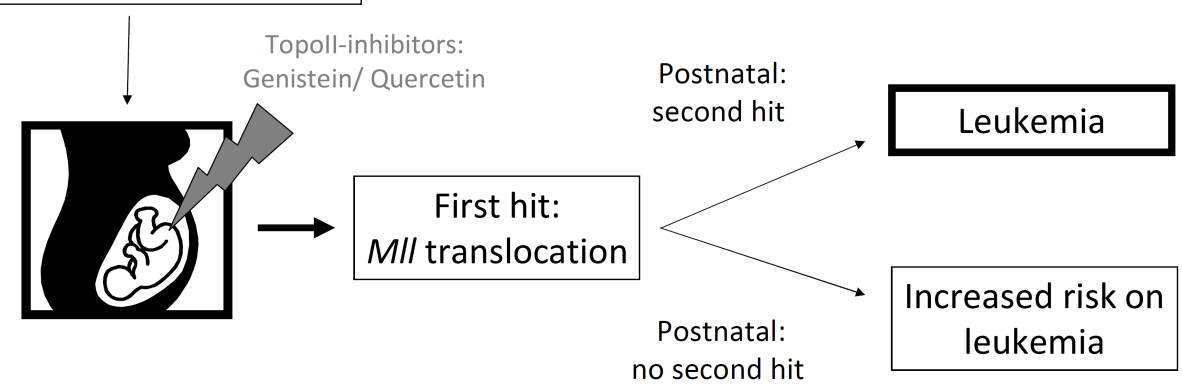

Figure 4. Assumed outcome of increased maternal intake of topoll-inhibitors during pregnancy on infant leukemia. Via the maternal diet the fetus will be exposed to increased levels of the topoll-inhibitors genistein or quercetin. This could result in M II translocation ('first hit') as fetal cells are rapidly dividing cells and therefore more sensitive towards topoll inhibitors. Throughout life, the offspring has an increased risk on developing leukemia. Whether or not the offspring will develop leukemia depends on following events ('second hit' or more) it will encounter throughout life.

Health effects later in life by persistent changes; examples studied in this thesis

\section{Persistent changes in gene expression}

It has been shown that prenatal exposure to genistein results in long-lasting alterations in gene expression of agouti mice. Therefore the long-lasting effects of prenatal exposure to genistein on bone marrow cell gene expression, concerning genes involved in hematopoiesis and estrogen responsive genes (as genistein is a know phytoestrogen) are investigated as described in Chapter 3. 


\section{Oxidative stress related processes}

Flavonoids are mostly known for their protective antioxidant effects in adults. However, there is no unambiguous hypothesis as some studies show that flavonoids act as antioxidants, while other studies attribute a pro-oxidant function to these compounds at high concentrations (95-97). Breinholt et al. (98) showed that female rats exposed to genistein or quercetin via the diet had reduced enzymatic antioxidant capacity of red blood cells. They hypothesized that the antioxidant enzymes in red blood cells were downregulated by the flavonoids in response to an improved antioxidant status of the red blood cells due to the presence of flavonoids. Furthermore, it has been demonstrated that quercetin up-regulates the gene expression of NQO1 and GSTP1, as well as the gene expression of Nrf2 in Caco-2 cells (99). This can be considered as a pro-oxidant effect, because when oxidative stress occurs, nuclear factor erythroid 2-related factor (Nrf2) pathway is activated to overcome this stress. Nrf2, a cytosolic protein, is associated with its chaperon Kelch-like ECH-associated protein (Keap1) via protein-protein interactions resulting in its proteasomal degradation. However, in the presence of oxidative stress, Keap1-Nrf2 interactions are disrupted and Nrf2 translocates into the nucleus were it binds to antioxidant response elements (ARE), resulting in the transcription of phase II enzymes, including NQO, GST and UGT (100). Other important antioxidant enzymes are superoxide dismutase (SOD) which scavenges $\mathrm{O}_{2}^{-}$and catalase and glutathione peroxidase (GPX) which scavenges hydrogen peroxide $\left(\mathrm{H}_{2} \mathrm{O}_{2}\right)$. The body's innate antioxidant capacity can be augmented by antioxidants delivered through the diet, for instance vitamin $C$ and $E, \beta$ carotene, but also for these dietary antioxidants it is known that they may promote oxidative stress under certain conditions (101), leading to damage to proteins and membranes $(18,102)$. Damage to membranes caused by free radicals (lipid peroxidation) results in the generation of malondialdehyde that can react with DNA resulting in the formation of $\mathrm{M}_{1} \mathrm{dG}$-adducts. However, $\mathrm{M}_{1} \mathrm{dG}$-adducts can also be generated by hydroxyl radicals, independently from lipid peroxidation by the removal of deoxyribose 4'-hydrogen in DNA, generating a base propenal. $M_{1} d G$-adducts are normally repaired via the nucleotide excision repair pathway, but malfunctioning of this pathway can result in mutations and eventually cancer (103). Oxidized proteins can be repaired by ascorbate or glutathione (GSH). If not, for instance if the levels of ascorbate and GSH are depleted, then these proteins are recycled by proteases. When irreversibly modified proteins cannot be processed by proteases and accumulate in the cell, making it impossible for the cell to properly function resulting in its death (102). ROS can also directly oxidize DNA resulting in the formation of 8-0xo-7,8-dihydro-2'deoxyguanosine (8-0xo-dG) (103).

As CYP450 activity also results in the formation of $\operatorname{ROS}(18,103)$, a link between the aryl hydrocarbon receptor (AhR) and Nrf2-pathway is suggested $(104,105)$. This has been confirmed by the finding of a xenobiotic binding site of AhR in the regulatory region of the Nrf2 gene (106). For this interaction, see section 'Quercetin as AhR agonist modifies xenobiotic metabolism' below.

Therefore, the effect of prenatal exposure to quercetin, but also to genistein on the antioxidant capacity at adult age is investigated to elucidate whether a pre-emptive trigger of the antioxidant system during fetal development will result in adaptations at adulthood (Chapter 4). 


\section{Iron chelating properties of quercetin as programming trigger}

In addition, as quercetin is a powerful iron chelator, the effects of prenatal exposure to quercetin on iron homeostasis and eryhtropoiesis was determined at adulthood but also during the fetal development, as iron is an essential micronutrient for a normal development (Chapter 5). Iron plays an essential role in the generation of ROS. Its redox cycling promotes the formation of the potent oxidating hydroxyl radical (Fenton reaction: $\mathrm{Fe}^{2+}+\mathrm{H}_{2} \mathrm{O}_{2} \rightarrow \mathrm{Fe}^{3+}+\mathrm{OH}^{\circ}+\mathrm{OH}^{-}$) (107). However, iron is also an essential micronutrient that besides the oxidative metabolism is also required for erythropoiesis and optimal functioning of immune responses. About 1-2 $\mathrm{mg}$ of iron is daily absorbed from the diet and this absorption is tightly regulated due to the fact that the body has no effective means of excreting iron. Once iron is released into the circulation it binds to transferrin and is transported to sites of use or to be stored. About $65 \%$ of the body's iron is used for the production of hemoglobin $(108,109)$. Hemoglobin consists out of a porphyrin ring containing an iron ion (heme part of hemoglobin) and 4 globin chains ( $2 \alpha$-globin and $2 \beta$ globin chains). The production of the globin chains is dependent on the availability of heme and because heme production is limited by iron supply it is the amount of available iron that limits the hemoglobin production (110).

Depending on the phase of life, different forms of hemoglobin are produced, namely embryonic hemoglobin and adult hemoglobin. In case of mice the first form of hemoglobin, that is the embryonic hemoglobin, consists out of embryonic globins, namely $\zeta$-globin, which is the embryonic form of $\alpha$-globin and $\beta \mathrm{H} 1$ - and $\varepsilon y$-globins the embryonic forms of the $\beta$ globin $(111,112)$. This form of hemoglobin is produced solely by primitive erythrocytes, which are generated by the yolk sac and consist of large erythroblasts which are present in the bloodstream from embryonic day (E) 7.5 (111-113). Adult hemoglobin consists out of the adult $\alpha$ - and $\beta$-globins $(111,112)$ and is produced by erythrocytes from the definitive adult lineage, but also by the primitive erythrocytes, though the amount of adult globins expressed in the primitive erythrocytes is negligible $(111,112)$. At E11.5 erythrocytes from the definitive adult lineage appear in the bloodstream. These cells are first formed by the fetal liver and from birth onwards, primarily by the bone marrow (111-113). After E16.5 the definitive erythrocytes are the predominant cell type in the fetal circulation and ultimately become the exclusive erythrocyte lineage in the adult (111-113). One main difference between both lineages is the place they undergo terminal maturation. Primitive erythroblasts enucleate in the bloodstream, resulting in the formation of a reticulocyte and a pyrenocyte (this is the extruded nucleus). Definitive adult erythrocytes on the other hand mature and enucleate in the fetal liver and later on in life in the bone marrow after which the reticulocyte is released into the bloodstream $(111,112,114)$. During erythroid ontogeny in humans, a third form of hemoglobin is produced, namely the fetal hemoglobin, which appears between the embryonic and the adult hemoglobin (112).

For both humans and mice, the switch from embryonic to adult globins is thought to be triggered by difference in oxygen environment at the different stages of pregnancy. During early development, in the uterus, the embryo resides in a low oxygen environment. This hypoxic state is necessary for the early embryogenesis and organogenesis, because at this time point the embryo is the most vulnerable for oxidative stress, which could lead to damage or disruption of the embryo $(115,116)$. In mice, the utero-placental circulation is 
well established between E9.5 and E11. This leads to a higher concentration of oxygen and therefore to an increase in ROS, but it also leads to an enhancement of the antioxidant defense system (116). Because of the low oxygen supply during early development, cells from the primitive erythroid lineage are expressed. Since they consist of embryonic globins which have a high affinity to oxygen they can permanently remove oxygen from the adult globins expressed in the maternal erythrocytes through the placenta $(117,118)$. Later, when the oxygen supplies increases between E9.5 and E11 (116), the switch from primitive to definitive erythroid lineage takes place (111-113).

During pregnancy the maternal iron absorption raises to fulfill the increasing iron requirement of the fetus However, the increase in iron absorption by the mother during pregnancy is normally not sufficient and therefore maternal iron stores are implemented what could result in iron deficiency anemia $(119,120)$. Iron deficiency represents the most common nutritional deficit worldwide (121) and has serious consequences for both the mother and the unborn child as it increases the risk of maternal mortality and the risk on cardiovascular disease for the child later in life $(119,120)$.

Iron homeostasis is highly regulated in adults to prevent the generation of ROS. Therefore, iron that is not used is mainly stored in the liver, where it is bound to ferittin. For an optimal erythropoiesis, internal turnover of iron is needed. Senescent erythrocytes are cleared by macrophages in the liver but primarily in the spleen. The heme part of hemoglobin is metabolized by hemoxygenase-1 (HO1) and the released iron is then recycled for the subsequent hemoglobin production $(108,109)$. In iron overload diseases the liver is the main organ suffering from injury. In mice, dietary quercetin supplementation decreased the hepatic iron storage and increased the excretion of iron through the feces, thereby lowering the risk on ROS induced damage (122). Previous studies have shown that quercetin can penetrate the cytoplasm of erythrocytes to interact with the heme iron in hemoglobin. This results in the oxidation of heme iron from the ferrous $\left(\mathrm{Fe}^{2+}\right)$ to the ferric $\left(\mathrm{Fe}^{3+}\right)$ state and consequentially to the formation of methemoglobin, which is inactive and incapable of transporting oxygen. However, it also decreases the risk on ROS induced hemolysis $(24,25,107)$.

\section{Quercetin as AhR agonist modifies xenobiotic metabolism}

Quercetin is also a know aryl hydrocarbon receptor (AhR) ligand an could therefore protect against DNA damage induced by compounds that need metabolism via the expression of phase I and II enzymes, including polycyclic aromatic hydrocarbons (PAH). Therefore, the effect of prenatal exposure to quercetin on detoxifying enzymes is described in Chapter 6 . Throughout their life, humans are exposed to drugs, environmental contaminants and other foreign compounds. To prevent that these substances cause any damage, they are usually neutralized by xenobiotic metabolism and excreted. Environmental genotoxicants and mutagens cause about $80 \%$ of human malignancies (4). PAHs are widespread environmental contaminants to which we are exposed to through inhalation of smoke from coal, wood, diesel fuel and tobacco; but also through ingestion of roasted, smoked or charbroiled foods. Benzo[a]pyrene (B[a]P) is the best studied PAH and is found to be a mutagenic and carcinogenic environmental pollutant. B[a]P needs to be metabolically activated to become genotoxic. This is mainly performed by the heme-containing phase I enzymes, cytochrome P450 (CYP) $1 \mathrm{~A} 1$ and CYP1B1 $(4,123,124)$. The initial step in B[a]P metabolism is performed by 
these phase I enzymes and results in the formation of epoxides, which are in turn the substrate for epoxide hydrolase, resulting in the formation of diols. Next the phase I enzymes will convert the diols into diol epoxides (125). The formed diol epoxide of $B[a] P$, namely B[a]P-7,8dihydrodiol-9,10-epoxide (BPDE), is a reactive intermediate that can bind covalently to nucleic acids and proteins. In addition, B[a]P can also be converted into phenols and subsequently to quinones by phase I enzymes (125). However B[a]P can also be detoxified by phase I and especially by phase II enzymes (glutathione-S-transferases (GST), UDP-glucurosyltransferases (UGT) and sulfotransferases (SULT)), converting it into a water-soluble derivate facilitating its excretion (see Figure 5). Activation of these enzymes is regulated through the activation of AhR. This cytosolic protein is activated by $B[a] P$, whereupon it transfers into the nucleus. Here it dimerizes with AhR nuclear translocator (ARNT) after which it can bind to xenobiotic responsive elements to induce phase I and phase II enzymes (124).

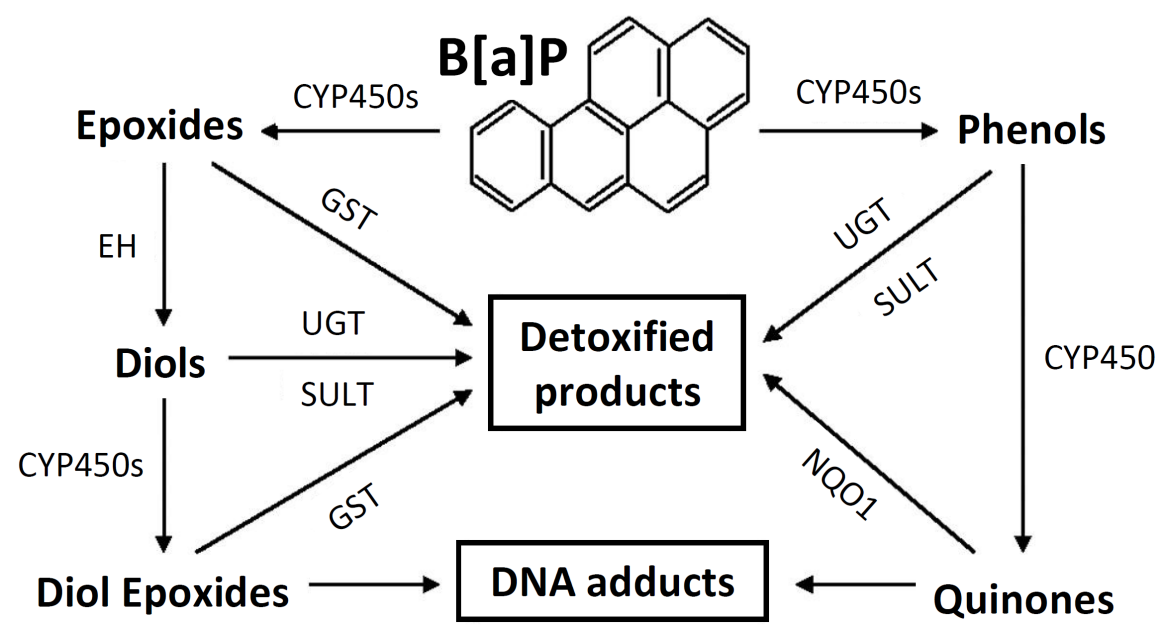

Figure 5. Simplified overview of B[a]P metabolism.

Simplified scheme of $\mathrm{B}[\mathrm{a}] \mathrm{P}$ metabolization, activation and detoxification performed by phase I (CYP450s) and phase II enzymes (EH: epoxide dehydrolase, GST: glutathione-S-transferases, UGT: UDP-glucurosyltransferases, SULT: sulfotransferase, and NQ01: NAD(P)H:quinine oxidereductase 1) (from Ambrosone et al. (126)).

Inter-individual variation in drug metabolism and associated cancer susceptibility can partly be explained by different expression and/ or activity of phase I and II enzymes induced by genetic polymorphisms in these genes (127-129), and therefore reduce or increase the exposure to harmful compounds. Other studies also suggest that there is a gender-dependent expression of phase I and II enzymes (130-133). This is thought to be the result of endocrine factors, namely estrogen, which is the female hormone and is also metabolized by CYPs. M etabolism of estrogen by CYPs can also result in reactive metabolites that can damage the DNA (134). Moreover, males and females have a differential susceptibility for B[a]P induced carcinogenicity as males seem to have more protection due to higher levels of GST isoenzymes compared to females (135). In addition, PAHs or their metabolites could have estrogenic effects, which could contribute to their carcinogenicity (136). Though, up till now epidemiological studies are inconsistent regarding the differences in carcinogen metabolism between genders $(137,138)$. 
Another important factor explaining inter-individual differences in xenobiotic metabolism are environmental factors, especially the diet $(139,140)$. It is estimated that the diet can reduce cancer death rates by $35 \%$ (139). For instance, flavonoids can bind and therefore activate AhR, resulting in an altered expression of phase I enzymes (100, 141, 142). Different studies have also shown that flavonoids can induce phase II gene expression preventing DNA damage $(100,143)$. M oreover, maternal quercetin intake leads to longterm alterations of CYP activity in female rat offspring (144). Besides altering phase I and phase II gene expression, quercetin also enhances the excretion of B[a]P metabolites from the body (145). When quercetin was co-incubated with $B[a] P$, it influenced the $B[a] P$ induced effects by increasing the B[a]P induced expression of CYP1A1 and 1A2. It also resulted in a diminishing $\mathrm{B}[\mathrm{a}] \mathrm{P}$ induced up-regulation of Nrf2 and some of its target genes and in an up-regulation of the AhR repressor, which was suppressed by B[a]P (99).

\section{Summary: overall aim of the thesis}

Taken together, Chapter $\mathbf{2}$ describes the possibility of in utero exposure to genistein and quercetin to affect genetic stability, namely by assessing the onset of MII translocations in a mouse model with an impaired DNA repair for double-strand breaks. Chapter 3 describes the long-lasting effects of prenatal exposure to genistein on hematopoiesis and on the expression of genes involved in hematopoiesis and estrogen responsive genes (as genistein is a know phytoestrogen). As genistein and quercetin both are potent antioxidants, the effect of prenatal exposure to both flavonoids on the antioxidant capacity at adult age is investigated in Chapter $\mathbf{4}$ by pre-emptive triggering of the antioxidant system during fetal development. Quercetin is, besides a potent antioxidant, also a powerful iron chelator. Therefore, the effect of prenatal exposure to quercetin on iron homeostasis and eryhtropoiesis was determined during fetal development and at adulthood as described in Chapter 5. Chapter 6 describes the effect of prenatal exposure to quercetin on detoxifying enzymes, as quercetin is also a know aryl hydrocarbon receptor (AhR) ligand and could therefore protect against $\mathrm{B}[\mathrm{a}] \mathrm{P}$ induced DNA damage, as $\mathrm{B}[\mathrm{a}] \mathrm{P}$ needs to be metabolized by AhR induced phase I and II enzymes. As in Chapter 3, 5 and $\mathbf{6}$ long-lasting changes in gene expression due to in utero exposure to genistein or quercetin are investigated, epigenetic mechanisms, namely the induction of changes in methylation status of repetitive elements, are also investigated in these chapters. Overall Chaptor 4-6 describes the effect of prenatal exposure to flavonoids on the overall risk of an individual to develop cancer. Finally, a summary and general discussion on the most important findings of all studies presented in this thesis and the future perspectives are given in Chapter $\mathbf{7 .}$ 


\section{References}

1. Darnton-Hill, I., Nishida, C., and James, W. P. (2004) A life course approach to diet, nutrition and the prevention of chronic diseases. Public Health Nutr 7, 101-121

2. Collins, F. S., and McKusick, V. A. (2001) Implications of the Human Genome Project for medical science. JAM A 285, 540-544

3. Sutandyo, N. (2010) Nutritional carcinogenesis. Acta Med Indones 42, 36-42

4. Khan, T. H., Jahangir, T., Prasad, L., and Sultana, S. (2006) Inhibitory effect of apigenin on benzo(a)pyrenemediated genotoxicity in Swiss albino mice. J Pharm Pharmacol 58, 1655-1660

5. Bolanos, J. P., Moro, M. A., Lizasoain, I., and Almeida, A. (2009) Mitochondria and reactive oxygen and nitrogen species in neurological disorders and stroke: Therapeutic implications. Adv Drug Deliv Rev 61, 1299-1315

6. Hensley, K., Butterfield, D. A., Hall, N., Cole, P., Subramaniam, R., Mark, R., Mattson, M. P., Markesbery, W. R., Harris, M. E., Aksenov, M., and et al. (1996) Reactive oxygen species as causal agents in the neurotoxicity of the Alzheimer's disease-associated amyloid beta peptide. Ann N Y Acad Sci 786, 120-134

7. Multhaup, G., Ruppert, T., Schlicksupp, A., Hesse, L., Beher, D., Masters, C. L., and Beyreuther, K. (1997) Reactive oxygen species and Alzheimer's disease. Biochem Pharmacol 54, 533-539

8. Tabner, B. J., Turnbull, S., El-Agnaf, O., and Allsop, D. (2001) Production of reactive oxygen species from aggregating proteins implicated in Alzheimer's disease, Parkinson's disease and other neurodegenerative diseases. Curr Top M ed Chem 1, 507-517

9. Tieu, K., Ischiropoulos, H., and Przedborski, S. (2003) Nitric oxide and reactive oxygen species in Parkinson's disease. IUBM B Life 55, 329-335

10. Touyz, R. M. (2004) Reactive oxygen species and angiotensin II signaling in vascular cells -- implications in cardiovascular disease. Braz J Med Biol Res 37, 1263-1273

11. Yoshizumi, M., Tsuchiya, K., and Tamaki, T. (2001) Signal transduction of reactive oxygen species and mitogen-activated protein kinases in cardiovascular disease. J M ed Invest 48, 11-24

12. Muhammad, S., Bierhaus, A., and Schwaninger, M. (2009) Reactive oxygen species in diabetes-induced vascular damage, stroke, and Alzheimer's disease. J Alzheimers Dis 16, 775-785

13. Lau, A. T., Wang, Y., and Chiu, J. F. (2008) Reactive oxygen species: current knowledge and applications in cancer research and therapeutic. J Cell Biochem 104, 657-667

14. Renschler, M. F. (2004) The emerging role of reactive oxygen species in cancer therapy. Eur J Cancer 40, 1934-1940

15. Weinberg, F., and Chandel, N. S. (2009) Reactive oxygen species-dependent signaling regulates cancer. Cell Mol Life Sci 66, 3663-3673

16. Dugan, L. L., and Quick, K. L. (2005) Reactive oxygen species and aging: evolving questions. Sci Aging Knowledge Environ 2005, pe20

17. Reuter, S., Gupta, S. C., Chaturvedi, M. M., and Aggarwal, B. B. (2010) Oxidative stress, inflammation, and cancer: how are they linked? Free Radic Biol Med 49, 1603-1616

18. Seifried, H. E., Anderson, D. E., Fisher, E. I., and Milner, J. A. (2007) A review of the interaction among dietary antioxidants and reactive oxygen species. J Nutr Biochem 18, 567-579

19. Ross, J. A., and Kasum, C. M. (2002) Dietary flavonoids: bioavailability, metabolic effects, and safety. Annu Rev Nutr 22, 19-34

20. Aherne, S. A., and O'Brien, N. M. (2002) Dietary flavonols: chemistry, food content, and metabolism. Nutrition 18, 75-81

21. Skibola, C. F., and Smith, M. T. (2000) Potential health impacts of excessive flavonoid intake. Free Radic Biol Med 29, 375-383

22. Erdman, J. W., Jr., Balentine, D., Arab, L., Beecher, G., Dwyer, J. T., Folts, J., Harnly, J., Hollman, P., Keen, C. L., M azza, G., M essina, M., Scalbert, A., Vita, J., Williamson, G., and Burrowes, J. (2007) Flavonoids and heart health: proceedings of the ILSI North America Flavonoids Workshop, May 31-June 1, 2005, Washington, DC.J Nutr 137, 718S-737S

23. Egert, S., and Rimbach, G. (2011) Which sources of flavonoids: complex diets or dietary supplements? Adv Nutr 2, 8-14

24. Ferrali, M., Signorini, C., Caciotti, B., Sugherini, L., Ciccoli, L., Giachetti, D., and Comporti, M. (1997) Protection against oxidative damage of erythrocyte membrane by the flavonoid quercetin and its relation to iron chelating activity. FEBS Lett 416, 123-129 
25. Kitagawa, S., Sakamoto, H., and Tano, H. (2004) Inhibitory effects of flavonoids on free radical-induced hemolysis and their oxidative effects on hemoglobin. Chem Pharm Bull (Tokyo) 52, 999-1001

26. Miodini, P., Fioravanti, L., Di Fronzo, G., and Cappelletti, V. (1999) The two phyto-oestrogens genistein and quercetin exert different effects on oestrogen receptor function. Br J Cancer 80, 1150-1155

27. Marik, R., Allu, M., Anchoori, R., Stearns, V., Umbricht, C. B., and Khan, S. (2011) Potent genistein derivatives as inhibitors of estrogen receptor alpha-positive breast cancer. Cancer Biol Ther 11, 883-892

28. Manach, C., Scalbert, A., M orand, C., Remesy, C., and Jimenez, L. (2004) Polyphenols: food sources and bioavailability. Am J Clin Nutr 79, 727-747

29. Setchell, K. D., Zimmer-Nechemias, L., Cai, J., and Heubi, J. E. (1998) Isoflavone content of infant formulas and the metabolic fate of these phytoestrogens in early life. Am J Clin Nutr 68, 1453S-1461S

30. Valsecchi, A. E., Franchi, S., Panerai, A. E., Rossi, A., Sacerdote, P., and Colleoni, M. (2011) The soy isoflavone genistein reverses oxidative and inflammatory state, neuropathic pain, neurotrophic and vasculature deficits in diabetes mouse model. Eur J Pharmacol 650, 694-702

31. Boots, A. W., Drent, M., de Boer, V. C., Bast, A., and Haenen, G. R. (2011) Quercetin reduces markers of oxidative stress and inflammation in sarcoidosis. Clin Nutr 30, 506-512

32. Mahn, K., Borras, C., Knock, G. A., Taylor, P., Khan, I. Y., Sugden, D., Poston, L., Ward, J. P., Sharpe, R. M ., Vina, J., Aaronson, P. I., and Mann, G. E. (2005) Dietary soy isoflavone induced increases in antioxidant and eNOS gene expression lead to improved endothelial function and reduced blood pressure in vivo. FASEB J 19, $1755-1757$

33. Loke, W. M., Proudfoot, J. M., Hodgson, J. M., M cKinley, A. J., Hime, N., Magat, M., Stocker, R., and Croft, K. D. (2010) Specific dietary polyphenols attenuate atherosclerosis in apolipoprotein E-knockout mice by alleviating inflammation and endothelial dysfunction. Arterioscler Thromb Vasc Biol 30, 749-757

34. Heo, H. J., and Lee, C. Y. (2004) Protective effects of quercetin and vitamin C against oxidative stressinduced neurodegeneration. J Agric Food Chem 52, 7514-7517

35. Mercer, L. D., Kelly, B. L., Horne, M. K., and Beart, P. M. (2005) Dietary polyphenols protect dopamine neurons from oxidative insults and apoptosis: investigations in primary rat mesencephalic cultures. Biochem Pharmacol 69, 339-345

36. Ganesan, S., Faris, A. N., Comstock, A. T., Chattoraj, S. S., Chattoraj, A., Burgess, J. R., Curtis, J. L., Martinez, F. J., Zick, S., Hershenson, M. B., and Sajjan, U. S. (2010) Quercetin prevents progression of disease in elastase/LPS-exposed mice by negatively regulating M M P expression. Respir Res 11, 131

37. Hirayama, F., Lee, A. H., Binns, C. W., Hiramatsu, N., M ori, M., and Nishimura, K. (2010) Dietary intake of isoflavones and polyunsaturated fatty acids associated with lung function, breathlessness and the prevalence of chronic obstructive pulmonary disease: possible protective effect of traditional Japanese diet. Mol Nutr Food Res 54, 909-917

38. Miyamoto, N., Izumi, H., Miyamoto, R., Kondo, H., Tawara, A., Sasaguri, Y., and Kohno, K. (2011) Quercetin induces the expression of peroxiredoxins 3 and 5 via the Nrf2/NRF1 transcription pathway. Invest Ophthalmol Vis Sci 52, 1055-1063

39. Cornish, K. M., Williamson, G., and Sanderson, J. (2002) Quercetin metabolism in the lens: role in inhibition of hydrogen peroxide induced cataract. Free Radic Biol M ed 33, 63-70

40. Arts, I. C., and Hollman, P. C. (2005) Polyphenols and disease risk in epidemiologic studies. Am J Clin Nutr 81, 317S-325S

41. Hollman, P. C., and Katan, M. B. (1999) Dietary flavonoids: intake, health effects and bioavailability. Food Chem Toxicol 37, 937-942

42. Yao, L. H., Jiang, Y. M., Shi, J., Tomas-Barberan, F. A., Datta, N., Singanusong, R., and Chen, S. S. (2004) Flavonoids in food and their health benefits. Plant Foods Hum Nutr 59, 113-122

43. Espin, J. C., Garcia-Conesa, M. T., and Tomas-Barberan, F. A. (2007) Nutraceuticals: facts and fiction. Phytochemistry 68, 2986-3008

44. Harwood, M., Danielewska-Nikiel, B., Borzelleca, J. F., Flamm, G. W., Williams, G. M., and Lines, T. C. (2007) A critical review of the data related to the safety of quercetin and lack of evidence of in vivo toxicity, including lack of genotoxic/ carcinogenic properties. Food Chem Toxicol 45, 2179-2205

45. Sullivan, K. M., Ford, E. S., Azrak, M. F., and Mokdad, A. H. (2009) Multivitamin use in pregnant and nonpregnant women: results from the Behavioral Risk Factor Surveillance System. Public Health Rep 124, 384-390

46. Schroder-van der Elst, J. P., van der Heide, D., Rokos, H., Morreale de Escobar, G., and Kohrle, J. (1998) Synthetic flavonoids cross the placenta in the rat and are found in fetal brain. Am J Physiol 274, E253-256 
47. Bonacasa, B., Siow, R. C., and Mann, G. E. (2011) Impact of dietary soy isoflavones in pregnancy on fetal programming of endothelial function in offspring. Microcirculation 18, 270-285

48. Barjesteh van Waalwijk van Doorn-Khosrovani, S., Janssen, J., Maas, L. M., Godschalk, R. W., Nijhuis, J. G., and van Schooten, F. J. (2007) Dietary flavonoids induce M LL translocations in primary human CD34+cells. Carcinogenesis 28, 1703-1709

49. Strick, R., Strissel, P. L., Borgers, S., Smith, S. L., and Rowley, J. D. (2000) Dietary bioflavonoids induce cleavage in the M LL gene and may contribute to infant leukemia. Proc Natl Acad Sci U SA 97, 4790-4795

50. Eden, T. (2010) Aetiology of childhood leukaemia. Cancer Treat Rev 36, 286-297

51. Emerenciano, M., Koifman, S., and Pombo-de-Oliveira, M. S. (2007) Acute leukemia in early childhood. Braz J Med Biol Res 40,749-760

52. Aplan, P. D. (2006) Chromosomal translocations involving the MLL gene: molecular mechanisms. DNA Repair (Amst) 5, 1265-1272

53. Zandvliet, D. W., Hanby, A. M., Austin, C. A., Marsh, K. L., Clark, I. B., Wright, N. A., and Poulsom, R. (1996) Analysis of foetal expression sites of human type II DNA topoisomerase alpha and beta mRNAs by in situ hybridisation. Biochim Biophys Acta 1307, 239-247

54. Gilliland, D. G., Jordan, C. T., and Felix, C. A. (2004) The molecular basis of leukemia. Hematology Am Soc Hematol Educ Program, 80-97

55. Nitiss, J. L. (2009) Targeting DNA topoisomerase II in cancer chemotherapy. Nat Rev Cancer 9, 338-350

56. Spector, L. G., Xie, Y., Robison, L. L., Heerema, N. A., Hilden, J. M., Lange, B., Felix, C. A., Davies, S. M., Slavin, J., Potter, J. D., Blair, C. K., Reaman, G. H., and Ross, J. A. (2005) Maternal diet and infant leukemia: the DNA topoisomerase II inhibitor hypothesis: a report from the children's oncology group. Cancer Epidemiol Biomarkers Prev 14, 651-655

57. Ross, J. A. (2000) Dietary flavonoids and the M LL gene: A pathway to infant leukemia? Proc Natl Acad Sci U S A $97,4411-4413$

58. Greaves, M. (2005) In utero origins of childhood leukaemia. Early Hum Dev 81, 123-129

59. Khanna, K. K. (2000) Cancer risk and the ATM gene: a continuing debate. J Natl Cancer Inst 92, 795-802

60. Barlow, C., Hirotsune, S., Paylor, R., Liyanage, M., Eckhaus, M., Collins, F., Shiloh, Y., Crawley, J. N., Ried, T., Tagle, D., and Wynshaw-Boris, A. (1996) Atm-deficient mice: a paradigm of ataxia telangiectasia. Cell 86, $159-171$

61. Meier, M., den Boer, M. L., Hall, A. G., Irving, J. A., Passier, M., Minto, L., van Wering, E. R., Janka-Schaub, G. E., and Pieters, R. (2005) Relation between genetic variants of the ataxia telangiectasia-mutated (ATM) gene, drug resistance, clinical outcome and predisposition to childhood T-lineage acute lymphoblastic leukaemia. Leukemia 19, 1887-1895

62. Oguchi, K., Takagi, M., Tsuchida, R., Taya, Y., Ito, E., Isoyama, K., Ishii, E., Zannini, L., Delia, D., and Mizutani, S. (2003) Missense mutation and defective function of ATM in a childhood acute leukemia patient with MLL gene rearrangement. Blood 101, 3622-3627

63. Gumy Pause, F., Wacker, P., Maillet, P., Betts, D., and Sappino, A. P. (2003) ATM gene alterations in childhood acute lymphoblastic leukemias. Hum M utat 21, 554

64. Spring, K., Ahangari, F., Scott, S. P., Waring, P., Purdie, D. M., Chen, P. C., Hourigan, K., Ramsay, J., McKinnon, P. J., Swift, M., and Lavin, M. F. (2002) Mice heterozygous for mutation in Atm, the gene involved in ataxia-telangiectasia, have heightened susceptibility to cancer. Nat Genet 32, 185-190

65. Spring, K., Cross, S., Li, C., Watters, D., Ben-Senior, L., Waring, P., Ahangari, F., Lu, S. L., Chen, P., Misko, I., Paterson, C., Kay, G., Smorodinsky, N. I., Shiloh, Y., and Lavin, M. F. (2001) Atm knock-in mice harboring an in-frame deletion corresponding to the human ATM 7636del9 common mutation exhibit a variant phenotype. Cancer Res 61, 4561-4568

66. Barker, D. J. (1991) The intrauterine environment and adult cardiovascular disease. Ciba Found Symp 156, 310; discussion 10-16

67. Barker, D. J., Osmond, C., and Law, C. M. (1989) The intrauterine and early postnatal origins of cardiovascular disease and chronic bronchitis. J Epidemiol Community Health 43, 237-240

68. M cM illen, I. C., MacLaughlin, S. M., Muhlhausler, B. S., Gentili, S., Duffield, J. L., and Morrison, J. L. (2008) Developmental origins of adult health and disease: the role of periconceptional and foetal nutrition. Basic Clin Pharmacol Toxicol 102, 82-89

69. Vickers, M. H., Breier, B. H., Cutfield, W. S., Hofman, P. L., and Gluckman, P. D. (2000) Fetal origins of hyperphagia, obesity, and hypertension and postnatal amplification by hypercaloric nutrition. Am J Physiol Endocrinol M etab 279, E83-87 
70. Li, Y., Jaddoe, V. W., Qi, L., He, Y., Lai, J., Wang, J., Zhang, J., Hu, Y., Ding, E. L., Yang, X., Hu, F. B., and Ma, G. (2011) Exposure to the Chinese famine in early life and the risk of hypertension in adulthood. J Hypertens 29, 1085-1092

71. Ravelli, A. C., van Der Meulen, J. H., Osmond, C., Barker, D. J., and Bleker, O. P. (1999) Obesity at the age of $50 \mathrm{y}$ in men and women exposed to famine prenatally. Am J Clin Nutr 70, 811-816

72. Roseboom, T. J., van der Meulen, J. H., Ravelli, A. C., Osmond, C., Barker, D. J., and Bleker, O. P. (2001) Effects of prenatal exposure to the Dutch famine on adult disease in later life: an overview. Twin Res 4, 293298

73. Barker, D. J., and Clark, P. M . (1997) Fetal undernutrition and disease in later life. Rev Reprod 2, 105-112

74. Inoue, T., Kido, Y., Asahara, S., Matsuda, T., Shibutani, Y., Koyanagi, M., and Kasuga, M. (2009) Effect of intrauterine undernutrition during late gestation on pancreatic beta cell mass. Biomed Res 30, 325-330

75. Prentice, A. M., and Moore, S. E. (2005) Early programming of adult diseases in resource poor countries. Arch Dis Child 90, 429-432

76. Dumortier, O., Blondeau, B., Duvillie, B., Reusens, B., Breant, B., and Remacle, C. (2007) Different mechanisms operating during different critical time-windows reduce rat fetal beta cell mass due to a maternal low-protein or low-energy diet. Diabetologia 50, 2495-2503

77. Garofano, A., Czernichow, P., and Breant, B. (1997) In utero undernutrition impairs rat beta-cell development. Diabetologia 40, 1231-1234

78. Liang, C., Oest, M. E., and Prater, M. R. (2009) Intrauterine exposure to high saturated fat diet elevates risk of adult-onset chronic diseases in C57BL/ 6 mice. Birth Defects Res B Dev Reprod Toxicol 86, 377-384

79. Jablonka, E., and Lamb, M. J. (2007) Precis of Evolution in Four Dimensions. Behav Brain Sci 30, 353-365; discusssion 365-389

80. Holliday, R. (2006) Epigenetics: a historical overview. Epigenetics 1, 76-80

81. Jablonka, E., and Lamb, M. J. (2002) The changing concept of epigenetics. Ann N Y Acad Sci 981, 82-96

82. Nelissen, E. C., van Montfoort, A. P., Dumoulin, J. C., and Evers, J. L. (2011) Epigenetics and the placenta. Hum Reprod Update 17, 397-417

83. Maccani, M. A., and Marsit, C. J. (2009) Epigenetics in the placenta. Am J Reprod Immunol 62, 78-89

84. Szyf, M. (2009) The early life environment and the epigenome. Biochim Biophys Acta 1790, 878-885

85. Atkinson, S. P., and Keith, W. N. (2007) Epigenetic control of cellular senescence in disease: opportunities for therapeutic intervention. Expert Rev M ol M ed 9, 1-26

86. Herman, J. G., and Baylin, S. B. (2003) Gene silencing in cancer in association with promoter hypermethylation. N EnglJ Med 349, 2042-2054

87. Bernal, A. J., and Jirtle, R. L. (2010) Epigenomic disruption: the effects of early developmental exposures. Birth Defects Res A Clin M ol Teratol 88, 938-944

88. Verona, R. I., Mann, M. R., and Bartolomei, M. S. (2003) Genomic imprinting: intricacies of epigenetic regulation in clusters. Annu Rev Cell Dev Biol 19, 237-259

89. Szyf, M. (2007) The dynamic epigenome and its implications in toxicology. Toxicol Sci 100, 7-23

90. Selevan, S. G., Kimmel, C. A., and M endola, P. (2000) Identifying critical windows of exposure for children's health. Environ Health Perspect 108 Suppl 3, 451-455

91. Dolinoy, D. C., Weidman, J. R., Waterland, R. A., and Jirtle, R. L. (2006) Maternal genistein alters coat color and protects Avy mouse offspring from obesity by modifying the fetal epigenome. Environ Health Perspect $114,567-572$

92. Xiao, R., Hennings, L. J., Badger, T. M., and Simmen, F. A. (2007) Fetal programming of colon cancer in adult rats: correlations with altered neonatal growth trajectory, circulating IGF-I and IGF binding proteins, and testosterone. J Endocrinol 195, 79-87

93. Newbold, R. R., Padilla-Banks, E., and Jefferson, W. N. (2006) Adverse effects of the model environmental estrogen diethylstilbestrol are transmitted to subsequent generations. Endocrinology 147, S11-17

94. Ozanne, S. E., Fernandez-Twinn, D., and Hales, C. N. (2004) Fetal growth and adult diseases. Semin Perinatol 28, 81-87

95. Choi, E. J., Chee, K. M., and Lee, B. H. (2003) Anti- and prooxidant effects of chronic quercetin administration in rats. Eur J Pharmacol 482, 281-285

96. Galati, G., Sabzevari, O., Wilson, J. X., and O'Brien, P. J. (2002) Prooxidant activity and cellular effects of the phenoxyl radicals of dietary flavonoids and other polyphenolics. Toxicology 177, 91-104

97. Mennen, L. I., Walker, R., Bennetau-Pelissero, C., and Scalbert, A. (2005) Risks and safety of polyphenol consumption. Am J Clin Nutr 81, 326S-329S 
98. Breinholt, V., Lauridsen, S. T., and Dragsted, L. O. (1999) Differential effects of dietary flavonoids on drug metabolizing and antioxidant enzymes in female rat. Xenobiotica 29, 1227-1240

99. Niestroy, J., Barbara, A., Herbst, K., Rode, S., van Liempt, M., and Roos, P. H. (2011) Single and concerted effects of benzo[a]pyrene and flavonoids on the AhR and Nrf2-pathway in the human colon carcinoma cell line Caco-2. Toxicol In Vitro 25, 671-683

100. Moon, Y. J., Wang, X., and Morris, M. E. (2006) Dietary flavonoids: effects on xenobiotic and carcinogen metabolism. Toxicol In Vitro 20, 187-210

101. van Helden, Y. G., Keijer, J., Knaapen, A. M., Heil, S. G., Briede, J. J., van Schooten, F. J., and Godschalk, R. W. (2009) Beta-carotene metabolites enhance inflammation-induced oxidative DNA damage in lung epithelial cells. Free Radic Biol Med 46, 299-304

102. Gebicki, J. M., Nauser, T., Domazou, A., Steinmann, D., Bounds, P. L., and Koppenol, W. H. (2010) Reduction of protein radicals by GSH and ascorbate: potential biological significance. Amino Acids 39, 1131-1137

103. Singh, R., Sram, R. J., Binkova, B., Kalina, I., Popov, T. A., Georgieva, T., Garte, S., Taioli, E., and Farmer, P. B. (2007) The relationship between biomarkers of oxidative DNA damage, polycyclic aromatic hydrocarbon DNA adducts, antioxidant status and genetic susceptibility following exposure to environmental air pollution in humans. Mutat Res 620, 83-92

104. Hayes, J. D., Dinkova-Kostova, A. T., and M cMahon, M . (2009) Cross-talk between transcription factors AhR and Nrf2: lessons for cancer chemoprevention from dioxin. Toxicol Sci 111, 199-201

105. Kohle, C., and Bock, K. W. (2007) Coordinate regulation of Phase I and II xenobiotic metabolisms by the Ah receptor and Nrf2. Biochem Pharmacol 73, 1853-1862

106. Miao, W., Hu, L., Scrivens, P. J., and Batist, G. (2005) Transcriptional regulation of NF-E2 p45-related factor (NRF2) expression by the aryl hydrocarbon receptor-xenobiotic response element signaling pathway: direct cross-talk between phase I and II drug-metabolizing enzymes. J Biol Chem 280, 20340-20348

107. Tsantes, A. E., Bonovas, S., Travlou, A., and Sitaras, N. M. (2006) Redox imbalance, macrocytosis, and RBC homeostasis. Antioxid Redox Signal 8, 1205-1216

108. Munoz, M., Villar, I., and Garcia-Erce, J. A. (2009) An update on iron physiology. World J Gastroenterol 15, 4617-4626

109. Zhang, A. S., and Enns, C. A. (2009) Molecular mechanisms of normal iron homeostasis. Hematology Am Soc Hematol Educ Program, 207-214

110. Koury, M. J., and Ponka, P. (2004) New insights into erythropoiesis: the roles of folate, vitamin B12, and iron. Annu Rev Nutr 24, 105-131

111. Kingsley, P. D., Malik, J., Emerson, R. L., Bushnell, T. P., M cGrath, K. E., Bloedorn, L. A., Bulger, M., and Palis, J. (2006) "M aturational" globin switching in primary primitive erythroid cells. Blood 107, 1665-1672

112. Palis, J. (2008) Ontogeny of erythropoiesis. Curr Opin Hematol 15, 155-161

113. Keller, G., Lacaud, G., and Robertson, S. (1999) Development of the hematopoietic system in the mouse. Exp Hematol 27, 777-787

114. M cGrath, K. E., Kingsley, P. D., Koniski, A. D., Porter, R. L., Bushnell, T. P., and Palis, J. (2008) Enucleation of primitive erythroid cells generates a transient population of "pyrenocytes" in the mammalian fetus. Blood $111,2409-2417$

115. Jauniaux, E., Gulbis, B., and Burton, G. J. (2003) The human first trimester gestational sac limits rather than facilitates oxygen transfer to the foetus--a review. Placenta 24 Suppl A, S86-93

116. Dennery, P. A. (2007) Effects of oxidative stress on embryonic development. Birth Defects Res C Embryo Today 81, 155-162

117. Amoyal, I., and Fibach, E. (2007) Hemoglobin switch in the newborn: a flow cytometry analysis. Neonatology 91, 61-68

118. Purdie, A., Wells, R. M., and Brittain, T. (1983) Molecular aspects of embryonic mouse haemoglobin ontogeny. Biochem J 215, 377-383

119. Gambling, L., and M cArdle, H. J. (2004) Iron, copper and fetal development. Proc Nutr Soc 63, 553-562

120. Andersen, H. S., Gambling, L., Holtrop, G., and M cArdle, H. J. (2006) M aternal iron deficiency identifies critical windows for growth and cardiovascular development in the rat postimplantation embryo. J Nutr 136, 1171-1177

121. Scholl, T. O. (2005) Iron status during pregnancy: setting the stage for mother and infant. Am J Clin Nutr 81, $1218 \mathrm{~S}-1222 \mathrm{~S}$

122. Zhang, Y., Li, H., Zhao, Y., and Gao, Z (2006) Dietary supplementation of baicalin and quercetin attenuates iron overload induced mouse liver injury. Eur J Pharmacol 535, 263-269 
123. Uno, S., Dalton, T. P., Derkenne, S., Curran, C. P., M iller, M. L., Shertzer, H. G., and Nebert, D. W. (2004) Oral exposure to benzo[a]pyrene in the mouse: detoxication by inducible cytochrome P450 is more important than metabolic activation. M ol Pharmacol 65, 1225-1237

124. Tarantini, A., Maitre, A., Lefebvre, E., Marques, M., Rajhi, A., and Douki, T. (2011) Polycyclic aromatic hydrocarbons in binary mixtures modulate the efficiency of benzo[a]pyrene to form DNA adducts in human cells. Toxicology 279, 36-44

125. Gelboin, H. V. (1980) Benzo[alpha]pyrene metabolism, activation and carcinogenesis: role and regulation of mixed-function oxidases and related enzymes. Physiol Rev 60, 1107-1166

126. Ambrosone, C. B., and Tang, L. (2009) Cruciferous vegetable intake and cancer prevention: role of nutrigenetics. Cancer Prev Res (Phila) 2, 298-300

127. Bosch, T. M., Doodeman, V. D., Smits, P. H., Meijerman, I., Schellens, J. H., and Beijnen, J. H. (2006) Pharmacogenetic screening for polymorphisms in drug-metabolizing enzymes and drug transporters in a Dutch population. Mol Diagn Ther 10, 175-185

128. Sailaja, K., Surekha, D., Rao, D. N., Rao, D. R., and Vishnupriya, S. (2010) Association of the GSTP1 gene (Ile105Val) polymorphism with chronic myeloid leukemia. Asian Pac J Cancer Prev 11, 461-464

129. 130. Catania, V. A., Dannenberg, A. J., Luquita, M. G., Sanchez Pozzi, E. J., Tucker, J. K., Yang, E. K., and Mottino, A. D. (1995) Gender-related differences in the amount and functional state of rat liver UDPglucuronosyltransferase. Biochem Pharmacol 50, 509-514

131. Zhu, B., Liu, Z. Q., Chen, G. L., Chen, X. P., Ou-Yang, D. S., Wang, L. S., Huang, S. L., Tan, Z. R., and Zhou, H. H. (2003) The distribution and gender difference of CYP3A activity in Chinese subjects. Br J Clin Pharmacol 55, 264-269

132. Mollerup, S., Berge, G., Baera, R., Skaug, V., Hewer, A., Phillips, D. H., Stangeland, L., and Haugen, A. (2006) Sex differences in risk of lung cancer: Expression of genes in the PAH bioactivation pathway in relation to smoking and bulky DNA adducts. Int J Cancer 119, 741-744

133. Uppstad, H., Osnes, G. H., Cole, K. J., Phillips, D. H., Haugen, A., and Mollerup, S. (2011) Sex differences in susceptibility to PAHs is an intrinsic property of human lung adenocarcinoma cells. Lung Cancer 71, 264-270

134. Gasperino, J. (2011) Gender is a risk factor for lung cancer. Med Hypotheses 76, 328-331

135. Singh, S. V., Benson, P. J., Hu, X., Pal, A., Xia, H., Srivastava, S. K., Awasthi, S., Zaren, H. A., Orchard, J. L., and Awasthi, Y. C. (1998) Gender-related differences in susceptibility of A/J mouse to benzo[a]pyrene-induced pulmonary and forestomach tumorigenesis. Cancer Lett 128, 197-204

136. Kummer, V., Maskova, J., Zraly, Z., Neca, J., Simeckova, P., Vondracek, J., and Machala, M. (2008) Estrogenic activity of environmental polycyclic aromatic hydrocarbons in uterus of immature Wistar rats. Toxicol Lett $180,212-221$

137. Daniel, C. R., Schwartz, K. L., Colt, J. S., Dong, L. M ., Ruterbusch, J. J., Purdue, M. P., Cross, A. J., Rothman, N., Davis, F. G., Wacholder, S., Graubard, B. I., Chow, W. H., and Sinha, R. (2011) Meat-cooking mutagens and risk of renal cell carcinoma. Br J Cancer 105, 1096-1104

138. Xu, X., Kelsey, K. T., Wiencke, J. K., Wain, J. C., and Christiani, D. C. (1996) Cytochrome P450 CYP1A1 Mspl polymorphism and lung cancer susceptibility. Cancer Epidemiol Biomarkers Prev 5, 687-692

139. Doll, R., and Peto, R. (1981) The causes of cancer: quantitative estimates of avoidable risks of cancer in the United States today. J Natl Cancer Inst 66, 1191-1308

140. Ingelman-Sundberg, M. (2001) Genetic susceptibility to adverse effects of drugs and environmental toxicants. The role of the CYP family of enzymes. Mutat Res 482, 11-19

141. Kang, Z. C., Tsai, S. J., and Lee, H. (1999) Quercetin inhibits benzo[a]pyrene-induced DNA adducts in human Hep G2 cells by altering cytochrome P-450 1A1 gene expression. Nutr Cancer 35, 175-179

142. Ciolino, H. P., Daschner, P. J., and Yeh, G. C. (1999) Dietary flavonols quercetin and kaempferol are ligands of the aryl hydrocarbon receptor that affect CYPIA1 transcription differentially. Biochem J 340 ( Pt 3), 715-722

143. Steiner, C., Peters, W. H., Gallagher, E. P., Magee, P., Rowland, I., and Pool-Zobel, B. L. (2007) Genistein protects human mammary epithelial cells from benzo(a)pyrene-7,8-dihydrodiol-9,10-epoxide and 4-hydroxy-2-nonenal genotoxicity by modulating the glutathione/ glutathione S-transferase system. Carcinogenesis 28, 738-748

144. Makaji, E., Ho, S. H., Holloway, A. C., and Crankshaw, D. J. (2011) Effects in rats of maternal exposure to raspberry leaf and its constituents on the activity of cytochrome p450 enzymes in the offspring. Int J Toxicol 30, 216-224

145. Ebert, B., Seidel, A., and Lampen, A. (2007) Phytochemicals induce breast cancer resistance protein in Caco2 cells and enhance the transport of benzo[a]pyrene-3-sulfate. Toxicol Sci 96, 227-236 



\section{Chapter 2}

\section{Prenatal exposure to flavonoids: implication for cancer risk}

Vanhees K, de Bock L, Godschalk RWL, van Schooten FJ, Barjesteh van Waalwijk van Doorn-Khosrovani S 


\section{Abstract}

Flavonoids are potent antioxidants, freely available as high-dose dietary supplements. However, they can induce DNA double-strand breaks (DSB) and rearrangements in the mixed-lineage leukemia (MLL) gene, which are frequently observed in childhood leukemia. We hypothesize that a deficient DSB-repair, as a result of an Atm mutation, may reinforce the clastogenic effect of dietary flavonoids and increase the frequency of MII rearrangements. Therefore we examined the effects of in vitro and transplacental exposure to high, but biological amounts of flavonoids in mice with different genetic capacities for DSB-repair (homozygous/ heterozygous knock-in for human Atm mutation (Atm- $\Delta$ SRI) versus wild-type). In vitro exposure to genistein/ quercetin induced higher numbers of MLL rearrangements in bone marrow cells of Atm- $\Delta S R I$ mutant mice compared to wild-type mice. Subsequently, heterozygous Atm- $\Delta$ SRI mice were placed on either a flavonoid-poor or a genistein-enriched $(270 \mathrm{mg} / \mathrm{kg}$ ) or quercetin-enriched (302 $\mathrm{mg} / \mathrm{kg}$ ) feed throughout pregnancy. Prenatal exposure to flavonoids associated with higher frequencies of $M \| l$ rearrangements and a slight increase in the incidence of malignancies in DNA repair-deficient mice. These data suggest that prenatal exposure to both genistein and quercetin supplements could increase the risk on $\mathrm{M} \| \mathrm{I}$ rearrangements especially in the presence of compromised DNA repair. 


\section{Introduction}

Bioflavonoids are a diverse group of polyphenolic compounds found in fruits, vegetables, soy, tea, coffee and wine. They are most commonly known for their protective effect against cardiovascular diseases, cancer and inflammation, as a result of their antioxidant capacity (1, 2). Because of the presumed health benefits flavonoid supplements are worldwide over-thecounter available in pharmacies and drugstores. Unfortunately, there is a general belief that these herbal supplements are safe because they are labeled as "natural". Reasons for concern are that besides their antioxidant properties, flavonoids are also potent topoisomerase II (topoll)-inhibitors. Topoll is a nuclear enzyme that plays an essential role in controlling the topology of DNA during replication and recombination. Topoll binds to specific sites on both DNA strands and generates a transient double strand break (DSB). These DSBs are normally relegated. However, certain topoll-inhibiting drugs, such as etoposide or flavonoids can stabilize DSBs and increase the risk of chromosomal abnormalities (3-5).

One of the most common loci involved in chromosomal translocations due to doublestranded DNA lesions caused by topoll-inhibitors, is the breakpoint cluster region (BCR) of the mixed-lineage leukemia (MLL) gene. This gene is involved in normal hematopoiesis and is located at chromosome 11q23 (6-8). Approximately $80 \%$ of infants which suffer from acute myelogenous leukemia (AML) or acute lymphoblastic leukemia (ALL) have chromosomal translocations involving the $M L L$ gene (3-5). These translocations are also identified in patients with secondary leukemia caused by chemotherapy with topollinhibitors (e.g. etoposide) (3, 9-11). It has previously been suggested that dietary flavonoids are also capable of introducing these translocations and cause leukemia (12). Although there are some indications that flavonoids might be involved in leukemogenesis (4), the complex nature of human diet made it impossible to elucidate the contribution of flavonoids. Our previous data (13) demonstrates that exposure of human CD34+ hematopoietic progenitor cells to biologically relevant levels of the flavonoids quercetin, genistein and kaempferol can induce $M L L$ translocations in vitro. Since the concentrations used in this in vitro study can also be obtained in vivo, and knowing that flavonoids can penetrate the placenta and accumulate in the fetus $(2,14,15)$, it is crucial to further examine the safety of flavonoids, especially during pregnancy. Fetal cells are rapidly proliferating cells and thus have high topoll activity (16), which can theoretically make them more sensitive to the topoll inhibiting effect of flavonoids.

As flavonoids execute their clastogenicity through inhibiting the religation of DSBs, one might expect that any defect in DSB-repair may predispose cells to clastogenic effects of these compounds. DSBs are normally detected by ataxia-telangiectasia-mutated (ATM) protein kinase (17-19). Ye et al. (20) demonstrated that exposure of human lymphoblastoid cell lines to quercetin or genistein leads to autophosphorylation of ATM on serine 1981 leading to the active form of ATM (21). Hence, ATM phophorylates its downstream targets (e.g. p53, Chk2 and histone $\mathrm{H} 2 \mathrm{AX}$ ), which based on the severity of the damage will either execute DNA repair or cell-cycle arrest and apoptosis (20,22-24). Patients with mutations in the ATM gene are prone to developing chromosomal abnormalities $(17,19)$. Heterozygous germ-line mutations in the ATM gene are frequent and occur in $0.5-1 \%$ of the general population $(25,26)$. These mutations are associated with an increased risk for developing different types of cancer, including leukemia $(19,23,27,28)$. Accordingly, missence mutations in the ATM gene have been detected in $25 \%$ of cases with childhood ALL (23). 
This study examines the effect of both in vitro and transplacental exposure to high, but biological amounts of flavonoids in mice with different genetic capacities for DSB-repair (homozygous/heterozygous knock-in for human Atm mutation (Atm- $\Delta$ SRI) versus wildtype). We examined whether a decreased capacity in DNA DSB-repair in Atm- $\Delta$ SRI mutant mice enhances flavonoid-induced clastogenicity.

\section{Material and methods}

Exposure of bone marrow cells to genistein, quercetin or etoposide

Bone marrow cells collected from one femur of adult wild-type (wt) and homozygote mutant (mut) Atm- $\Delta$ SRI mice were isolated by flushing the marrow with Iscove's M odified Dulbecco's M edia (IM DM , Invitrogen, Breda, the Netherlands) supplemented with $10 \%$ FCS. Next, cells were washed, incubated in IM DM and treated for one day with $50 \mu \mathrm{M}$ of etoposide (Sigma-Aldrich, St. Louis, MO, USA), genistein (LC Laboratories, Woburn, MA, USA), quercetin (Sigma) or the vehicle dimethylsulphoxide $(0.05 \%$ DM SO). After exposure cells were washed twice, and left to recover for another day before DNA isolation. Cell counts and viability were determined by a hemocytometer and trypan blue exclusion.

\section{Mice and sample collection}

Female Atm- $\Delta$ SRI heterozygous mice (129/Sv):C57BL/6J background) approximately 8 weeks of age, received either normal chow (low phytoestrogen content complete feed for mice breeding, in which neither soybean nor alfalfa products were used, resulting in minimized concentrations of the phytoestrogens genistein, daidzein and coumestrol, ssniff $\circledast$, Soest, Germany, $\mathrm{n}=8$ ) or the same chow (ssniff $\circledast$ ) supplemented with genistein (270 mg/ kg feed, $\mathrm{n}=9$ ) (LC Laboratories) or quercetin (302 mg/ kg feed, $\mathrm{n}=8$ ) (Sigma) from 3 days before conception until the end of pregnancy. Male Atm- $\Delta$ SRI heterozygous mice were placed in the cage only for the duration of copulation. Heterozygote female and male mice were mated because this gives the opportunity to study the in utero effects of the three expected genotypes in offspring (homozygous/heterozygous Atm$\triangle \mathrm{SRI}$ and wild-type). After delivery all mothers and pups received the normal chow. At day 5 after birth, pups were weighted and genotype and gender was determined. At 12 weeks of age, offspring were sacrificed by cardiac puncture, checked for tumor development and blood was collected in EDTA-tubes (Terumo, Leuven, Belgium) to determine the blood composition. Bone marrow was isolated by removing the femurs and flushing the marrow with PBS. Offspring that died before sacrificing day were also checked for tumor development.

To study the direct effects of diet on fetal hematopoiesis, wild-type mice (129/Sv):C57BL/6) background, control $n=5$, genistein $n=4$, quercetin $n=3$ ) were mated overnight. The presence of a vaginal plug the next morning was defined as 0.5 day post conception. On day 14.5 of pregnancy (E14.5), mice were sacrificed to isolate the fetuses and fetal liver (please note that the liver is the organ for hematopoiesis at this time point). 


\section{Blood composition}

Blood composition was determined in duplicate, using the ADVIA 120 Hematology System (Siemens AG, Erlangen, Germany) following the manufacturer's protocol. The following blood cell parameters were measured: total number of red blood cells $\left(10^{12} / \mathrm{L}\right)$, hemoglobin level $(\mathrm{mmol} / \mathrm{L})$, hematocrit level $(\mathrm{L} / \mathrm{L})$, mean corpuscular volume $(\mathrm{fL})$, mean corpuscular hemoglobin (fmol), mean corpuscular hemoglobin concentration $(\mathrm{mmol} / \mathrm{L})$, red blood cell distribution width $(\%)$, hemoglobin distribution width $(\mathrm{mmol} / \mathrm{L})$, total amount of platelets $\left(10^{9} / \mathrm{L}\right)$, mean platelet volume $(\mathrm{fl})$, total amount $\left(10^{9} / \mathrm{L}\right)$ and percentage of reticulocytes, mean corpuscular hemoglobin concentration of reticulocytes (fmol), total number of white blood cells $\left(10^{9} / \mathrm{L}\right)$, total amount $\left(10^{9} / \mathrm{L}\right)$ and percentage of neutrophils, lymphocytes, monocytes, eosinophils and basophils. In case of suspected leukemia by abnormal blood composition, the diagnosis was further confirmed by performing a M ay-Grünwald staining on blood smear preparations. Briefly, $10 \mu \mathrm{l}$ of blood was fixed by methanol. Next, smears were stained in May-Grünwald solution (Sigma) for 5 minutes and washed in tap water. Subsequently, the smears were stained with Giemsa solution (M erck, Darmstadt, Germany) for 20 minutes and washed again in tap water. All preparations were judged by an experienced animal pathologist.

\section{Inverse-PCR assay and sequencing}

Genomic DNA was isolated from bone marrow cells (in vitro culture or in vivo from 12 week old mice) and from the fetal liver of E14.5 fetuses, using DNeasy Blood \& Tissue Kit (Qiagen, Venlo, the Netherlands). Fetal livers were first homogenized using an Ultra-Turrax homogenizer (IKA, Staufen, Germany). Next, $1 \mu \mathrm{g}$ of each DNA sample was subjected to SAP digestion (1 unit of shrimp alkaline phosphatase) (Promega, Madison, WI, USA) for 1 hour at $37^{\circ} \mathrm{C}$ followed by an inactivation at $65^{\circ} \mathrm{C}$ for 20 minutes. Then, the DNA was digested with 3 units of Pcil (Biolabs, Leusden, the Netherlands) for 1 hour at $37^{\circ} \mathrm{C}$ followed by 20 minutes inactivation at $80^{\circ} \mathrm{C}$. The DNA was circularized overnight at $6{ }^{\circ} \mathrm{C}$ followed by 2 hours at $22^{\circ} \mathrm{C}$ and 20 minutes of inactivation at $75{ }^{\circ} \mathrm{C}$ using 3 units of T4 DNA ligase (Promega) in a final volume of $50 \mu$. Approximately, $80 \mathrm{ng}$ of the circularized DNA was used for the first PCR, in which the circularized DNA was amplified. Both the first PCR and nested PCR were performed using $0.7 \mu \mathrm{l}$ expand long template polymerase mix (Roche, Mannheim, Germany), system 2 reaction buffer, 20 pmol of each primer (Eurogentec, Liege, Belgium, Table 1) and dNTPs $(500 \mu \mathrm{M})$ in a volume of $50 \mu$ l. The reaction was performed using a Biometra Tprofessional thermocycler (Biometra, Leusden, the Netherlands) under the following cycling conditions: $94{ }^{\circ} \mathrm{C}$ for 2 minutes, 10 cycles: $94{ }^{\circ} \mathrm{C}$ for 30 seconds, $56{ }^{\circ} \mathrm{C}$ for 45 seconds, $68^{\circ} \mathrm{C}$ for 4 minutes; 25 cycles: $94{ }^{\circ} \mathrm{C}$ for 30 seconds, $56{ }^{\circ} \mathrm{C}$ for 45 seconds, $68{ }^{\circ} \mathrm{C}$ for 4 minutes ( $+20 \mathrm{~s} /$ cycle); followed by 7 minutes at $68^{\circ} \mathrm{C}$. The amplified fragments from the first PCR were diluted $(1 / 50)$ and $2 \mu l$ was taken for the nested PCR.

The nested PCR products were separated by electrophoresis on a $1 \%$ agarose gel, aberrant sized bands were excised and DNA was isolated using the QIAquick Gel Extraction Kit (Qiagen). The purified PCR products were subsequently sequenced using big dye v3.1 (Applied Biosystems, Foster city, CA, USA) and 5 pmol primer (Table 1) under the following cycling conditions: 1 minute at $96^{\circ} \mathrm{C}, 25$ cycles: $96^{\circ} \mathrm{C}$ for 30 seconds, $50{ }^{\circ} \mathrm{C}$ for 15 seconds, $60{ }^{\circ} \mathrm{C}$ for 4 minutes followed by 10 minutes at $72{ }^{\circ} \mathrm{C}$. After purification by sephadex columns, the products were sequenced by ABI 3730 Automatic DNA Sequencer (Applied 
Biosystems). Nucleotide sequences were analyzed using 'Nucleotide blast' tool of the National Center for Biotechnology Information (BLAST NCBI, Bethesda, MD, USA).

Table 1. Overview of used primers

\begin{tabular}{lll}
\hline Primer & Forward primer $\left(\mathbf{5}^{\prime} \mathbf{3}^{\prime} \mathbf{)}\right.$ & Reverse primer $\left(\mathbf{5}^{\prime} \mathbf{3}^{\prime} \mathbf{)}\right.$ \\
\hline First PCR primer & CCA GAG TAG TGT GCT TTC TC & AGG TGG CTT CTC CTG AGA CAG \\
Nested PCR primer & AGT GGG CAT GTA GAG GTA AG & AAC AAT GAC TTG CCC TCA TAT TG \\
Sequence PCR primers: & \\
1 & AAA CAG TGT GCA CAG GTA CG & \\
2 & AAC CGC TGA ACC ATC TCT CC & \\
3 & TGG TGG GA GGT CAT TAG CC & \\
\hline
\end{tabular}

\section{Statistical analysis}

Statistical analysis was performed with Statistical Package for Social Sciences (SPSS version 15 for Windows, SPSS Inc., Chicago, IL, USA). The non-parametric M ann-Whitney test was used to compare the distribution of gender, genotype, pup survival, litter sizes, average weight of pups at postnatal day 5 and tumor development between litters of the different diet groups. $2 \times 2 \times 2$ multifactorial univariate ANOVA was performed to identify predictors (diet, genotype, gender) of persistent hematological changes in mice.

\section{Results}

Bone marrow cells with Atm- $\Delta$ SRI mutation are more sensitive to genistein- and quercetininduced chromosomal aberrations

In order to examine whether dietary exposure to topoll-inhibitors can induce chromosomal aberrations and whether Atm- $\Delta$ SRI mutations actually increase this risk, an inverse-PCR method was set-up to detect murine MII translocations. The assay was validated by detecting $\mathrm{M} I \mathrm{I}$ translocations in murine bone marrow cells after exposure to the known topoll-inhibitor etoposide $(50 \mu \mathrm{M})$. In addition, bone marrow cells from homozygous wild-type and mutant Atm- $\Delta$ SRI mice were isolated and cultured for approximately 24 hours with either genistein $(50 \mu \mathrm{M})$ or quercetin $(50 \mu \mathrm{M})$. Cell viability was evaluated by trypan blue exclusion. We observed no significant decrease in cell viability due to exposure to either flavonoids or etoposide or due to genotype of bone marrow cells in comparison with DM SO treated cells (Figure 1).

Cells were allowed to repair the DSBs for 24 hours in a drug-free medium. Subsequently, DNA was extracted and screened for MII aberrations by inverse-PCR. The DNA isolated from DM SO treated samples resulted in amplification of the wild-type (wt) MII (5.6kb) as visualized by agarose gel electrophoresis (Figure 2) and the identity was confirmed by sequence analysis. In contrast, exposure of bone marrow cells to quercetin, genistein or etoposide generated multiple bands of different sizes. The variety in the size of PCR products was determined by both the location of the breakpoint junction in $\mathrm{MII}$ and the position of the Pcil site in the fusion partner. Smaller sized bands were more likely to be detected by inverse-PCR than the wt M II, because wt M II is more difficult to amplify due to its length. Sequencing of the breakpoint junction of several distinct M II translocations 


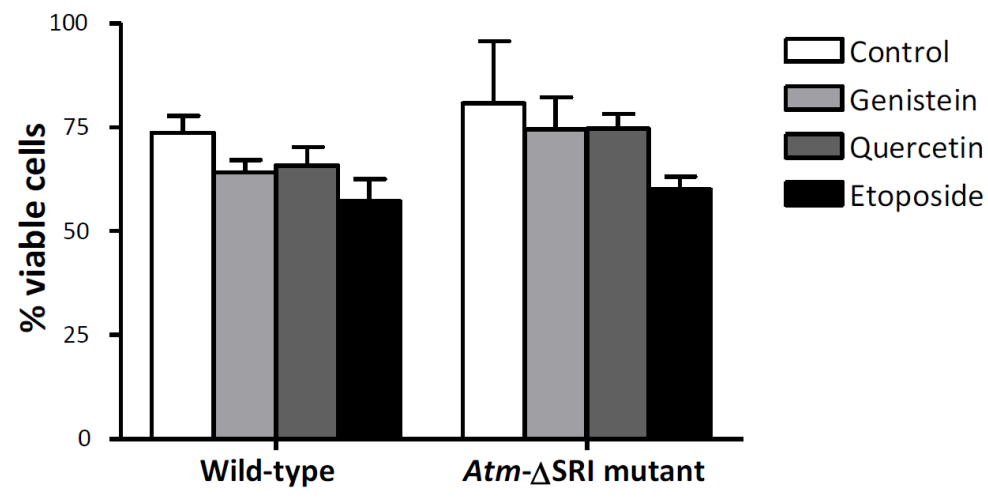

Figure 1. Viability of wt and Atm- $\Delta$ SRI mutant bone marrow cells was determined after 1 day of exposure to $50 \mu \mathrm{M}$ of the flavonoids genistein and quercetin, $50 \mu \mathrm{M}$ etoposide and the vehicle DMSO (0.05\%) by trypan blue exclusion.

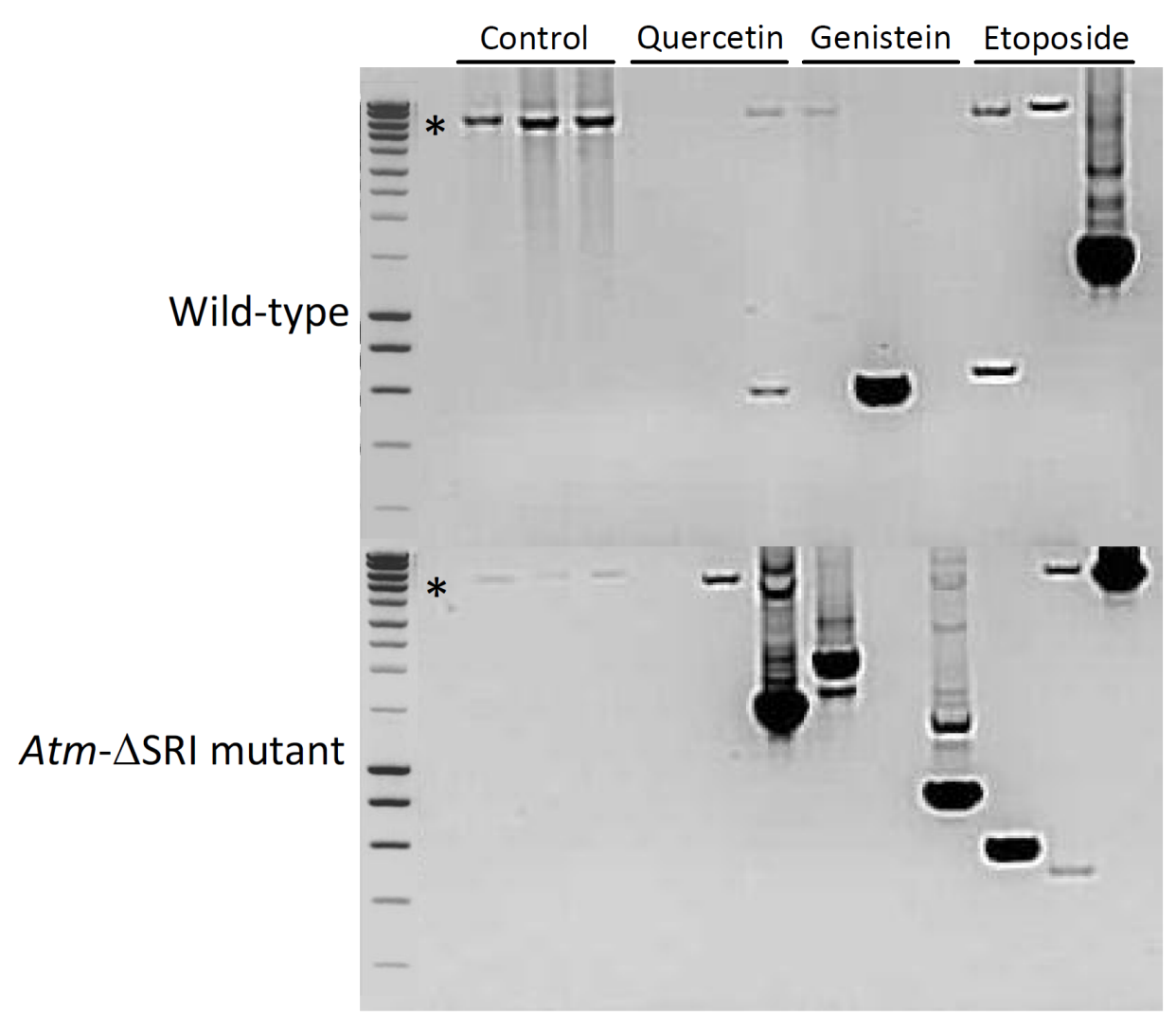

Figure 2. Inverse-PCR products representing $M I I$ rearrangements found in bone marrow of wild-type and Atm- $\triangle$ SRI mutant cells after 24 hours in vitro exposure to quercetin $(50 \mu \mathrm{M})$, genistein $(50 \mu \mathrm{M})$ or etoposide $(50 \mu \mathrm{M})$.

Equal aliquots of DNA were used for each inverse-PCR reaction. The samples were visualized by gel electrophoresis. Each band with a size different from the wt $5.6 \mathrm{~kb}$ band represents a translocation that results in an abberant size of the PCR product. Wild-type M II is indicated with *. 
induced by flavonoids or etoposide confirmed that the bands of abberant size were indeed translocations (Table 4). Although etoposide and both flavonoids induced $\mathrm{MI}$ rearrangements in bone marrow cells regardless of the genotype of the mice, the Atm- $\Delta$ SRI mutant cells $(0,2.1,5,1.2$ translocations/ 80 ng genomic DNA for the control, quercetin, genistein or etoposide exposed cells, respectively, Figure 2) showed more chromosomal translocations than the wt cells $(0.7,0.2,0.2,3$ translocations/ $80 \mathrm{ng}$ genomic DNA for the control, quercetin, genistein or etoposide exposed cells, respectively). This indicates that the Atm mutation predisposes cells to the clastogenic effects of flavonoids.

\section{Effect of prenatal diet on litter characteristics}

Heterozygous Atm- $\Delta$ SRI mice were exposed to genistein $(270 \mathrm{mg} / \mathrm{kg}$ feed, $\mathrm{n}=9$ ) or quercetin (302 mg/ kg feed, $n=8$ ) or control diet $(n=8)$ throughout their pregnancy. There were no differences in gender ratio, average weight of the offspring measured at day 5 after birth or average liter size between control, genistein or quercetin exposed groups (Table 2). Interestingly, the incidence of different genotypes was to some extent affected by prenatal diet. Theoretically, the homozygous wild-type (wt) and mutant (mut) offspring should each count for approximately $25 \%$ of the offspring. Accordingly, wt and mut offspring showed equal prevalence (respectively $28 \%$ and $29 \%$ ) in the control group (Table 2). The genistein and quercetin diet groups however, had different prevalences of the genotypes. The number of mut mice born in the quercetin group was lower than in the control or genistein group ( $\mathrm{P}=0.06$ and $\mathrm{P}=0.01$, respectively). In the genistein group, the percentage of heterozygote animals seemed to be low, however the distribution of distinct genotypes was not significantly different from the control group.

Changes in blood composition and incidence of malignancies in mice prenatally exposed to flavonoids

A total number of 45 control, 45 genistein- and 40 quercetin-exposed mice reached the age of 12 weeks. The percentage of animals that died before this time point was not significantly different for all three diet groups (Table 2). We were unable to determine the cause of death, but at autopsy no tumors were noted. The mice that reached 12 weeks of age were sacrificed and their internal organs were examined for visual signs of abnormalities and presence of gross tumors (Table 2). In a previous study (29), malignancies were detected in heterozygous Atm- $\Delta$ SRI mice on average after 18.6 months. In our study, several mice had already developed malignancies at 12 weeks of age. One mouse in the control group (1/45) demonstrated splenomegaly with concomitant erythroleukemia and thymoma. On the other hand, thymoma were detected in three mice $(3 / 45,7 \%)$ of the genistein exposed group and in one of the 40 mice $(2.5 \%)$ that were prenatally exposed to quercetin. Blood count and blood smear examination showed concomitant acute lymphoblastic leukemia in two mice that were exposed to genistein. In general, leukemia and thymoma were only detected in mice that were homozygous for the Atm mutation. The only heterozygous mouse that was diagnosed with malignancy (fallopian tube tumor) belonged to the genistein group. Altogether, mutant mice prenatally exposed to genistein showed a slightly higher risk for developing tumors and leukemia compared with wt control mice. 
Table 2 Characteristics of the litters and malignancies detected in offspring within different diet groups

\begin{tabular}{llll}
\hline & Control & Genistein & Quercetin \\
\hline $\begin{array}{l}\text { Average litter size } \\
\text { Genotype (\%) }\end{array}$ & $6.38 \pm 2.07$ & $5.22 \pm 2.28$ & $5.13 \pm 2.30$ \\
$\quad$ Total numbers of litters & 8 & & 8 \\
$\quad$ wt & 28 & 9 & 38 \\
$\quad$ hetero & 43 & 41 & 53 \\
$\quad$ mut & 29 & $28^{* * c}$ & $8^{\# * * c}$ \\
Average pup weight $^{\mathrm{a}}$ & $3.18 \pm 0.71$ & $3.32 \pm 0.58$ & $3.13 \pm 0.26$ \\
Percentage of males & 47 & 57 & 51 \\
\% of deceased pups & & 7 & 2.5 \\
\hline
\end{tabular}

Malignancies detected in offspring at 12 weeks of age

\begin{tabular}{|c|c|c|c|}
\hline $\begin{array}{l}\text { Number of animals with } \\
\text { malianancies/ total analyzed (\%) }\end{array}$ & $1 / 45(2 \%)$ & $4 / 45$ (9\%) & $1 / 40(2 \%)$ \\
\hline Tumor type & erythroleukemia & $\begin{array}{l}\text { acute lymphoblastic } \\
\text { leukemia, thymoma, } \\
\text { fallopian tube cancer }\end{array}$ & thymoma \\
\hline Tissue involved & $\begin{array}{l}\text { bone marrow, thymus, } \\
\text { spleen }\end{array}$ & $\begin{array}{l}\text { bone marrow, } \\
\text { thymus, ovarian } \\
\text { ducts }\end{array}$ & thymus \\
\hline Genotype & Mut & mut, hetero & mut \\
\hline
\end{tabular}

General characteristics of the litters prenatally exposed to genistein-, quercetin-supplemented or normal diet. Results represent the mean \pm the standard deviation. $\# P=0.06, * * P \leq 0.01 .{ }^{a}$ Average pup weight (grams) at day $5 .{ }^{b}$ Average number of deceased pups after birth and before sacrifice day (week 12). ${ }^{\text {C }}$ Significant difference between quercetin and genistein group.

The complete blood count at 12 weeks of age was successfully carried out in duplicate for 41 control, 41 genistein and 39 quercetin exposed mice. The three mice that suffered from leukemia (as assessed by ADVIA 1200 Hematology System and subsequent May-Grünwald staining of blood smears) were excluded from the analysis due to the extreme outlying measurements. As shown in Table $3,2 \times 2 \times 2$ multifactorial univariate analysis was used to adjust for confounding variables (gender and genotype). Analysis of the red blood cell fraction demonstrated an increase in the mean corpuscular volume (MCV) for both genistein and quercetin group in comparison to the control (mean \pm SE respectively $46.31 \pm 0.34 \mathrm{fL}, \mathrm{P}=0.01 ; 46.33 \pm 0.50 \mathrm{fL}, \mathrm{P}=0.4$ and 44.96 $\pm 0.45 \mathrm{fL}$ for control,). The red blood cell distribution width (RDW) was only significantly increased in the genistein group $(13.92 \pm 0.19 \%$ versus $13.35 \pm 0.12 \%$ for control, $P=0.03)$. A combined high MCV and RDW could be an indication of a higher reticulocyte count. Indeed, the total amount of reticulocytes was elevated in the genistein group $\left(157.57 \pm 17.51 \times 10^{9} / \mathrm{L}\right.$ versus $106.79 \pm 15.88 \times 10^{9} / \mathrm{L}$ in control, $\left.\mathrm{P}=0.4\right)$. Although prenatal quercetin exposure was not associated with an increased reticulocyte count, the mean hemoglobin content of reticulocytes (MCHR) was higher $(1.03 \pm 0.01 \mathrm{fmol})$ compared to the control group $(0.96 \pm 0.01 \mathrm{fmol}, P=0.07)$. Prenatal exposure to genistein on the contrary significantly decreased M CHR $(0.94 \pm 0.03 \mathrm{fmol}, P=0.02)$. In the genistein group, the total number of red blood cells $\left(7.44 \pm 0.12 \times 10^{12} / \mathrm{L}\right.$ versus $7.03 \pm 0.13 \times 10^{12} / \mathrm{L}$ for control, $\left.\mathrm{P}=0.07\right)$ and consequently the hemoglobin $(7.25 \pm 0.09$ $\mathrm{mmol}$ versus $6.78 \pm 0.11 \mathrm{mmol}$ for control, $\mathrm{P}=0.009)$ and hematocrit levels $(0.35 \pm 0.01$ $L / L$ versus $0.32 \pm 0.01 L / L$ for control, $P=0.02$ ) levels were significantly elevated. 


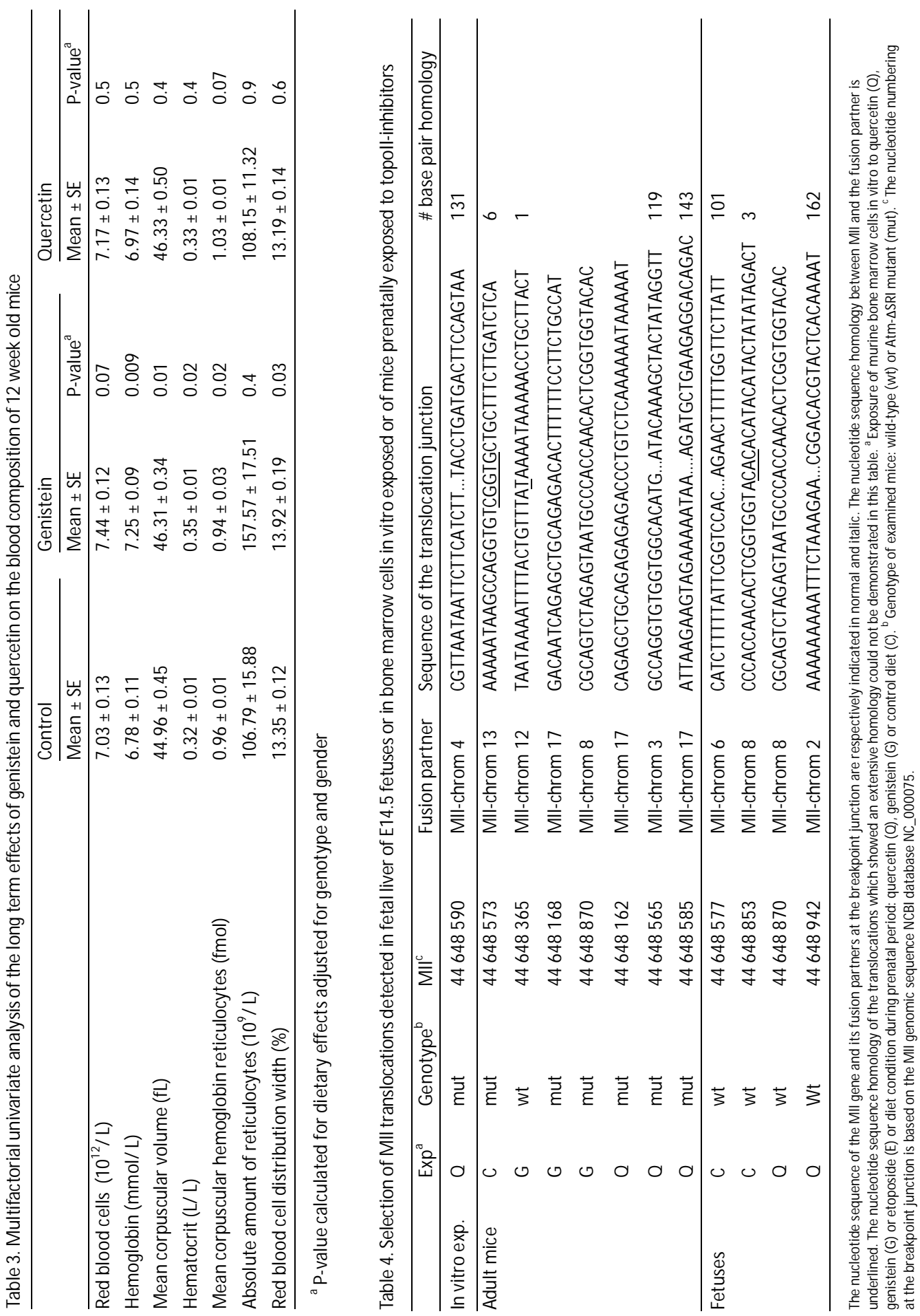


Detection of M II translocations in mice prenatally exposed to flavonoids

In order to investigate the clastogenic effects of prenatal genistein and quercetin exposure we studied the occurrence of MII translocations in the fetal liver of E14.5 wt fetuses by inverse-PCR. Genomic DNA obtained from the fetal liver was screened for chromosomal aberrations (Figure 3).

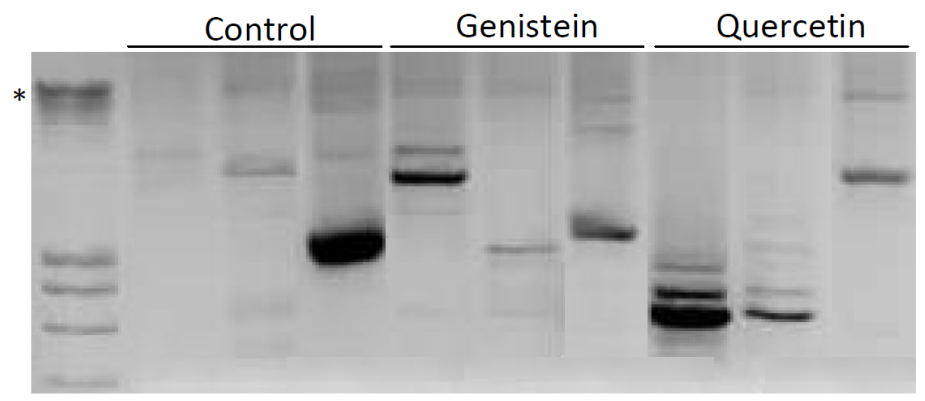

Figure 3. Inverse-PCR products representing M II rearrangements found in fetal liver cells of fetuses exposed to genistein or quercetin.

Equal aliquots of DNA were used for each inverse-PCR reaction. The samples were visualized by gel electrophoresis. Each band with a size different from the wt $5.6 \mathrm{~kb}$ band represents a translocation that results in an abberant size of the PCR product. Wild-type MII is indicated with *.

Interestingly, regardless of the maternal diet M II rearrangements could be detected in all the fetuses. The rate of translocations between the control group and both exposure groups showed no differences (control: 4.3 translocations/ $80 \mathrm{ng}$ genomic DNA versus 2.5 translocations/ $80 \mathrm{ng}$ genomic DNA and 6.5 translocations/ $80 \mathrm{ng}$ genomic DNA for the genistein and quercetin exposed fetuses, respectively). The average number of translocations is calculated as average number of alternative sized band seen in one inverse-PCR reaction/ DNA input in an inverse-PCR reaction. However, when both flavonoid exposed groups were compared, the quercetin exposed fetuses showed more chromosomal translocations compared to the genistein exposed fetuses. In order to confirm the mutant sized bands as genuine translocations instead of PCR-artifacts, a selection of aberrant MII products were sequenced (Table 4) and all appeared to be real M II translocations with various chromosomes as fusion partners.

Next, bone marrow of 12 week old wt or Atm- $\Delta$ SRI mut mice prenatally exposed to genistein or quercetin was screened for M II translocations. As shown in Figure 4, prenatal exposure to both genistein and quercetin increased the frequency of $\mathrm{M} \| \mathrm{I}$ rearrangements. In wt control mice we identified 0.9 translocations/ $80 \mathrm{ng}$ genomic DNA by inverse-PCR. Prenatal exposure to genistein increased the mutation rate in wt mice to 2.5 translocations/ 80 ng genomic DNA, whereas wt mice prenatally exposed to quercetin showed no change in the frequency of $\mathrm{MII}$ rearrangements ( 1 translocations/ 80 ng genomic DNA).

All three diet groups increased the incidence on M II translocations in mice carrying the Atm mutation. In the control group the mutation rate increased up to 2.7 translocations/ $80 \mathrm{ng}$ genomic DNA. This is comparable with the rate seen in wt mice prenatally exposed to genistein. Atm- $\triangle$ SRI mut mice prenatally exposed to genistein had a 2 fold higher translocation rate (5.6 translocations/ $80 \mathrm{ng}$ genomic DNA) compared with their wt siblings. Although prenatal exposure to quercetin had no effect on the occurrence of MII translocations in wt mice, it increased the mutation rate in Atm- $\Delta$ SRI mut mice considerably (up to 16 
translocations/ $80 \mathrm{ng}$ genomic DNA). This suggests that prenatal exposure to genistein leads to a modest increase in the number of $M \| I$ rearrangements, while prenatal quercetin exposure considerably elevates the rearrangement rate in Atm- $\Delta$ SRI mut mice. Again, a selection of aberrant MII products was sequenced to confirm that the alternative PCR products were comprised of genuine translocations (Table 4). No genuine translocations were detected in the wt mice on control diet.

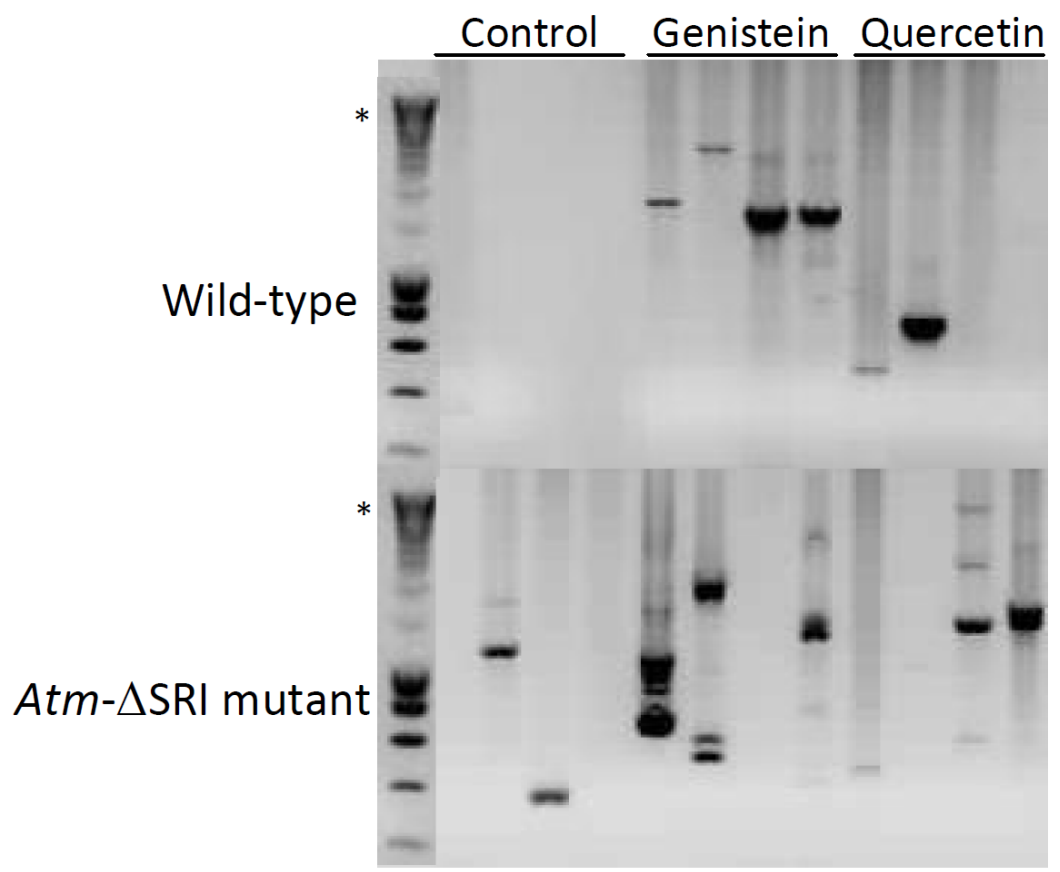

Figure 4. Inverse-PCR products representing MII rearrangements found in bone marrow cells of wild-type and Atm- $\Delta$ SRI mutant offspring mice at 12 weeks of age, prenatally exposed to genistein or quercetin.

Equal aliquots of DNA were used for each inverse-PCR reaction. The samples were visualized by gel electrophoresis. Each band with a size different from the wt $5.6 \mathrm{~kb}$ band represents a translocation that results in an abberant size of the PCR product. Wild-type M II is indicated with*.

\section{Discussion}

It has been suggested that high intake of dietary flavonoids contributes to infant leukemia (4, 30). However, no direct experimental evidence has yet been presented. Our previous study (13), together with the study of Strick (5), showed that flavonoids could induce MLL translocations in CD34+cells. However, we are the first to report that prenatal exposure to flavonoids can increase the risk for leukemia onset, as assessed by the frequency of MII translocations in a mouse model prone to develop cancer. To detect potential translocations, an inverse-PCR method was developed. In order to validate this method, murine bone marrow cells of wt and Atm- $\Delta$ SRI mut mice were exposed to $50 \mu \mathrm{M}$ of genistein, quercetin and the known topoll-inhibitor etoposide. DNA isolated from these cells was then subjected to inversePCR amplification to detect murine M II translocations. Although all exposures induced M II 
translocations, Atm- $\Delta$ SRI mut bone marrow cells that lack adequate DSB-repair were more susceptible for flavonoid and etoposide induced M II rearrangements.

To investigate the effect of prenatal exposure to flavonoids and the predisposing role of deficient DSB-repair, Atm- $\triangle$ SRI hetero mice were mated to obtain pups with different genetic capacity for DNA repair from a single mother. Bone marrow of 12 week old wt and Atm- $\Delta$ SRI mut offspring mice that were prenatally exposed to genistein or quercetin, were screened for MII translocations, by using the inverse-PCR method. Both flavonoids were capable of inducing M II translocations in wt and Atm- $\Delta$ SRI mut mice, but Atm- $\Delta$ SRI mut mice showed a higher susceptibility to develop these chromosomal aberrations, which was expected from the in vitro results. This suggests that exposure to flavonoid supplements can have more severe consequences in individuals with a malfunctioning DNA repair system. Alike flavonoids, radiation induces DNA DSBs. Accordingly, radiation exposure has been shown to induce significantly more cell death and chromosomal aberrations in Atm- $\triangle$ SRI mut thymocytes than in wt cells (31).

In order to study the direct effects of flavonoid exposure on the growing fetus, fetal livers were isolated at day 14.5 of pregnancy and screened for M II translocations. These translocations were detectable in all fetuses, regardless of the maternal diet. This indicates that such translocations might be common events during fetal development, which are probably generated due to high topoll activity of the proliferating cells (16). However, the fact that less MII translocations were detected at 12 weeks of age, suggests that the cells carrying these translocations are either eliminated or have restricted expansion capacity.

Prenatal quercetin exposure in this study, led to a minor decrease in average litter size. It seems that quercetin exposure is more lethal to fetuses with homozygous Atm- $\Delta S R I$ mutations. In fact studying the direct effect of the flavonoids on the fetuses shows that transplacental quercetin exposure induces more chromosomal translocations than genistein. Both prenatal genistein and quercetin exposure had no effect on gender ratio and average birth weight, which suggest that in utero dietary supplementation did not affect normal development. Also the number of pups that died spontaneously after birth was not influenced by the diet. Three mice, all Atm- $\Delta$ SRI mut, developed leukemia (acute lymphoblastic leukemia or erythroleukemia), at 12 weeks of age, confirming our hypothesis that a decrease in DNA DSB-repair (ATM dysfunction) could enhance the leukemia risk. One mouse that developed erythroleukemia was not prenatally exposed to flavonoid supplements, suggesting that in this case the Atm- $\Delta$ SRI predisposition was responsible for the development of leukemia. Indeed, Atm- $\Delta$ SRI mut mice are known to have a $50 \%$ chance on developing malignancies (31). The ratio of malignancies between control and genistein exposed mice suggests that prenatal genistein exposure may increase the risk on developing malignancies. All malignancies, except acute lymphoblastic leukemia detected in our mice, were previously described in Atm- $\Delta S R I$ mice $(29,31)$. Atm- $\Delta$ SRI hetero mice develop different categories of tumors at an average age of 18.6 months. However, $44 \%$ of the Atm- $\Delta$ SRI mut mice die of thymic lymphomas up to 10 months of age. In our study, 1 out of $13 \mathrm{Atm}-\Delta \mathrm{SRI}$ mut mice in the control group had developed malignancy at the age of 3 months. The percentage of malignancies in the genistein and quercetin group was respectively $23 \%$ ( 3 out of $13 \mathrm{Atm}-\Delta \mathrm{SRI}$ mut mice) and $25 \%$ (1 out of 4 Atm- $\Delta$ SRI mut mice). The decrease in the number of Atm- $\Delta$ SRI mut mice born in the quercetin group further suggests the hazards of such exposure in a vulnerable population that lacks an effective DNA DSB-repair.

A complete blood count analysis showed that prenatal exposure to genistein not only influenced the lymphoblastic cell development, but also the myeloblastic cell development and overall 
erythropoiesis. Prenatal exposure to genistein associates with an up-regulation of erythropoiesis in adult mice, as seen in the increase in the number of red blood cells, which results in an increase in hemoglobin and hematocrit levels (ratio cells/plasma). The increase in red blood cell distribution width could be the result of an increase in the number of reticulocytes, which could also explain the increase in mean cell volume. However, it could also indicate that there is a coexistence of young and old red blood cells, suggesting a longer survival of these cells. Prenatal exposure to quercetin on the other hand only increased the size of the red blood cells and the amount of hemoglobin in reticulocytes. The increase in red blood cell size could be the result of an increase in the amount of hemoglobin per cell. An increase in the amount of hemoglobin in reticulocytes, would automatically lead to an increase in the amount of hemoglobin in erythrocytes. Knowing that quercetin has iron ion chelating capacities (32) and the fact that the heme part of hemoglobin contains iron, it can be suggested that the effects seen is due to a disturbed iron metabolism in these mice. Further investigation is needed to unravel these aspects of prenatal genistein/ quercetin exposure and the mechanisms behind the long term effects of diet during pregnancy on blood composition.

Due to the fact that flavonoids are present in a variety of food sources, the incidental daily intake can be as high as $1 \mathrm{~g}$, but can increase up to several grams in those supplementing their diet with flavonoids. The average daily dietary intake of quercetin is in the range of 4-68 mg. Daily isoflavone intake in Western countries is approximately 1 to $9 \mathrm{mg}$. In Asian countries however, the daily intake of isoflavones is much higher, reaching levels of $20-240 \mathrm{mg}$, due to the high consumption of soy (3). In our study pregnant mice were exposed to approximately 26.7-36.7 $\mathrm{mg} / \mathrm{kg}$ bodyweight genistein and 33.3-46.7 mg/ kg bodyweight quercetin per day. Record et al. (33) determined that mice fed $20 \mathrm{mg} / \mathrm{kg}$ genistein had an average plasma concentration of 10 $\mu \mathrm{M}$. In this study, pregnant mice were exposed to a higher dose of genistein and quercetin, probably resulting in even higher plasma concentrations. These concentrations are also higher compared with plasma concentrations seen in humans on both a Western or Asian diet (34). However, both flavonoids are freely available as supplements and the daily dose recommended by manufacturers can be as high as $1-2 \mathrm{~g}$ per day. When supplements are taken, plasma concentrations can be 10 to 20 times higher (35) than the levels we tested in mice, indicating that the doses used in this study are biologically relevant. It is also noteworthy that the metabolism of phytoestrogens is different in the fetus and adults. In human, fetal cord blood has a higher genistein level than maternal serum $(14,15,36)$. Taken together it is important to establish clear guidelines for the use of flavonoid supplements during pregnancy.

\section{Acknowledgments}

The authors sincerely thank Prof. Lavin (Queensland Institute of Medical Research) for providing the Atm- $\Delta$ SRI mice and Inger Rhijn, Marike van Gisbergen and Erik Ruijters for their assistance during the sacrificing of the mice and Yvonne Wallbrink for the blood composition determination.

This work was supported by grant number 06A031 from the American Institute for Cancer Research. 


\section{References}

1. Formica, J. V., and Regelson, W. (1995) Review of the biology of Quercetin and related bioflavonoids. Food Chem Toxicol 33, 1061-1080

2. Ross, J. A., and Kasum, C. M. (2002) Dietary flavonoids: bioavailability, metabolic effects, and safety. Annu Rev Nutr 22, 19-34

3. Skibola, C. F., and Smith, M. T. (2000) Potential health impacts of excessive flavonoid intake. Free Radic Biol M ed 29, 375-383

4. Spector, L. G., Xie, Y., Robison, L. L., Heerema, N. A., Hilden, J. M., Lange, B., Felix, C. A., Davies, S. M., Slavin, J., Potter, J. D., Blair, C. K., Reaman, G. H., and Ross, J. A. (2005) Maternal diet and infant leukemia: the DNA topoisomerase II inhibitor hypothesis: a report from the children's oncology group. Cancer Epidemiol Biomarkers Prev 14, 651-655

5. Strick, R., Strissel, P. L., Borgers, S., Smith, S. L., and Rowley, J. D. (2000) Dietary bioflavonoids induce cleavage in the M LL gene and may contribute to infant leukemia. Proc Natl Acad Sci U SA 97, 4790-4795

6. Felix, C. A., and Lange, B. J. (1999) Leukemia in infants. Oncologist 4, 225-240

7. Felix, C. A., Lange, B. J., Hosler, M. R., Fertala, J., and Bjornsti, M. A. (1995) Chromosome band 11q23 translocation breakpoints are DNA topoisomerase II cleavage sites. Cancer Res 55, 4287-4292

8. Libura, J., Slater, D. J., Felix, C. A., and Richardson, C. (2005) Therapy-related acute myeloid leukemia-like $M L L$ rearrangements are induced by etoposide in primary human CD34+cells and remain stable after clonal expansion. Blood 105, 2124-2131

9. Blanco, J. G., Edick, M. J., and Relling, M. V. (2004) Etoposide induces chimeric M II gene fusions. Faseb J 18, 173-175

10. Felix, C. A. (1998) Secondary leukemias induced by topoisomerase-targeted drugs. Biochim Biophys Acta 1400, 233-255

11. Libura, J., Ward, M., Solecka, J., and Richardson, C. (2008) Etoposide-initiated M LL rearrangements detected at high frequency in human primitive hematopoietic stem cells with in vitro and in vivo long-term repopulating potential. Eur J Haematol 81, 185-195

12. Ross, J. A. (2000) Dietary flavonoids and the MLgene: A pathway to infant leukemia? Proc Natl Acad Sci U SA 97, 4411-4413

13. Barjesteh van Waalwijk van Doorn-Khosrovani, S., Janssen, J., M aas, L. M., Godschalk, R. W., Nijhuis, J. G., and van Schooten, F. J. (2007) Dietary flavonoids induce MLL translocations in primary human CD34+cells. Carcinogenesis 28, 1703-1709

14. Adlercreutz, H., Yamada, T., Wahala, K., and Watanabe, S. (1999) Maternal and neonatal phytoestrogens in Japanese women during birth. Am J Obstet Gynecol 180, 737-743

15. Schroder-van der Elst, J. P., van der Heide, D., Rokos, H., Morreale de Escobar, G., and Kohrle, J. (1998) Synthetic flavonoids cross the placenta in the rat and are found in fetal brain. Am J Physiol 274, E253-256

16. Zandvliet, D. W., Hanby, A. M., Austin, C. A., Marsh, K. L., Clark, I. B., Wright, N. A., and Poulsom, R. (1996) Analysis of foetal expression sites of human type II DNA topoisomerase alpha and beta mRNAs by in situ hybridisation. Biochim Biophys Acta 1307, 239-247

17. Khanna, K. K. (2000) Cancer risk and the ATM gene: a continuing debate. J Natl Cancer Inst 92, 795-802

18. Montecucco, A., and Biamonti, G. (2007) Cellular response to etoposide treatment. Cancer Lett 252, 9-18

19. Oguchi, K., Takagi, M., Tsuchida, R., Taya, Y., Ito, E., Isoyama, K., Ishii, E., Zannini, L., Delia, D., and Mizutani, S. (2003) Missense mutation and defective function of ATM in a childhood acute leukemia patient with MLL gene rearrangement. Blood 101, 3622-3627

20. Ye, R., Goodarzi, A. A., Kurz, E. U., Saito, S., Higashimoto, Y., Lavin, M. F., Appella, E., Anderson, C. W., and LeesMiller, S. P. (2004) The isoflavonoids genistein and quercetin activate different stress signaling pathways as shown by analysis of site-specific phosphorylation of ATM, p53 and histone H2AX. DNA Repair (Amst) 3, 235-244

21. Bakkenist, C. J., and Kastan, M. B. (2003) DNA damage activates ATM through intermolecular autophosphorylation and dimer dissociation. Nature 421, 499-506

22. Golding, S. E., Rosenberg, E., Khalil, A., M cEwen, A., Holmes, M., Neill, S., Povirk, L. F., and Valerie, K. (2004) Double strand break repair by homologous recombination is regulated by cell cycle-independent signaling via ATM in human glioma cells. J Biol Chem 279, 15402-15410

23. Gumy-Pause, F., Wacker, P., and Sappino, A. P. (2004) ATM gene and lymphoid malignancies. Leukemia 18, 238-242

24. van Gent, D. C., Hoeijmakers, J. H., and Kanaar, R. (2001) Chromosomal stability and the DNA doublestranded break connection. Nat Rev Genet 2, 196-206

25. Barlow, C., Hirotsune, S., Paylor, R., Liyanage, M., Eckhaus, M., Collins, F., Shiloh, Y., Crawley, J. N., Ried, T., Tagle, D., and Wynshaw-Boris, A. (1996) Atm-deficient mice: a paradigm of ataxia telangiectasia. Cell 86, 159-171

26. FitzGerald, M. G., Bean, J. M., Hegde, S. R., Unsal, H., MacDonald, D. J., Harkin, D. P., Finkelstein, D. M., Isselbacher, K. J., and Haber, D. A. (1997) Heterozygous ATM mutations do not contribute to early onset of breast cancer. Nat Genet 15, 307-310

27. Stankovic, T., Stewart, G. S., Byrd, P., Fegan, C., Moss, P. A., and Taylor, A. M. (2002) ATM mutations in sporadic lymphoid tumours. Leuk Lymphoma 43, 1563-1571 
28. Sung, P. A., Libura, J., and Richardson, C. (2006) Etoposide and illegitimate DNA double-strand break repair in the generation of MLL translocations: new insights and new questions. DNA Repair (Amst) 5, 1109-1118

29. Spring, K., Ahangari, F., Scott, S. P., Waring, P., Purdie, D. M., Chen, P. C., Hourigan, K., Ramsay, J., McKinnon, P. J., Swift, M., and Lavin, M. F. (2002) Mice heterozygous for mutation in Atm, the gene involved in ataxia-telangiectasia, have heightened susceptibility to cancer. Nat Genet 32, 185-190

30. Ross, J. A., Potter, J. D., Reaman, G. H., Pendergrass, T. W., and Robison, L. L. (1996) Maternal exposure to potential inhibitors of DNA topoisomerase II and infant leukemia (United States): a report from the Children's Cancer Group. Cancer Causes Control 7, 581-590 




\section{Chapter 3}

\section{Epigenetics: Prenatal exposure to genistein leavesa permanent signature on the hematopoietic lineage}

Vanhees K, Coort S, Ruijters EJB, Godschalk RWL, van Schooten FJ, Barjesteh van Waalwijk van Doorn-Khosrovani S 


\begin{abstract}
Recent studies demonstrate that maternal diet during pregnancy results in long-lasting effects on the progeny. Supplementation of maternal diet with genistein, a phytoestrogen ubiquitous in the daily diet, altered coat color of Agouti mice due to epigenetic changes. We studied hematopoiesis of mice prenatally exposed to genistein $(270 \mathrm{mg} / \mathrm{kg}$ feed) compared with mice prenatally exposed to phytoestrogen-poor feed and observed a significant increase in granulopoiesis, erythropoiesis and mild macrocytosis at the adult age of 12 weeks. Genistein exposure was associated with hypermethylation of certain repetitive elements, which coincided with a significant down-regulation of estrogen responsive genes and genes involved in hematopoiesis in bone marrow cells of genisteinexposed mice, as assessed by microarray technology. Although, genistein exposure did not affect global methylation in fetal liver of fetuses at embryonic day 14.5, it accelerated the switch from primitive to definitive erythroid lineage. Altogether, our data demonstrate that prenatal exposure to genistein affects fetal erythropoiesis and exerts life-long alterations in gene expression and DNA methylation of hematopoietic cells.
\end{abstract}




\section{Introduction}

Genistein is a naturally occurring phytoestrogen found in soy products. There is an increasing interest in this flavonoid due to its antioxidant properties, but also because there is a general believe that phytoestrogen intake has beneficial effects $(1,2)$.

However, recent studies have revealed that genistein exposure through maternal diet during pregnancy can result in long-lasting effects on the progeny. Prenatal exposure of heterozygous yellow agouti mice to genistein, through maternal diet, altered both coat color and body weight. These changes were caused by hypermethylation of transposable repetitive elements (IAP) upstream of the transcription start site of the Agouti gene (3). Other studies have shown that transplacental exposure of rats to genistein exerts longlasting effects on the endocrine and immune system and altered stress response and postweaning growth $(4,5)$. Recently, Möller et al. (6) demonstrated that genistein exposure during development induces long-term effects on the uterine gene expression profile.

Nutritional deficiencies (including vitamin B12 and folate) and drug exposure can affect blood composition; for instance macrocytosis can have different causes, ranging from primary bone marrow disorders to nutritional deficiencies (7). Prolonged use of estrogenic compounds such as oral contraceptives is also reported to induce macrocytosis, presumably by interfering with folate cofactor interactions and affecting DNA synthesis (8).

In the present study we observed significant changes in blood composition of mice that were prenatally exposed to genistein. Prenatal genistein exposure was associated with increased granulopoiesis and erythropoiesis together with moderate macrocytosis at adult age. The macrocytosis observed in the genistein exposed animals may be attributed to estrogenic properties of this compound, due to its structural similarity to 17ß-estradiol (9). However, it is remarkable that such effects are observed at adult age, while genistein exposure has taken place only during the prenatal period. We therefore assume that the past exposure to genistein has left a permanent signature on the hematopoietic lineage of these mice. As genistein exposure is known to alter both global DNA methylation (3) and gene expression (6), we hypothesize that prenatal exposure to genistein leads to adaptation of hematopoiesis by altering both DNA methylation as well as gene expression. In order to find out whether genistein leaves permanent transcriptomic/epigenetic signatures in hematopoietic cells, we compared both DNA methylation of repetitive elements and gene expression profiles in hematopoietic cells of mice prenatally exposed to genistein with the control group at adult age. The methylation status and fetal blood development was also assessed during the fetal period, to study the direct effects of the genistein supplementation.

\section{Material and methods}

Mice and sample collection

Mice (129/Sv):C57BL/6J background) approximately 8 weeks of age, received either normal chow $(n=8$, low phytoestrogen content complete feed for mice breeding, in which neither soybean nor alfalfa products are used, resulting in minimized concentrations of the phytoestrogens genistein, daidzein and coumestrol, ssniff $\Theta_{\text {, }}$ 
Soest, Germany) or the same chow (ssniff $\AA$ ) supplemented with genistein $(270 \mathrm{mg} / \mathrm{kg}$ feed, $n=9$ ) (LC Laboratories, Woburn, MA, USA) from 3 days before conception until the end of pregnancy. Male mice were placed in the cage only for the duration of copulation. After delivery litters were not equalized and all mothers and pups received normal (low phytoestrogen) diet, making the prenatal period the only window of exposure. Offspring were sacrificed at 12 weeks of age by cardiac puncture (Figure 1). Blood was collected in EDTA-tubes (Terumo, Leuven, Belgium). Bone marrow was isolated by removing the femurs and flushing the marrow with PBS.

To study the direct effects of diet on fetal hematopoiesis, mice were mated overnight. The presence of a vaginal plug the next morning was defined as 0.5 day post conception. On day 14.5 of pregnancy (E14.5), mice were sacrificed to isolate the fetuses, fetal blood and fetal liver.

The mouse experiments were conducted in accordance with Dutch animal protection laws by the guidelines of the local veterinary authorities.

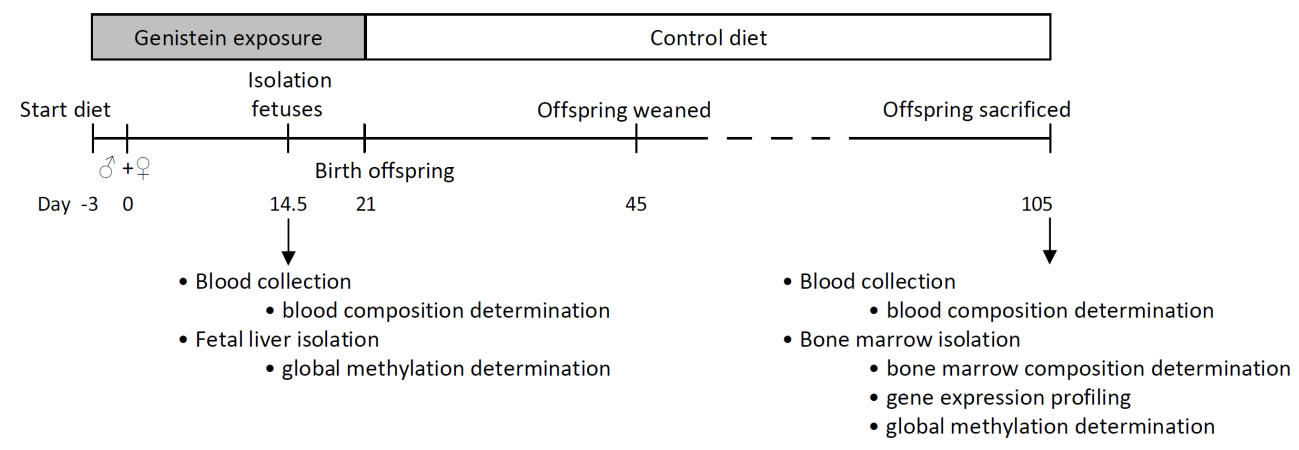

Figure 1. Study design

Blood composition of adult mice

Blood composition was determined in duplicate, using ADVIA 120 Hematology System (Siemens AG, Erlangen, Germany) following user's manual. The following parameters were measured: total number of red blood cells $\left(10^{12} / \mathrm{L}\right)$, hemoglobin level $(\mathrm{mmol} / \mathrm{L})$, hematocrit level (L/ L), mean corpuscular volume (fL), mean corpuscular hemoglobin (fmol), mean corpuscular hemoglobin concentration (mmol/ L), red blood cell distribution width (\%), hemoglobin distribution width ( $\mathrm{mmol} / \mathrm{L})$, total amount of platelets $\left(10^{9} / \mathrm{L}\right)$, mean platelet volume $(\mathrm{fl})$, total amount $\left(10^{9} / \mathrm{L}\right)$ and percentage of reticulocytes, mean corpuscular hemoglobin concentration of reticulocytes (fmol), total number of white blood cells $\left(10^{9} / \mathrm{L}\right)$, total amount $\left(10^{9} / \mathrm{L}\right)$ and percentage of neutrophils, lymphocytes, monocytes, eosinophils and basophils.

Blood (fetuses) and bone marrow (adult mice) cytology

After initial fixation of blood $(10 \mu \mathrm{l})$ or bone marrow smears (isolated from one of both femurs) by methanol, smears were stained in May-Grünwald solution (SigmaAldrich, Steinham, Germany) for 5 minutes and washed in tap water. Subsequently, the smears were stained with Giemsa solution (Merck, Darmstadt, Germany) for 20 
minutes and washed again in tap water. The blood and bone marrow smears were examined by two independent, experienced examiners, counting approximately 500 cells per slide, using a Leica DM RB microscope (Leica M icrosystems B.V., Rijswijk, the Netherlands).

\section{Genome-wide gene expression analysis of adult mice}

RNA from bone marrow cells isolated from one femur was isolated with TRIzol Reagent (Invitrogen, Breda, the Netherlands) according to the manufacturer's instructions. Genomewide gene expression was determined using whole mouse genome (4X44K) oligonucleotide microarrays (Agilent, Santa Clara, CA, USA) according to the manufacturer's instructions. Using the Low RNA Input Linear Amplification Kit (Agilent), cyanine-5-labeled cRNA was generated from RNA of each sample (a total of 6 bone marrow samples: 3 controls and 3 genisteinexposed male mice). Next, samples were hybridized together with cyanine-3-labeled reference CRNA produced from the RNA pool of the 3 control mice (reference sample). Image analysis and initial quality control were performed using the Agilent Feature Extraction (FE) Software v10.5 and Spotfire DesicionSite v9.1 (TIBCO Spotfire, Somerville, MA, USA). Thereafter, microarray data analysis was performed by importing the text-files generated by the Agilent FE Software into R2.8.1 using the Bioconductor 'limma' package 2.8.1 (10). The values for control spots and spots that did not meet the quality control criteria were flagged. The flagged spots were not used in the statistical analysis. In addition, the background-corrected intensities of all microarrays were normalized using the locally weighted scatterplot smoothing (LOESS) algorithm. Finally, a linear model was fitted to the intensities for each reporter, and the genistein-treated mice were compared to controls using an unpaired moderated t-test using the 'limma' functions Imfit and eBayes (10). Benjamini-Hochberg adjusted P-values were used to correct for multiple testing. All Agilent reporters were re-annotated to ensure reporter specificity and to optimize recognition by the pathway analysis procedures (11).

M ethylation-sensitive M crBC-real-time polymerase chain reaction (PCR) assay of fetuses and adult mice

Analysis of methylation pattern of the repetitive elements, i.e. long interspersed nucleotide elements (LINEs), short interspersed nucleotide elements (SINEs), intracisternal A particle (IAP), major and minor satellites, was performed using the methylation-sensitive M crBC-real-time PCR assay (12). $1 \mu \mathrm{g}$ of genomic DNA was digested overnight at $37^{\circ} \mathrm{C}$ using $10 \mathrm{U}$ of M crBC (New England Biolabs, Beverly, M A, USA), an endonuclease which cleaves DNA containing 5-methylcytosine, but will not cleave unmethylated DNA. The DNA strand breaks prevent amplification of methylated DNA in the quantitative real-time PCR assay. Two-step quantitative realtime PCR was performed using IQ SYBR Green Supermix (Bio-Rad Laboratories, Veenendaal, the Netherlands) with $4 \mathrm{ng}$ of $\mathrm{McrBC}$-digested DNA and $25 \mathrm{pmol}$ of each primer (Eurogentec, M aastricht, the Netherlands) in a reaction volume of $25 \mu \mathrm{l}$. The forward and reverse primers sequence for the different repetitive elements and endogenous reference were: LINE: 5'-TTTGGGACACAATGAAAGCA-3' and 5'CTGCCGTCTACTCCTCTTGG-3'; SINEB1: 5'-GTGGCGCACGCCTTTAATC-3' and 5'GACAGGGTTTCTCTGTGTAG-3`; SINEB2: 5`- GAGATGGCTCAGTGGTTAAG-3` and 5'CTGTCTTCAGACACTCCAG-3`; IAP-GAG: 5`-AGCAGGTGAAGCCACTG-3` and 5'- 
CTTGCCACACTTAGAGC-3; M ajor satellite: 5`-GACGACTTGAAAAATGACGAAATC-3`and 5`CATATTCCAGGTCCTTCAGTGTGC-3`; and M inor satellite: 5 '-CATGGAAAATGATAAAAACC3 ' and 5'-CATCTAATATGTTCTACAGTGTGG-3`. The cycling conditions consisted of an initial denaturation at $95{ }^{\circ} \mathrm{C}$ for 10 minutes, followed by 40 cycles of $95^{\circ} \mathrm{C}$ for 45 seconds, $58{ }^{\circ} \mathrm{C}$ for 90 seconds, with an exception for the major and minor satellites for which this step was performed at $60^{\circ} \mathrm{C}$, using the iCycler (Bio-Rad). Data were analyzed by M yiQ Software system (Bio-rad), Ct values were normalized for endogenous reference (HPRT), compared with the calibrator (i.e. average $\mathrm{Ct}$ value of 4 control samples for the adult mice and of 3 control samples for the fetuses) and expressed as relative expression $\left(2^{-\Delta \Delta C t}\right)$. An increase in PCR amplification products is indicative of hypomethylation, whereas a decrease in PCR amplification products indicates hypermethylation.

\section{Results}

Prenatal exposure to genistein influences hematopoiesis in adulthood

A comparison of the complete blood count of 41 male and female adult mice (12 weeks of age) from 9 different litters (with an average size of $6.4 \pm 2.1$ ) that were prenatally exposed to genistein through maternal diet (supplemented with $270 \mathrm{mg}$ genistein/ $\mathrm{kg}$ diet from 3 days before conception throughout pregnancy), with the same number of age matched male and female control mice from 8 different litters (with an average litter size of $5.2 \pm 2.3$ ), demonstrated significant differences in blood composition (Table 1). Prenatal exposure to genistein was associated with higher number of red blood cells (mean \pm SD, $7.44 \pm 0.71 \times 10^{12}$ cells versus $7.03 \pm 0.80 \times 10^{12}$ cells, $P=0.03)$ and reticulocytes (157.57 $\pm 52.54 \times 10^{9}$ cells versus $106.79 \pm 42.00 \times 10^{9}$ cells, $P=0.06)$. In accordance, the mean corpuscular volume $(46.31 \pm 2.10 \mathrm{fL}$ versus $44.96 \pm 2.80 \mathrm{fL}, P=0.02$ ), red blood cell distribution width (13.92 \pm 1.12 versus $13.35 \pm$ $0.75, P=0.01)$, hemoglobin $(7.25 \pm 0.53 \mathrm{mmol} / \mathrm{L}$ versus $6.78 \pm 0.67 \mathrm{mmol} / \mathrm{L}, P=0.001$ ) and hematocrit levels $(0.35 \pm 0.04 \mathrm{~L} / \mathrm{L}$ versus $0.32 \pm 0.05 \mathrm{~L} / \mathrm{L}, \mathrm{P}=0.004)$ were elevated in the genistein group. Examination of the bone marrow cellularity of adult mice $(n=3)$, which were prenatally exposed to genistein, showed no significant difference in the number of early and late erythroid progenitors with the control group.

Table 1. Persistent effects of prenatal genistein exposure on blood composition in 12 week old mice

\begin{tabular}{|c|c|c|c|}
\hline & \multirow{2}{*}{$\begin{array}{l}\text { Control }(\mathbf{n = 4 1 )} \\
\text { Mean } \pm \text { SE }\end{array}$} & \multicolumn{2}{|l|}{ Genistein ( $n=41)$} \\
\hline & & Mean \pm SE & P-value \\
\hline Red blood cells $\left(10^{12} / \mathrm{L}\right)$ & $7.03 \pm 0.13$ & $7.44 \pm 0.12$ & 0.026 \\
\hline Hemoglobin (mmol / L) & $6.78 \pm 0.11$ & $7.25 \pm 0.09$ & 0.001 \\
\hline Mean corpuscular volume (fL) & $44.96 \pm 0.45$ & $46.31 \pm 0.34$ & 0.018 \\
\hline Hematocrit (L/ L) & $0.32 \pm 0.008$ & $0.35 \pm 0.007$ & 0.004 \\
\hline Absolute amount of reticulocytes ( $\left.10^{9} / \mathrm{L}\right)$ & $106.79 \pm 15.88$ & $157.57 \pm 17.51$ & 0.056 \\
\hline Red blood cell distribution width (\%) & $13.35 \pm 0.12$ & $13.92 \pm 0.19$ & 0.013 \\
\hline White blood cells $\left(10^{9} / \mathrm{L}\right)$ & $1.45 \pm 0.9$ & $1.79 \pm 0.16$ & 0.064 \\
\hline Absolute amount of neutrophils ( $\left.10^{9} / \mathrm{L}\right)$ & $0.23 \pm 0.14$ & $0.32 \pm 0.03$ & 0.021 \\
\hline Absolute amount of eosinophils $\left(10^{9} / \mathrm{L}\right)$ & $0.06 \pm 0.005$ & $0.09 \pm 0.02$ & 0.041 \\
\hline
\end{tabular}


However, the number of pyrenocytes was significantly elevated in the genistein exposed animals, indicating an increased enucleation of the erythroid cells (10.47 \pm $5.39 \%$ versus $1.28 \pm 1.49 \%, P=0.047$ ) (Figure 2 ). Furthermore, we observed a higher number of granulocytic cells in the genistein exposed animals $(39.57 \pm 4.93 \%$ versus $24.91 \pm 9.58 \%$, $P=0.08$ ), which is in accordance with the significantly higher number of neutrophils $\left(0.32 \pm 0.20 \times 10^{9}\right.$ cells versus $0.23 \pm 0.09 \times 10^{9}$ cells, $\left.\mathrm{P}=0.02\right)$ and eosinophils $\left(0.09 \pm 0.09 \times 10^{9}\right.$ cells versus $0.06 \pm 0.03 \times 10^{9}$ cells, $\left.P=0.04\right)$ in the peripheral blood.

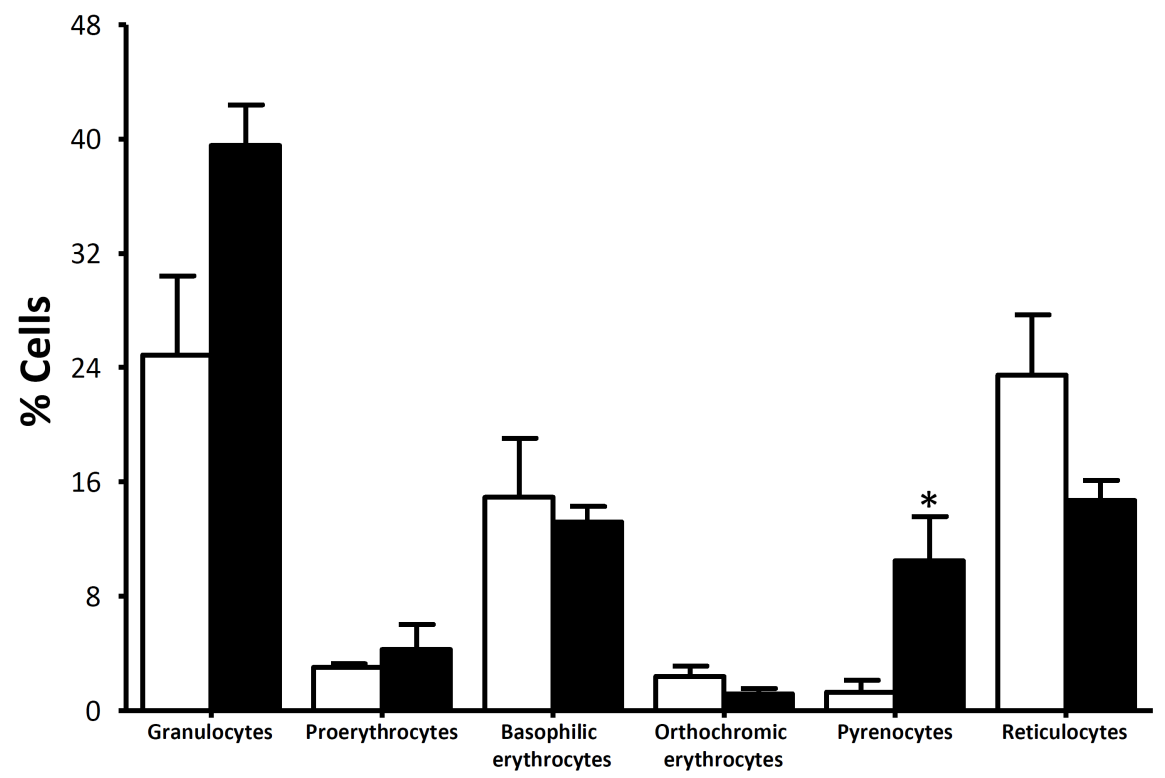

Figure 2. Long-term effect of prenatal exposure to genistein on bone marrow cellularity.

Bone marrow smears of 12 week old mice from the control ( $n=3$; white bars) and genistein exposed ( $n=3$; black bars) group were analyzed to determine the number of pyrenocytes, early and late (proerythroblast, basophilic erythroblast and ortochromic erythroblast) erythroid progenitors and granulocytic cells. Bars represent the percentage of cells. Error bars represent the standard error. Statistically significant differences were analyzed using One-way ANOVA: *: $\mathrm{P} \varangle .05$.

Prenatal genistein exposure modifies gene expression in adulthood

As prenatal exposure to genistein had induced long-term effects on the blood and bone marrow composition, we hypothesized that the effects of this past exposure to genistein would still be detectable in the gene expression profile of the hematopoietic cells. Therefore, we compared the gene expression profile of bone marrow cells of animals which were prenatally exposed to genistein $(n=3)$ with that of the control group $(n=3)$, using whole mouse genome $(4 X 44 K)$ oligonucleotide microarrays (Agilent). The animals selected for the microarray analysis were all male mice and belonged to different litters to minimize possible litter effects. Approximately $20 \%$ of the 21,742 annotated gene products was differentially expressed between the genistein and the control group ( $n=4352,1.2 \varangle$ old change or fold change $<-1.2$, $\mathrm{P}<0.05$ ). $83 \%$ and $36 \%$ of the gene products belonging respectively to the estrogen receptor signaling and hematopoiesis pathway (according to GO terms and literature) 
were differentially expressed. Unsupervised hierarchical clustering of differentially expressed genes with a high degree of statistical significance $(P<0.001)$ demonstrates overall differences in gene expression between groups. It is noteworthy that the gene products that were significantly up-regulated in the genistein group (fold change $>1.2$, $P<0.001$ ) represent only $10 \%$ of the total number of differentially expressed genes.

Previously, it has been demonstrated that in vitro exposure of XG-1 myeloma cell line to genistein results in down-regulation of NF- $\mathrm{kB}$ and NF-kB-regulated gene products, including Bc|2|1, Cyclin D1 and intercellular adhesion molecule-1 (Icam-1) (13). In our study, genistein exposure resulted in a down-regulation of NF- $\kappa B$ and NF- $\mathrm{BB}$-regulated gene products, including $\mathrm{Bc}|2| 1$, Cyclin D1 and intercellular adhesion molecule-1 (Icam-1) in the hematopoietic cells of mice prenatally exposed to genistein. In addition to Icam-1, prenatal genistein exposure attenuated the expression of several other adhesion molecules, such as neural cell adhesion molecule 1 (Ncam1), Ecadherin (Cdh1), integrin beta $1(\operatorname{Intgb} 1)$, integrin alpha $1(\operatorname{Itga} 1)$ and chemoattractant protein 1 (M CP-1), P-selectin and selectin P ligand (Selplg). Also Nocht1, M dm2 and Pdkcd showed a significantly lower mRNA expression, 12 weeks after withdrawal from genistein exposure. Likewise, the expression levels of certain genes, such as Cdkn1b (p27kip1) and retinoblastoma binding protein 8 (Rbbp8) were elevated in the genistein exposed animals. Interestingly, some other genes that were previously reported to be up-regulated in reaction to direct genistein exposure at adulthood (Stat3, Pten and component C3) $(14,15)$ were significantly suppressed in mice that were exposed to genistein during in utero development.

Although some of the differences in gene expression can partly be attributed to differences in bone marrow cellularity, persistent effects of genistein exposure on gene expression were still observed 12 weeks after withdrawal of the genistein exposure.

Significant down-regulation of estrogen responsive genes

Because it is known that genistein is a phytoestrogen, and thus has estrogenic properties (16), we studied the expression of different estrogen responsive genes. Notably, several estrogen responsive genes (Grin2d, ApoE, Cdknla, Macrod, Vegfa, Hdac6, Tacc1, Abcc5, Ctsd, Ccnd1, Pcna, Igf2) were suppressed in the hematopoietic cells of adult mice prenatally exposed to genistein (Table 2). It is known that activation of the aryl hydrocarbon receptor (AhR) by its ligands, e.g. benzo[a]pyrene and 2,3,7,8-tetrachlorodibenzo-p-dioxin (TCDD), promotes the expression of the estrogen-responsive genes (17). It is remarkable that the AhR expression level was indeed significantly elevated (fold change $=1.49$, P-value $=0.006$ ) in the bone marrow of mice that were prenatally exposed to genistein.

Changes in expression of genes involved in hematopoiesis

AhR is known to regulate mRNA expression of several genes with important roles in hematopoiesis, including Cdkn1b (p27Kip1), Cdkn1a (p21 waf1/cip1), Cdk2, Myc and genes encoding for CCAAT/ enhancer-binding protein (18). Strikingly, the expression of Cdkn1b, Cebpa, Cebpb was up-regulated, while the expression of Myc was downregulated, indicating that granulocyte differentiation was stimulated. Cdk2, up- 
regulated during primitive erythropoiesis, was significantly repressed in the genistein group, suggesting an increase in adult erythropoiesis (Table 3 ). AhR normally binds its chaperon Arnt to associate with the estrogen receptors and to activate transcription of estrogen-responsive genes (19). However, Arnt mRNA expression was significantly down-regulated (fold change $=3.06, \mathrm{P}$-value $=6.4 \times 10^{-6}$ ) in the genistein group. In addition to the genes regulated by AhR, we encountered several other hematopoiesisrelated genes that were differentially expressed in bone marrow of the genistein group. A deficiency in Cdkn 1a, Egln1, Stat3, Dok1 and Pten gene expression is known to increase proliferation of hematopoietic stem cells. All these genes were significantly repressed in the genistein group; while Bmil and Angpt1, which are required respectively for the self-renewal and protection of hematopoietic stem cells, were up-regulated. A down-regulation of $\mathrm{M} \mathrm{yc}$ in the genistein group was also associated with lower expression of Thbs1 and Vegf, resulting in a lower expression of the cellsurface receptor of Vegf $(\mathrm{Kdr})$. In general, the expression of several genes that regulate erythroid cell function and development (Bcl211, Stat5a, Gata1, Mapk14, Epb4.2, Maea, Slc12a4, Dhfr, Flvcr1, Thpo, Epb4.1 and Ptprc) were significantly altered in the genistein group, resulting in an up-regulation of erythrocyte proliferation. Moreover, genistein exposed mice showed an altered expression of genes contributing to an enhanced granulocytic differentiation/proliferation (Lrg1, Cebpa, Icam1, JunB, Thbs1, Cdk2 and Cdknlb).

Table 2. Down-regulation of estrogen responsive genes in the bone marrow of adult mice prenatally exposed to genistein

\begin{tabular}{|c|c|c|c|c|}
\hline Gene & $\begin{array}{l}\text { Genebank } \\
\text { accession } \\
\text { number }\end{array}$ & Description & $\begin{array}{l}\text { Fold } \\
\text { change }\end{array}$ & P-value \\
\hline $\begin{array}{l}\text { Cdkn1a (p21 } \\
\text { waf1/cip1) }\end{array}$ & NM_007669 & Cyclin-dependent kinase inhibitor $1 \mathrm{~A}$ & -1.78 & 0.006 \\
\hline Ctsd & NM_009983 & Cathepsin D & -2.05 & 0.0002 \\
\hline Condl & NM_008796 & Cyclin D1 & -2.04 & 0.0002 \\
\hline Pcna & $\mathrm{NM}^{-} 011045$ & Proliferating cell nuclear antigen & -1.99 & 0.0007 \\
\hline ApoE & $N M^{-} 009696$ & Apolipoprotein $\mathrm{E}$ & -2.14 & 0.002 \\
\hline $\mathrm{C} 3$ & NM_-009778 & Complement component 3 & -1.50 & 0.009 \\
\hline $\operatorname{lgf} 2$ & $\mathrm{NM}^{-} 010514$ & Insulin-like growth factor 2 & -2.69 & 0.02 \\
\hline Grin2d & NM_-008172 & $\begin{array}{l}\text { Glutamate receptor, ionotropic, N-methyl- } \\
\text { D-aspartate subunit } 2 d\end{array}$ & -1.50 & 0.02 \\
\hline Macrod1 & NM_134147 & Macro domain-containing 1 & -1.73 & 0.003 \\
\hline Vegfa & NM ${ }^{-} 001025250$ & Vascular endothelial growth factor & -1.93 & 0.004 \\
\hline Hdac6 & NM_010413 & Histone deacetylase 6 & -1.89 & 0.006 \\
\hline Abcc5 & NM_-013790 & ATP-binding cassette subfamily $\mathrm{C}$ member 5 & -2.50 & 0.00008 \\
\hline Taccl & NM_-177089 & $\begin{array}{l}\text { Transforming, acidic, coiled-coil- } \\
\text { containing protein }\end{array}$ & -2.52 & 0.0003 \\
\hline
\end{tabular}




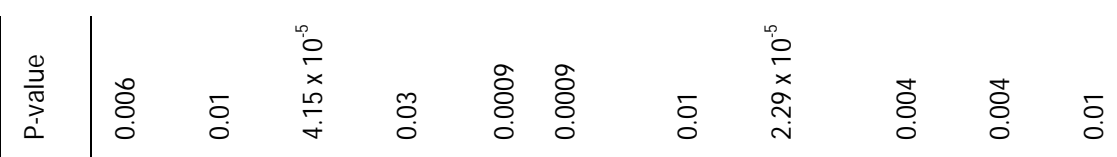

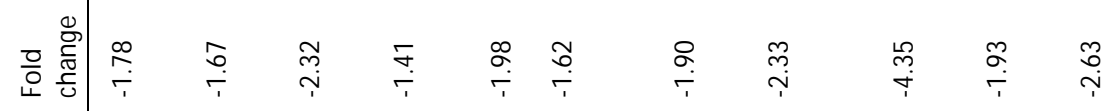

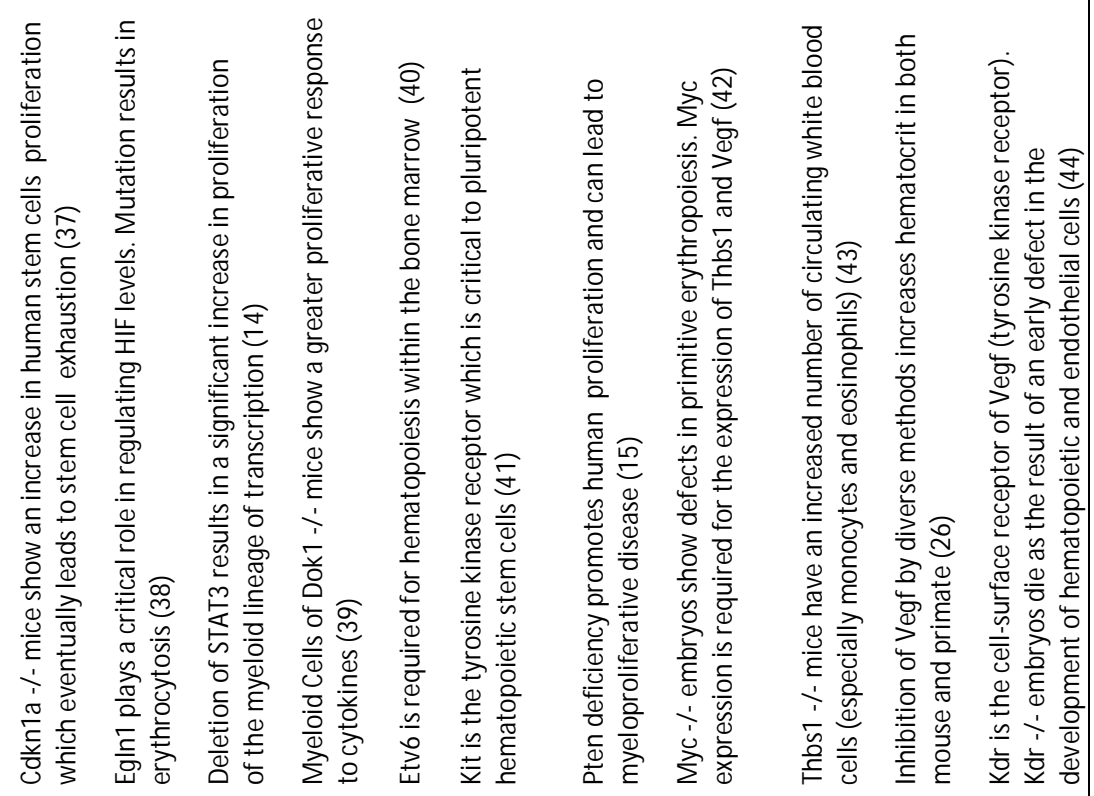

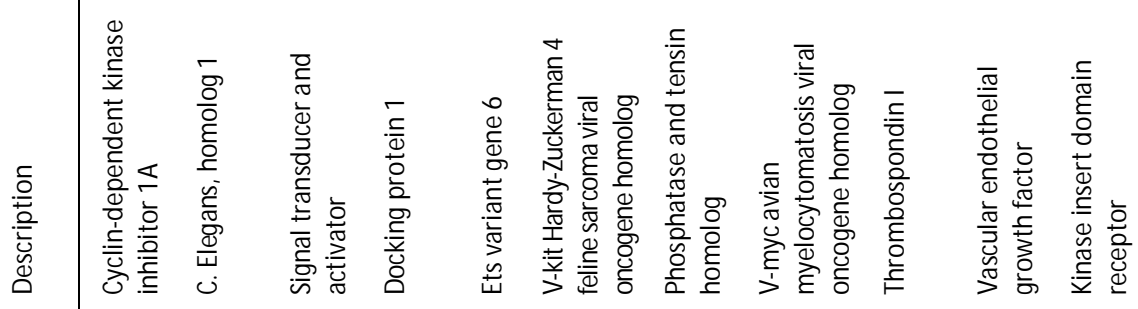

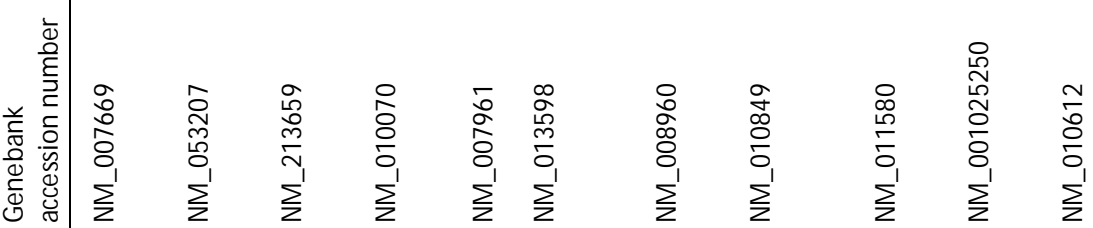
क

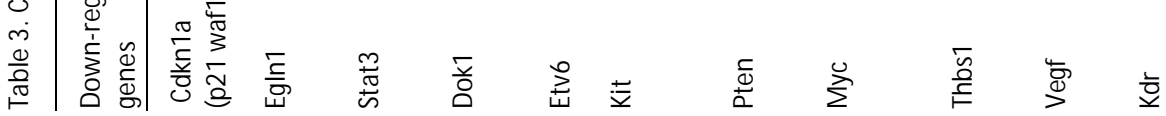




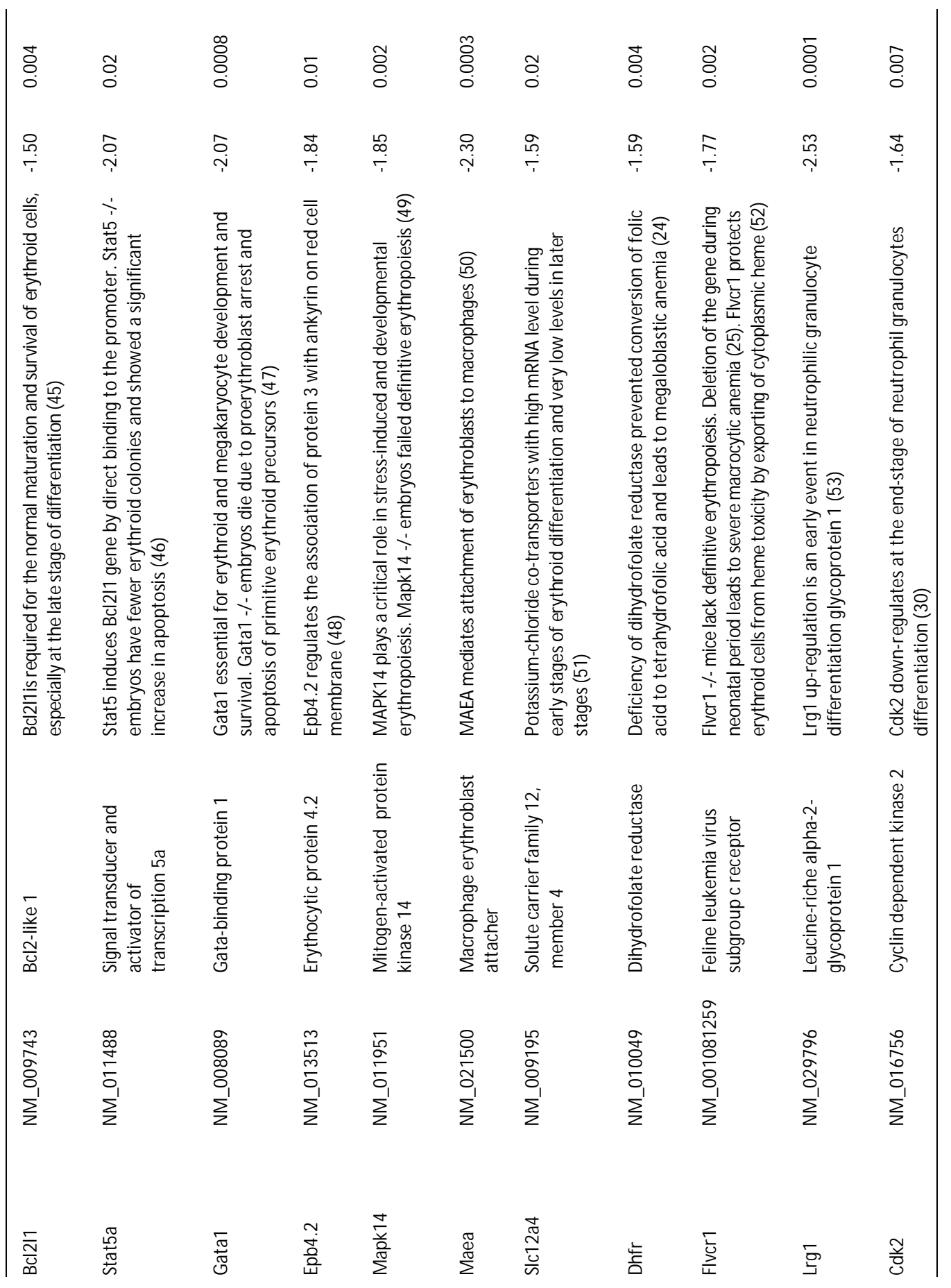




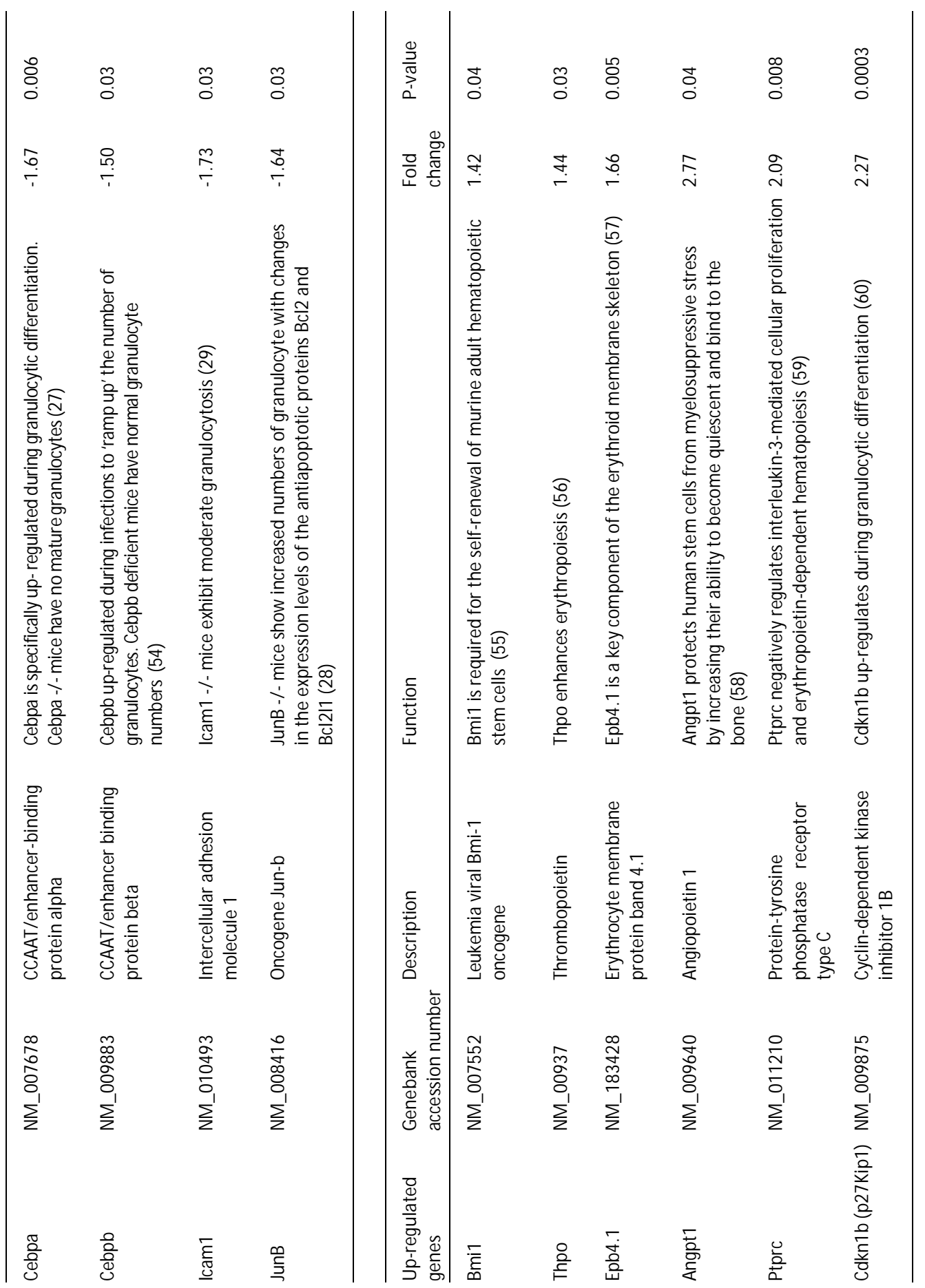




\section{Prenatal genistein exposure leads to long-term epigenetic changes}

As genistein exposure, early in development, exerts long-term changes in gene expression, we assumed that these effects might be mediated through epigenetic modification.

To examine whether prenatal genistein exposure could lead to long-term epigenetic modifications, we employed an assay in which the methylation-sensitive endonuclease $\mathrm{M}$ crBC cleaves methylated DNA but leaves unmethylated CpGs intact. By subsequent PCR amplification, one could quantify the unmethylated repetitive elements (12).

Using this assay, we determined the methylation status of major and minor satellites, intracisternal A particle (IAP-GAG), long interspersed nucleotide elements (LINE1) and short interspersed nucleotide elements (SINEB1 and SINEB2) in hematopoietic cells of both the control and the genistein group.
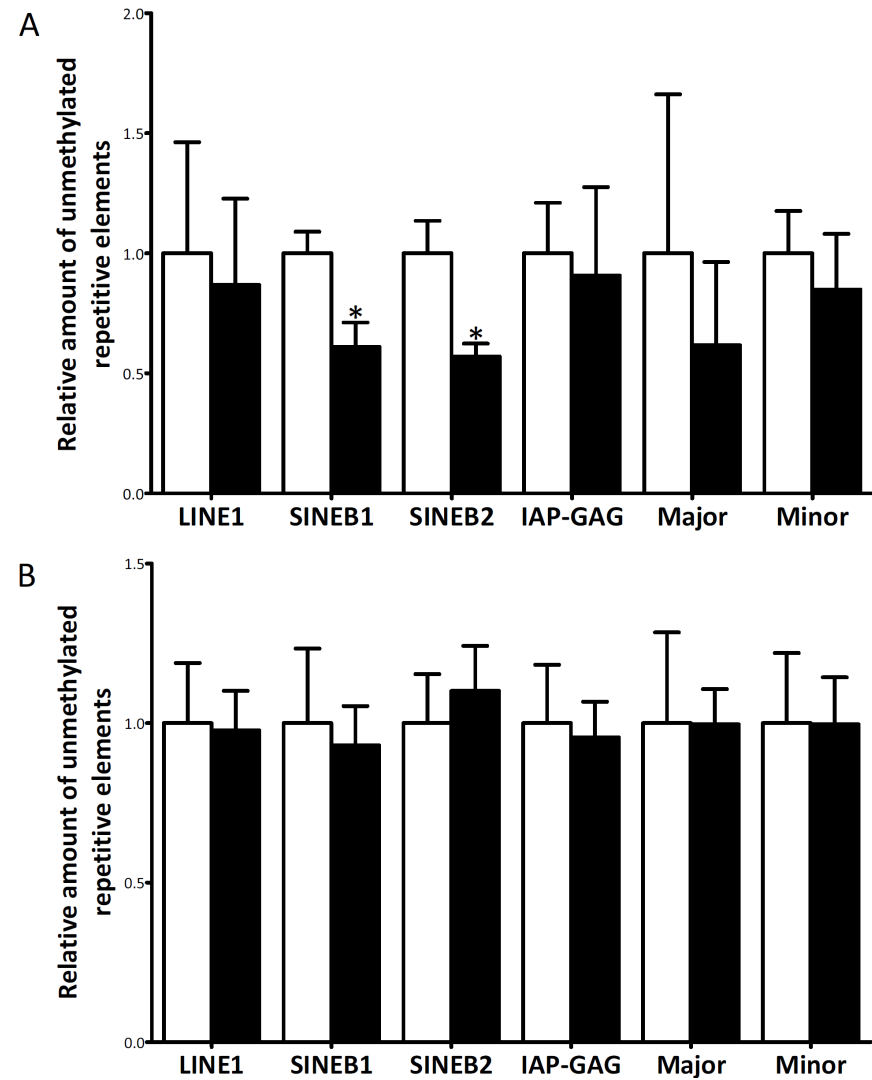

Figure 3. The effect of genistein on DNA methylation of repetitive elements.

A Long-term effects of prenatal exposure to genistein on DNA methylation of repetitive elements in bone marrow cells of mice prenatally exposed to genistein $(n=3)$ compared with control mice $(n=3)$. B Short-term effects of prenatal exposure to genistein on DNA methylation of repetitive elements in fetal liver at E14.5 (genistein exposed fetuses $n=4$ versus control fetuses $n=4$ ). The degree of methylation of repetitive elements: long interspersed nucleotide elements (LINE1), short interspersed nucleotide elements (SINEB1 and SINEB2), intracisternal A particle (IAP-GAG), and Major and Minor satellites were determined by methylation-sensitive McrBC-real-time PCR assay. Bars represent the normalized average expression level of the unmethylated repetitive elements between the genistein-exposed (black bars) and the control group (white bars). Error bars represent standard error. Statistical significance was determined by One-way ANOVA: *: $\mathrm{\diamond} \diamond .05$. 
These elements constitute almost $37.5 \%$ of the mouse genome (20). Overall, bone marrow cells of the genistein group $(n=3)$ showed moderate hypermethylation of the repetitive elements observed as lower level of PCR products after $M$ crBC digestion compared with the control group ( $n=3$, Figure 3A). Especially, the SINEB1 and SINEB2 elements were significantly hypermethylated $(P=0.045$ and $P=0.042$, respectively). In order to investigate whether these epigenetic modifications had already occurred in utero, we studied the methylation status of the repetitive DNA elements in the fetal liver (E14.5) of the control group $(n=4)$ and compared with genistein exposed fetuses $(n=4)$. We did not, however, observed any difference in the methylation status of repetitive elements between the diet groups at that particular time point (Figure 3B).

\section{Genistein exposure affects fetal blood cell development}

Although methylation status of the repetitive elements in fetuses which were exposed to genistein through maternal diet was not significantly different from that of the control group, their blood composition already showed substantial differences. Normally the switch from primitive to definitive erythroid lineage starts at embryonic day 11.5 (21).

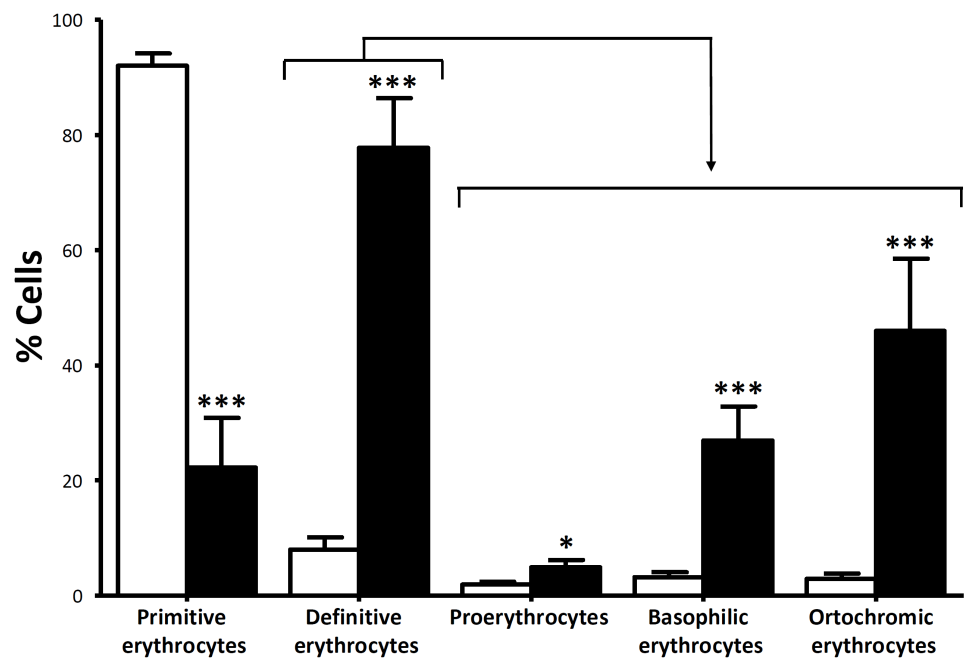

Figure 4. Effect of genistein exposure on the primitive and definitive erythroid lineage.

Blood smears of fetuses (E14.5) from the control ( $n=15$; white bars) and genistein exposed ( $n=9$; black bars) group were analyzed. Bars represent the percentage of cells from the primary and different definitive erythroid (i.e. proerythroblast, basophilic erythroblast and ortochromic erythroblast) lineage. Error bars represent

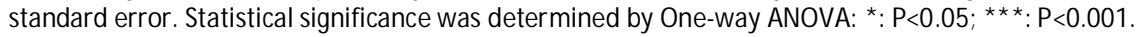

A comparison of fetal blood composition (Figure 4) between the genistein (9 mice from 2 litters, $n=9$ ) and the control animals ( 15 mice from 2 litters, $n=15$ ) at E14.5, demonstrated an accelerated switch from primitive erythroid lineage to definitive lineage in the fetuses that were exposed to genistein. The percentage of primary erythrocytes was significantly decreased due to genistein exposure $(22.23 \pm 26.02 \%$ versus $92.05 \pm 8.31 \%, P<0.001)$ while the percentage of definitive erythrocytes was increased $(77.77 \pm 26.01 \%$ versus 7.96 $\pm 8.31 \%, P<0.001$ ). This increase reflected an overall expansion of definitive progenitors at various stages. The percentage of proerythroblasts $(4.92 \pm 3.86 \%$ versus $1.92 \pm 1.75 \%$, 
$\mathrm{P}=0.02)$, and especially of basophilic ( $26.89 \pm 17.88 \%$ versus $3.17 \pm 3.27 \%, \mathrm{P} \varangle 0.001)$ and orthochromic erythroblasts $(45.97 \pm 37.57 \%$ versus $2.86 \pm 3.82 \%$, $\mathrm{P}<0.001)$ were significantly different between the diet groups.

\section{Discussion}

In this study, we demonstrate that prenatal exposure of mice to genistein affects fetal red blood cell development and leaves a permanent signature on the hematopoietic lineage. Microarray analysis of hematopoietic cells of mice at 12 weeks of age revealed that prenatal genistein exposure had induced a distinct gene expression profile. Strikingly, some persistent effects of genistein exposure on gene expression could be observed (e.g. down-regulation of NF- $k \mathrm{~B}$, NF-kB-regulated gene products and several adhesion molecules), while genistein was no longer provided through diet. In general, prenatal genistein exposure was associated with pronounced down-regulation of gene expression. This down-regulation might be partly due to hypermethylation of CpG motifs in the regulatory regions of certain genes. In fact, we demonstrate that prenatal genistein exposure induced hypermethylation of some CpG-rich repetitive elements. However there is no straightforward relation between the hypermethylation seen in the repetitive elements and the change in gene expression. Pogribny et al. (22) previously reported that DNA hypermethylation and macrocytosis coincided, as observed in our study. This is presumably by interfering with folate cofactor interactions what affects DNA synthesis and points to the involvement of one-carbon metabolism pathway. It is noteworthy that several genes involved in this pathway, e.g. dihydrofolate reductase (Dhfr; fold change $=1.59$; P-value $=0.004)$, serine hydroxymethyltransferase 2 (Shmt2; fold change $=1.76$; P-value $=0.005$ ), methylenetetrahydrofolate dehydrogenase 2 ( $M$ thfd2; fold change $=2.98 ; P$-value $=8.93 \times$ $10^{-5}$ ), 5,10-methenyl-tetrahydrofolate synthetase ( $M$ thfs; fold change $=1.58 ; P$-value $=0.05$ ) and S-adenosylhomocysteine hydrolase-like 2 (Ahcyl2; fold change=3.31; Pvalue $=0.0008$ ), were significantly down-regulated in the genistein exposed animals.

Prenatal genistein exposure in mice resulted in significant alterations in blood and bone marrow composition later in life, manifested as increased granulopoiesis and erythropoiesis. It is noteworthy that genistein exposed mice exhibited macrocytosis (3 \% increase in mean corpuscular volume). The increase in mean corpuscular volume is partly due to the higher number of reticulocytes. On the other hand, the increased erythropoiesis may demand recruitment of more primitive erythroid cells and the progenitor cells may differentiate without prior division. All these phenomena can lead to macrocytosis (23). Remarkably, both Dhfr (24) and Flvcr1 (25), whose deficiencies associate with macrocytosis were down-regulated in the genistein exposed mice. Furthermore, these mice showed down-regulation of Vegf. Inhibition of Vegf is reported to increase the hematocrit level (26). Hence the hematocrit level was significantly increased $(P=0.004)$ in mice prenatally exposed to genistein.

$M$ ice in the genistein group had significantly higher numbers of neutrophils $(P=0.02)$ and eosinophils $(P=0.04)$ in the peripheral blood, which was probably a result of the increased granulopoiesis in their bone marrow as seen in Figure 2. Microarray analysis showed that several genes, whose lack of expression associates with defects in granulocytic lineage, were down-regulated in the genistein group (e.g. Cebpa (27), JunB (28) and Icam1 (29)). 
Furthermore, Cdk2 expression was down-regulated in the bone marrow, while Cdknlb mRNA was increased. This gene expression pattern relates to end-stage differentiation of neutrophil granulocytes (30). Thus indicating that prenatal exposure to genistein results in an up-regulation of the granlulocytic differentiation, what also could be seen in the increased level of granulocytes detected in both blood and bone marrow of these mice.

As it is know that genistein can stimulate bone marrow formation (31), we assume that most alterations in gene expression are related to genistein-induced changes in bone marrow cellularity. However there are certain changes that do not seem to be directly related to differences in marrow cellularity, for instance changes in the expression of genes that are directly related to genistein exposure or changes in estrogen responsive genes.

Genistein is a well known endocrine-disrupting compound that, due to its structural similarity to $17 \beta$-estradiol, exerts its effect through estrogen receptors (9). Several estrogen responsive genes were suppressed in the bone marrow of adult mice that were prenatally exposed to genistein. Down-regulation of estrogen responsive genes has also been reported after exposure to certain other endocrine-disrupting chemicals, known as AhR agonists (e.g. benzo[a]pyrene and TCDD) (17). It is therefore possible that AhR is involved in the genistein-induced gene expression pattern. In fact Zhang et al. (32) demonstrated that genistein is a ligand of AhR. It has previously been shown that exposure to AhR ligands can affect hematopoietic blood composition. Exposure of mice to TCDD, skewed differentiation of bone marrow cells in favor of granulocytic and myeloid lineage and altered transcription of several genes (e.g. M yc, Hes1, Cdknla, Cdknlb, Cebp, Per1 and Per2). Likewise, culturing CD34+progenitors with the polyaromatic hydrocarbon benzo[a]pyrene, another AhR ligand, skews differentiation toward myeloid cells (30). Therefore, not only the distinct gene expression profile, but also cellular composition of the blood and bone marrow of the genistein exposed mice show signs of AhR involvement. Future studies need to explore the effects of prenatal exposure to other AhR-ligands on hematopoiesis.

In our study, direct exposure of mice fetus to genistein accelerated the switch from primitive erythroid lineage to definitive erythroid lineage. Normally, this switch starts at embryonic day 11.5 when blood circulation has been fully established (21). Examination of fetal blood composition at E14.5 revealed that the percentage of definitive erythrocytes were significantly higher in the genistein group ( $\mathrm{P} \varangle .001$ ). It is therefore evident that genistein exposure during development has both direct- and long-term effects on hematopoiesis.

Prenatal genistein exposure leads to long-term epigenetic changes. Exposure of heterozygous yellow agouti mice to genistein via maternal diet shifted the coat color by hypermethylation of transposable repetitive elements upstream of the transcription start site of the Agouti gene. Although genistein exposure terminated after weaning, the altered coat color remained unchanged throughout life (3). Our results show that prenatal genistein exposure associates with hypermethylation of the SINEB1 ( $P=0.045)$ and SINEB2 $(P=0.042)$ repetitive elements in bone marrow, at adult age. SINE transcripts are normally up-regulated in response to cell stress. Both the SINEB1 and SINEB2 classes are strongly up-regulated in mice after prolonged exposure to gamma radiation or DNA-damaging compounds, e.g. cisplatin, etoposide (33). Genistein is also a potent DNA-damaging agent, due to its topoisomerase-II inhibiting property (34). It is also interesting to study the direct effects of genistein exposure on SINE repetitive elements. The results presented here demonstrate that despite of the long-term effects of genistein on SINEB1 and SINEB2, the 
methylation status of these repeats is not affected directly by genistein exposure during fetal development, but occurs at later time points.

In our study pregnant mice were exposed to approximately $0.8 \mathrm{mg}$ genistein per day. In human, adults consuming modest amounts of soy-containing foods have a total dialy isoflavone intake of approximately 1 to $9 \mathrm{mg}$. In Asian countries however, the daily intake of isoflavones is much higher, reaching levels of $20-240 \mathrm{mg}$, due to the high consumption of soy (35). Also vegetarians, who consume large amounts of soy products, have a high intake of genistein. Due to potential health benefits associated with genistein intake, observed as decreased risk for developing breast and prostate cancer in Asian countries (36), genistein supplements are becoming increasingly popular. The manufacturers recommend a daily dose of up to 6 tablets of $25-100 \mathrm{mg}$ of these supplements. It is noteworthy that the metabolism of phytoestrogens is different in the fetus. In human, fetal cord blood has a higher genistein level than maternal serum (16). As genistein accumulates in the fetus and affects hematopoiesis, it is important to establish clear guidelines for fetal exposure to soy derivatives.

\section{Acknowledgments}

The authors sincerely thank Igor Pogribny and his lab (National Center for Toxicological Research) for their valuable support in setting-up the DNA methylation assay and Ralph Gottschalk for the assistance during the microarray experiment.

This work was supported by grant number $06 \mathrm{~A} 031$ from the American Institute for Cancer Research. 


\section{References}

1. Kurzer, M. S., and Xu, X. (1997) Dietary phytoestrogens. Annu Rev Nutr 17, 353-381

2. Scalbert, A., and Williamson, G. (2000) Dietary intake and bioavailability of polyphenols. J Nutr 130, 2073S-2085S

3. Dolinoy, D. C., Weidman, J. R., Waterland, R. A., and Jirtle, R. L. (2006) Maternal genistein alters coat color and protects Avy mouse offspring from obesity by modifying the fetal epigenome. Environ Health Perspect 114, 567-572

4. Klein, S. L., Wisniewski, A. B., Marson, A. L., Glass, G. E., and Gearhart, J. P. (2002) Early exposure to genistein exerts long-lasting effects on the endocrine and immune systems in rats. Mol M ed 8, 742-749

5. Ohta, R., Shirota, M., Kanazawa, Y., Shindo, T., Furuya, M., Seki, T., Ono, H., Kojima, K., Asai, S., Watanabe, G., and Taya, K. (2009) Effects of transmaternal exposure to genistein in Hatano high- and low-avoidance rats. Exp Anim 58, 471-479

6. Moller, F. J., Zerau, O., Hertrampf, T., Bliedtner, A., Diel, P., and Vollmer, G. (2009) Long-term effects of dietary isoflavones on uterine gene expression profiles. J Steroid Biochem M ol Biol 113, 296-303

7. Aslinia, F., Mazza, J. J., and Yale, S. H. (2006) Megaloblastic anemia and other causes of macrocytosis. Clin Med Res 4, 236-241

8. Scott, J. M ., and Weir, D. G. (1980) Drug-induced megaloblastic change. Clin Haematol 9, 587-606

9. Miodini, P., Fioravanti, L., Di Fronzo, G., and Cappelletti, V. (1999) The two phyto-oestrogens genistein and quercetin exert different effects on oestrogen receptor function. Br J Cancer 80, 1150-1155

10. Smyth, G. K., Michaud, J., and Scott, H. S. (2005) Use of within-array replicate spots for assessing differential expression in microarray experiments. Bioinformatics 21, 2067-2075

11. Gaj, S., van Erk, A., van Haaften, R. I., and Evelo, C. T. (2007) Linking microarray reporters with protein functions. BM C Bioinformatics 8, 360

12. Pogribny, I. P., Ross, S. A., Tryndyak, V. P., Pogribna, M., Poirier, L. A., and Karpinets, T. V. (2006) Histone H3 lysine 9 and $\mathrm{H} 4$ lysine 20 trimethylation and the expression of Suv4-20h2 and Suv-39h1 histone methyltransferases in hepatocarcinogenesis induced by methyl deficiency in rats. Carcinogenesis 27, 1180-1186

13. He, H., Chen, L., Zhai, M., and Chen, J. Z (2009) Genistein down-regulates the constitutive activation of nuclear factor-kappaB in human multiple myeloma cells, leading to suppression of proliferation and induction of apoptosis. Phytother Res 23, 868-873

14. Welte, T., Zhang, S. S., Wang, T., Zhang, Z, Hesslein, D. G., Yin, Z., Kano, A., Iwamoto, Y., Li, E., Craft, J. E., Bothwell, A. L., Fikrig, E., Koni, P. A., Flavell, R. A., and Fu, X. Y. (2003) STAT3 deletion during hematopoiesis causes Crohn's disease-like pathogenesis and lethality: a critical role of STAT3 in innate immunity. Proc Natl Acad Sci U SA 100, 1879-1884

15. Yilmaz, O. H., Valdez, R., Theisen, B. K., Guo, W., Ferguson, D. O., Wu, H., and M orrison, S. J. (2006) Pten dependence distinguishes haematopoietic stem cells from leukaemia-initiating cells. Nature 441, 475-482

16. Adlercreutz, H., Yamada, T., Wahala, K., and Watanabe, S. (1999) Maternal and neonatal phytoestrogens in Japanese women during birth. Am J Obstet Gynecol 180, 737-743

17. Tanaka, J., Yonemoto, J., Zaha, H., Kiyama, R., and Sone, H. (2007) Estrogen-responsive genes newly found to be modified by TCDD exposure in human cell lines and mouse systems. Mol Cell Endocrinol 272, 38-49

18. Singh, K. P., Casado, F. L., Opanashuk, L. A., and Gasiewicz, T. A. (2009) The aryl hydrocarbon receptor has a normal function in the regulation of hematopoietic and other stem/progenitor cell populations. Biochem Pharmacol 77, 577-587

19. Ohtake, F., Takeyama, K., Matsumoto, T., Kitagawa, H., Yamamoto, Y., Nohara, K., Tohyama, C., Krust, A., Mimura, J., Chambon, P., Yanagisawa, J., Fujii-Kuriyama, Y., and Kato, S. (2003) Modulation of oestrogen receptor signalling by association with the activated dioxin receptor. Nature 423, 545-550

20. Waterston, R. H., Lindblad-Toh, K., Birney, E., Rogers, J., Abril, J. F., Agarwal, P., Agarwala, R., Ainscough, R., Alexandersson, M., An, P., Antonarakis, S. E., Attwood, J., Baertsch, R., Bailey, J., Barlow, K., Beck, S., Berry, E., Birren, B., Bloom, T., Bork, P., Botcherby, M., Bray, N., Brent, M. R., Brown, D. G., Brown, S. D., Bult, C., Burton, J., Butler, J., Campbell, R. D., Carninci, P., Cawley, S., Chiaromonte, F., Chinwalla, A. T., Church, D. M., Clamp, M., Clee, C., Collins, F. S., Cook, L. L., Copley, R. R., Coulson, A., Couronne, O., Cuff, J., Curwen, V., Cutts, T., Daly, M., David, R., Davies, J., Delehaunty, K. D., Deri, J., Dermitzakis, E. T., Dewey, C., Dickens, N. J., Diekhans, M., Dodge, S., Dubchak, I., Dunn, D. M., Eddy, S. R., Elnitski, L., Emes, R. D., Eswara, P., Eyras, E., Felsenfeld, A., Fewell, G. A., Flicek, P., Foley, K., Frankel, W. N., Fulton, L. A., Fulton, R. S., Furey, T. S., Gage, 
D., Gibbs, R. A., Glusman, G., Gnerre, S., Goldman, N., Goodstadt, L., Grafham, D., Graves, T. A., Green, E. D., Gregory, S., Guigo, R., Guyer, M., Hardison, R. C., Haussler, D., Hayashizaki, Y., Hillier, L. W., Hinrichs, A., Hlavina, W., Holzer, T., Hsu, F., Hua, A., Hubbard, T., Hunt, A., Jackson, I., Jaffe, D. B., Johnson, L. S., Jones, M., Jones, T. A., Joy, A., Kamal, M., Karlsson, E. K., Karolchik, D., Kasprzyk, A., Kawai, J., Keibler, E., Kells, C., Kent, W. J., Kirby, A., Kolbe, D. L., Korf, I., Kucherlapati, R. S., Kulbokas, E. J., Kulp, D., Landers, T., Leger, J. P., Leonard, S., Letunic, I., Levine, R., Li, J., Li, M., Lloyd, C., Lucas, S., Ma, B., Maglott, D. R., Mardis, E. R., Matthews, L., Mauceli, E., Mayer, J. H., M cCarthy, M., McCombie, W. R., M cLaren, S., M cLay, K., M cPherson, J. D., M eldrim, J., Meredith, B., M esirov, J. P., Miller, W., Miner, T. L., Mongin, E., Montgomery, K. T., Morgan, M., M ott, R., M ullikin, J. C., Muzny, D. M., Nash, W. E., Nelson, J. O., Nhan, M. N., Nicol, R., Ning, Z., Nusbaum, C., O'Connor, M. J., Okazaki, Y., Oliver, K., Overton-Larty, E., Pachter, L., Parra, G., Pepin, K. H., Peterson, J., Pevzner, P., Plumb, R., Pohl, C. S., Poliakov, A., Ponce, T. C., Ponting, C. P., Potter, S., Quail, M., Reymond, A., Roe, B. A., Roskin, K. M., Rubin, E. M., Rust, A. G., Santos, R., Sapojnikov, V., Schultz, B., Schultz, J., Schwartz, M. S., Schwartz, S., Scott, C., Seaman, S., Searle, S., Sharpe, T., Sheridan, A., Shownkeen, R., Sims, S., Singer, J. B., Slater, G., Smit, A., Smith, D. R., Spencer, B., Stabenau, A., StangeThomann, N., Sugnet, C., Suyama, M., Tesler, G., Thompson, J., Torrents, D., Trevaskis, E., Tromp, J., Ucla, C., Ureta-Vidal, A., Vinson, J. P., Von Niederhausern, A. C., Wade, C. M., Wall, M., Weber, R. J., Weiss, R. B., Wendl, M. C., West, A. P., Wetterstrand, K., Wheeler, R., Whelan, S., Wierzbowski, J., Willey, D., Williams, S., Wilson, R. K., Winter, E., Worley, K. C., Wyman, D., Yang, S., Yang, S. P., Zdobnov, E. M., Zody, M. C., and Lander, E. S. (2002) Initial sequencing and comparative analysis of the mouse genome. Nature 420, 520-562

21. Kingsley, P. D., Malik, J., Emerson, R. L., Bushnell, T. P., M cGrath, K. E., Bloedorn, L. A., Bulger, M., and Palis, J. (2006) "M aturational" globin switching in primary primitive erythroid cells. Blood 107, 1665-1672

22. Pogribny, I. P., Karpf, A. R., James, S. R., M elnyk, S., Han, T., and Tryndyak, V. P. (2008) Epigenetic alterations in the brains of Fisher 344 rats induced by long-term administration of folate/ methyl-deficient diet. Brain Res 1237, 25-34

23. Tsantes, A. E., Bonovas, S., Travlou, A., and Sitaras, N. M. (2006) Redox imbalance, macrocytosis, and RBC homeostasis. Antioxid Redox Signal 8, 1205-1216

24. Tauro, G. P., Danks, D. M., Rowe, P. B., Van der Weyden, M. B., Schwarz, M. A., Collins, V. L., and Neal, B. W. (1976) Dihydrofolate reductase deficiency causing megaloblastic anemia in two families. N EnglJ Med 294, 466-470

25. Keel, S. B., Doty, R. T., Yang, Z., Quigley, J. G., Chen, J., Knoblaugh, S., Kingsley, P. D., De Domenico, I., Vaughn, M. B., Kaplan, J., Palis, J., and Abkowitz, J. L. (2008) A heme export protein is required for red blood cell differentiation and iron homeostasis. Science 319, 825-828

26. Tam, B. Y., Wei, K., Rudge, J. S., Hoffman, J., Holash, J., Park, S. K., Yuan, J., Hefner, C., Chartier, C., Lee, J. S., Jiang, S., Nayak, N. R., Kuypers, F. A., Ma, L., Sundram, U., Wu, G., Garcia, J. A., Schrier, S. L., Maher, J. J., Johnson, R. S., Yancopoulos, G. D., Mulligan, R. C., and Kuo, C. J. (2006) VEGF modulates erythropoiesis through regulation of adult hepatic erythropoietin synthesis. Nat Med 12, 793-800

27. Pabst, T., Mueller, B. U., Zhang, P., Radomska, H. S., Narravula, S., Schnittger, S., Behre, G., Hiddemann, W., and Tenen, D. G. (2001) Dominant-negative mutations of CEBPA, encoding CCAAT/enhancer binding protein-alpha (C/EBPalpha), in acute myeloid leukemia. Nat Genet 27, 263-270

28. Passegue, E., Jochum, W., Schorpp-Kistner, M., Mohle-Steinlein, U., and Wagner, E. F. (2001) Chronic myeloid leukemia with increased granulocyte progenitors in mice lacking junB expression in the myeloid lineage. Cell 104, 21-32

29. Sligh, J. E., Jr., Ballantyne, C. M., Rich, S. S., Hawkins, H. K., Smith, C. W., Bradley, A., and Beaudet, A. L. (1993) Inflammatory and immune responses are impaired in mice deficient in intercellular adhesion molecule 1. Proc Natl Acad Sci U SA 90, 8529-8533

30. Singh, K. P., Wyman, A., Casado, F. L., Garrett, R. W., and Gasiewicz, T. A. (2009) Treatment of mice with the Ah receptor agonist and human carcinogen dioxin results in altered numbers and function of hematopoietic stem cells. Carcinogenesis 30, 11-19

31. Hertrampf, T., Schleipen, B., Offermanns, C., Velders, M., Laudenbach, U., and Diel, P. (2009) Comparison of the bone protective effects of an isoflavone-rich diet with dietary and subcutaneous administrations of genistein in ovariectomized rats. Toxicol Lett 184, 198-203

32. Zhang, S., Qin, C., and Safe, S. H. (2003) Flavonoids as aryl hydrocarbon receptor agonists/antagonists: effects of structure and cell context. Environ Health Perspect 111, 1877-1882 
33. Williams, W. P., Tamburic, L., and Astell, C. R. (2004) Increased levels of B1 and B2 SINE transcripts in mouse fibroblast cells due to minute virus of mice infection. Virology 327, 233-241

34. Barjesteh van Waalwijk van Doorn-Khosrovani, S., Janssen, J., M aas, L. M., Godschalk, R. W., Nijhuis, J. G., and van Schooten, F. J. (2007) Dietary flavonoids induce M LL translocations in primary human CD34+cells. Carcinogenesis 28, 1703-1709

35. Skibola, C. F., and Smith, M. T. (2000) Potential health impacts of excessive flavonoid intake. Free Radic Biol Med 29, 375-383

36. Coward, L., Barnes, N., Setchell, K., and Barnes, S. (1993) Genistein, daidzein, and their .beta.-glycoside conjugates: antitumor isoflavones in soybean foods from American and Asian diets. J Agric Food Chem 41, 1961-1967

37. Cheng, T., Rodrigues, N., Shen, H., Yang, Y., Dombkowski, D., Sykes, M., and Scadden, D. T. (2000) Hematopoietic stem cell quiescence maintained by p21cip1/waf1. Science 287, 1804-1808

38. Percy, M. J., Zhao, Q., Flores, A., Harrison, C., Lappin, T. R., Maxwell, P. H., M cM ullin, M. F., and Lee, F. S. (2006) A family with erythrocytosis establishes a role for prolyl hydroxylase domain protein 2 in oxygen homeostasis. Proc Natl Acad Sci U S A 103, 654-659

39. Yasuda, T., Shirakata, M., Iwama, A., Ishii, A., Ebihara, Y., Osawa, M., Honda, K., Shinohara, H., Sudo, K., Tsuji, K., Nakauchi, H., Iwakura, Y., Hirai, H., Oda, H., Yamamoto, T., and Yamanashi, Y. (2004) Role of Dok-1 and Dok-2 in myeloid homeostasis and suppression of leukemia. J Exp M ed 200, 1681-1687

40. Wang, L. C., Swat, W., Fujiwara, Y., Davidson, L., Visvader, J., Kuo, F., Alt, F. W., Gilliland, D. G., Golub, T. R., and Orkin, S. H. (1998) The TEL/ETV6 gene is required specifically for hematopoiesis in the bone marrow. Genes Dev 12, 2392-2402

41. Geissler, E. N., Ryan, M. A., and Housman, D. E. (1988) The dominant-white spotting (W) locus of the mouse encodes the c-kit proto-oncogene. Cell 55, 185-192

42. Baudino, T. A., M cKay, C., Pendeville-Samain, H., Nilsson, J. A., Maclean, K. H., White, E. L., Davis, A. C., Ihle, J. N., and Cleveland, J. L. (2002) C-Myc is essential for vasculogenesis and angiogenesis during development and tumor progression. Genes Dev 16, 2530-2543

43. Lawler, J., Sunday, M., Thibert, V., Duquette, M., George, E. L., Rayburn, H., and Hynes, R. O. (1998) Thrombospondin-1 is required for normal murine pulmonary homeostasis and its absence causes pneumonia. J Clin Invest 101, 982-992

44. Shalaby, M. R., Carter, P., Maneval, D., Giltinan, D., and Kotts, C. (1995) Bispecific HER2 x CD3 antibodies enhance T-cell cytotoxicity in vitro and localize to HER2-overexpressing xenografts in nude mice. Clin Immunol Immunopathol 74, 185-192

45. Gregoli, P. A., and Bondurant, M. C. (1997) The roles of Bcl-X(L) and apopain in the control of erythropoiesis by erythropoietin. Blood $\mathbf{9 0}, 630-640$

46. Socolovsky, M., Fallon, A. E., Wang, S., Brugnara, C., and Lodish, H. F. (1999) Fetal anemia and apoptosis of red cell progenitors in Stat5a-/-5b-/- mice: a direct role for Stat5 in Bcl-X(L) induction. Cell 98, 181-191

47. Fujiwara, Y., Browne, C. P., Cunniff, K., Goff, S. C., and Orkin, S. H. (1996) Arrested development of embryonic red cell precursors in mouse embryos lacking transcription factor GATA-1. Proc Natl Acad Sci U SA 93, 12355-12358

48. Davies, K. A., and LuX, S. E. (1989) Hereditary disorders of the red cell membrane skeleton. Trends Genet 5, 222-227

49. Tamura, K., Sudo, T., Senftleben, U., Dadak, A. M., Johnson, R., and Karin, M. (2000) Requirement for p38alpha in erythropoietin expression: a role for stress kinases in erythropoiesis. Cell 102, 221-231

50. Hanspal, M., Smockova, Y., and Uong, Q. (1998) M olecular identification and functional characterization of a novel protein that mediates the attachment of erythroblasts to macrophages. Blood 92, 2940-2950

51. Pellegrino, C. M., Rybicki, A. C., Musto, S., Nagel, R. L., and Schwartz, R. S. (1998) Molecular identification and expression of erythroid $\mathrm{K}: \mathrm{Cl}$ cotransporter in human and mouse erythroleukemic cells. Blood Cells M ol Dis 24, 31-40

52. Quigley, J. G., Yang, Z., Worthington, M. T., Phillips, J. D., Sabo, K. M., Sabath, D. E., Berg, C. L., Sassa, S., Wood, B. L., and Abkowitz, J. L. (2004) Identification of a human heme exporter that is essential for erythropoiesis. Cell 118, 757-766

53. O'Donnell, L. C., Druhan, L. J., and Avalos, B. R. (2002) Molecular characterization and expression analysis of leucine-rich alpha2-glycoprotein, a novel marker of granulocytic differentiation. J Leukoc Biol 72, 478-485

54. Kincade, P. W. (2006) Supplying the demand for granulocytes. Nat Immunol 7, 701-702

55. Park, I. K., Qian, D., Kiel, M., Becker, M. W., Pihalja, M., Weissman, I. L., M orrison, S. J., and Clarke, M. F. (2003) Bmi1 is required for maintenance of adult self-renewing haematopoietic stem cells. Nature 423, 302-305 
56. Kaushansky, K., Broudy, V. C., Grossmann, A., Humes, J., Lin, N., Ren, H. P., Bailey, M. C., Papayannopoulou, T., Forstrom, J. W., and Sprugel, K. H. (1995) Thrombopoietin expands erythroid progenitors, increases red cell production, and enhances erythroid recovery after myelosuppressive therapy. J Clin Invest 96, 1683-1687

57. Takakuwa, Y. (2001) Regulation of red cell membrane protein interactions: implications for red cell function. Curr Opin Hematol 8, 80-84

58. Arai, F., Hirao, A., Ohmura, M., Sato, H., Matsuoka, S., Takubo, K., Ito, K., Koh, G. Y., and Suda, T. (2004) Tie2/angiopoietin-1 signaling regulates hematopoietic stem cell quiescence in the bone marrow niche. Cell 118, 149-161

59. Irie-Sasaki, J., Sasaki, T., Matsumoto, W., Opavsky, A., Cheng, M., Welstead, G., Griffiths, E., Krawczyk, C., Richardson, C. D., Aitken, K., Iscove, N., Koretzky, G., Johnson, P., Lu, P., Rothstein, D. M., and Penninger, J. M. (2001) CD45 is a JAK phosphatase and negatively regulates cytokine receptor signalling. Nature 409, 349-354

60. Klausen, P., Bjerregaard, M. D., Borregaard, N., and Cowland, J. B. (2004) End-stage differentiation of neutrophil granulocytes in vivo is accompanied by up-regulation of p27kip1 and down-regulation of CDK2, CDK4, and CDK6. J Leukoc Biol 75, 569-578 



\section{Chapter 4}

\section{Intrauterine exposure to flavonoids modifies antioxidant status at adulthood and protects against oxidative stress induced DNA damage}

Vanhees K, van Schooten FJ, Barjesteh van Waalwijk van Doorn-Khosrovani

$S$, van Helden S, M aas LM , Pachen D, Drittij MJ, M unnia A, Peluso M, Briedé JJ, Haenen GRM M, Godschalk RWL 


\begin{abstract}
The in utero environment is predominantly determined by the maternal diet and may alter the risk for several diseases at adult age. Flavonoids are polyphenolic compounds in our diet that are known for their antioxidant properties and their ability to up-regulate the enzymatic antioxidant capacity of cells. Therefore, we investigated whether maternal intake of genistein (1 mmol/ $\mathrm{kg}$ feed) or quercetin (1 mmol/ $\mathrm{kg}$ feed) could modulate antioxidant capacity and subsequent oxidative stress induced DNA damage in liver and lung tissue of 12 week old offspring mice. At day 14.5 of gestation, intake of these flavonoids increased gene expression of several antioxidant genes in the liver of fetuses. This effect persisted till adult age, because 12 week old mice prenatally exposed to flavonoids still had enhanced expression of some of these antioxidant genes in liver and lung. In liver, relative expression of hemeoxygenase-1 (Hol) was $>6$-fold enhanced by maternal quercetin intake, which indicates Nrf2-pathway activation. This is in line with the observation that prenatal exposure to genistein, but especially to quercetin resulted in lower levels of oxidative stress induced DNA lesions in liver, while no effects were found in lung. Prenatal diet had mild effect on the non-enzymatic antioxidant capacity of the liver at adult age, which was vitamin $\mathrm{C}$ independent. Prenatal exposure to genistein increased the non-enzymatic antioxidant capacity of the lung, though no changes in the amount of oxidative stress induced DNA lesions were found. These results suggest that prenatal exposure to flavonoids protects against oxidative stress induced DNA damage in the liver by a persistent pre-emptive trigger of the enzymatic antioxidant system.
\end{abstract}




\section{Introduction}

Studies in humans and animals have shown that the in utero environment is determinant for the risk of several diseases at older age, including cancer $(1,2)$ as well as metabolic $(3-5)$ and cardiovascular disorders $(3,6)$. Since reactive oxygen species (ROS) are thought to play an important role in the development and progression of all these chronic diseases (7) and because the in utero environment is predominantly determined by the maternal diet, one could speculate that intake of dietary antioxidants during pregnancy may provide an in utero environment that may prevent the development of chronic diseases later in life. One major source of antioxidants in our diet are the polyphenolic flavonoids (8). The daily dietary intake of mixed flavonoids in the human population ranges from 65 to $250 \mathrm{mg} /$ day (9). The most predominant flavonoid in the human diet is quercetin, which is mainly found in onions, apples, tea and red wine $(8,10)$. Another widely consumed flavonoid is the phytoestrogen genistein, which is mainly found in soy products $(11,12)$. Flavonoids are thought to be health beneficial since in epidemiological studies they were associated with protection against cardiovascular diseases $(13,14)$ and neurodegenerative diseases $(15,16)$ and they acted anti-inflammatory $(17,18)$. These effects are mainly thought to be the result of their antioxidant property $(8,19)$ as ROS play a major role in disease development and progression (20-26). However, prooxidant effects have also been reported (27-30).

Besides antioxidant nutrients, cells also possess enzymatic antioxidants to protect them against endogenous and exogenous sources of oxidative stress, like superoxide dismutase (Sod) which scavenges superoxide $\left(\mathrm{O}_{2}^{-{ }^{-}}\right)$and catalase (Cat) and glutathione peroxidase (Gpx) which scavenge hydrogen peroxide $\left(\mathrm{H}_{2} \mathrm{O}_{2}\right)(31,32)$. An important transcription factor that regulates gene expression to counteract oxidative stress is the nuclear erythroid 2-related factor 2 (Nrf2). This transcription factor is normally targeted for proteasomal degradation by binding to its chaperon Kelch-like ECH-associated protein (Keap1). However, ROS and electrophiles can alter the conformation of the Nrf2-Keap1 complex resulting in the nuclear translocation of Nrf2. Here, it can bind to antioxidant response elements (ARE) in the promoter region of target genes (for instance hemeoxygenase-1, Hol) resulting in up-regulation of their gene expression $(33,34)$. The flavonoid quercetin was found to regulate the Nrf2-pathway and as such enhance the antioxidant potential of cells $(35,36)$. Hur et al. (34) stated that a pre-emptive activation of the Nrf2 pathway potentiates the level of a wide range of protective enzymes that counteract oxidative and environmental stresses, and confers resistance to subsequent challenges of cellular stress. On the other hand, Breinholt et al. (37) showed that female mice exposed for 2 weeks to high doses of several flavonoids, including genistein and quercetin, had reduced activity of glutathione reductase, Cat and Gpx in red blood cells. Still, these rats were protected from 2-amino-1-methyl-6-phenylimidazo [4,5-b]pyridine (PhIP)-induced oxidative stress as seen in the decreased levels of plasma malondialdehyde.

Overall, these data indicate that there is a close relation between dietary and enzymatic antioxidants and this relation can potentially be affected by the presence of antioxidants in the in utero environment. Therefore, we investigated whether prenatal exposure to genistein and quercetin could affect the antioxidant capacity at adult age. To this end, we exposed female mice from 3 days before and throughout the gestation to genistein $(1 \mathrm{mmol} / \mathrm{kg}$ feed) or quercetin $(1 \mathrm{mmol} / \mathrm{kg}$ feed). The gene expression of genes involved in the Nrf2-pathway and of several other antioxidant genes (Cat, Sod2 and Gpx3) was determined in liver and lung of adult offspring mice, and also in the liver of fetuses (at day 14.5 of gestation) exposed to 
genistein or quercetin. To study the non-enzymatic antioxidant capacity of liver and lung the trolox equivalent antioxidant capacity (TEAC), vitamin C levels and the presence of vitamin C radicals in 12 week old mice prenatally exposed to genistein or quercetin was determined. ROS induced DNA damage was determined in adult mice by measuring 8-0xo-7,8-dihydro-2'deoxyguanosine (8-oxo-dG) and malondialdehyde-deoxyguanosine $\left(M_{1} \mathrm{dG}\right)$ levels in DNA from liver and lung.

\section{Material and methods}

Mice and sample collection

Female mice (129/Sv):C57BL/6] background) approximately 8 weeks of age, received either normal chow (low phytoestrogen content complete feed for mice breeding, ssniff $@$, Soest, Germany) or the same chow supplemented with genistein $(1 \mathrm{mmol}(270 \mathrm{mg}) / \mathrm{kg}$ feed, LC Laboratories, Woburn, MA, USA) or with quercetin (1 mmol $(302 \mathrm{mg}) / \mathrm{kg}$ feed, Sigma, Zwijndrecht, the Netherlands) from 3 days before conception until the end of gestation. After delivery all mothers and pups, regardless of their prenatal diet, received normal chow and the offspring were sacrificed by cardiac puncture after anesthesia at 12 weeks of age. Liver and lung tissue of 5 male mice per diet were isolated.

To determine the direct effects of genistein and quercetin exposure on antioxidant gene expression, female mice (129/Sv):C57BL/6] background) were mated overnight and conception day was determined by recognition of a vaginal plug the next morning (considered as day 0.5 of gestation). Female mice were placed on the same control or genistein- or quercetin-enriched chow as described above, starting three days before conception. On day 14.5 of gestation (E14.5), mice were sacrificed to isolate fetal livers.

\section{Quantitative real-time PCR}

RNA was isolated from liver of E14.5 fetuses and from the lung and liver of 12 week old mice by homogenizing the tissue using TRIzol Reagent (Invitrogen, Breda, the Netherlands) according to manufacturer's instructions and using the Ultra-Turrax homogenizer (IKA, Staufen, Germany). Quantity and purity control of the RNA was spectrophotometrically assessed by using the Nanodrop 1000 (Thermo Scientific, Wilmington, USA). Next, $1 \mu \mathrm{g}$ of RNA was used to synthesize CDNA using the iScript CDNA synthesis kit (Biorad, Hercules, USA) following manufacturer's instructions. The reaction was performed using a Biometra Tprofessional thermocycler (Biometra, Leusden, the Netherlands).

An aliquot of one $10^{\text {th }}$ of the resulting CDNA was applied for quantitative PCR amplification together with $12.5 \mu \mathrm{l} \mathrm{SYBR}$ Green (Qiagen) and $7.5 \mathrm{pmol}$ of each primer (see Table 1, Eurogentec, M aastricht, the Netherlands) in a volume of $25 \mu \mathrm{l}$. The reactions were carried out using a MyiQ Single Color RT-PCR detection system (Bio-rad), under the following conditions: 1 cycle at $95{ }^{\circ} \mathrm{C}$ for 3 minutes and then 40 cycles at $95{ }^{\circ} \mathrm{C}$ for 15 seconds and 60 ${ }^{\circ} \mathrm{C}$ for 1 minute followed by 1 cycle at $95{ }^{\circ} \mathrm{C}$ for 1 minute and 1 cycle at $65{ }^{\circ} \mathrm{C}$. Data were analyzed by MyiQ Software system (Bio-rad), Ct values were normalized for an endogenous reference gene ( $\beta$-actin) and compared with the calibrator (i.e. average $\mathrm{Ct}$ value of control samples) and expressed as fold change $\left(2^{-\Delta \Delta C t}\right)$. 
Table 1: Forward and reverse primers used for quantitative real-time PCR

\begin{tabular}{lll}
\hline & Forward primer (5'-3') & Reverse primer (5'-3') \\
\hline Cat & AGCGACCAGATGAAGCAGTG & TCCGCTCTCTGTCAAAGTGTG \\
Sod2 & CAGACCTGCCTACGACTATGG & CTCGGTGGCGTGAGATTGTT \\
Gpx3 & CCTTITAAGCAGTATGCAGGCA & CAAGCCAAATGGCCCAAGTT \\
Keap1 & CGGGGACGCAGTGATGTATG & TGTGTAGCTGAAGGTCGGTA \\
Nrf2 & CTTAGTCAGCGACAGAAGGAC & AGGCATCTTGTTGGGAATGTG \\
Ho1 & TCCAGAGTTCCGCATAC & CGGACTGGGCTAGTCA \\
-actin & CAAGAAGGAAGGCTGGAAAAGA & ACGGCCAGGTCATCACTATTG \\
\hline
\end{tabular}

Liver and lung tissue homogenates

To determine TEAC, vitamin C level and vitamin Cradical formation in liver and lung tissue, liver and lung extracts were obtained by homogenizing the tissue in cold $10 \mathrm{mM}$ Tris 150 $\mathrm{mM} \mathrm{KCl}$ buffer ( $\mathrm{pH}$ 7.4), using the Ultra-Turrax homogenizer (IKA), followed by centrifugation at $4{ }^{\circ} \mathrm{C}$ for 15 minutes. Protein concentration of the homogenates was determined by the Lowry assay (Bio-Rad) with bovine serum albumin as a standard.

\section{Trolox equivalent antioxidant capacity}

The antioxidant capacity (TEAC) was quantified as TEAC according to Fischer et al. (38). The samples were deproteinized with a final concentration of $5 \%$ trichloroacetic acid (TCA). The samples were than incubated with ABTS radical solution prepared according the procedure described previously (38). After five minute incubation, the absorbance at $734 \mathrm{~nm}$ was determined. The assay was calibrated using solutions of the synthetic vitamin E analog trolox. The TEAC is expressed in trolox equivalents.

Vitamin C concentration in liver and lung tissue

To determine the vitamin C level, $250 \mu$ of liver or lung homogenate was deproteinized using $10 \%$ trichloroacetic acid (TCA) (1:4). Ascorbate was oxidized to dehydroascorbate using ascorbate oxidase. Subsequently, o-phenylene diamine was added, to convert dehydroascorbate into a fluorescent product that was quantified using HPLC. HPLC analysis of the samples was performed using a reverse phase $\mathrm{C} 18$ column with methanol potassium phosphate buffer (20/80) as eluens, using a fluorescence detector with $355 \mathrm{~nm}$ as excitation and $425 \mathrm{~nm}$ as emission wavelengths.

\section{Electron spin resonance spectroscopy}

To determine the presence of vitamin $\mathrm{C}$ radicals, liver and lung homogenates were placed on ice for direct measurements using electron spin resonance (ESR) spectroscopy. ESR spectra were recorded using the settings as previously described by Linschooten et al. (39) on a Bruker EMX 1273 spectrometer equipped with an ER 4119HS high sensitivity resonator. Vitamin $\mathrm{C}$ radical signals, characterized by a doublet with a splitting constant (AH) of $1.8 \mathrm{G}$ were quantified (in arbitrary units) through peak surface measurements using the WIN-EPR spectrum manipulation program. 


\section{8-oxo-dG measurements}

Genomic DNA isolation and 8-oxo-dG measurements were performed as described previously (40). Briefly, HPLC with electrochemical detection (ECD) was performed using genomic DNA obtained by grinding frozen liver and lung, followed by standard phenol extraction (41). The DNA-extraction procedure was optimized to minimize artificial induction of 8-oxo-dG, by using radical-free phenol, minimizing exposure to oxygen and by addition of $1 \mathrm{mM}$ deferoxamine mesylate and $20 \mathrm{mM}$ TEMPO $(2,2,6,6$ tetramethylpiperidine- $\mathrm{N}-\mathrm{oxyl}$ ). DNA concentrations were spectrophotometrically quantified at $260 \mathrm{~nm}$. HPLC-ECD of 8-0xo-dG was performed by digesting $30 \mu \mathrm{g}$ DNA to deoxyribonucleosides by adding of $6 \mu \mathrm{l} 0.5 \mathrm{M} \mathrm{NaAc}, 9 \mu \mathrm{l} 10 \mathrm{mM} \mathrm{ZnCl}$ and $1.5 \mu \mathrm{l}$ nuclease P1 (stock: $1 \mathrm{U} / \mu \mathrm{l}$ ) and incubation for 90 minutes at $37^{\circ} \mathrm{C}$. Subsequently, $30 \mu \mathrm{l} 0.5 \mathrm{M}$ Tris$\mathrm{HCl}(\mathrm{pH} 7.4)$ and $1.5 \mu \mathrm{l}$ alkaline phosphatase $(0.014 \mathrm{U} / \mu \mathrm{l})$ were added followed by incubation at $37^{\circ} \mathrm{C}$ for 45 minutes. The digest was then analyzed by HPLC-ECD on a Supelcosil ${ }^{T M}$ LC-18S column $(250 \mathrm{~mm} \times 4.6 \mathrm{~mm})$ (Supelco Park, Bellefonte, PA, USA) in combination with a DECADE electrochemical detector (Antec, Leiden, the Netherlands).

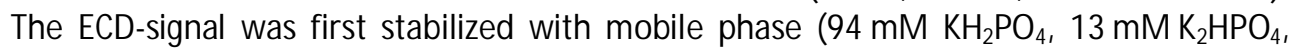
$26 \mathrm{mM} \mathrm{KCl}$ and $0.5 \mathrm{mM}$ EDTA, $10 \%$ methanol) for approximately 3 hours at a flow rate of $1 \mathrm{ml} / \mathrm{minute}$. After stabilization, 8-0xo-dG was detected at a potential of $400 \mathrm{mV}$ and dG was simultaneously monitored by UV absorption at $260 \mathrm{~nm}$.

$\mathrm{M}_{1} \mathrm{dG}$ level measurements

Genomic DNA was isolated from liver and lung tissue of adult mice using DNAzol Reagent (Invitrogen, Bleiswijk, the Netherlands) following the manufacturer's protocol and by homogenizing the tissue using an Ultra-Turrax homogenizer (IKA, Staufen, Germany). ${ }^{32} \mathrm{P}$ DNA post-labeling of $M_{1} d G$ was performed as described previously (42). Reference adduct standards were used for the optimization of the ${ }^{3}$ 2P-DNA post-labeling procedure. DNA (2 $\mu \mathrm{g})$ was digested by micrococcal nuclease and spleen phosphodiesterase. Hydrolyzed samples were subsequently treated with $2.5 \mu \mathrm{g}$ of nuclease $\mathrm{P} 1$ for 30 minutes at $37^{\circ} \mathrm{C}$. The nuclease P1-treated samples were incubated with $15-25 \mu \mathrm{Ci}$ of [p-32P]-ATP $(3000 \mathrm{Ci} / \mathrm{mmol})$ and T4-polynucleotide kinase $(0.75 \mathrm{U} / \mu \mathrm{l})$ to generate ${ }^{32} \mathrm{P}$-labeled $\mathrm{M}_{1} \mathrm{dG}$. Samples were applied to the origin of polyethyleneimine-cellulose (PEI) sheets $(10 \times 20 \mathrm{~cm})$ and developed with $0.35 \mathrm{M} \mathrm{gCl}_{2}$ for $2.0 \mathrm{~cm}$ on a filter paper wick. Plates were developed in the opposite direction with $2.1 \mathrm{M}$ lithium formate, $3.75 \mathrm{M}$ urea (pH 3.75), and then run at the right angle to the previous development with $0.24 \mathrm{M}$ sodium phosphate, $2.4 \mathrm{M}$ urea (pH 6.4). Detection and quantification of $M_{1} d G$ and total nucleotides was obtained by storage phosphor imaging technique employing intensifying screens (Molecular Dynamics, Sunnyvale, CA, USA) for 0.20-48 hour. The screens were scanned using a Typhoon 9210 (Amersham, Buckinghamshire, UK). To process the data ImageQuant (Molecular Dynamics) was used. After background subtraction, the levels of $\mathrm{M}_{1} \mathrm{dG}$-adducts were expressed as relative adduct labeling (RAL=screen pixel in adducted nucleotides/ screen pixel in total normal nucleotides). To calculate the levels of total normal nucleotides, aliquots of hydrolyzed DNA were appropriately diluted and reacted in the same mixtures used for $M_{1} \mathrm{dG}$ labeling. The obtained ${ }^{32} \mathrm{P}$-labeled total nucleotides were separated on PEI-cellulose-sheets using $280 \mathrm{mM}$ ammonium sulfate and $50 \mathrm{mM}$ sodium phosphate. The values measured for $\mathrm{M}_{1} \mathrm{dG}$-adducts 
were corrected across experiments based on the recovery of internal standard after the ${ }^{32} \mathrm{P}$ DNA postlabeling assay.

Statistical analysis

Statistical analysis was performed with Statistical Package for Social Sciences (SPSS version 17 for Windows, SPSS Inc., Chicago, IL, USA). Nested ANOVA was performed to investigate the effect of genistein or quercetin exposure on genes involved in antioxidant defense system of the fetal liver (day 14.5 of gestation). ANOVA was applied to test differences in antioxidant gene expression, non-enzymatic antioxidant capacity, vitamin C level and radical formation; and oxidative stress induced DNA damage in liver and lung of 12 week old control mice compared to 12 week old mice prenatally exposed to genistein or quercetin. To avoid litter effects no more than two adult mice per litter were used for statistical analysis.

\section{Results}

Exposure to quercetin induced Nrf2 and Sod2 expression in the liver of fetuses at day 14.5 of the pregnancy

To investigate whether exposure to antioxidants/ pro-oxidants could directly affect the gene expression of several antioxidant genes including the key regulators of the oxidative stress response pathway, namely Nrf2, its negative regulator Keapl and down-stream target gene Hol, of the unborn child, female mice were exposed via their diet to genistein (1 $\mathrm{mmol} / \mathrm{kg}$ feed) or quercetin ( $1 \mathrm{mmol} / \mathrm{kg}$ feed) starting from three days before conception and female mice were sacrificed at day 14.5 of gestation. The liver of the fetuses were isolated to determine gene expression. Results showed that only exposure to quercetin could induce the gene expression significantly at day 14.5 of the gestation, namely of Sod2 ( $P=0.001)$ and Nrf2 ( $P=0.04$, Figure 1$)$.

Prenatal exposure to flavonoids induced Nrf2-pathway in liver and antioxidant genes in liver and lung of 12 week old mice

To investigate whether the prenatal diet still had a measurable effect on gene expression of enzymatic antioxidants in offspring at adulthood, expression of genes involved in the antioxidant defense system (Cat, Sod2, Gpx3, Nrf2, Keap1 and Ho1) was assessed in liver and lung of adult offspring mice. In the liver of 12 week old mice prenatally exposed to quercetin we found that Nrf2 ( $P=0.002)$, Ho1 $(P=0.02)$, Cat $(P=0.04)$ and $\mathrm{Gpx3}(P=0.05)$ gene expression was increased compared to offspring mice of non-supplemented mothers (Figure 2A). Interestingly, of these genes only Nrf2 gene expression was already upregulated in liver of fetuses at day 14.5 of gestation. Adult mice prenatally exposed to genistein also showed a significant increase in gene expression of Nrf2 $(P=0.01)$, while induction of Cat in the liver did just not reach statistical significance $(P=0.06)$.

In the lung of the genistein exposed mice only Gpx3 gene expression showed a significant increase $(\mathrm{P}=0.03)$ compared to control animals (Figure $2 \mathrm{~B})$. In addition, prenatal exposure to genistein also resulted in a modest increase in gene expression of Sod2 gene expression $(P=0.07)$ in the lung of 12 week old mice whereas prenatal exposure to quercetin induced 
Sod2 gene expression significantly $(\mathrm{P}=0.01)$. Keap1 gene expression was also significantly increased $(P=0.04)$ in mice prenatally exposed to quercetin, as was for Nrf2, though not statistically significant $(P=0.09)$.

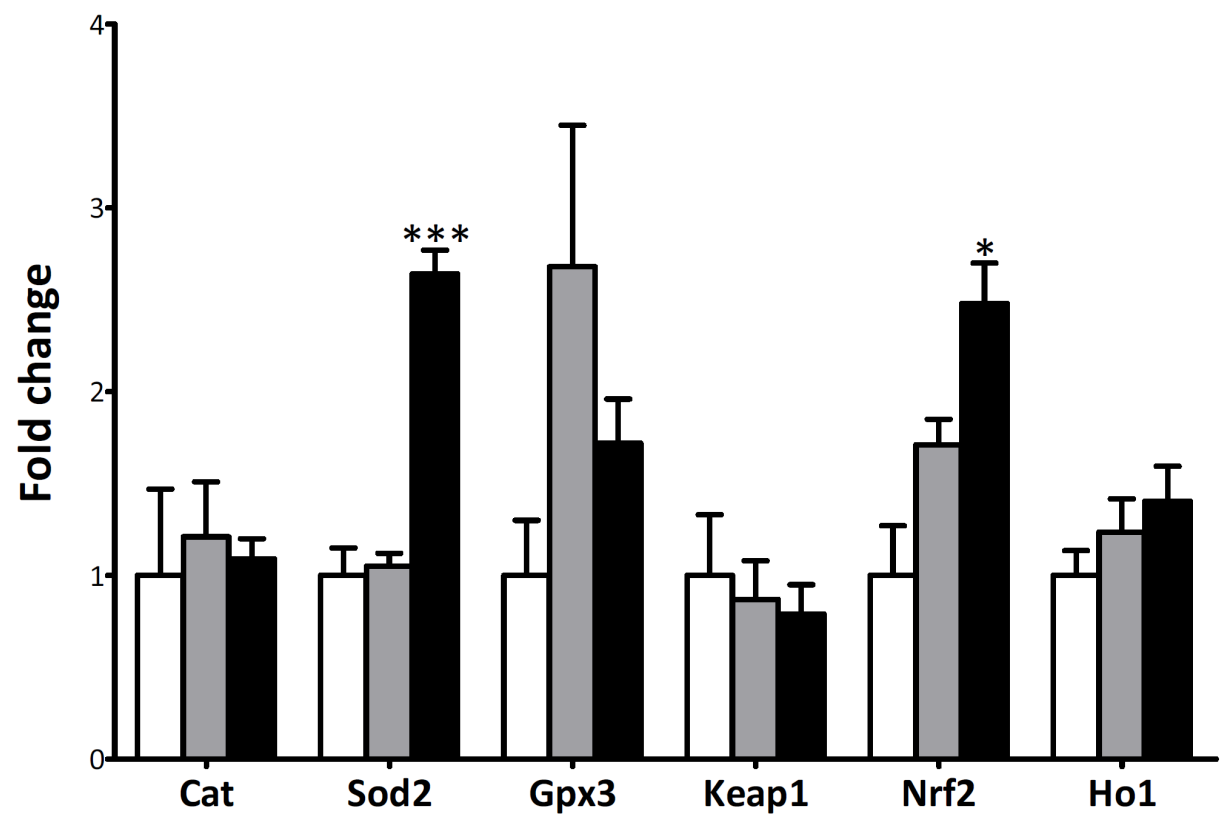

Figure 1. Direct effect of genistein and quercetin exposure on antioxidant, Keap1, Nrf2 and Ho1 gene expression in the liver of E14.5 fetuses.

mRNA expression level of antioxidant genes (Cat, Sod2 and Gpx3), Keap1, Nrf2 and Ho1 were measured in the liver of E14.5 fetuses. Grey bars represent the genistein exposed group ( $n=5)$, black bars the quercetin exposed group $(n=5)$ and white bars the control group $(n=5)$. Bars represent the normalized average fold change (calculated as $2^{-\Delta \Delta C T}$ ) and error bars represent the standard errors. ${ }^{*}: \mathrm{P} \varangle 0.05,{ }^{* * *}$ : $\mathrm{P} \leq 0.001$.

Prenatal exposure to genistein increases the non-enzymatic antioxidant capacity of the lung

Although a relation between maternal flavonoid intake during gestation and enzymatic antioxidant expression was observed, one cannot exclude that there might also be a longlasting effect on the non-enzymatic antioxidant capacity directly induced by the prenatal diet or in response to alterations in the enzymatic antioxidant defense system. Therefore, the non-enzymatic antioxidant capacity of both liver and long tissue of 12 week old mice prenatally exposed to genistein or quercetin was determined. Hence, the trolox equivalent antioxidant capacity (TEAC) was assessed, in combination with vitamin C levels and the presence of vitamin $\mathrm{C}$ radicals in tissue extracts. In liver tissue of adult mice prenatally exposed to genistein or quercetin no significant differences in TEAC were noticeable, though it seemed that the liver TEAC levels were slightly decreased, while for the lung prenatal exposure to genistein significantly increased TEAC levels $(P<0.05$, Table 2$)$. This suggests that only prenatal exposure to genistein could affect the non-enzymatic antioxidant capacity of liver and lung at adult age. 

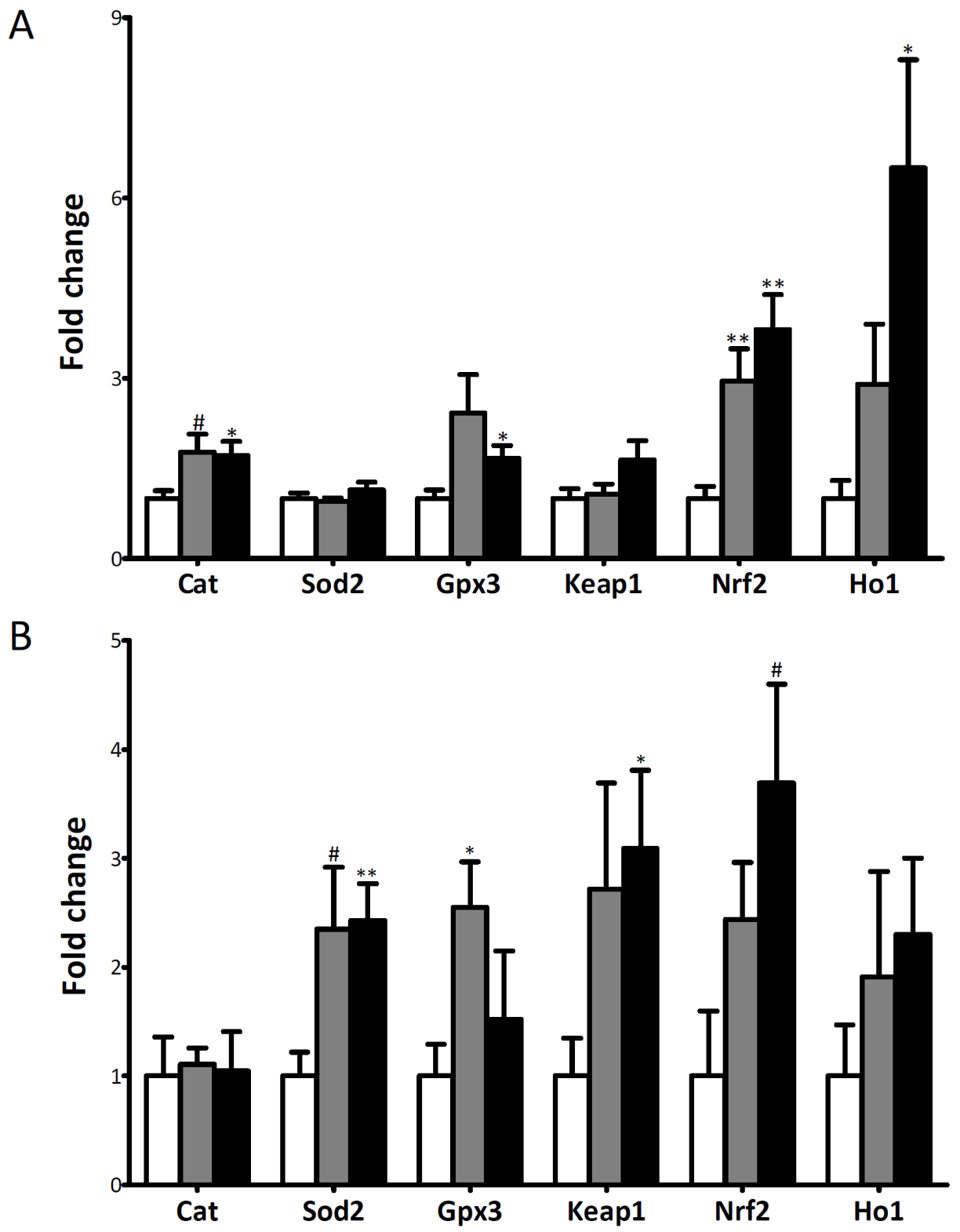

Figure 2. Long-term effect of genistein and quercetin exposure on antioxidant, Keap1, Nrf2 and Hol gene expression in the liver and lung of 12 week old mice.

mRNA expression level of antioxidant genes (Cat, Sod2 and Gpx3), Keap1, Nrf2 and Hol were measured in the liver (A) and lung (B) of 12 week old mice prenatally exposed to either genistein (grey bars, $n=5$ ) or quercetin (black bars, $n=5$ ) compared to the control group (white bars, $n=5$ ). Bars represent the normalized average fold change (calculated as $2^{-\Delta \Delta C T}$ ) and error bars represent the standard errors. ${ }^{*}: P \leq 0.09,{ }^{*}: P \varangle 0.05,{ }^{* *}: P \leq 0.01$. 
Next, vitamin C levels were measured in liver and lung tissues of mice prenatally exposed to either genistein or quercetin. Although it appeared that more vitamin $C$ was present in the lung of adult mice prenatally exposed to genistein compared to quercetin exposed and control mice, no significant differences were found, due to the high variation within the genistein exposed group (Table 2). In addition, when comparing the contribution of vitamin $C$ to the trolox capacity of these organs, there was no difference between control and exposed animals (Table 2).

Table 2: TEAC, vitamin C concentration and vitamin C radical level measured in the liver and lung of 12 week old mice prenatally exposed to genistein or quercetin

\begin{tabular}{lllll}
\hline & & Control & Genistein & Quercetin \\
\hline Liver & TEAC $(\mu \mathrm{mol} / \mathrm{g})$ & $54.2 \pm 8.9$ & $41.8 \pm 4.1$ & $40.9 \pm 8.7$ \\
& Vitamin C $(\mu \mathrm{mol} / \mathrm{g})$ & $21.5 \pm 4.4$ & $20.2 \pm 1.7$ & $21.2 \pm 1.8$ \\
& Vitamin C/ TEAC ratio & 0.4 & 0.5 & 0.5 \\
& Vitamin C radical $\left(1 \times 10^{5} \mathrm{AUC} / \mathrm{g}\right)$ & $0.3 \pm 0.2$ & $0.4 \pm 0.2$ & $0.3 \pm 0.1$ \\
\hline Lung & TEAC $(\mu \mathrm{mol} / \mathrm{g})$ & $50.3 \pm 4.7$ & $64.6 \pm 4.0^{*}$ & $49.3 \pm 4.6$ \\
& Vitamin C $(\mu \mathrm{mol} / \mathrm{g})$ & $7.5 \pm 1.7$ & $19.2 \pm 7.2$ & $8.2 \pm 4.2$ \\
& Vitamin C/ TEAC ratio & 0.1 & 0.3 & 0.2 \\
& Vitamin C radical $\left(1 \times 10^{5} \mathrm{AUC} / \mathrm{g}\right)$ & $8.5 \pm 0.6$ & $7.2 \pm 0.3^{\text {\#a }}$ & $7.2 \pm 0.2^{\text {\#螘 }}$ \\
\hline
\end{tabular}

For each measurement $n=5$ for all three the diets. AUC: area under the curve. Data represent mean $\pm S E$.

*: $\mathrm{P} \varangle 0.05$; *: $\mathrm{P} \varangle 0.08$; : $\mathrm{P}=0.05$ for both flavonoids compared to control.

Prenatal exposure to flavonoids decreased the in vivo scavenging of ROS by vitamin $\mathrm{C}$ in the lung tissue of adult mice

Next, we investigated how these organs coped with oxidative stress in vivo by measuring the vitamin C radical level in tissue homogenates using ESR spectroscopy. In the liver of mice prenatally exposed to genistein or quercetin there were no differences seen in the amount of vitamin $\mathrm{C}$ radicals compared to control mice (Table 2 ). In the lung on the contrary, prenatal exposure to flavonoids resulted in a decrease in the amount of vitamin $C$ radicals formed in vivo $(P=0.05$ taken both flavonoids together; $P=0.06$ for genistein; $P=$ 0.08 for quercetin) compared to control mice.

Prenatal exposure to flavonoids protected the liver against oxidative stress induced DNA damage

In both liver and lung of adult offspring mice, Nrf2 expression was upreglated by maternal flavonoid intake. However, its downstream regulated gene Hol was only increased in liver, which indicates that an antioxidant response may have been triggered in the liver. In lung, increased Nrf2 expression coincided with enhanced Keap1 expression, which may inhibit further Nrf2 signaling. Therefore, it was expected that a persistent antioxidant effect can only be seen in the liver. Indeed, oxidative stress induced DNA damage in liver was decreased in mice prenatally exposed to genistein $(P=0.04)$ or quercetin $(P=0.003)$ as they displayed lower levels of 8-oxo-dG compared to control mice (Figure $3 \mathrm{~A}$ ). In the lung, prenatal exposure to genistein or quercetin had no effect on the amount of 8-oxo-dG levels compared to control mice (Figure $3 \mathrm{C}$ ). 
Another type of DNA damage induced by oxidative stress and lipid peroxidation is $M_{1} d G$. Interestingly, these data confirmed the findings observed for 8-oxo-dG, since prenatal exposure to both genistein and quercetin resulted in decreased levels of $M_{1} d G$ in liver $(P=0.008$ for genistein and $P=0.001$ for quercetin; Figure $3 B$ ), while no differences in the amount of $\mathrm{M}_{1} \mathrm{dG}$ was detected in the lung of 12 week old mice (Figure 3D).

A

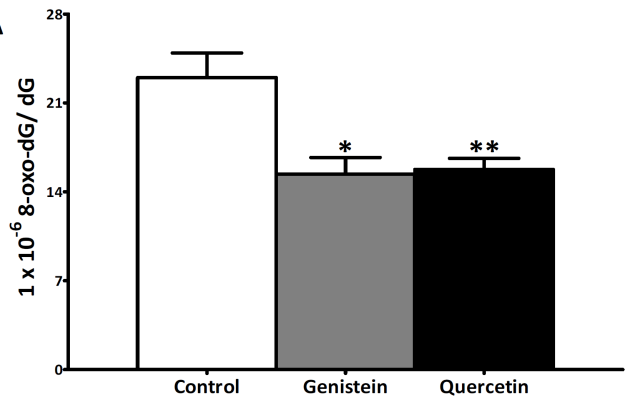

C

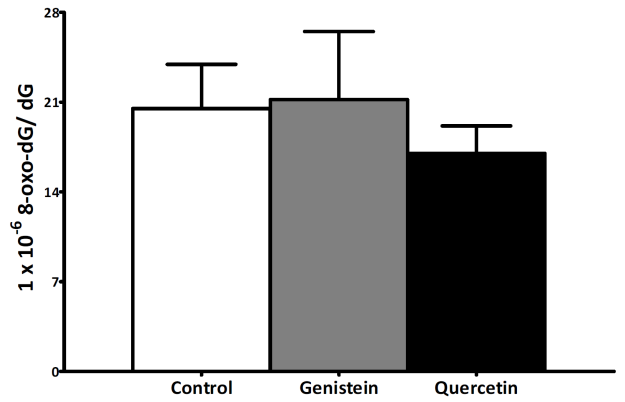

B

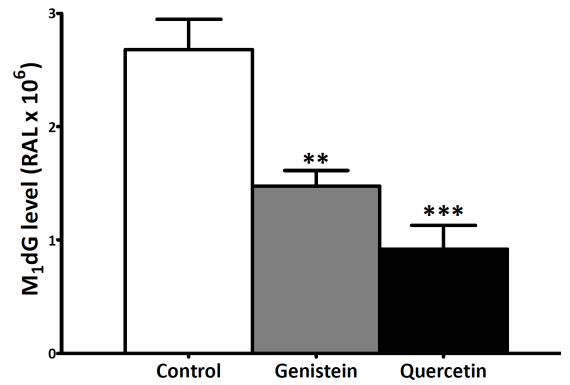

D

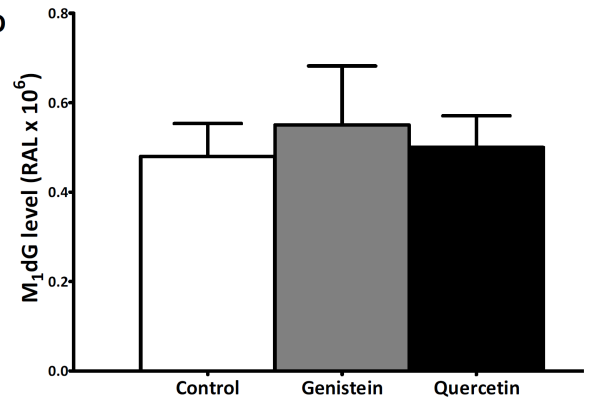

Figure 3. ROS induced DNA damage in liver and lung tissue of 12 week old mice prenatally exposed to genistein or quercetin.

8-0xo-dG $(A, C)$ and $M_{1} d G(B, D)$ levels were assessed as measure for ROS induced DNA damage in the liver ( $A$, $B)$ and lung (C, D) of 12 week old mice prenatally exposed to either genistein (grey bars) or quercetin (black bars) compared to the control group (white bars). Data represents the mean \pm SE. RAL=relative adduct labeling. $*: P \varangle 0.05, * *: P \leq 0.01, * * *: P \leq 0.001$

\section{Discussion}

In this study we showed that prenatal exposure to both genistein and quercetin protected against oxidative stress induced DNA damage in the liver, as shown by lower levels of 8oxo-dG and $\mathrm{M}_{1} \mathrm{dG}$ in 12 week old mice. We assume that this is the result of long-lasting adaptations made in the antioxidant network as seen in the up-regulation of the enzymatic antioxidants.

During development, direct exposure to quercetin resulted in an up-regulation of Nrf2 gene expression in the fetal liver at day 14.5 of gestation. $\mathrm{Nrf2}$ is the key transcription factor regulating the antioxidant response. It is normally targeted for proteasomal degradation by Keap1. However it translocates into the nucleus when oxidative stress occurs, since this 
results in a conformational change of Keap1 and therefore the release of Nrf2 (43). The increase in Nrf2 gene expression suggests that quercetin acted as a pro-oxidant in utero, which has also been shown in vitro $(35,44)$. Fetuses exposed to genistein also had an increase in Nrf2 gene expression, though not statistically significant. This suggests that genistein also had a pro-oxidant action in utero, but milder compared to quercetin. However, the lower induction of Nrf2 gene expression seen in fetuses exposed to genistein could also be due to the fact that genistein impedes the nuclear export and degradation of Nrf2 after it has activated antioxidant response genes (45). This suggests that an upregulation of Nrf2 gene expression is not essential for genistein induced activation of the Nrf2-pathway, which may in our model also result in a different effect in the adult offspring. Although Nrf2 gene expression was elevated in exposed fetuses compared to control fetuses, expression of a major target gene of Nrf2, namely Hol was only modestly elevated. This indicates that gene expression levels of Nrf2 does not necessarily result in more functional Nrf2 proteins; or upon an oxidative stress induced trigger, Nrf2 could not translocate into the nucleus to perform its function. Moreover, due to the fact that Nrf2 has to reach a threshold before it can enter the nucleus and induce downstream effects (43), it could be that in our model at gestationa day 14.5 this threshold has not been reached yet. Fetuses exposed to quercetin were also found to have increased gene expression of Sod2. Sod2 normally converts $\mathrm{O}_{2}{ }^{-}$, a byproduct of the mitochondrial electron transport chain into $\mathrm{H}_{2} \mathrm{O}_{2}$ and $\mathrm{O}_{2}$. De $\mathrm{M}$ archi et al. (46) showed that rat liver mitochondria exposed to quercetin had an increased production of $\mathrm{O}_{2}{ }^{-}$, explaining the up-regulation of Sod2 gene expression seen in fetuses exposed to quercetin.

At adult age, mice prenatally exposed to genistein, but especially to quercetin still had increased expression of Nrf2 in their liver. Moreover, they also showed an increased expression of the Nrf2 target gene $\mathrm{Hol}$ in their liver, suggesting that the increased expression of Nrf2 also resulted in an increased down-stream effect, modulating oxidative stress responses.

Moreover, prenatal exposure to genistein and quercetin resulted in the increased expression of the antioxidant genes Cat and $\mathrm{Gpx3}$ in the liver of adult mice. Both antioxidants are responsible for scavenging $\mathrm{H}_{2} \mathrm{O}_{2}$ and their mRNAs are shown to accumulate in utero to be translated in advance of birth (47), as these enzymes are needed from then onwards for protection against oxidative stress by aerobic respiration. Therefore, it is possible that the effect of genistein and quercetin exposure on the induction of gene expression of these genes could not be observed during mid-gestation, but long-lasting effects are seen in adult offspring.

The lung of mice prenatally exposed to genistein and quercetin showed a totally different enzymatic antioxidant network compared to the liver. Here, Nrf2 gene expression was also up-regulated in case of both flavonoids. However, Keapl gene expression was increased to a comparable extent. Therefore, we assume that the oxidative stress response pathway was activated to a lesser degree, which was also confirmed by the modest increase in Hol gene expression and no effect on DNA damage parameters. In the lung, prenatal exposure to genistein and quercetin also resulted in the up-regulation of Sod2 and Gpx3 gene expression, while Cat gene expression remained unaffected. Differences in antioxidant gene expression profiles between liver and lung tissue of adult mice prenatally exposed to genistein or quercetin could be explained by the fact that the liver is largely differentiated before birth (48), while the lung develops mainly in the final stages of pregnancy and even continues to 
develop after birth (49). Therefore, the different responses of both tissues to the flavonoids could be the result of a difference in maturation state of the organ during exposure.

Although prenatal exposure to genistein and quercetin resulted in the up-regulation of the gene expression of enzymatic antioxidants, it had only minor effects on the non-enzymatic antioxidant capacity. TEAC levels in liver were slightly decreased while in lung they were only increased in case of prenatal exposure to genistein. The contribution of vitamin $\mathrm{C}$ to the TEAC did not differ between diet groups, suggesting that prenatal exposure to genistein or quercetin affected other components of the non-enzymatic antioxidant network. Still, lungs of mice prenatally exposed to genistein had increased levels of vitamin $C$, although not significantly due to the large variation within the genistein exposed group, compared to the control group. Unlike humans, mice synthesize vitamin $\mathrm{C}$ from glucose in the liver (50). As genistein exposure can result in an increased uptake of glucose by cells (51) and improves glucose tolerance (52), we assume that mice prenatally exposed to genistein produce more vitamin $C$ and transport it throughout the body, for instance to the lung, as they may be programmed to take up more glucose.

Vitamin C radicals were measured in liver and lung homogenates as they seem to provide a stable and reliable signal for oxidative stress (39). In the liver of mice prenatally exposed to genistein and quercetin, there was no difference in the amount of vitamin $\mathrm{C}$ radicals formed in vivo. In the lung however, the amount of vitamin C radicals was slightly decreased in mice prenatally exposed to flavonoids, probably as a result of modest increase in both the enzymatic as non-enzymatic antioxidant activity.

In our study pregnant mice were exposed to approximately $26.7-36.7 \mathrm{mg} / \mathrm{kg}$ bodyweight genistein and 33.3-46.7 mg/ kg bodyweight quercetin per day. This is a high, but biological relevant dose, because the average human daily dietary intake of quercetin is in the range of $10-100 \mathrm{mg} \mathrm{(53)}$ and the average human daily dietary isoflavone intake lies between 1$40 \mathrm{mg}$ (54). Both flavonoids are freely available as dietary supplements with a daily recommended dose that can be as high as $1-2$ gram per day $(55,56)$, which could correspond to $14-28 \mathrm{mg}$ for a person weighing $70 \mathrm{~kg}$. Moreover, it is noteworthy that the metabolism of flavonoids differs between fetuses and adults. In humans, fetal cord blood has a higher genistein level than maternal serum (57), suggesting that the fetus could be exposed to even higher concentrations.

These data show that prenatal exposure to genistein but especially quercetin results in a pro-oxidant trigger in utero, with long-lasting effects on the antioxidant capacity of the liver and lung. These long-lasting effects may be mediated through epigenetic mechanisms and need further study. Mild effects were seen for the non-enzymatic antioxidants, suggesting that prenatal exposure to genistein and quercetin results in an adapted antioxidant defense system in both organs and activated the Nrf2-antioxidant pathway in the liver. This resulted in the protection from oxidative stress induced DNA damage in the liver of adult mice prenatally exposed to genistein and quercetin. 


\section{References}

1. Vanhees, K., de Bock, L., Godschalk, R. W., van Schooten, F. J., and van Waalwijk van Doorn-Khosrovani, S. B. (2011) Prenatal exposure to flavonoids: implication for cancer risk. Toxicol Sci 120, 59-67

2. Ahlgren, M., Sorensen, T., Wohlfahrt, J., Haflidadottir, A., Holst, C., and M elbye, M . (2003) Birth weight and risk of breast cancer in a cohort of 106,504 women. Int J Cancer 107, 997-1000

3. Vickers, M. H., Breier, B. H., Cutfield, W. S., Hofman, P. L., and Gluckman, P. D. (2000) Fetal origins of hyperphagia, obesity, and hypertension and postnatal amplification by hypercaloric nutrition. Am J Physiol Endocrinol M etab 279, E83-87

4. Ravelli, A. C., van Der Meulen, J. H., Osmond, C., Barker, D. J., and Bleker, O. P. (1999) Obesity at the age of $50 \mathrm{y}$ in men and women exposed to famine prenatally. Am J Clin Nutr 70, 811-816

5. Dolinoy, D. C., Weidman, J. R., Waterland, R. A., and Jirtle, R. L. (2006) Maternal genistein alters coat color and protects Avy mouse offspring from obesity by modifying the fetal epigenome. Environ Health Perspect $114,567-572$

6. Barker, D. J. (1991) The intrauterine environment and adult cardiovascular disease. Ciba Found Symp 156, 310; discussion 10-16

7. Reuter, S., Gupta, S. C., Chaturvedi, M. M., and Aggarwal, B. B. (2010) Oxidative stress, inflammation, and cancer: how are they linked? Free Radic Biol Med 49, 1603-1616

8. Ross, J. A., and Kasum, C. M. (2002) Dietary flavonoids: bioavailability, metabolic effects, and safety. Annu Rev Nutr 22, 19-34

9. Erdman, J. W., Jr., Balentine, D., Arab, L., Beecher, G., Dwyer, J. T., Folts, J., Harnly, J., Hollman, P., Keen, C. L., Mazza, G., M essina, M., Scalbert, A., Vita, J., Williamson, G., and Burrowes, J. (2007) Flavonoids and heart health: proceedings of the ILSI North America Flavonoids Workshop, May 31-June 1, 2005, Washington, DC. J Nutr 137, 718S-737S

10. Aherne, S. A., and O'Brien, N. M. (2002) Dietary flavonols: chemistry, food content, and metabolism. Nutrition 18, 75-81

11. Marik, R., Allu, M., Anchoori, R., Stearns, V., Umbricht, C. B., and Khan, S. (2011) Potent genistein derivatives as inhibitors of estrogen receptor alpha-positive breast cancer. Cancer Biol Ther $\mathbf{1 1}$

12. Miodini, P., Fioravanti, L., Di Fronzo, G., and Cappelletti, V. (1999) The two phyto-oestrogens genistein and quercetin exert different effects on oestrogen receptor function. Br J Cancer 80, 1150-1155

13. Loke, W. M., Proudfoot, J. M., Hodgson, J. M., M cKinley, A. J., Hime, N., Magat, M., Stocker, R., and Croft, K. D. (2010) Specific dietary polyphenols attenuate atherosclerosis in apolipoprotein E-knockout mice by alleviating inflammation and endothelial dysfunction. Arterioscler Thromb Vasc Biol 30, 749-757

14. Mahn, K., Borras, C., Knock, G. A., Taylor, P., Khan, I. Y., Sugden, D., Poston, L., Ward, J. P., Sharpe, R. M., Vina, J., Aaronson, P. I., and Mann, G. E. (2005) Dietary soy isoflavone induced increases in antioxidant and eNOS gene expression lead to improved endothelial function and reduced blood pressure in vivo. FASEB J 19, 1755-1757

15. Heo, H. J., and Lee, C. Y. (2004) Protective effects of quercetin and vitamin C against oxidative stressinduced neurodegeneration. J Agric Food Chem 52, 7514-7517

16. Mercer, L. D., Kelly, B. L., Horne, M. K., and Beart, P. M. (2005) Dietary polyphenols protect dopamine neurons from oxidative insults and apoptosis: investigations in primary rat mesencephalic cultures. Biochem Pharmacol 69, 339-345

17. Boots, A. W., Drent, M., de Boer, V. C., Bast, A., and Haenen, G. R. (2011) Quercetin reduces markers of oxidative stress and inflammation in sarcoidosis. Clin Nutr

18. Valsecchi, A. E., Franchi, S., Panerai, A. E., Rossi, A., Sacerdote, P., and Colleoni, M. (2011) The soy isoflavone genistein reverses oxidative and inflammatory state, neuropathic pain, neurotrophic and vasculature deficits in diabetes mouse model. Eur J Pharmacol 650, 694-702

19. Formica, J. V., and Regelson, W. (1995) Review of the biology of Quercetin and related bioflavonoids. Food Chem Toxicol 33, 1061-1080

20. Bolanos, J. P., Moro, M. A., Lizasoain, I., and Almeida, A. (2009) Mitochondria and reactive oxygen and nitrogen species in neurological disorders and stroke: Therapeutic implications. Adv Drug Deliv Rev 61, 1299-1315

21. Hensley, K., Butterfield, D. A., Hall, N., Cole, P., Subramaniam, R., Mark, R., Mattson, M. P., Markesbery, W. R., Harris, M. E., Aksenov, M., and et al. (1996) Reactive oxygen species as causal agents in the neurotoxicity of the Alzheimer's disease-associated amyloid beta peptide. Ann N Y Acad Sci 786, 120-134

22. Multhaup, G., Ruppert, T., Schlicksupp, A., Hesse, L., Beher, D., Masters, C. L., and Beyreuther, K. (1997) Reactive oxygen species and Alzheimer's disease. Biochem Pharmacol 54, 533-539 
23. Tabner, B. J., Turnbull, S., El-Agnaf, O., and Allsop, D. (2001) Production of reactive oxygen species from aggregating proteins implicated in Alzheimer's disease, Parkinson's disease and other neurodegenerative diseases. Curr Top Med Chem 1, 507-517

24. Tieu, K., Ischiropoulos, H., and Przedborski, S. (2003) Nitric oxide and reactive oxygen species in Parkinson's disease. IUBM B Life 55, 329-335

25. Touyz, R. M. (2004) Reactive oxygen species and angiotensin II signaling in vascular cells -- implications in cardiovascular disease. Braz J Med Biol Res 37, 1263-1273

26. Yoshizumi, M., Tsuchiya, K., and Tamaki, T. (2001) Signal transduction of reactive oxygen species and mitogen-activated protein kinases in cardiovascular disease. J Med Invest 48, 11-24

27. Boots, A. W., Li, H., Schins, R. P., Duffin, R., Heemskerk, J. W., Bast, A., and Haenen, G. R. (2007) The quercetin paradox. Toxicol Appl Pharmacol 222, 89-96

28. Cao, G., Sofic, E., and Prior, R. L. (1997) Antioxidant and prooxidant behavior of flavonoids: structure-activity relationships. Free Radic Biol Med 22, 749-760

29. Choi, E. J., Chee, K. M., and Lee, B. H. (2003) Anti- and prooxidant effects of chronic quercetin administration in rats. Eur J Pharmacol 482, 281-285

30. Ullah, M. F., Shamim, U., Hanif, S., Azmi, A. S., and Hadi, S. M. (2009) Cellular DNA breakage by soy isoflavone genistein and its methylated structural analogue biochanin A. M ol Nutr Food Res 53, 1376-1385

31. Gebicki, J. M., Nauser, T., Domazou, A., Steinmann, D., Bounds, P. L., and Koppenol, W. H. (2010) Reduction of protein radicals by GSH and ascorbate: potential biological significance. Amino Acids 39, 1131-1137

32. Seifried, H. E., Anderson, D. E., Fisher, E. I., and Milner, J. A. (2007) A review of the interaction among dietary antioxidants and reactive oxygen species. J Nutr Biochem 18, 567-579

33. Siow, R. C., and Mann, G. E. (2010) Dietary isoflavones and vascular protection: activation of cellular antioxidant defenses by SERM s or hormesis? M ol Aspects M ed 31, 468-477

34. Hur, W., and Gray, N. S. (2011) Small molecule modulators of antioxidant response pathway. Curr Opin Chem Biol 15, 162-173

35. Niestroy, J., Barbara, A., Herbst, K., Rode, S., van Liempt, M., and Roos, P. H. (2011) Single and concerted effects of benzo[a]pyrene and flavonoids on the AhR and Nrf2-pathway in the human colon carcinoma cell line Caco-2. Toxicol In Vitro 25, 671-683

36. Chow, J. M., Shen, S. C., Huan, S. K., Lin, H. Y., and Chen, Y. C. (2005) Quercetin, but not rutin and quercitrin, prevention of $\mathrm{H} 2 \mathrm{O} 2$-induced apoptosis via anti-oxidant activity and heme oxygenase 1 gene expression in macrophages. Biochem Pharmacol 69, 1839-1851

37. Breinholt, V., Lauridsen, S. T., and Dragsted, L. O. (1999) Differential effects of dietary flavonoids on drug metabolizing and antioxidant enzymes in female rat. Xenobiotica 29, 1227-1240

38. Fischer, M. A., Gransier, T. J., Beckers, L. M., Bekers, O., Bast, A., and Haenen, G. R. (2005) Determination of the antioxidant capacity in blood. Clin Chem Lab Med 43, 735-740

39. Linschooten, J. O., Laubenthal, J., Cemeli, E., Baumgartner, A., Anderson, D., Sipinen, V. E., Brunborg, G., Haenen, G. R., Fthenou, E., Briede, J. J., van Schooten, F. J., and Godschalk, R. W. (2011) Incomplete protection of genetic integrity of mature spermatozoa against oxidative stress. Reprod Toxicol

40. Langie, S. A., Kowalczyk, P., Tudek, B., Zabielski, R., Dziaman, T., Olinski, R., van Schooten, F. J., and Godschalk, R. W. (2010) The effect of oxidative stress on nucleotide-excision repair in colon tissue of newborn piglets. M utat Res 695, 75-80

41. Godschalk, R. W., Maas, L. M., Van Zandwijk, N., van 't Veer, L. J., Breedijk, A., Borm, P. J., Verhaert, J., Kleinjans, J. C., and van Schooten, F. J. (1998) Differences in aromatic-DNA adduct levels between alveolar macrophages and subpopulations of white blood cells from smokers. Carcinogenesis 19, 819-825

42. Peluso, M., Srivatanakul, P., M unnia, A., Jedpiyawongse, A., Ceppi, M., Sangrajrang, S., Piro, S., and Boffetta, P. (2010) Malondialdehyde-deoxyguanosine adducts among workers of a Thai industrial estate and nearby residents. Environ Health Perspect 118, 55-59

43. Li, W., and Kong, A. N. (2009) Molecular mechanisms of Nrf2-mediated antioxidant response. Mol Carcinog 48, 91-104

44. Kimura, S., Warabi, E., Yanagawa, T., Ma, D., Itoh, K., Ishii, Y., Kawachi, Y., and Ishii, T. (2009) Essential role of Nrf2 in keratinocyte protection from UVA by quercetin. Biochem Biophys Res Commun 387, 109-114

45. Kaspar, J. W., and Jaiswal, A. K. (2011) Tyrosine phosphorylation controls nuclear export of Fyn, allowing Nrf2 activation of cytoprotective gene expression. FASEB J 25, 1076-1087

46. De Marchi, U., Biasutto, L., Garbisa, S., Toninello, A., and Zoratti, M. (2009) Quercetin can act either as an inhibitor or an inducer of the mitochondrial permeability transition pore: A demonstration of the ambivalent redox character of polyphenols. Biochim Biophys Acta 1787, 1425-1432

47. el-Hage, S., and Singh, S. M. (1990) Temporal expression of genes encoding free radical-metabolizing enzymes is associated with higher mRNA levels during in utero development in mice. Dev Genet 11, 149-159 
48. Zaret, K. S. (2002) Regulatory phases of early liver development: paradigms of organogenesis. Nat Rev Genet 3, 499-512

49. Ten Have-Opbroek, A. A. (1991) Lung development in the mouse embryo. Exp Lung Res 17, 111-130

50. Naidu, K. A. (2003) Vitamin C in human health and disease is still a mystery? An overview. Nutr J 2, 7

51. Ha, B. G., Nagaoka, M., Yonezawa, T., Tanabe, R., Woo, J. T., Kato, H., Chung, U. I., and Yagasaki, K. (2011) Regulatory mechanism for the stimulatory action of genistein on glucose uptake in vitro and in vivo. J Nutr Biochem

52. Cederroth, C. R., and Nef, S. (2009) Fetal programming of adult glucose homeostasis in mice. PLoS One 4, e7281

53. Egert, S., and Rimbach, G. (2011) Which sources of flavonoids: complex diets or dietary supplements? Adv Nutr 2, 8-14

54. Manach, C., Scalbert, A., M orand, C., Remesy, C., and Jimenez, L. (2004) Polyphenols: food sources and bioavailability. Am J Clin Nutr 79, 727-747

55. Espin, J. C., Garcia-Conesa, M. T., and Tomas-Barberan, F. A. (2007) Nutraceuticals: facts and fiction. Phytochemistry 68, 2986-3008

56. Harwood, M., Danielewska-Nikiel, B., Borzelleca, J. F., Flamm, G. W., Williams, G. M., and Lines, T. C. (2007) A critical review of the data related to the safety of quercetin and lack of evidence of in vivo toxicity, including lack of genotoxic/carcinogenic properties. Food Chem Toxicol 45, 2179-2205

57. Todaka, E., Sakurai, K., Fukata, H., M iyagawa, H., Uzuki, M., Omori, M., Osada, H., Ikezuki, Y., Tsutsumi, O., Iguchi, T., and Mori, C. (2005) Fetal exposure to phytoestrogens--the difference in phytoestrogen status between mother and fetus. Environ Res 99, 195-203 




\section{Chapter 5}

\section{Maternal quercetin intake during pregnancy results in an adapted iron homeostasis at adulthood}

Vanhees K, Godschalk RWL, Sanders A, Barjesteh van Waalwijk van DoornKhosrovani S, van Schooten FJ 


\begin{abstract}
The flavonoid quercetin is a powerful iron chelator, capable of oxidizing heme iron in hemoglobin from $\mathrm{Fe}^{2+}$ to $\mathrm{Fe}^{3+}$. Moreover, quercetin crosses the placenta and accumulates in the fetus. Since adaptations made by the fetus to cope with inappropriate nutrition may lead to permanent changes, a relative high intake of quercetin may have detrimental affects later in life. Therefore, we investigated the effects of maternal exposure to quercetin (302 mg/ kg feed), starting from 3 days before conception until the end of gestation, on erythropoiesis and iron homeostasis at embryonic day 14.5 and in 12 week old mice. During fetal development, quercetin exposure had no effect on the erythroid lineage switch and concomitant globin switch. However, adult mice prenatally exposed to quercetin had significant increased iron storage in the liver, by up-regulating ironassociated cytokine expression (hepcidin, IL-16, IL-6 and IL-10). These long-term changes in gene expression could be mediated through epigenetic modifications, as prenatal quercetin exposure resulted in a modest hypermethylation of repetitive elements. Despite the increased iron levels, oxidative stress was significantly decreased in the liver of these animals as assessed by $8-0 \times 0-d G$ levels. These data suggest that prenatal quercetin exposure results in increased iron storage, while decreasing oxidative stress induced DNA damage together with a shift towards increased expression of inflammation associated cytokines in the liver at adult age.
\end{abstract}




\section{Introduction}

Flavonoids are polyphenolic compounds found in diverse foods and beverages of plant origin, such as fruits, vegetables, soy products, tea and wine. They are most commonly known for the health benefits they provide against cancer and heart diseases, which is attributed to their antioxidant capacity (1). Quercetin (3,3',4',5,7-pentahydroxyflavone) is the most widely consumed flavonoid in the diet. This polyphenolic compound is a potent free radical scavenger and iron chelator. Previous studies have shown that quercetin can penetrate the cytoplasm of erythrocytes $(2,3)$. Here, it interacts with the heme iron in hemoglobin and oxidizes it from the ferrous $\left(\mathrm{Fe}^{2+}\right)$ to the ferric $\left(\mathrm{Fe}^{3+}\right)$ state. This latter form of hemoglobin, namely methemoglobin, is inactive and is incapable of transporting oxygen (3). About $65 \%$ of the body's iron is used for the production of hemoglobin. Iron is an essential micronutrient that besides erythropoiesis is also required for oxidative metabolism and immune responses. Iron absorption is tightly regulated due to the fact that the body has no effective means of excreting iron and iron overload leads to toxicity due to increased free radical formation (4). Quercetin can also have pro-oxidant capacities (5), especially in the presence of transition metal iron (6). As it has been shown that several flavonoids can cross the placenta to accumulate in fetal tissue (7), and because we previously showed that prenatal exposure to quercetin resulted in a higher incidence of $M \|$ translocations in mice with an impaired DNA repair (8), we assume that quercetin can also cross the placenta. Therefore it is interesting to study the iron chelating effect of quercetin in developing fetuses. Godfrey et al. (9) stated that adaptations made by the fetus to cope with inappropriate nutrition may lead to morphological and physiological changes that persist into postnatal life. These changes, although ensuring fetal survival, may have detrimental affects later in life. We therefore investigated whether prenatal exposure to the iron chelator quercetin could result in a permanent change in iron homeostasis and erythropoiesis later in life.

To this end, mice were prenatally exposed to quercetin (302 mg/ kg feed) and erythropoiesis (red blood cell (RBC) progenitor composition, RBC turnover and globin status) was assessed at adult age. Microarray analysis of the bone marrow cells was performed to investigate the expression of genes involved in erythropoiesis and iron homeostasis. Liver and spleen iron levels and gene expression of hepcidin and interleukins (IL) involved in iron storage in the liver were investigated. In addition, 8-oxo-dG levels were measured in the liver of 12 week old mice as a measure for iron induced oxidative stress. To investigate whether long-term effects already occurred in utero, the effect of quercetin exposure on fetal erythropoiesis was studied in female mice that were exposed to quercetin and sacrificed at gestational day 14.5 as the switch in erythroid lineage occurs at that developmental time point. Subsequently, erythropoiesis in the liver of fetuses was investigated. Also the total amount of iron, bilirubin and erythropoietin (EPO) levels were measured in the amniotic fluid of these fetuses to characterize iron status and homeostasis.

\section{Material and methods}

Mice and sample collection

Female mice (129/Sv):C57BL/6) background) approximately 8 weeks of age, received either normal chow (low phytoestrogen content complete feed for mice breeding, ssniff $@$, Soest, Germany, $n=8$ ) or the same chow supplemented with quercetin (302 mg/ $\mathrm{kg}$ feed, $n=8$, 
Sigma, Zwijndrecht, the Netherlands) from 3 days before conception until the end of gestation. After delivery all mothers and pups, regardless of their prenatal diet, received normal chow and the offspring were anesthetized and sacrificed by cardiac puncture at 12 weeks of age. Bone marrow was isolated by removing the femurs and flushing the marrow with PBS; liver and spleen were isolated and stored at $-80^{\circ} \mathrm{C}$ until further analysis.

To determine the direct effects of quercetin on erythropoiesis in fetuses, female mice (129/Sv):C57BL/6 background, $n=5$ for control group and $n=3$ for quercetin exposed group) were mated overnight and conception day was determined by recognition of a vaginal plug the next morning (E0.5). Female mice were placed on the same control or quercetin enriched chow, as described above, from three days before conception. On day 14.5 of gestation, mice were sacrificed and the amniotic fluid, placentas, fetuses and their blood and liver were isolated. Also the liver of the mothers was isolated for further analysis.

Fetal blood and adult bone marrow cytology

After initial fixation of the fetal blood or adult bone marrow smears by methanol, smears were stained for 5 minutes with May-Grünwald solution (Sigma). After removing the excess May-Grünwald solution by washing the smears in tap water, they were stained with Giemsa solution (Merck, Darmstadt, Germany) for 20 minutes. Afterwards, smears were again washed in tap water. Blood and bone marrow smears were examined using a Leica DM RB microscope (Leica M icrosystems B.V., Rijswijk, the Netherlands) under a $620 \times$ oil-immersion magnification and analyzed using the Leica IM 50 image manager (Leica). Two independent examiners assessed the blood and bone marrow smears and judged approximately 500 cells on each slide.

Microarray analysis of bone marrow cells

RNA from bone marrow cells isolated from one femur ( $n=3$ for both diet groups) was isolated with TRIzol Reagent (Invitrogen, Breda, the Netherlands) according to the manufacturer's instructions. Genome-wide gene expression was determined using whole mouse genome (4X44K) oligonucleotide microarrays (Agilent, Santa Clara, CA, USA) as described previously (10). More detailed information regarding the analysis of microarray data can be found in the supplementary data ${ }^{\dagger}$.

\section{Quantitative real-time PCR analysis}

RNA was isolated from the liver of E14.5 fetuses, from the spleen and liver of 12 week old mice and from the liver of maternal mice at gestational day 14.5 by homogenizing the tissue using the Ultra-Turrax homogenizer (IKA, Staufen, Germany), after which TRIzol Reagent (Invitrogen) was added according to the manufacturer's instructions. RNA isolation of the bone marrow samples of 12 week old mice was performed using TRIzol LS Reagent (Invitrogen) according to the manufacturer's instructions. Quantity and purity control of the RNA was spectrophotometrically assessed by using the Nanodrop 1000 (Thermo Scientific, Wilmington, USA). Next, $1 \mu \mathrm{g}$ of RNA was used to synthesize cDNA using the iscript CDNA synthesis kit (Biorad, Hercules, USA) following manufacturer's instructions. The reaction was performed using a Biometra Tprofessional thermocycler (Biometra, Leusden, the Netherlands). 


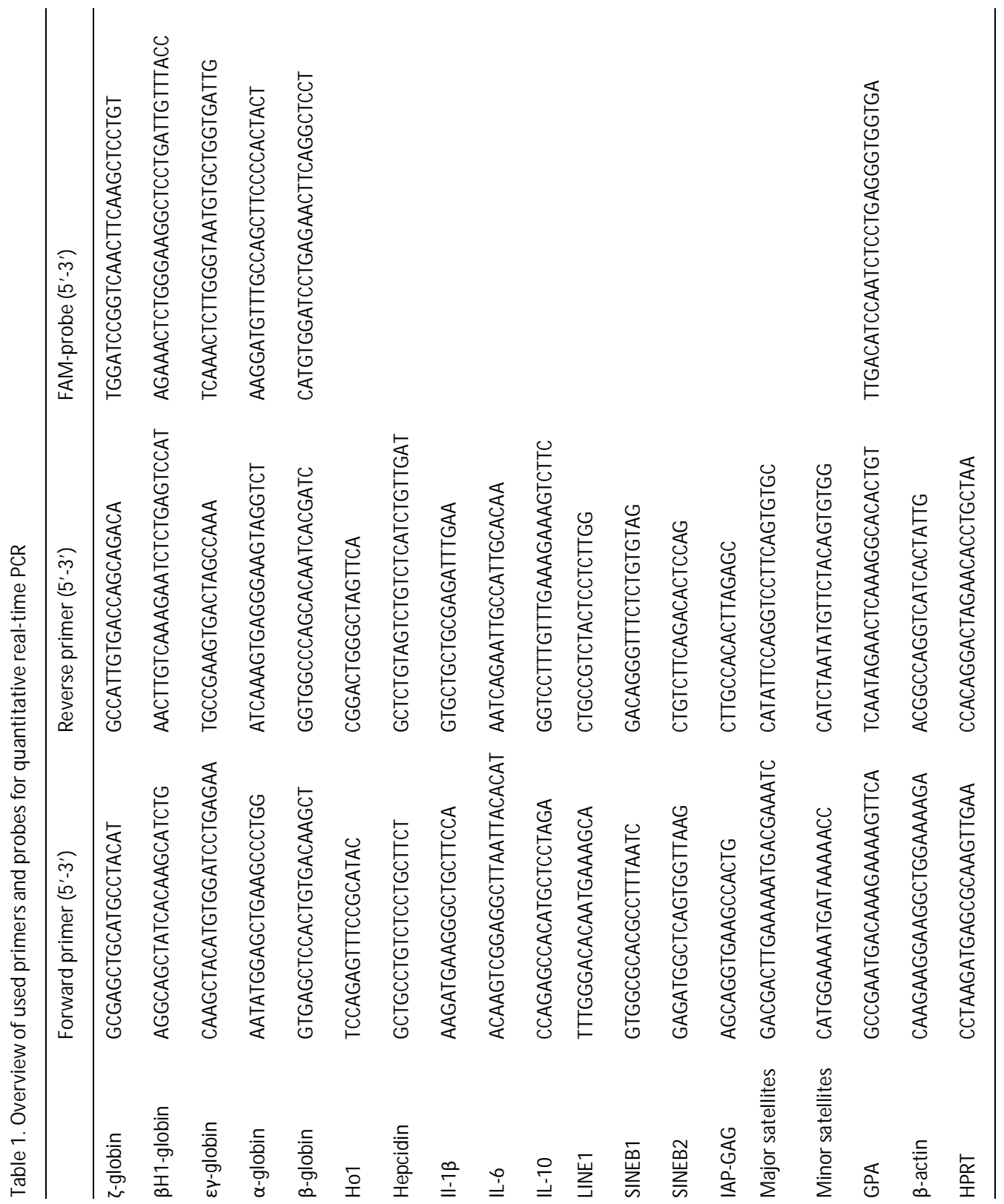

For determination of globin mRNA levels a quantitative real time-PCR was carried out using $12.5 \mu \mathrm{l}$ iQ Supermix (Biorad), $7.5 \mathrm{pmol}$ of each forward/reverse primer (see Table 1, Eurogentec, M aastricht, the Netherlands), 5 pmol FAM-probe (Eurogentec) in a volume of $25 \mu \mathrm{l}$. cDNA concentration used depended on the analyzed gene $(\zeta-, 6 \mathrm{H1} 1-, \varepsilon v$-globin: 667 $\mathrm{ng} ; \alpha$-, 6 -globin: $67 \mathrm{ng}$ for adults and $667 \mathrm{ng}$ for fetuses). For determination of hemeoxygenase-1 (Ho1), hepcidin and interleukin (IL)-16, IL-6, IL-10, a quantitative realtime PCR mixture comprising of $12.5 \mu \mathrm{l}$ IQ SYBR Green (Qiagen), $7.5 \mathrm{pmol}$ of each 
forward/reverse primer (see Table 1, Eurogentec) in a volume of $25 \mu$ was used. cDNA concentration used depended on the analyzed gene (hepcidin, IL-16, IL-6, IL-10: $667 \mathrm{ng}$; Hol: $200 \mathrm{ng}$ ). All of the reactions were performed using a MyiQ Single Color RT-PCR detection system (Biorad) under the following cycling conditions: 1 cycle at $95{ }^{\circ} \mathrm{C}$ for 3 minutes and then 40 cycles at $95{ }^{\circ} \mathrm{C}$ for 15 seconds and $60^{\circ} \mathrm{C}$ for 1 minute followed by 1 cycle at $95^{\circ} \mathrm{C}$ for 1 minute and $1 \mathrm{cycle}$ at $65^{\circ} \mathrm{C}$. Data were analyzed by M yiQ Software system (Biorad), Ct values were normalized for endogenous reference (GPA for $\zeta, 6 \mathrm{H} 1-$, $\varepsilon \gamma^{-}, \alpha-, 6$-globin; and 6 -actin for Hol, hepcidin, IL-16, IL-6 and IL-10), compared with the calibrator (i.e. average Ct value of control samples) and expressed as fold change using the $2^{-\Delta \mathrm{Ct}}$ method for the globin genes and the $2^{-\Delta \Delta \mathrm{Ct}}$ for $\mathrm{Ho} 1$, hepcidin and IL genes.

\section{Biochemical component determination in amniotic fluid}

For the determination of the total amount of iron, bilirubin and EPO levels, the amniotic fluid of all pups from one litter were pooled. The total iron amount and bilirubin levels were determined in the amniotic fluid using the Synchron LX20 system (Beckman Coulter, Fullerton, USA). Briefly, the Synchron LX20 system determined the iron concentration using a fixed-time endpoint method. First, iron was dissociated from the transport protein transferrin and $\mathrm{Fe}^{3+}$ was reduced to $\mathrm{Fe}^{2+}$. Hereafter, the total amount of $\mathrm{Fe}^{2+}$ was complexed with the Ferrozine iron reagens. The difference in absorption was measured and was proportional to the amount of total iron in the sample.

Bilirubin was determined using a timed-endpoint diazo method to measure the concentration of total bilirubin. In the reaction, bilirubin reacted with diazo reagent in the presence of caffeine, benzoate, and acetate as accelerators to form azobilirubin. The system monitored the change in absorbance at $520 \mathrm{~nm}$ at a fixed time interval. This change in absorbance was directly proportional to the concentration of total bilirubin in the sample.

The amount of EPO was detected in the amniotic fluid by IM MULITE 1000 (Siemens), an automated quantitative immunoassay analyzer that uses the immulite chemiluminescent immunoassay system. Sample and ligand-labeled anti-EPO antibody were incubated with the solid phase. EPO in the sample bound to the monoclonal antibody was immobilized onto the solid phase. Alkaline phosphatase labeled polyclonal anti-EPO antibody was then introduced, which bound to the EPO attached to the solid phase, and unbound enzyme conjugate was removed by a wash step. A chemiluminescent substrate was added, and the photon output, which was proportional to the EPO concentration in the sample, was measured by a luminometer.

\section{Total iron levels measured by atomic absorption spectrometry}

Total amount of iron was measured in the liver of the mothers during gestation, and liver and spleen of 12 week old offspring by atomic absorption spectrometry. Ground tissues were hydrolyzed overnight in $1 \mathrm{ml}$ of $7 \mathrm{M} \mathrm{HNO}_{3}$ at $60^{\circ} \mathrm{C}$. After centrifugation, $20 \mu \mathrm{l}$ of the supernatant was directly injected into a graphite-furnace atomic absorption spectrometer with Zeeman background correction (Varian, Bergen op Zoom, the Netherlands). Fe concentrations were determined at $372 \mathrm{~nm}$. Solutions with known concentrations of Fe were used for calibration. All the glassware was rinsed with $1 \% \mathrm{HNO}_{3}$ to avoid contamination. Total Fe-concentration in $\mathrm{ng}$ Fe per mg tissue was calculated from the calibration curves and the weight of the tissue. 


\section{8-0xo-dG measurements}

Genomic DNA isolation and 8-0xo-7,8-dihydro-2'-deoxyguanosine (8-0xo-dG) measurements were performed as described earlier (11). Briefly, to detect the base-oxidation product 8-oxodG, HPLC with electrochemical detection (ECD) was performed. Genomic DNA was obtained by grinding frozen liver tissues followed by standard phenol extraction. The DNA-extraction procedure was optimized to minimize artificial induction of 8-oxo-dG, by using radical-free phenol, minimizing exposure to oxygen and by addition of $1 \mathrm{mM}$ deferoxamine mesylate and $20 \mathrm{mM}$ TEMPO (2,2,6,6-tetramethylpiperidine-N-oxyl). DNA concentrations were spectrophotometrically quantified. HPLC-ECD of 8-oxo-dG was performed by digesting $30 \mu \mathrm{g}$ DNA to deoxyribonucleosides by addition of $6 \mu \mathrm{l} 0.5 \mathrm{M} \mathrm{NaAc}, 9 \mu \mathrm{l} 10 \mathrm{mM} \mathrm{ZnCl}$ and $1.5 \mu \mathrm{l}$ nuclease P1 (stock: $1 \mathrm{U} / \mu \mathrm{l}$ ) and incubation for 90 minutes at $37^{\circ} \mathrm{C}$. Subsequently, $30 \mu \mathrm{l} 0.5 \mathrm{M}$ Tris- $\mathrm{HCl}(\mathrm{pH} 7.4)$ and $1.5 \mu \mathrm{l}$ alkaline phosphatase $(0.014 \mathrm{U} / \mu \mathrm{l})$ were added followed by incubation at $37^{\circ} \mathrm{C}$ for 45 minutes. The digest was then analyzed by HPLC-ECD on a Supelcosil ${ }^{\mathrm{TM}}$ LC-18S column ( $250 \mathrm{~mm} \times 4.6 \mathrm{~mm}$ ) (Supelco Park, Bellefonte, PA, USA) in combination with a DECADE electrochemical detector (Antec, Leiden, the Netherlands). The ECD-signal was first stabilized with mobile phase $\left(94 \mathrm{mM} \mathrm{KH_{2 }} \mathrm{PO}_{4}, 13 \mathrm{mM} \mathrm{K}_{2} \mathrm{HPO}_{4}, 26 \mathrm{mM} \mathrm{KCl}\right.$ and $0.5 \mathrm{mM} E D T A$, $10 \%$ methanol) for approximately 3 hours at a flow rate of $1 \mathrm{ml} /$ minute. After stabilization, 8oxo-dG was detected at a potential of $400 \mathrm{mV}$ and $\mathrm{dG}$ was simultaneously monitored by UV absorption at $260 \mathrm{~nm}$.

\section{M ethylation-sensitive M crBC-real-time PCR assay}

Genomic DNA isolation was performed by lysating livers of E14.5 fetuses and bone marrow cells of 12 week old mice using $0.5 \mathrm{ml}$ lysis buffer (25 mM EDTA, $10 \mathrm{mM}$ TRIS-HCl, pH 8.0, $100 \mathrm{mM} \mathrm{NaCl}, 1 \% \mathrm{SDS}$ ) and $20 \mu \mathrm{l}$ of proteinase $\mathrm{K}$ (Qiagen). Tissue was homogenized, incubated at $56{ }^{\circ} \mathrm{C}$ for 1 hour and homogenized again. Samples were then allowed to completely lyse by incubating at $56{ }^{\circ} \mathrm{C}$ overnight. DNA was extracted with phenol/chloroform extraction (phenol/chloroform/isoamyl alcohol (25:24:1)) and DNA concentration and purity determined by measuring the OD $260 / 280$. Analysis of methylation pattern of the repetitive elements, i.e. Iong interspersed nucleotide elements (LINEs), short interspersed nucleotide elements (SINEs), intracisternal A particle (IAP), Major and M inor satellites, was performed as described earlier (10). Briefly, $1 \mu \mathrm{g}$ of genomic DNA was digested overnight at $37^{\circ} \mathrm{C}$ using $10 \mathrm{U}$ of $\mathrm{M} \mathrm{CrBC}$ (New England Biolabs, Beverly, MA, USA). The DNA strand breaks prevent amplification of methylated DNA in the subsequent two-step quantitative real-time PCR, which consisted of IQ SYBR Green Supermix (Biorad) with $4 \mathrm{ng}$ of McrBC-digested DNA and $25 \mathrm{pmol}$ of each primer (See Table 1, Eurogentec) in a reaction volume of $25 \mu \mathrm{l}$. The cycling conditions consisted of an initial denaturation at $95{ }^{\circ} \mathrm{C}$ for 10 minutes, followed by 40 cycles of $95{ }^{\circ} \mathrm{C}$ for 45 seconds, $58{ }^{\circ} \mathrm{C}$ for 90 seconds, with an exception for the Major and Minor satellites for which this step was performed at $60^{\circ} \mathrm{C}$, using the iCycler (Biorad). Data were analyzed by MyiQ Software system (Biorad), Ct values were normalized for endogenous reference (HPRT), compared with the calibrator (i.e. average $\mathrm{Ct}$ ) and expressed as relative expression $\left(2^{-\Delta \Delta C t}\right)$. An increase in PCR amplification products is indicative of hypomethylation, whereas a decrease in PCR amplification products indicates hypermethylation. 
Statistical analysis

Statistical analysis was performed with Statistical Package for Social Sciences (SPSS version 17 for Windows, SPSS Inc., Chicago, IL, USA). Nested ANOVA was performed to analyze erythropoietic changes in fetuses prenatally exposed to quercetin to account for litter effects. One-way ANOVA was used to assess the impact of quercetin on: 1. litter sizes at birth and at day 14.5 of gestation, 2. average pup weight at postnatal day 5 or at day 14.5 of gestation, 3. placental weight at day 14.5 of gestation, 4. dietary effects between control and prenatally exposed 12 week old mice and maternal iron homeostasis. To avoid litter effects in the analyses of 12 week old animals, not more than two mice per litter were used for analysis and nests with less than 5 litters were excluded from the analysis. Log transformed data were used for analysis by an independent sample t-test for the biochemical determination of amniotic fluid and the gene expression levels of IL-16, II-6, IL-10 and hepcidin as these results were not normally distributed.

\section{Results}

Quercetin exposure during fetal development

To investigate the effect of quercetin exposure on fetal development and fetal erythropoiesis, female mice were exposed to quercetin ( $302 \mathrm{mg} / \mathrm{kg}$ feed) from 3 days before conception until day 14.5 of gestation, at which the mice were sacrificed and fetuses were isolated. As shown in Table 2, no differences in litter size, fetal weight or placental weight could be observed between control and quercetin exposed fetuses.

Furthermore, as quercetin is known to chelate iron in vitro $(2,3)$, the total amount of free iron was measured in the amniotic fluid. Again, no differences between fetuses exposed to quercetin and control fetuses could be detected $(4.1 \pm 0.6 \mu \mathrm{mol} / \mathrm{L}$ for quercetin exposed fetuses versus $5.9 \pm 0.3 \mu \mathrm{mol} / \mathrm{L}$ for control fetuses, $P=0.54$, amniotic fluid was pooled per litter, $n=3$ in case of both diets).

Although we could not directly measure the iron level of fetal livers, levels measured in the liver of their mothers were assessed to gain insight in the fetal situation. Iron levels measured in the liver of maternal mice were similar for both diet groups (84.5 \pm $17.0 \mathrm{ng} / \mathrm{mg}$ versus $85.2 \pm 5.5 \mathrm{ng} / \mathrm{mg}, \mathrm{P}=0.97, \mathrm{n}=3$ for quercetin exposed mothers and $\mathrm{n}=5$ for control mothers). In addition we also measured the gene expression of hepcidin, the main iron regulatory hormone (4), in the liver of the mothers and found no differences between both diet groups $(0.5 \pm 0.2$-fold versus $1.0 \pm 0.2$-fold for control animals $(n=5), n=3$ for quercetin exposed, $P=0.11$ ). Interestingly, Hol levels in the maternal spleen were significantly increased in expression in case of the mothers that were exposed to quercetin (3.6 \pm 0.9 -fold versus $1.0 \pm 0.3$-fold for control animals $(n=5), P=0.03, n=3$ for quercetin exposed).

As $65 \%$ of the body's iron is used for the production of hemoglobin (4), the globin status was analyzed in the liver of E14.5 fetuses (Supplementary data, Table $1^{\dagger}$ ) using a quantitative real-time PCR method Results showed that fetuses exposed to quercetin ( $n=8$ : 8 fetuses from 3 different litters) had no changes in the level of embryonic ( $\zeta-, 6 \mathrm{H} 1-$, and $\varepsilon \gamma$-globins) and adult ( $\alpha$ - and 6 -globins) globins compared 
with control fetuses ( $n=9: 9$ fetuses from 3 different litters), suggesting that quercetin exposure also had no effect on hemoglobin profile in utero.

Since the globin status is expected to change simultaneously with the change in erythroid lineage, the distribution of primitive and adult RBCs in E14.5 fetuses was determined (Supplementary data, Table $2^{\dagger}$ ) by blood smear analysis. Here, quercetin exposure had no statistically significant effect on the amount of primitive erythrocytes or definitive erythrocytes (proerythrocytes, basophilic erythrocytes and ortochromic erythrocytes, $n=9$ : 9 fetuses from 2 different quercetin exposed litters and $n=15: 15$ fetuses from 3 different control litters), suggesting that prenatal exposure to quercetin did not influence the switch in erythroid lineage during fetal development. The level of bilirubin, a breakdown product of the heme part of hemoglobin (12), was measured in the amniotic fluid (amniotic fluid was pooled per litter, $n=3$ in case of both diets). This showed a slight elevation in bilirubin levels in the amniotic fluid of fetuses exposed to quercetin $(2.7 \pm 0.5 \mu \mathrm{mol} / \mathrm{L}$ for quercetin exposed fetuses versus $1.2 \pm 0.1 \mu \mathrm{mol} / \mathrm{L}$ for control fetuses, $\mathrm{P}=0.05$ ). Therefore, $\mathrm{Hol}$ gene expression level was measured in the liver of E14.5 fetuses using quantitative real-time PCR to further investigate the possibility of higher heme degradation. The results showed no effect of quercetin exposure on the expression of $\mathrm{Hol}$ (1.4-fold, $\mathrm{P}=0.43, \mathrm{n}=4$ for both diets). Finally, EPO, the principal regulator of erythropoiesis which stimulates erythrocyte production in response to a decrease in oxygen delivery (13), was not significantly modulated in the amniotic fluid of fetuses exposed to quercetin as compared with control fetuses $(3.1 \pm 0.5 \mathrm{U} / \mathrm{mL}$ for quercetin exposed fetuses versus $2.6 \pm 0.8 \mathrm{U} / \mathrm{mL}$ for control fetuses; $P=0.19$; amniotic fluid was pooled per litter, $n=3$ in case of both diets).

Table 2. Characteristics of the control and quercetin exposed litters during fetal period and after birth

\begin{tabular}{llll}
\hline & Control & Quercetin & P-value \\
\hline Litter size during gestation & $4.6 \pm 1.6$ & $7.3 \pm 1.2$ & 0.28 \\
Fetal weight (mg) & $192.4 \pm 22.8$ & $212.6 \pm 32.8$ & 0.62 \\
Placental weight (mg) & $91.9 \pm 11.0$ & $84.5 \pm 4.6$ & 0.64 \\
Litter size at birth & $6.4 \pm 0.7$ & $5.1 \pm 0.8$ & 0.27 \\
Pup weight (g) at day 5 & $3.2 \pm 0.3$ & $3.1 \pm 0.1$ & 0.87 \\
\hline
\end{tabular}

General characteristics of the litters prenatally exposed to quercetin-supplemented or normal diet. Results represent the mean \pm SE. At day 14.5 of gestation: $n=5$ for control litters and $n=3$ for quercetin exposed litters. $\mathrm{N}=8$ for litters that were born in case of both diets. No significant differences were found by nested ANOVA accounting for litter effects.

Prenatal exposure to quercetin and erythropoiesis in adulthood

Since there were no statistically significant differences in litter characteristics at day 14.5 of gestation, we did not expect any differences in litter characteristics at birth (average litter size and pup weight ( $\mathrm{g}$ ) at day 5 after birth), as was confirmed and shown in Table 2. Additionally, we investigated whether prenatal exposure to quercetin resulted in changes in globin gene expression at adult age by determining the globin mRNA expression levels in the bone marrow of 12 week old mice using quantitative real-time PCR (Figure 1A-B). At adult age there were also no differences in globin gene expression noticeable. 
Next, RBC maturation in the bone marrow of three 12 week old mice from 2 different litters per diet group was analyzed using May-Grünwald staining. Bone marrow smears showed that prenatal quercetin exposure had no effect on maturation of RBCs as there were also no observed differences in the number of RBC progenitors (proerythroblast, basophilic erythroblast, ortochromic eryhtroblast, reticulocyte) and pyrenocytes (measure for enucleation of immature RBCs, Figure 1C).

Hemoglobin degradation was examined by determining Hol mRNA expression level (Figure 1D), which catalyzes the rate-limiting step in heme degradation during RBC degradation (12). Hol gene expression was determined by quantitative real-time PCR in the spleen which is the main site for RBC degradation and in the bone marrow, where RBC production takes place. Results did not indicate an increase in heme degradation and therefore in RBC turnover in the bone marrow ( $n=4$ for both diets) in 12 week old mice prenatally exposed to quercetin. In spleen, however, a significant increase in $\mathrm{Hol}$ expression $(\mathrm{P}=0.04, \mathrm{n}=4$ from different litters for both diets) was detected, suggesting that there is an increase in heme degradation in the spleen of 12 week old mice prenatally exposed to quercetin.

A

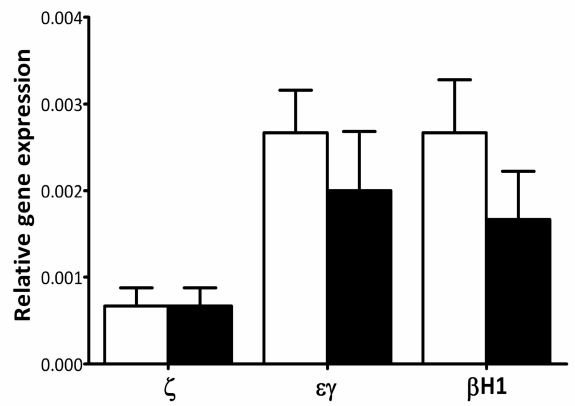

C

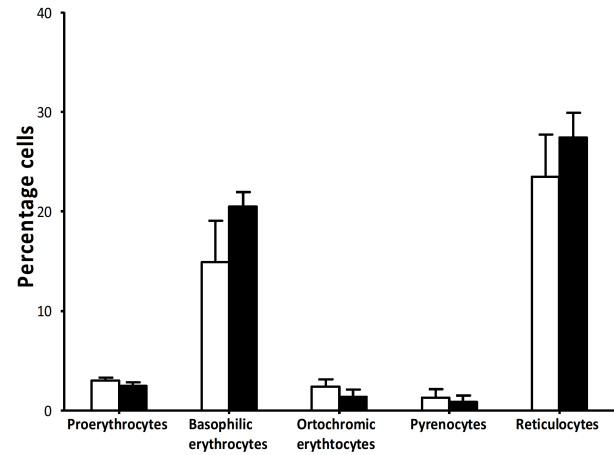

B

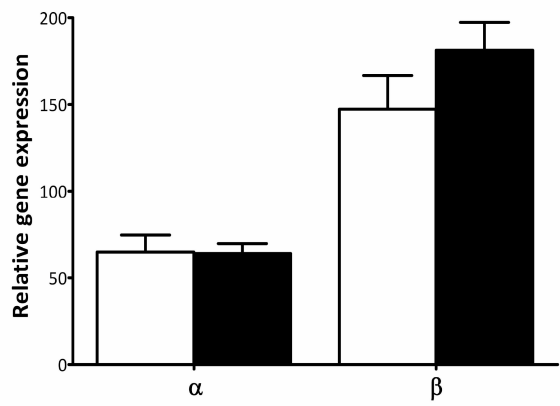

D

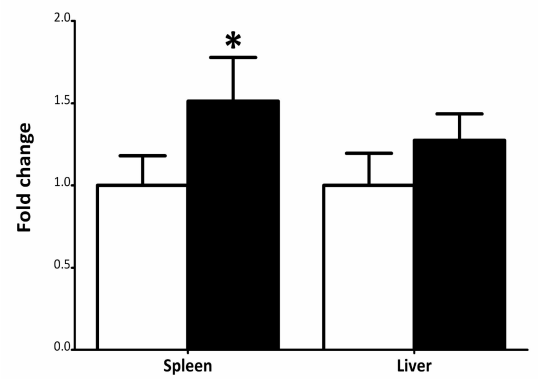

Figure 1. Prenatal exposure to quercetin has no effect on erythropoiesis at adulthood.

mRNA expression level of embryonic globins $(\zeta, 6 \mathrm{H} 1, \varepsilon \gamma ; \mathrm{A})$ and adult globins $(\alpha, \beta ; B)$ were measured in the bone marrow of 12 week old control $(n=6)$ or quercetin exposed $(n=6)$ mice. Bars represent the average fold change (calculated as $2^{-\Delta C T}$ ) of each globin gene quantified by quantitative real-time PCR. $C$. Bone marrow smears of 12 week old mice from the control $(n=3)$ and quercetin exposed $(n=3)$ group were analyzed to determine the different RBC progenitors cells in the bone marrow. Bars represent the percentage of cells of each cell type. D. mRNA expression level of Hol measured in the spleen and bone marrow of 12 week old mice from the control group $(n=4)$ and the quercetin exposed group $(n=4)$. Bars represent the normalized average fold change (calculated as $2^{-\Delta \Delta C T}$ ) of Hol gene quantified by quantitative real-time PCR. White bars represent the control group, black bars the quercetin exposed group. Error bars represent the standard error. ${ }^{*}: P \leq 0.05$ 
Finally, gene expression analysis of the bone marrow cells of 12 week old mice ( $n=3$ for both groups) were performed using microarrays and showed that of the 88 genes involved in erythropoiesis or iron homeostasis according to their Gene-Ontology terms, there was only one gene differentially expressed, namely Steap4 (-1.7-fold, $P=0.009$, Supplementary data, Table $3^{\dagger}$ ), indicating that these pathways were not affected by prenatal maternal intake of quercetin during gestation.

\section{Prenatal quercetin exposure and liver iron storage}

Previously, it has been shown that quercetin chelates iron in vitro $(2,3)$ and attenuates iron induced liver injury in vivo (14). We assessed the amount of total iron at 12 weeks of age in the liver and spleen, which are respectively the major and minor iron storage organs. In the liver, iron levels were indeed significantly increased in case of in utero quercetin exposure $(94.74 \pm 5.3 \mathrm{ng} / \mathrm{mg}$ versus $62.9 \pm 5.0 \mathrm{ng} / \mathrm{mg}$ for control animals, $P=0.002, n=5$ for both diets, Figure $2 A$ ). Iron levels measured in the spleen of mice prenatally exposed to quercetin were also higher, although not statistically significant $(929.5 \pm 265.1 \mathrm{ng} / \mathrm{mg}$ versus $724.5 \pm 124.3 \mathrm{ng} / \mathrm{mg}$ for control animals, $\mathrm{P}=0.41, \mathrm{n}=5$ for both diets, Figure 2B).

A

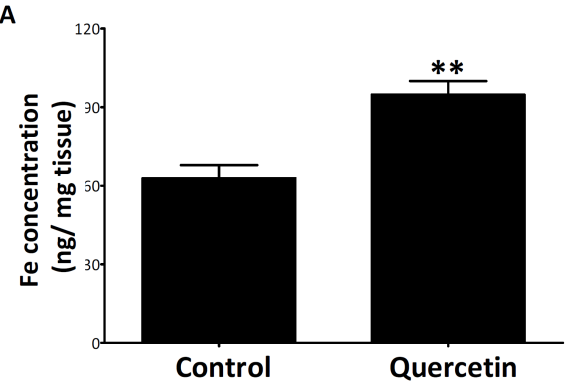

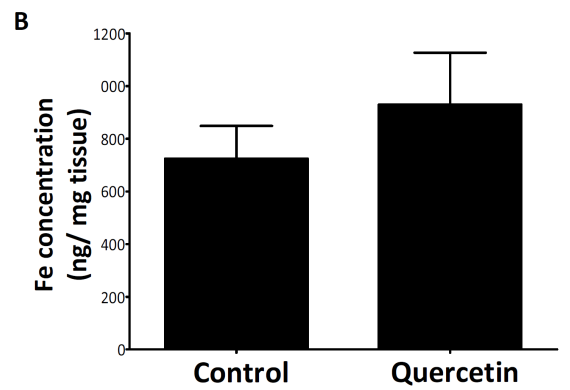

Figure 2. Prenatal quercetin exposure results in increased iron levels in the liver of 12 week old mice. Iron levels were measured in liver $(A)$ and spleen $(B)$ of control $(n=5)$ and quercetin exposed $(n=5)$ mice at 12 weeks of age. Bars represent the amount of total iron expressed as $\mathrm{ng} / \mathrm{mg}$ tissue. Error bars represent the standard error. ${ }^{* *}: P \leq 0.01$

The increased iron storage in the liver of 12 week old mice prenatally exposed to quercetin could be the result of a long-lasting change in iron homeostasis. Therefore, we examined the expression of iron homeostasis related genes using quantitative real-time PCR. Hepcidin showed a slightly, though not significant increase in expression in mice prenatally exposed to quercetin $(n=10)$ compared with the control group ( $n=5$, Figure $3 A$ ). The same was found for IL6 that normally regulates hepcidin production (15), which showed a slight, although not significant increased expression in quercetin exposed mice $(n=10)$ compared to control mice $(n=5$, Figure 3B). However, when comparing the overall median of hepcidin and IL-6 expression with the individual data in the quercetin exposed and control group, we found that in case of the control group only 1 in 5 mice had an expression of hepcidin or IL-6 above the median, while in the quercetin exposed group this was 6 out of 10 mice. Other cytokines, namely IL-18, a component of IL-1, which induces ferritin expression resulting in an increased storage of iron (15), and IL-10, which stimulates the uptake of iron via the transferrin-receptor (15), showed a statistically significant increase in expression in quercetin exposed mice ( $n=10, \mathrm{IL}-16$ : $P=0.05$; IL- 
10: $P=0.02$, Figure $3 C, E)$ compared to controls $(n=5)$. Although the gene expression of hepcidin and ILs involved in iron homeostasis were generally increased in adult mice prenatally exposed to quercetin, they were not all statistically significant increased. Interestingly, gene expression of IL-1 6 was not altered in bone marrow of 12-week old mice prenatally exposed to quercetin (IL-16: -1.2-fold change, $\mathrm{P}=0.5$; no microarray data were available for IL-6, IL-10 and hepcidin as the expression signal could not be detected).

As iron overload could result in oxidative stress, 8-0xo-dG levels were measured in the livers of mice prenatally exposed to quercetin $(n=5)$ compared to controls $(n=5)$. Interestingly, mice prenatally exposed to quercetin had lower 8-oxo-dG levels (14.6 \pm $1.5 \times 10^{-6} 8-0 \times 0-d G / d G$ versus $26.8 \pm 2.0 \times 10^{-6} 8-0 \times 0-d G / d G$ for control, $P=0.001$ ).

A

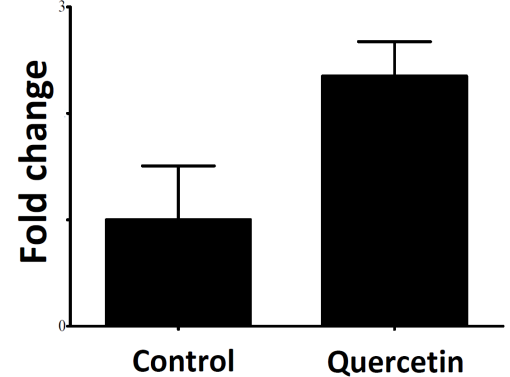

C

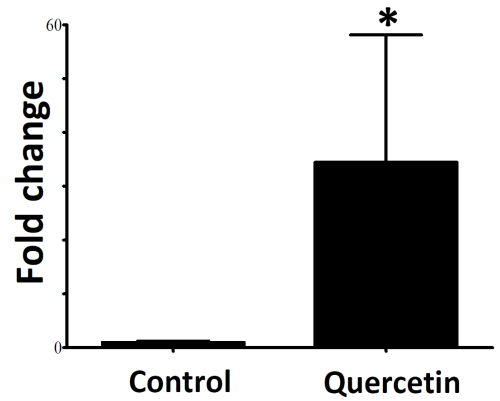

B

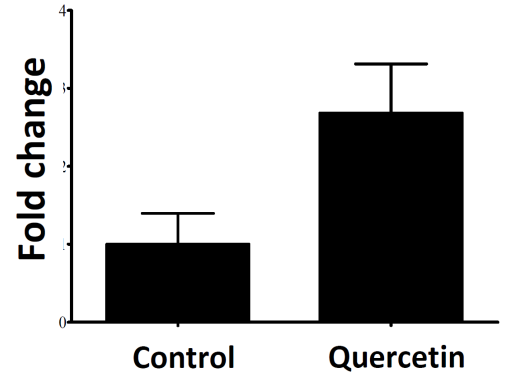

D

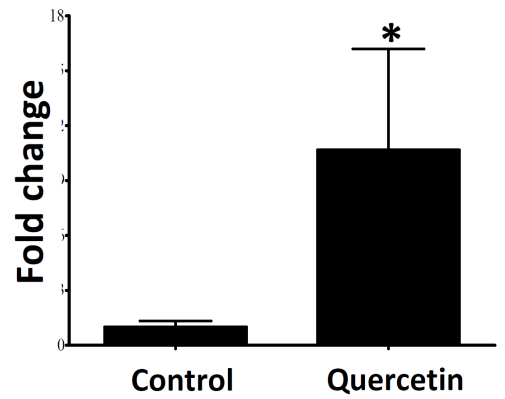

Figure 3. Prenatal quercetin exposure induces hepcidin and interleukins involved in iron uptake in the liver of 12 week old mice.

mRNA expression levels of hepcidin (A), IL-6 (B), IL-16 (C), IL-10 (D) were measured in the liver of 12 week old mice from the control group $(n=5)$ and the quercetin exposed group $(n=7)$. Bars represent the normalized average fold change (calculated as $2^{-\Delta \Delta C T}$ ) of hepcidin and interleukin genes quantified by quantitative real-time PCR. Error bars represent the standard error. ${ }^{*}: \mathrm{P} \leq 0.05$.

\section{Prenatal quercetin leads to long-term epigenetic changes}

As quercetin exposure early in development exerted long-term changes in the expression of certain genes, we assumed that these effects might be mediated through epigenetic modifications. Therefore, we employed an assay in which the methylation-sensitive endonuclease $M \mathrm{crBC}$ cleaves methylated DNA, but leaves unmethylated CPGs intact. By subsequent PCR amplification, one could quantify the unmethylated repetitive elements. Using this assay, we determined the methylation status of $M$ ajor and Minor satellites, intracisternal-A-particle (IAP-GAG), long interspersed nucleotide elements (LINE1) and short interspersed nucleotide elements (SINEB1 and SINEB2), which constitute almost $37.5 \%$ of the mouse genome (1), in bone marrow cells. 
Overall, bone marrow cells of adult mice prenatally exposed to quercetin $(n=3)$ showed moderate hypermethylation of the repetitive elements observed as lower level of PCR products after $M c r B C$ digestion compared with the control group ( $n=3$, Figure $4 A$ ). Especially, the SINEB1 elements were hypermethylated $(P=0.01)$.

In the fetuses, quercetin exposure exerted no effect on the gene expression. Still, to investigate whether global epigenetic modifications had already occurred in utero, we studied the methylation status of the repetitive DNA elements in the liver of control $(n=4)$ and quercetin exposed fetuses $(n=4)$ at E14.5. Indeed, we did not observe any difference in the methylation status of repetitive elements between the diet groups at this particular developmental time point (Figure 4B).
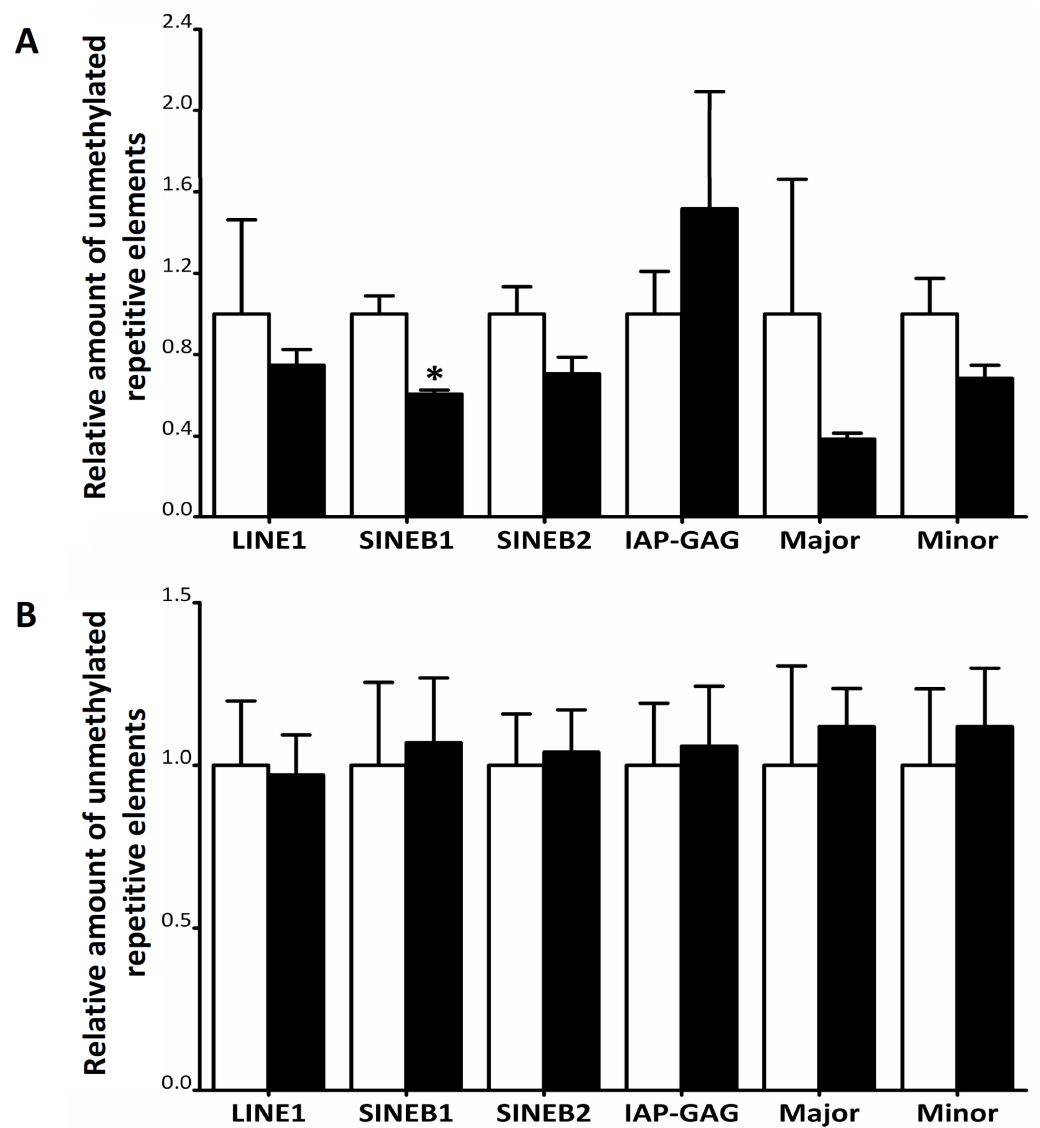

Figure 4. The effect of quercetin on DNA methylation of repetitive elements.

A. Long-term effect of prenatal exposure to quercetin on DNA methylation of repetitive elements in bone marrow cells of quercetin exposed mice $(n=3)$ compared to control mice $(n=3)$. B. Short-term effect of prenatal exposure to quercetin on DNA methylation of repetitive elements in fetal liver of quercetin exposed fetuses $(n=4)$ compared to control fetuses $(n=4)$ at day 14.5 of gestation. The degree of methylation of repetitive elements: long interspersed nucleotide elements (LINE1), short interspersed nucleotide elements (SINEB1 and SINEB2), intracisternal-A-particle (IAP-GAG), and Major and Minor satellites were determined by methylationsensitive McrBC-real-time PCR assay. Bars represent the normalized average expression level of the unmethylated repetitive elements between the quercetin-exposed (black bars) and the control group (white bars). Error bars represent the standard error. ${ }^{*}: \mathrm{P} \leq 0.05$. 


\section{Discussion}

In this study, pregnant mice were exposed to a high dose of quercetin $(302 \mathrm{mg} / \mathrm{kg}$ feed), which is higher than the average daily dietary intake of quercetin in humans (4$68 \mathrm{mg}$ per day) (17). However, we do not expect that this dose has been toxic to the fetuses as Prater et al. (18) showed that a high dose of quercetin ( $333 \mathrm{mg} / \mathrm{kg}$ feed) administered to mice throughout their pregnancy, did not have teratogenic effects on the fetuses. Moreover, the quercetin dose administered to mice in our study is comparable with quercetin supplement intake: the daily dose of quercetin supplements lies between 200-1800 mg quercetin (manufacturers' recommendations) $(19,20)$. These high dose supplements are freely available in pharmacies and drugstores. Besides, it has also been shown that daily quercetin supplementation results in increased plasma quercetin levels (19), suggesting that the fetus could also be exposed to increased concentrations of quercetin and its metabolites.

In this study, we show that prenatal exposure to quercetin results in an adapted iron homeostasis as seen in the significantly increased iron storage in the liver of adult mice. We assumed that the effects seen in adult mice prenatally exposed to quercetin were most probably the result of a disturbed iron homeostasis in utero with persisting consequences for iron homeostasis and erythropoiesis later in life.

At gestational day 14.5 no clear effects of quercetin on erythropoiesis or iron levels could be observed. Iron levels measured in the liver of mothers and gene expression levels of liver hepcidin did not indicate any differences between control and quercetin exposed mothers, suggesting that mothers fed a diet containing iron chelators did not suffer from severe iron depletion during gestation. In addition, maternal iron deficiency normally results in a reduced fetal weight (21). However, E14.5 fetuses exposed to quercetin had an average weight comparable to control. High placental weight is usually also associated with iron deficient pregnancies (22), but no difference in placental weight were noticeable between quercetin exposed and control fetuses. Finally, the average weight at day 5 after birth did not differ between control and quercetin exposed mice. Taken together, this would suggest that the situation created by quercetin exposure did not result in severe iron deficiency and did not cause early termination of gestation, as the litter size both at day 14.5 of gestation and at birth did not differ between both diet groups.

However, mother mice exposed to quercetin did have increased expression of Hol, which could suggest that quercetin did decrease the amount of available iron and therefore the mother had to make more iron available for the fetuses by degradation of heme. Indeed, during a normal gestation, when the mother needs to cope with the increasing iron requirement of the fetus, she first addresses her own iron stores. Only when the fetal demands are too high or there is maternal iron deficiency, hematocrit levels will decrease (23), because iron is made available by increased degradation of heme. Degradation of heme by Hol results in the formation of bilirubin, (12), and bilirubin levels were increased in the amniotic fluid of fetuses exposed to quercetin. Please note that this increase was not statistically significant, but fetal bilirubin is transfered via the placenta to the mother (24), suggesting that the levels of bilirubin actually formed in the fetus could have been even higher. However, as increased levels of bilirubin are normally found in anemic fetuses (24), and because we did not see any differences in globin expression or RBC composition in fetuses exposed to quercetin, we 
assume that quercetin exposure at this time point in gestation had a very mild effect that cannot be distinguished from a non-anemic situation. In addition, it should also be emphasized that the iron requirement of the fetus increases throughout the pregnancy (25). Therefore, pronounced effects of quercetin may not be present at this time point in gestation. Moreover, as flavonoids have shown to accumulate in fetal tissue (7), the direct effects of quercetin exposure may be visible at a later time point of gestation. Nonetheless, we had chosen day 14.5 of gestation to sacrifice the pregnant mice, since at that time point the switch from primitive to adult erythroid lineage and concomitantly the switch from fetal to adult hemoglobin occurs (26-28). However, exposure to quercetin did not have any effects on these events.

Once born, pups were no longer exposed to high levels of quercetin. We assumed that this resulted in the increased availability of dietary iron, which could be experienced as an iron overload as we suspect that these animals were 'developmentally programmed' to cope with lower iron levels in utero. The mismatch between the in utero environment and postnatal life with regard to iron availability resulted in a differently regulated iron homeostasis in mice prenatally exposed to quercetin. However erythropoiesis was not affected, since we did not observe any differences in globin status and RBC maturation in the bone marrow. Interestingly, $\mathrm{Hol}$ gene expression in the spleen was significantly up-regulated, suggesting increased RBC turnover. However, as there were no observed differences in bone marrow maturation or the amount of red blood cells $(7.2 \pm 0.1 \mathrm{x}$ $10^{12} / \mathrm{L}$ versus $7.0 \pm 0.1 \times 10^{12} / \mathrm{L}$ for control group, $\mathrm{P}=0.53, \mathrm{n}=39$ for quercetin group and $\mathrm{n}=41$ for control group), we assumed that the increase in $\mathrm{Hol}$ gene expression is the result of an increase in hemoglobin per $\mathrm{RBC}$. Indeed, there were 1 ) a slight elevation in hemoglobin level of reticulocytes $(1.03 \pm 0.01 \mathrm{fmol}$ versus $0.96 \pm 0.01 \mathrm{fmol}$ in control group, $P=0.07, n=39$ for quercetin group and $n=41$ for control group) and 2) an increase in the mean corpuscular volume of red blood cells (mean $\pm S E, 46.33 \pm 0.50 \mathrm{fL}$ versus $44.96 \pm 0.45 \mathrm{fL}$ for control group, $\mathrm{n}=39$ for quercetin group and $n=41$ for control group) compared with control mice, which both indicate that more hemoglobin is formed by RBCs of mice prenatally exposed to quercetin.

In addition, gene expression profile analysis of bone marrow cells did not show any alterations in gene expression of genes involved in erythropoiesis or iron homeostasis between prenatally exposed and control mice. Only the expression of Steap4 was significantly decreased in mice prenatally exposed to quercetin. Steap4 has been shown to function as a ferrireductase, capable of increasing the uptake of iron by cells in vitro. It has also been postulated that Steap4 could play a role in the pathologic deposition of iron in many tissues (29). Decreased expression of Steap4 by prenatal exposure to quercetin thus limits the iron uptake by the bone marrow, probably to protect the bone marrow from excessive iron uptake, which could induce oxidative stress.

The increase in iron availability after birth could activate pathways to overcome the iron 'overload' as it is toxic to cells $(4,30)$. Indeed, expression of hepcidin and IL-16, IL-6 and $\mathrm{IL}-10$, all involved in the storage of iron, were up-regulated resulting in increased storage of iron in the liver. It is remarkable to see that this pathway is activated, as it is normally triggered during chronic inflammation induced anemia $(4,15)$. An overview of the mechanism by which we assume that iron accumulation occurs in the liver of mice prenatally exposed to high levels of quercetin is given in Figure 5. 


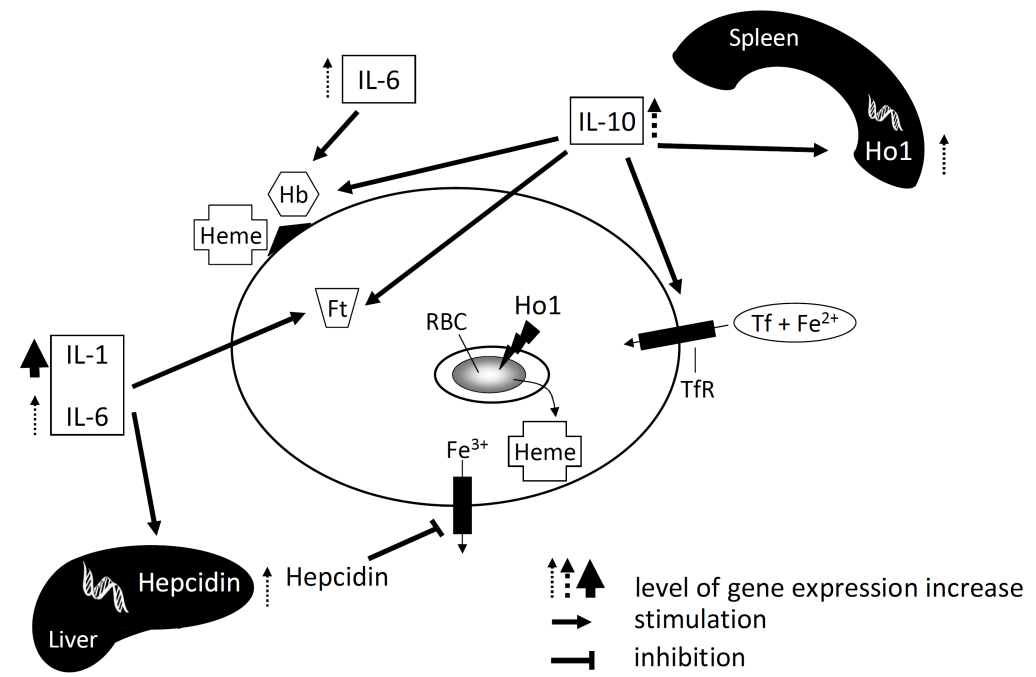

Figure 5. Overview of the hypothesis.

Prenatal quercetin exposure results in a relative iron excess after birth because iron chelation by quercetin ceases, which will activate pathways to overcome the iron 'overload' as it is toxic to cells. Since these pathways are permanently activated in adult life, iron will accumulate in the liver. Iron accumulation in cells occurs through the up-regulation of several interleukins (IL1 $\beta$, IL6 and IL10) involved in the storage of iron. The increase in IL-1 and IL-6 will up-regulate the expression of hepcidin by the liver, resulting in iron retention by limiting the iron efflux. In addition, IL-1 and IL-6, but also IL-10, is known to increase the production of ferritin (Ft), increasing the iron storage capacity of cells. M oreover, IL- 6 and IL-10 increase the uptake of heme and hemoglobin (Hb). IL-10 also induces the production of hemeoxygenase-1 ( $\mathrm{Hol}$ ) by the spleen, resulting in the release of iron from heme. In addition, it increases the uptake of transferrin (Tf) bound iron. The increase in gene expression is indicated by 3 different arrows which represent a fold change of approximately 5,20 and 60, respectively.

As quercetin exposure early in development was found to exert long-term changes in the expression of certain genes, we assume that these effects might be mediated through epigenetic modifications. Our results show that prenatal exposure to quercetin was associated with a moderate hypermethylation of repetitive elements (SINEB1, SINEB2, LINE1, Major and M inor satellites) in bone marrow cells at 12 weeks of age. However the methylation status of these repeats was not affected directly by quercetin exposure during fetal development, therefore we assume that this occurred at a later time point. However, one should keep in mind that for some experiments performed in this study numbers of animals were on the low side.

The expression of inflammation related cytokines was enhanced, although there was no apparent inflammation present. Therefore, future studies should further elucidate the critical window of exposure, as this study suggests that quercetin exerts an effect after day 14.5 of gestation in mice. Furthermore, it also needs to be investigated whether these mice would react differently if inflammation would indeed be triggered at adult age.

Besides quercetin, other iron chelators which are administered to overcome iron overload resulting from for instance chronic blood transfusion $(31,32)$, should be used with caution during pregnancy. 


\section{Acknowledgments}

The authors sincerely thank Edwin Moonen for performing the iron storage measurements, Lou M aas for the 8-oxo-dG measurements and Eric Ruijters for the global methylation assay.

This work was supported by grant number 06A031 from the American Institute for Cancer Research.

\section{†Supplementary data}

The supplementary data can be viewed at:

http://www.sciencedirect.com/science/article/pii/S0300483X11004562.

Supplementary Table 1. Gene expression profile by Q-PCR of globins in the liver of quercetin exposed fetuses at embryonic day 14.5 .

Supplementary Table 2. Red blood cell composition in blood of quercetin exposed fetuses at embryonic day 14.5 .

Supplementary Table 3. Go term analysis of the mRNA expression of bone marrow cells of 12 week old mice prenatally exposed to quercetin.

Supplementary data. Identification of relevant genes by Gene Ontology terms. Statistical analysis of microarray data. 


\section{References}

1. Ross, J. A., and Kasum, C. M. (2002) Dietary flavonoids: bioavailability, metabolic effects, and safety. Annu Rev Nutr 22, 19-34

2. Ferrali, M., Signorini, C., Caciotti, B., Sugherini, L., Ciccoli, L., Giachetti, D., and Comporti, M. (1997) Protection against oxidative damage of erythrocyte membrane by the flavonoid quercetin and its relation to iron chelating activity. FEBS Lett 416, 123-129

3. Kitagawa, S., Sakamoto, H., and Tano, H. (2004) Inhibitory effects of flavonoids on free radical-induced hemolysis and their oxidative effects on hemoglobin. Chem Pharm Bull (Tokyo) 52, 999-1001

4. Munoz, M., Villar, l., and Garcia-Erce, J. A. (2009) An update on iron physiology. WorldJ Gastroenterol 15, 4617-4626

5. Cao, G., Sofic, E., and Prior, R. L. (1997) Antioxidant and prooxidant behavior of flavonoids: structure-activity relationships. Free Radic Biol Med 22, 749-760

6. Laughton, M. J., Halliwell, B., Evans, P. J., and Hoult, J. R. (1989) Antioxidant and pro-oxidant actions of the plant phenolics quercetin, gossypol and myricetin. Effects on lipid peroxidation, hydroxyl radical generation and bleomycin-dependent damage to DNA. Biochem Pharmacol 38, 2859-2865

7. Todaka, E., Sakurai, K., Fukata, H., M iyagawa, H., Uzuki, M., Omori, M., Osada, H., Ikezuki, Y., Tsutsumi, O., Iguchi, T., and Mori, C. (2005) Fetal exposure to phytoestrogens--the difference in phytoestrogen status between mother and fetus. Environ Res 99, 195-203

8. Vanhees, K., de Bock, L., Godschalk, R. W., van Schooten, F. J., and van Waalwijk van Doorn-Khosrovani, S. B. (2011) Prenatal exposure to flavonoids: implication for cancer risk. Toxicol Sci 120, 59-67

9. Godfrey, K. M., and Barker, D. J. (2000) Fetal nutrition and adult disease. Am J Clin Nutr 71, 1344S-1352S

10. Vanhees, K., Coort, S., Ruijters, E. J., Godschalk, R. W., van Schooten, F. J., and van Doorn-Khosrovani, S. B. (2011) Epigenetics: prenatal exposure to genistein leaves a permanent signature on the hematopoietic lineage. FASEB J 25, 797-807

11. Langie, S. A., Kowalczyk, P., Tudek, B., Zabielski, R., Dziaman, T., Olinski, R., van Schooten, F. J., and Godschalk, R. W. (2010) The effect of oxidative stress on nucleotide-excision repair in colon tissue of newborn piglets. M utat Res $695,75-80$

12. Maines, M. D. (1988) Heme oxygenase: function, multiplicity, regulatory mechanisms, and clinical applications. FASEB J 2, 2557-2568

13. Koury, M. J., and Ponka, P. (2004) New insights into erythropoiesis: the roles of folate, vitamin B12, and iron. Annu Rev Nutr 24, 105-131

14. Zhang, Y., Li, H., Zhao, Y., and Gao, Z. (2006) Dietary supplementation of baicalin and quercetin attenuates iron overload induced mouse liver injury. EurJ Pharmacol 535, 263-269

15. Weiss, G. (2009) Iron metabolism in the anemia of chronic disease. Biochim Biophys Acta 1790, 682-693

16. Waterston, R. H., Lindblad-Toh, K., Birney, E., Rogers, J., Abril, J. F., Agarwal, P., Agarwala, R., Ainscough, R., Alexandersson, M., An, P., Antonarakis, S. E., Attwood, J., Baertsch, R., Bailey, J., Barlow, K., Beck, S., Berry, E., Birren, B., Bloom, T., Bork, P., Botcherby, M., Bray, N., Brent, M. R., Brown, D. G., Brown, S. D., Bult, C., Burton, J., Butler, J., Campbell, R. D., Carninci, P., Cawley, S., Chiaromonte, F., Chinwalla, A. T., Church, D. M., Clamp, M., Clee, C., Collins, F. S., Cook, L. L., Copley, R. R., Coulson, A., Couronne, O., Cuff, J., Curwen, V., Cutts, T., Daly, M., David, R., Davies, J., Delehaunty, K. D., Deri, J., Dermitzakis, E. T., Dewey, C., Dickens, N. J., Diekhans, M., Dodge, S., Dubchak, I., Dunn, D. M., Eddy, S. R., Elnitski, L., Emes, R. D., Eswara, P., Eyras, E., Felsenfeld, A., Fewell, G. A., Flicek, P., Foley, K., Frankel, W. N., Fulton, L. A., Fulton, R. S., Furey, T. S., Gage, D., Gibbs, R. A., Glusman, G., Gnerre, S., Goldman, N., Goodstadt, L., Grafham, D., Graves, T. A., Green, E. D., Gregory, S., Guigo, R., Guyer, M., Hardison, R. C., Haussler, D., Hayashizaki, Y., Hillier, L. W., Hinrichs, A., Hlavina, W., Holzer, T., Hsu, F., Hua, A., Hubbard, T., Hunt, A., Jackson, I., Jaffe, D. B., Johnson, L. S., Jones, M., Jones, T. A., Joy, A., Kamal, M., Karlsson, E. K., Karolchik, D., Kasprzyk, A., Kawai, J., Keibler, E., Kells, C., Kent, W. J., Kirby, A., Kolbe, D. L., Korf, I., Kucherlapati, R. S., Kulbokas, E. J., Kulp, D., Landers, T., Leger, J. P., Leonard, S., Letunic, I., Levine, R., Li, J., Li, M., Lloyd, C., Lucas, S., Ma, B., Maglott, D. R., Mardis, E. R., Matthews, L., Mauceli, E., Mayer, J. H., McCarthy, M., McCombie, W. R., M cLaren, S., M cLay, K., McPherson, J. D., Meldrim, J., Meredith, B., Mesirov, J. P., Miller, W., Miner, T. L., Mongin, E., Montgomery, K. T., M organ, M., M ott, R., Mullikin, J. C., M uzny, D. M., Nash, W. E., Nelson, J. O., Nhan, M. N., Nicol, R., Ning, Z., Nusbaum, C., O'Connor, M. J., Okazaki, Y., Oliver, K., Overton-Larty, E., Pachter, L., Parra, G., Pepin, K. H., Peterson, J., Pevzner, P., Plumb, R., Pohl, C. S., Poliakov, A., Ponce, T. C., Ponting, C. P., Potter, S., Quail, M., Reymond, A., Roe, B. A., Roskin, K. M., Rubin, E. M., Rust, A. G., Santos, R., Sapojnikov, V., Schultz, B., Schultz, J., Schwartz, M. S., Schwartz, S., Scott, C., Seaman, S., Searle, S., Sharpe, T., Sheridan, A., Shownkeen, R., Sims, S., Singer, J. B., Slater, G., Smit, A., Smith, D. R., Spencer, B., Stabenau, A., Stange-Thomann, N., Sugnet, C., Suyama, M., Tesler, G., Thompson, J., Torrents, D., Trevaskis, E., Tromp, 
J., Ucla, C., Ureta-Vidal, A., Vinson, J. P., Von Niederhausern, A. C., Wade, C. M., Wall, M., Weber, R. J., Weiss, R. B., Wendl, M. C., West, A. P., Wetterstrand, K., Wheeler, R., Whelan, S., Wierzbowski, J., Willey, D., Williams, S., Wilson, R. K., Winter, E., Worley, K. C., Wyman, D., Yang, S., Yang, S. P., Zdobnov, E. M., Zody, M. C., and Lander, E. S. (2002) Initial sequencing and comparative analysis of the mouse genome. Nature 420, 520-562

17. Skibola, C. F., and Smith, M. T. (2000) Potential health impacts of excessive flavonoid intake. Free Radic Biol Med 29, 375-383

18. Prater, M. R., Laudermilch, C. L., Liang, C., and Holladay, S. D. (2008) Placental oxidative stress alters expression of murine osteogenic genes and impairs fetal skeletal formation. Placenta 29, 802-808

19. Egert, S., Wolffram, S., Bosy-Westphal, A., Boesch-Saadatmandi, C., Wagner, A. E., Frank, J., Rimbach, G., and Mueller, M. J. (2008) Daily quercetin supplementation dose-dependently increases plasma quercetin concentrations in healthy humans. J Nutr 138, 1615-1621

20. Mennen, L. I., Walker, R., Bennetau-Pelissero, C., and Scalbert, A. (2005) Risks and safety of polyphenol consumption. Am J Clin Nutr 81, 326S-329S

21. Gambling, L., Charania, Z, Hannah, L., Antipatis, C., Lea, R. G., and McArdle, H. J. (2002) Effect of iron deficiency on placental cytokine expression and fetal growth in the pregnant rat. Biol Reprod 66, 516-523

22. Hindmarsh, P. C., Geary, M. P., Rodeck, C. H., Jackson, M. R., and Kingdom, J. C. (2000) Effect of early maternal iron stores on placental weight and structure. Lancet 356, 719-723

23. Gambling, L., Czopek, A., Andersen, H. S., Holtrop, G., Srai, S. K., Krejpcio, Z., and M cArdle, H. J. (2009) Fetal iron status regulates maternal iron metabolism during pregnancy in the rat. Am J Physiol Regul Integr Comp Physiol 296, R1063-1070

24. Sikkel, E., Pasman, S. A., Oepkes, D., Kanhai, H. H., and Vandenbussche, F. P. (2004) On the origin of amniotic fluid bilirubin. Placenta 25, 463-468

25. Bothwell, T. H. (2000) Iron requirements in pregnancy and strategies to meet them. Am J Clin Nutr 72, 257S-264S

26. Palis, J. (2008) Ontogeny of erythropoiesis. Curr Opin Hematol 15, 155-161

27. Keller, G., Lacaud, G., and Robertson, S. (1999) Development of the hematopoietic system in the mouse. Exp Hematol 27, 777-787

28. Kingsley, P. D., Malik, J., Emerson, R. L., Bushnell, T. P., McGrath, K. E., Bloedorn, L. A., Bulger, M., and Palis, J. (2006) "M aturational" globin switching in primary primitive erythroid cells. Blood 107, 1665-1672

29. Ohgami, R. S., Campagna, D. R., McDonald, A., and Fleming, M. D. (2006) The Steap proteins are metalloreductases. Blood 108, 1388-1394

30. Ganz, T. (2006) Hepcidin and its role in regulating systemic iron metabolism. Hematology Am Soc Hematol Educ Program, 29-35, 507

31. Olivieri, N. F., and Brittenham, G. M. (1997) Iron-chelating therapy and the treatment of thalassemia. Blood 89, 739-761

32. Taher, A., Sheikh-Taha, M., Sharara, A., Inati, A., Koussa, S., Ellis, G., Dhillon, A. P., and Hoffbrand, A. V. (2005) Safety and effectiveness of $100 \mathrm{mg} / \mathrm{kg} /$ day deferiprone in patients with thalassemia major: a twoyear study. Acta Haematol 114, 146-149 



\section{Chapter 6}

\section{Maternal intake of quercetin during gestation alters ex vivo benzo[a]pyrene metabolism and DNA- adduct formation in adult offspring}

Vanhees K, van Schooten FJ, M oonen EJ, Maas LM , Barjesteh van Waalwijk van Doorn-Khosrovani S, Godschalk RWL 


\begin{abstract}
Variation in xenobiotic metabolism can not entirely be explained by genetic diversity in metabolic enzymes. We suggest that maternal diet during gestation can contribute to variation in metabolism by creating an in utero environment that shapes the offspring's defence against chemical carcinogens. Therefore, pregnant mice were supplemented with the natural aryl hydrocarbon receptor (AhR) agonist quercetin ( $1 \mathrm{mmol}$ quercetin/ $\mathrm{kg}$ feed) until delivery. Next, it was investigated whether the adult offspring at the age of 12 weeks had altered biotransformation of the environmental pollutant benzo[a]pyrene (B[a]P). In utero quercetin exposure resulted in significantly enhanced gene expression of Cyplal, Cyplb1, Nqo 1 and Ugtla 6 in liver of fetuses at day 14.5 of gestation. Despite cessation of supplementation after delivery, altered gene expression persisted into adulthood, but in a tissue and gender dependent manner. Expression of phase I enzymes (Cypla1 and Cyp1b1) was up-regulated in liver of adult female mice in utero exposed to quercetin, whereas expression of phase II enzymes (Gstp1, Nqo1 and Ugtla6) was predominantly enhanced in lung tissue of female mice. Epigenetic mechanisms may contribute to this adapted gene expression, as the repetitive elements (SINEB1) were hypomethylated in liver of female mice prenatally exposed to quercetin. Studies on ex vivo metabolism of $\mathrm{B}[\mathrm{a}] \mathrm{P}$ by lung and liver microsomes showed that the amount of $\mathrm{B}[\mathrm{a}] \mathrm{P}-9,10$-dehydrodiol, $\mathrm{B}[\mathrm{a}] \mathrm{P}-7,8$-dihydrodiol and 3-hydroxy-B[a]P did not change, but the amount of unmetabolized $B[a] P$ was significantly lower after incubation with lung microsomes from offspring that received quercetin during gestation. Moreover, ex vivo B[a]P induced DNAadduct formation was significantly lower for liver microsomes of offspring that were exposed to quercetin during gestation. These results suggest that prenatal diet leads to persistent alterations in phase I and II enzymes of adult mice and may affect cancer risk.
\end{abstract}




\section{Introduction}

A vast amount of research has been performed to determine the effects of genetic polymorphisms in enzymes involved in xenobiotic metabolism on inter-individual variation in cancer susceptibility (1-4). However, analysis of genetic polymorphisms did not explain a large part of the variation and other factors, especially the diet, have been postulated as additional contributors to individual reactions after exposure to xenobiotics (5). For instance, intake of dietary flavonoids is common in the human diet as they are found in fruit, vegetables and beverages such as wine, tea and coffee. They are mostly known for their anticancer properties, as they are potent antioxidants (6). Quercetin is the most widely consumed flavonoid in the diet. This polyphenolic compound is not only a potent free radical scavenger and iron chelator $(7,8)$, it can also modulate the expression and activity of cytochrome P450 (CYP450) and phase II detoxifying enzymes (9-11). The expression of phase I and phase II enzymes is important for the metabolism of many xenobiotics, including benzo[a]pyrene (B[a]P). $\mathrm{B}[\mathrm{a}] \mathrm{P}$ is produced during the incomplete combustion of organic compounds like tobacco, fuels, wood and meat (12-14). On its own, $\mathrm{B}[\mathrm{a}] \mathrm{P}$ has no mutagenic or carcinogenic properties $(10,15)$. However, it can diffuse into the cell due to its lipophilic character, bind to the aryl hydrocarbon receptor (AhR) and translocate into the nucleus. Here, AhR heterodimerizes with the aryl hydrocarbon receptor nuclear translocator (ARNT) and this complex binds to xenobiotic responsive elements, leading to the transcription of genes of phase I and II enzymes $(10,16)$. The metabolic activation of $\mathrm{B}[\mathrm{a}] \mathrm{P}$ is thought to be principally performed by cytochrome $\mathrm{P} 450$ (CYP450) enzymes (CYP1A1, CYP1B1), resulting in the formation of the reactive B[a]P-7,8dihydrodiol-9,10-epoxide (BPDE), leading to DNA-adduct formation and subsequent mutations, thus increasing the risk of cancer. Although it is known that quercetin prevents $\mathrm{B}[\mathrm{a}] \mathrm{P}$ induced DNA damage, there is a disagreement about the underlying mechanism (10, 17-20). Similar to B[a]P, quercetin is a potent ligand for AhR (9) and could thus alter the expression of enzymes involved in both activation as well as detoxification of $B[a] P$.

A diet rich in fruit and vegetables and therefore containing high amounts of flavonoids is thought to protect against cancer development (6). However, the time point of exposure to these flavonoids can also contribute to the inter-individual differences (21). Without any doubt, maternal diets can affect fetal programming by inducing epigenetic alterations that can lead to long-lasting changes in gene expression $(21,22)$. Due to altered genetic imprinting, individuals may acquire distinct responses to carcinogenic exposures and may therefore have different risks for developing DNA damage and cancer. The fetal origin of adult cancer needs more attention.

Therefore, in this study we aim to investigate whether gene expression of $\mathrm{B}[\mathrm{a}] \mathrm{P}$ metabolizing enzymes can be modulated by prenatal exposure to quercetin $(1 \mathrm{mmol}$ (302 $\mathrm{mg}$ ) quercetin/ $\mathrm{kg}$ feed ) via the maternal diet, starting 3 days before conception until delivery. At the adult age of 12 weeks male and female offspring mice were sacrificed and phase I and II gene expression was determined. Direct effect of quercetin was investigated by determining gene expression levels of phase I and II enzymes in the liver of fetuses at day 14.5 of gestation. B[a]P metabolism and DNA-adduct formation was determined ex vivo using $\mathrm{S} 9 \mathrm{mix}$ of liver and lung tissue of 12 week old male and female offspring. 


\section{Material and methods}

Mice and sample collection

Mice (129/Sv):C57BL/6] background) approximately 8 weeks of age, received either normal chow ( $n=8$, low phytoestrogen content complete feed for mice breeding, ssniff $@$, Soest, Germany) or the same chow (ssniff ${ }^{\circledR}$ ) supplemented with quercetin $(n=8,1 \mathrm{mmol}$ (302 mg)/ kg feed) (Sigma, Zwijndrecht, the Netherlands) from 3 days before conception until the end of gestation. Male mice were placed in the cage only for the duration of copulation. After delivery all mothers and pups received normal chow. Offspring mice were anesthetized and sacrificed by cardiac puncture at 12 weeks of age, and liver and lung were removed and frozen at $-80{ }^{\circ} \mathrm{C}$ until analysis.

To study the direct effects of the maternal diet on fetal phase I and II gene expression, a different group of mice were mated overnight. The presence of a vaginal plug the next morning was defined as 0.5 day post conception. On day 14.5 of gestation, mice were sacrificed to isolate the fetuses and their livers, as AhR mRNA and protein expression peaks between gestational day 14 and 16 (23).

\section{Quantitative real-time polymerase chain reaction}

The liver of fetuses and one half of the lung and liver of 12 week old mice were homogenized, using the Ultra-Turrax homogenizer (IKA, Staufen, Germany). Next, RNA was isolated using TRIzol Reagent (Invitrogen, Breda, the Netherlands) according to the manufacturer's instructions.

Using iScript reverse transcriptase (Bio-rad, Hercules, USA), $1 \mu \mathrm{g}$ RNA was transcribed into CDNA. An aliquot of one $10^{\text {th }}$ of the resulting CDNA was applied for quantitative PCR amplification together with $12.5 \mu$ SYBR Green (Qiagen, Venlo, the Netherlands) and 7.5 pmol of each primer (see Table 1, Eurogentec, M aastricht, the Netherlands) in a volume of $25 \mu \mathrm{l}$. The reactions were carried out using a M yiQ Single Color RT-PCR detection system (Bio-rad), under the following conditions: 1 cycle at $95^{\circ} \mathrm{C}$ for 3 minutes and then 40 cycles at $95{ }^{\circ} \mathrm{C}$ for 15 seconds and $60{ }^{\circ} \mathrm{C}$ for 1 minute followed by 1 cycle at $95{ }^{\circ} \mathrm{C}$ for 1 minute and 1 cycle at $65^{\circ} \mathrm{C}$. Data were analyzed by MyiQ Software system (Bio-rad), Ct values were normalized for an endogenous reference gene (b-actin), compared with the calibrator (i.e. average Ct value of control samples) and expressed as fold change $\left(2^{-\Delta \Delta C t}\right)$.

Table 1: Forward and reverse primers used for quantitative real-time PCR

\begin{tabular}{|c|c|c|}
\hline & Forward primer (5'-3') & Reverse primer (5'-3') \\
\hline Cypla1 & TGCCCTTCATTGGTCACATG & CGTCCCCATACTGCTGACTCA \\
\hline Cyp1b1 & AACGCAGCCGGTGATTGT & TGTACCGACAGCCGAAGCA \\
\hline Comt & AGAGAAGGAGTGGGCCATGA & CCGAATCACTGCATCCATGA \\
\hline Gstp1 & AGAACCAGGGAGGCAAAGCT & CAGGTCCAGCAAGTTGTAATCG \\
\hline Nqol & CAGTTCCCATTGCAGTGGTTT & ССTGCTACGAGCACTCTCTCAA \\
\hline Ugtla6 & GCTACCCCAAAATGATCTGCTT & AATACCATGGGAGCCAGAGTGT \\
\hline AhR & TGTGCAGAATCCCACATCCG & AATCAAGCGTGCATTGGACTG \\
\hline$\beta$-actin & ACGGCCAGGTCATCACTATTG & CAAGAAGGAAGGCTGGAAAAGA \\
\hline SINEB1 & GTGGCGCACGCCTTTAATC & GACAGGGTTTCTCTGTGTAG \\
\hline SINEB2 & GAGATGGCTCAGTGGTTAAG & CTGTCTTCAGACACTCCAG \\
\hline LINE1 & TITGGGACACAATGAAAGCA & CTGCCGTCTACTCCTCTTGG \\
\hline
\end{tabular}


M ethylation-sensitive $\mathrm{M} \mathrm{crBC}$-real-time polymerase chain reaction (PCR) assay of fetuses and adult mice

Analysis of methylation patterns of the short- and long interspersed nucleotide elements (SINEB1, SINEB2 and LINE1) was performed using the methylation-sensitive M crBC-real-time PCR assay (24). $1 \mu \mathrm{g}$ of genomic DNA was digested overnight at $37{ }^{\circ} \mathrm{C}$ using $10 \mathrm{U}$ of $\mathrm{McrBC}$ (New England Biolabs, Beverly, MA, USA), an endonuclease which cleaves DNA containing 5methylcytosine, but will not cleave unmethylated DNA. The DNA strand-breaks prevent amplification of methylated DNA in the quantitative real-time PCR assay. Two-step quantitative real-time PCR was performed using IQ SYBR Green Supermix (Bio-Rad Laboratories, Veenendaal, the Netherlands) with $4 \mathrm{ng}$ of $\mathrm{McrBC}$-digested DNA and $25 \mathrm{pmol}$ of each primer (Table 1, Eurogentec, Maastricht, the Netherlands) in a reaction volume of $25 \mu$ l. The cycling conditions consisted of an initial denaturation at $95^{\circ} \mathrm{C}$ for 10 minutes, followed by 40 cycles of $95^{\circ} \mathrm{C}$ for 45 seconds, $58{ }^{\circ} \mathrm{C}$ for 90 seconds, using the iCycler (Bio-Rad). Data were analyzed by MyiQ Software system (Bio-rad), Ct values were normalized for Ct values of undigested DNA and subsequently compared to a calibrator (i.e. average $\mathrm{Ct}$ value of 5 control samples for the adult mice and of 4 control samples for the fetuses). Results were expressed as relative expression $\left(2^{-\Delta \Delta C t}\right)$. An increase in PCR amplification is indicative of hypomethylation, whereas a decrease in PCR amplification products indicates hypermethylation. Alterations in DNA methylation were assessed in fetal liver and adult liver and lung.

High-performance liquid chromatography (HPLC) and fluorescence detection of $B[a] P$ metabolites

To mimic lung and liver biotransformation, an aliquot of $\mathrm{S9}$ mix (4 mg of proteins), obtained from homogenizing the other half of the lung and liver of 12 week old mice in lysis buffer (10 mM Tris, $150 \mathrm{mM} \mathrm{KCl}, \mathrm{pH}$ 7.4) using the Ultra-Turrax homogenizer (IKA), was incubated with a mixture consisting of $1 \mu \mathrm{M} B$ [a]P in DM SO and a NADPH-generating system (10 mM NADPH, 100 mM glucose-6-phosphate, 40 mM M gCl 2,400 mM Tris (pH 8), $17.8 \mu \mathrm{g}$ glucose-6-phoshate dehydrogenase and milli-Q in a final volume of $500 \mu \mathrm{l}$ ), without addition of cofactors for phase II metabolizing enzymes. The incubation was carried out at $37{ }^{\circ} \mathrm{C}$ for 1 hour. Afterwards, metabolites were extracted using ethylacetate, evaporated and dissolved in methanol. Next, samples were applied to a HPLC system equipped with a fluorescence detector (excitation $257 \mathrm{~nm}$, emission $350 \mathrm{~nm}$ ) and an analytical reversed-phase column (ODS Hypersil, length $2.5 \mathrm{~cm}$, I.D. $3 \mathrm{~mm}$, particle size $5 \mu \mathrm{m}$; Supelco, Belafonte, USA). Separation was performed with solvent A (100\% methanol) and solvent $B$ (40\% methanol, mobile phase), using following elution gradient: $30 \% \mathrm{~A}$ and $70 \% \mathrm{~B}$ (0-29 minutes), $90 \% \mathrm{~A}$ and $10 \% \mathrm{~B}$ (30-35 minutes), $30 \% \mathrm{~A}$ and $70 \% \mathrm{~B}$ (36-40 minutes) while the flow rate was maintained at $0.5 \mathrm{ml} / \mathrm{minutes}$.

\section{${ }^{32} \mathrm{P}$-postlabeling analysis}

To determine the BPDE induced DNA-adduct formation $10 \mu \mathrm{g}$ calf thymus DNA (Sigma) was incubated with the $S 9$ mix of lung and liver tissue of 12 week old mice and $1 \mu \mathrm{M}$ of $\mathrm{B}[\mathrm{a}] \mathrm{P}$. The DNA was isolated using a phenol-chloroform extraction method and BPDE DNAadduct levels were determined by the nuclease P1 enrichment technique as described by Reddy and Randerath (25) with the modifications described by Godschalk et al. (26). In all 
experiments, three BPDE DNA standards with known BPDE DNA-adduct levels (one adduct per $10^{6}, 10^{7}$ and $10^{8}$ normal nucleotides) were analyzed in parallel for quantification purposes. Adduct spots on the chromatograms were quantified using Phosphor-Imaging technology (Fujifilm FLA-3000, Rotterdam, the Netherlands) using the Aida Imager Analyser (Raytest, Milan, Italy), with a detection limit of approximately 1 adduct per $10^{9}$ nucleotides per individual DNA adduct spot.

Statistical analysis

Statistical analysis was performed with Statistical Package for Social Sciences (SPSS version 17 for Windows, SPSS Inc., Chicago, IL, USA). Nested ANOVA was used to compare the mRNA expression level of phase I and II enzymes in the liver of fetuses. The nonparametric Mann-Whitney test was used to determine the mRNA expression level of phase I and II enzymes in the liver and lung of adults, unconjugated B[a]P metabolites, unmetabolized B[a]P and BPDE DNA-adducts formed after incubation with liver or lung S9 mix of adult mice. To avoid litter effects no more than two adult mice per litter were used for analysis. One-way ANOVA was used to test differences in methylation pattern of SINEB1, SINEB2 and LINE1 between control and quercetin exposed fetuses and adult mice.

\section{Results}

Quercetin exposure increased gene expression of phase I and II enzymes in fetuses

To investigate the effects of quercetin exposure on the fetuses' gene expression of phase I and II enzymes, mice fetuses were exposed to quercetin (1 mmol/ kg feed) via the maternal diet. Pregnant mice were sacrificed at day 14.5 of gestation. Phase I and II gene expression levels were examined in the liver of the fetuses ( $n=5$ per diet group). In line with the AhR agonistic action of quercetin maternal exposure resulted in a significant increase in expression of both phase I (Cypla1: $F_{1,3}: 22.5, P=0.004$; Cyp1b1: $F_{1,3}: 76.1$, $P \varangle .001$; Table 2) and phase II (Gstp1: $F_{1,3}: 5.2, P=0.07$; Nq01: $F_{1,3}: 20.5, P=0.005$ and Ugtla6: $F_{1,3}: 1.8, P=0.004$ ) enzymes, without a statistically significant litter effect. AhR gene expression did not change by quercetin exposure.

Table 2. Relative gene expression profile of phase I and II enzymes in the liver of quercetin exposed fetuses at day $\mathbf{1 4 . 5}$ of gestation

\begin{tabular}{|c|c|c|c|c|}
\hline & \multirow{2}{*}{$\begin{array}{l}\text { Control }(n=5) \\
\text { Mean } \pm \text { SE }\end{array}$} & \multicolumn{3}{|l|}{ Quercetin (n=5) } \\
\hline & & Mean \pm SE & Diet & Litter effect \\
\hline Cypla1 & $1.0 \pm 0.4$ & $16.5 \pm 3.1$ & $F_{1,3}: 22.5 ; \quad P=0.004$ & $F_{5,3}: 0.9 ; P=0.6$ \\
\hline Cyp1b1 & $1.0 \pm 0.4$ & $7.9 \pm 1.3$ & $F_{1,3}: 76.1 ; \quad P<0.001$ & $F_{5,3}: 0.1 ; P=1.0$ \\
\hline Comt & $1.0 \pm 0.4$ & $2.5 \pm 0.2$ & $F_{1,3}: 3.8 ; P=0.1$ & $F_{5,3}: 3.5 ; P=0.2$ \\
\hline Gstp1 & $1.0 \pm 0.4$ & $2.5 \pm 0.4$ & $F_{1,3}: 5.2 ; P=0.07$ & $F_{5,3}: 3.7 ; P=0.2$ \\
\hline Nqol & $1.0 \pm 0.2$ & $2.5 \pm 0.3$ & $F_{1,3}: 20.5 ; \quad P=0.005$ & $F_{5,3}: 0.5 ; P=0.7$ \\
\hline Ugtla6 & $1.0 \pm 0.5$ & $3.9 \pm 1.0$ & $F_{1,3}: 1.8 ; P=0.004$ & $F_{5,3}: 4.3 ; P=0.6$ \\
\hline$A h R$ & $1.0 \pm 0.4$ & $1.2 \pm 0.1$ & $F_{1,3}: 0.1 ; P=0.7$ & $F_{5,3}: 9.0 P=0.05$ \\
\hline
\end{tabular}

F-value with corresponding degrees of freedom for respectively diet groups and number of litters 
Prenatal exposure to quercetin affects gene expression profile of $\mathrm{B}[\mathrm{a}] \mathrm{P}$ metabolizing enzymes in adult liver and lung

As in utero exposure to quercetin up-regulated gene expression of phase I and II enzymes, we investigated whether these changes persisted into adulthood. Therefore mice were in utero exposed to quercetin $(1 \mathrm{mmol} / \mathrm{kg}$ feed) and they were sacrificed at the age of 12 weeks. Basal gene expression of phase I and II enzymes was determined in liver and lung tissue of 5 male and 5 female offspring mice. As shown in Table 3, prenatal exposure to quercetin enhanced gene expression in the liver of female offspring mice of phase I enzymes, Cyp1b1 ( $\mathrm{P}=0.01)$ and Cypla1 $(P=0.05)$, involved in $B[a] P$ metabolism in the liver of female offspring mice. However, the gene expression of AhR was significantly induced in the liver of males prenatally exposed to quercetin $(P=0.009)$. On the contrary, the expression of phase ll enzymes was not altered in the liver.

In lungs of these mice, no significant changes in phase I or AhR gene expression levels were observed (Table 3). On the other hand, female mice prenatally exposed to quercetin showed an increase in expression of the following phase Il enzymes in their lung: Gstp1 ( $P=0.009)$, Nqo1 $(P=0.009)$ and Ugtla6 $(P \varangle 0.05)$ compared to control females.

Also interesting to see were the significant tissue specific differences in gene expression between male and female mice (Table 4). In case of the liver, Cyp1b1 ( $P=0.05)$, Gstp1 $(P=0.009)$, Nqo1 ( $P=0.009)$ and Ugtla6 $(P=0.02)$ were differentially regulated in control males and females. In the lung, only the expression of Gstp1 $(P \varangle 0.05)$ and Nqo1 $(P=0.009)$ differed between male and female control mice. Moreover, prenatal exposure to quercetin seemed to counteract these gender differences for almost all genes, with an exception for Gstp1 in liver $(P=0.009)$ and $\mathrm{NqO1}(\mathrm{P}=0.01)$ in lung.

Table 3. Relative gene expression of phase I and II enzymes in the liver and lung of 12 week old male and female offspring mice prenatally exposed to quercetin

\begin{tabular}{llllll}
\hline & & \multicolumn{3}{c}{ Females $^{1}(\mathbf{n}=\mathbf{5})$} \\
\cline { 2 - 5 } Males $^{1}(\mathbf{n}=\mathbf{5})$ & Qontrol & Quercetin & Control & Quercetin \\
\hline Liver & Cyp1a1 & $1.0 \pm 0.3$ & $1.0 \pm 0.1$ & $1.0 \pm 0.1$ & $1.5 \pm 0.2^{*}$ \\
& Cyp1b1 & $1.0 \pm 0.2$ & $1.9 \pm 0.6$ & $1.0 \pm 0.3$ & $2.9 \pm 0.8^{* *}$ \\
& Comt & $1.0 \pm 0.1$ & $0.9 \pm 0.2$ & $1.0 \pm 0.2$ & $1.2 \pm 0.3$ \\
& Gstp1 & $1.0 \pm 0.4$ & $0.9 \pm 0.2$ & $1.0 \pm 0.2$ & $1.4 \pm 0.4$ \\
& Nq01 & $1.0 \pm 0.1$ & $4.5 \pm 2.9$ & $1.0 \pm 0.5$ & $2.4 \pm 1.0$ \\
& Ugt1a6 & $1.0 \pm 0.2$ & $1.0 \pm 0.3$ & $1.0 \pm 0.2$ & $1.0 \pm 0.4$ \\
& AhR & $1.0 \pm 0.1$ & $2.6 \pm 0.4^{* *}$ & $1.0 \pm 0.3$ & $1.5 \pm 0.4$ \\
\hline Lung & Cyp1a1 & $1.0 \pm 0.5$ & $0.9 \pm 0.3$ & $1.0 \pm 0.2$ & $0.9 \pm 0.1$ \\
& Cyp1b1 & $1.0 \pm 0.2$ & $1.2 \pm 0.5$ & $1.0 \pm 0.4$ & $1.4 \pm 0.2$ \\
& Comt & $1.0 \pm 0.3$ & $1.5 \pm 0.2$ & $1.0 \pm 0.1$ & $1.2 \pm 0.2$ \\
& Gstp1 & $1.0 \pm 0.1$ & $1.4 \pm 0.2$ & $1.0 \pm 0.1$ & $2.2 \pm 0.3^{* *}$ \\
& Nq01 & $1.0 \pm 0.7$ & $1.6 \pm 0.6$ & $1.0 \pm 0.2$ & $11.3 \pm 3.8^{* *}$ \\
& Ugt1a6 & $1.0 \pm 0.3$ & $1.6 \pm 0.6$ & $1.0 \pm 0.1$ & $2.3 \pm 0.4^{*}$ \\
& AhR & $1.0 \pm 0.4$ & $1.9 \pm 0.6$ & $1.0 \pm 0.6$ & $1.0 \pm 0.2$ \\
\hline
\end{tabular}

${ }^{1}$ Control male and female mice were used as reference sample to calculate $\Delta \Delta C T$ for respectively males and females. Results represent mean \pm SE. Significant differences between diets: *: $P \varangle 0.05, * *$ : $P \leq 0.01$

Prenatal exposure to quercetin results in long-lasting epigenetic modifications of repetitive elements in liver of female mice prenatally exposed to quercetin

As gene expression of phase I and phase II enzymes were altered by prenatal exposure to quercetin and were maintained till adulthood, we also investigated whether exposure to quercetin could affect the methylation status of the repetitive elements SINEB1, SINEB2 and 
LINE1. SINE and LINE repetitive elements are normally expressed during early embryogenesis, after which their expression rapidly decreases with development. Later in life, expression of SINEB1, SINEB2 and LINE1 is associated with cell stress, for instance by DNA-damaging agents $(27,28)$. At gestational day 14.5 , no changes in methylation of repetitive elements were detected in fetuses exposed to quercetin (Figure 1A), suggesting that quercetin exposure did not influence methylation status at that point in gestation.

Although no differences in global methylation status could be detected in the liver at gestational day 14.5, SINEB1 in the liver of adult female mice prenatally exposed to quercetin was hypomethylated compared to control female mice ( $P=0.01$, Figure $1 B)$. DNA methylation of SINEB2 and LINE1 repetitive elements was also decreased in female mice prenatally exposed to quercetin, though not significantly when analysed seperately. Combined analysis of all three repetitive sequences also indicated that these were hypomethylated in liver of female offspring that received quercetin in utero, with borderline significance $(P=0.06)$. No alterations in methylation were observed for male liver or lung of both genders (Figure $1 \mathrm{~B}$ and $1 \mathrm{C}$ ). These data suggests that in utero exposure to quercetin results in the hypomethylation of the repetitive elements SINEB1, SINEB2 and LINE1 in the liver of adult female mice.

Prenatal exposure to quercetin diminished the B[a]P-induced DNA-adduct formation ex vivo using liver microsomes of adult mice

Prenatal exposure to quercetin resulted in long-lasting alterations in the gene expression profile of enzymes involved in B[a]P metabolism in liver and lung of mainly female offspring. However, as mRNA expression levels do not necessarily reflect enzyme activity, S9 mix from liver or lung tissue of 5 male and 5 female mice prenatally exposed to quercetin were incubated ex vivo with B[a]P. $\mathrm{S9}$ mix of liver of mice prenatally exposed to quercetin did not show an altered B[a]P metabolism (Table 5). On the other hand, lung S9 mix of mice prenatally exposed to quercetin resulted in decreased amounts of $\mathrm{B}[\mathrm{a}] \mathrm{P}-9,10-$ dihydrodiol (9,10-diOH-B[a]P, $\mathrm{P}=0.007)$ and $\mathrm{B}[\mathrm{a}] \mathrm{P}-7,8$-dihydrodiol (7,8-diOH-B[a]P, $\mathrm{P}=0.05$ ). The amount of $9,10-\mathrm{diOH}-\mathrm{B}[\mathrm{a}] \mathrm{P}$ was especially decreased in case of $\mathrm{S9} \mathrm{mix}$ derived from male mice prenatally exposed to quercetin compared to control males $(P=0.03)$. In addition, the total amount of unmetabolized $B[a] P$ was significantly lower $(P=0.01)$ when using lung 59 mix of mice prenatally exposed to quercetin compared to the control group, especially in males $(P<0.05)$.

Despite the clear differences in gene expression between male and female mice, no gender differences were observed for B[a]P metabolism, except maybe for the liver $\mathrm{S} 9 \mathrm{mix}$ where 9,10-diOH-B[a]P levels were higher for control males compared to their female littermates, but this did not reach statistical significance $(P=0.09)$. The overall profile of metabolites strongly differed between lung and liver $\mathrm{S} 9 \mathrm{mix}$; using $\mathrm{S9}$ mix obtained from the lung, the major metabolite was 3-hydroxy-B[a]P $(3-\mathrm{OH}-\mathrm{B}[\mathrm{a}] \mathrm{P})$, which is considered to be a detoxification product of B[a]P. No B[a]P DNA-adducts could be detected in calf thymus DNA that was added to the S9 mix obtained from lung tissue, regardless of the prenatal diet (Table 5). When using liver derived $\mathbf{S 9}$ mix, prenatal quercetin exposure resulted in a significant decrease in DNA-adduct formation $(P=0.04)$, with no differences between genders. 
A

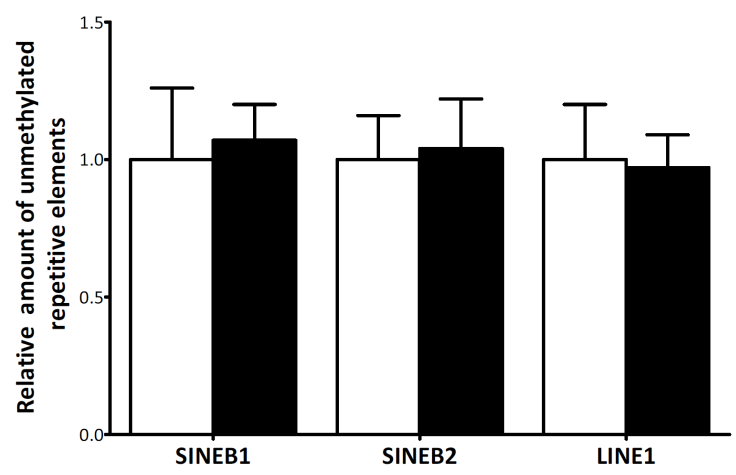

B
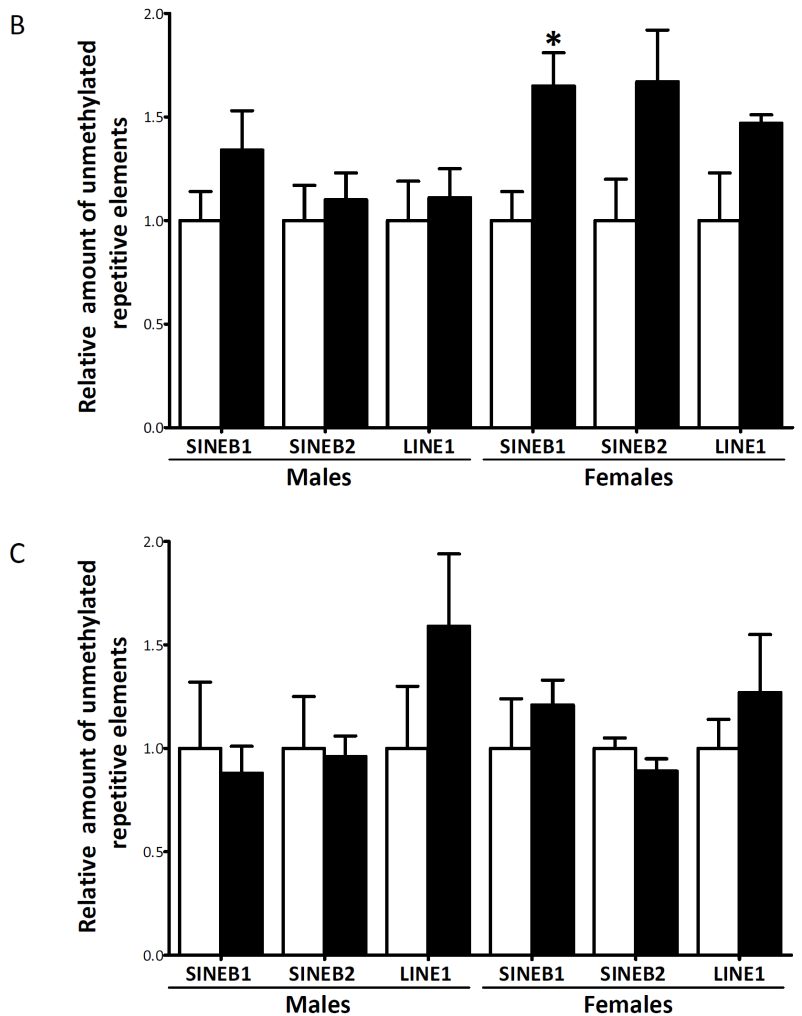

Figure 1. Methylation status of SINEB1, SINEB2 and LINE1 repetitive elements in fetal and adult liver and lung after (prenatal) exposure to quercetin

Short-term effects of prenatal exposure to quercetin on DNA methylation of SINEB1, SINEB2 and LINE1 repetitive elements in fetal liver of quercetin exposed fetuses ( $n=4$, black bars) compared to control fetuses $(n=4$, white bars) at day 14.5 of gestation (A). Long-term effects of prenatal exposure to quercetin on DNA methylation of SINEB1, SINEB2 and LINE1 repetitive elements in liver (B) and lung (C) of male and female mice prenatally exposed to quercetin ( $n=5$ for each gender, black bars) compared with control mice ( $n=5$ for each gender, white bars). The degree of methylation of SINEB1, SINEB2 and LINE1 repetitive elements were determined by methylation-sensitive McrBC-real-time PCR assay. Bars represent the normalized average expression level of the unmethylated repetitive elements. Error bars represent standard error. Statistical significance was determined by One-way ANOVA: *: $P \varangle 0.05$. 


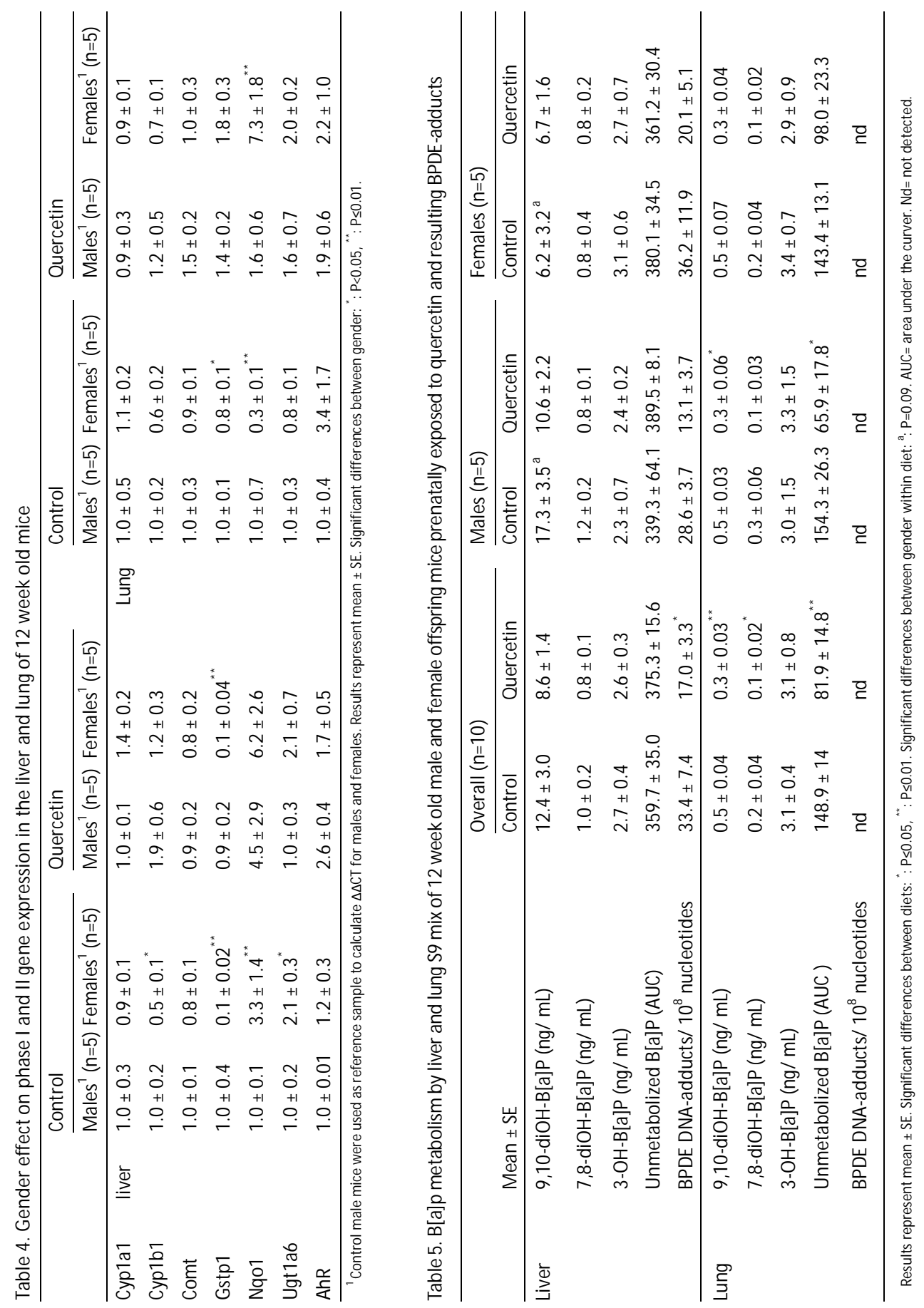




\section{Discussion}

As genetic polymorphisms (1-4) do not entirely explain the inter-individual differences in xenobiotic metabolism, we investigated whether prenatal exposure to the natural flavonoid quercetin, which is a potent AhR ligand, could permanently alter the expression of enzymes involved in both activation as well as detoxification of B[a]P.

We found that in utero exposure to quercetin affected the gene expression of phase I and II enzymes of the fetal liver at gestational day 14.5. Gene expression of Cypla1 and Cyp1b1 was significantly increased, indicating that quercetin or its metabolites functioned as an AhR ligand in the fetus. However, these alterations in gene expression could also have other reasons. For instance, Santini et al. (29) showed that exposure of swine granulose cells in vitro to a low dose of quercetin resulted in increased levels of $17 \beta$ estradiol. As 17 $\beta$-estradiol is a substrate for CYP1B1 and 1A1 (30) and because fetuses, both males and females, are continuously exposed to $17 \beta$-estradiol throughout gestation via the mother (31) this route of exposure could additionally increase the gene expression of phase I enzymes. M oreover, as CYP's are hemeproteins that contain iron (32), the iron scavenging properties of quercetin (7) could result in less CYP activity, therefore enhanced gene expression is needed as compensation. Gene expression of the phase II enzymes Ugtla6 and Nqol was also significantly enhanced in the liver of quercetin exposed fetuses. This increase could theoretically be the result of an increase in CYP activity, detoxifying the reactive compounds formed by the phase I reactions. Regardless of the underlying mechanism, from our experiments it is clear that supplementation with quercetin altered gene expression in utero.

According to the hypothesis of 'fetal programming' impaired maternal nutrition during pregnancy results in fetal adaptations that are meant to improve survival. However, when these adaptations are permanent, they could also alter the risk for diseases later in life. In this study, we investigated whether the changes in phase I and II gene expression due to the in utero environment are maintained throughout life. Indeed, 12 week old female mice prenatally exposed to quercetin had increased phase I (Cypla1 and Cyp1b1) gene expression levels in their liver, while the phase II enzymes (Gstp1, Nqol and Ugt1a6) were predominantly enhanced in lung tissue of these female mice. Interestingly, AhR gene expression was only increased in the liver of male mice prenatally exposed to quercetin.

The assumed AhR-induced up-regulation of Cyp450s seen in the liver due to prenatal exposure to quercetin did not occur in the lung. Since the lung develops mainly in the final stages of pregnancy and even continues to develop after birth (33), while the liver is largely differentiated before birth (34), the different responses of both tissues to quercetin exposure could be due to the difference in maturation state of the organ during exposure. The enhanced expression of phase II enzymes in mice prenatally exposed to quercetin could be the result of the pro-oxidant capacity of quercetin $(35,36)$, resulting in the up-regulation of phase II enzymes through the Nrf2-pathway (9), which could then be maintained throughout life.

In the control group significant differences were observed between male and female offspring regarding the gene expression of certain phase I and II enzymes both in liver as well as lung. This has already been reported for several species (37-40). However, prenatal exposure to quercetin seemed to reduce this gender difference. Only for Gstp1 (liver) and Nqo1 (lung) the gender effect was persistent. Makaji et al. (11) also reported that prenatal 
intake of flavonoids only resulted in long-term alterations of CYP activity in female rat offspring, by making the CYP profile more masculine, as was also observed in our study. They suggested that quercetin could influence phase I and II gene expression by regulating constitutive androstene receptor or Ah receptor. They also suggested that the gender differences in mRNA expression of phase I enzymes seen in adult animals is imprinted by the presence (or absence) of increased androgen levels at puberty.

We suspected that epigenetic modulations underlie the persistent changes in phase I and II gene expression. Therefore the potential of quercetin to alter the epigenome was assessed and showed that prenatal quercetin exposure resulted in the hypomethylation of repetitive elements in liver of adult female mice. Interestingly, most pronounced changes in gene expression were observed in liver and lung of female mice prenatally exposed to quercetin. However, changes in DNA methylation of repetitive elements were only seen in liver. As we did not measure gene specific DNA methylation levels, we can only assume that in utero exposure to quercetin resulted in gene specific hypomethylation for the genes or their regulators that were up-regulated in liver and lung tissue of male and female mice prenatally exposed to quercetin. Since these epigenetic modifications could not be detected in fetuses at day 14.5 of gestation, we suggest that they occurred at a later time point in pregnancy or even after birth. This is plausible as during the late gestational and early postnatal period, tissue maturation results in most epigenetic modifications. M oreover, it has been suggested that transcriptional inactivity attracts de novo methylation while transcriptional activity can eventually override DNA methylation (41).

To study the effects of maternal quercetin intake during gestation on B[a]P metabolism by adult liver and lung, we used $\mathrm{S} 9$ mix of lungs and livers of animals that did not receive B[a]P at adult age. In that case, analysis of ex vivo B[a]P metabolism using $\mathrm{S9}$ mix is more straightforward, because there is no bias by for instance B[a]P uptake and kinetics, DNA repair and altered cell turnover. The identified metabolites formed using liver and lung S9 mix did not differ between control and quercetin exposed animals. However, due to the limited number of metabolites detected, false representation of the B[a]P metabolite profile can not be excluded. Although there were no differences in the amount of unmetabolized B[a]P for liver S9 mix after the one hour incubation, the BPDE DNA-adduct levels were lower for mice prenatally exposed to quercetin. This suggests that prenatal exposure to quercetin did not result in an accelerated metabolism of $\mathrm{B}[\mathrm{a}] \mathrm{P}$ (as seen in lung), but in $\mathrm{B}[\mathrm{a}] \mathrm{P}$ detoxification, e.g. less formation of DNA reactive metabolites including BPDE.

No BPDE DNA-adducts could be detected for the lung $\mathrm{S} 9 \mathrm{mix}$ of both control and quercetin exposed mice, indicating that the B[a]P-adduct forming ability of the lung is lower compared to the liver. M oreover, for the lung less unmetabolized B[a]P was detected after incubation, indicating that the conversion of $\mathrm{B}[\mathrm{a}] \mathrm{P}$ to water soluble derivatives was significantly increased in offspring that received quercetin during gestation. This suggested that more detoxification of $\mathrm{B}[\mathrm{a}] \mathrm{P}$ can take place in the lung of mice prenatally exposed to quercetin as a result of the adapted gene expression of phase II enzymes, which is an important finding as the lung is the primary target organ for airborne $B[a] P(42)$. This finding therefore indicates that prenatal exposure to quercetin could decrease the risk on $\mathrm{B}[\mathrm{a}] \mathrm{P}$ induced DNA damage and therefore the susceptibility to lung cancer.

These results show that prenatal exposure to the natural AhR agonist quercetin leads to tissue and gender specific long-lasting alterations in the gene expression of phase I and II enzymes of adult mice, probably by epigenetic modifications. This seems to result in 
increased protection against B[a]P-induced DNA-adduct formation. However, as gene expression levels of phase I and phase II enzymes do not reflect actual enzyme activities, and because B[a]P metabolism and BPDE DNA-adduct formation experiments occurred ex vivo, it is now warranted to continue with similar studies with in vivo exposure to $B[a] P$ of adult mice prenatally exposed to quercetin to confirm our theory.

\section{Acknowledgements}

The authors sincerely thank Daniëlle Pachen for performing the DNA methylation assay.

This work was supported by grant number $06 \mathrm{~A} 031$ from the American Institute for Cancer Research. 


\section{References}

1. Cabral, R. E., Caldeira-de-Araujo, A., Cabral-Neto, J. B., and Costa Carvalho M da, G. (2010) Analysis of GSTM 1 and GSTT1 polymorphisms in circulating plasma DNA of lung cancer patients. Mol Cell Biochem 338, 263-269

2. Rojas, M., Cascorbi, I., Alexandrov, K., Kriek, E., Auburtin, G., Mayer, L., Kopp-Schneider, A., Roots, I., and Bartsch, H. (2000) M odulation of benzo[a]pyrene diolepoxide-DNA adduct levels in human white blood cells by CYP1A1, GSTM 1 and GSTT1 polymorphism. Carcinogenesis 21, 35-41

3. Wang, S., Chanock, S., Tang, D., Li, Z., Jedrychowski, W., and Perera, F. P. (2008) Assessment of interactions between PAH exposure and genetic polymorphisms on PAH-DNA adducts in African American, Dominican, and Caucasian mothers and newborns. Cancer Epidemiol Biomarkers Prev 17, 405-413

4. Pande, M., Amos, C. I., Eng, C., and Frazier, M. L. (2010) Interactions between cigarette smoking and selected polymorphisms in xenobiotic metabolizing enzymes in risk for colorectal cancer: A case-only analysis. Mol Carcinog 49, 974-980

5. Doll, R., and Peto, R. (1981) The causes of cancer: quantitative estimates of avoidable risks of cancer in the United States today. J Natl Cancer Inst 66, 1191-1308

6. Ross, J. A., and Kasum, C. M. (2002) Dietary flavonoids: bioavailability, metabolic effects, and safety. Annu Rev Nutr 22, 19-34

7. Ferrali, M., Signorini, C., Caciotti, B., Sugherini, L., Ciccoli, L., Giachetti, D., and Comporti, M. (1997) Protection against oxidative damage of erythrocyte membrane by the flavonoid quercetin and its relation to iron chelating activity. FEBS Lett 416, 123-129

8. Kitagawa, S., Sakamoto, H., and Tano, H. (2004) Inhibitory effects of flavonoids on free radical-induced hemolysis and their oxidative effects on hemoglobin. Chem Pharm Bull (Tokyo) 52, 999-1001

9. Moon, Y. J., Wang, X., and Morris, M. E. (2006) Dietary flavonoids: effects on xenobiotic and carcinogen metabolism. Toxicol In Vitro 20, 187-210

10. Ciolino, H. P., Daschner, P. J., and Yeh, G. C. (1999) Dietary flavonols quercetin and kaempferol are ligands of the aryl hydrocarbon receptor that affect CYP1A1 transcription differentially. Biochem J 340 ( Pt 3), 715-722

11. Makaji, E., Ho, S. H., Holloway, A. C., and Crankshaw, D. J. (2011) Effects in rats of maternal exposure to raspberry leaf and its constituents on the activity of cytochrome p450 enzymes in the offspring. Int J Toxicol 30, 216-224

12. Gelboin, H. V. (1980) Benzo[alpha]pyrene metabolism, activation and carcinogenesis: role and regulation of mixed-function oxidases and related enzymes. Physiol Rev 60, 1107-1166

13. Kim, J. H., Stansbury, K. H., Walker, N. J., Trush, M. A., Strickland, P. T., and Sutter, T. R. (1998) M etabolism of benzo[a]pyrene and benzo[a]pyrene-7,8-diol by human cytochrome P450 1B1. Carcinogenesis 19, 1847-1853

14. Long, D. J., 2nd, and Jaiswal, A. K. (2000) NRH:quinone oxidoreductase2 (NQO2). Chem Biol Interact 129, 99112

15. Uno, S., Dalton, T. P., Derkenne, S., Curran, C. P., Miller, M. L., Shertzer, H. G., and Nebert, D. W. (2004) Oral exposure to benzo[a]pyrene in the mouse: detoxication by inducible cytochrome P450 is more important than metabolic activation. M ol Pharmacol 65, 1225-1237

16. Singhal, R., Badger, T. M., and Ronis, M. J. (2008) Rats fed soy protein isolate (SPI) have impaired hepatic CYP1A1 induction by polycyclic aromatic hydrocarbons as a result of interference with aryl hydrocarbon receptor signaling. Toxicol Appl Pharmacol 227, 275-283

17. Kang, Z. C., Tsai, S. J., and Lee, H. (1999) Quercetin inhibits benzo[a]pyrene-induced DNA adducts in human Hep G2 cells by altering cytochrome P-450 1 A1 gene expression. Nutr Cancer 35, 175-179

18. Sergent, T., Dupont, I., Van der Heiden, E., Scippo, M. L., Pussemier, L., Larondelle, Y., and Schneider, Y. J. (2009) CYP1A1 and CYP3A4 modulation by dietary flavonoids in human intestinal Caco-2 cells. Toxicol Lett 191, 216-222

19. Delgado, M. E., Haza, A. I., Arranz, N., Garcia, A., and M orales, P. (2008) Dietary polyphenols protect against $\mathrm{N}$-nitrosamines and benzo(a)pyrene-induced DNA damage (strand breaks and oxidized purines/ pyrimidines) in HepG2 human hepatoma cells. EurJ Nutr 47, 479-490

20. Walle, T., and Walle, U. K. (2007) Novel methoxylated flavone inhibitors of cytochrome P450 1B1 in SCC-9 human oral cancer cells. J Pharm Pharmacol 59, 857-862

21. Vanhees, K., Coort, S., Ruijters, E. J., Godschalk, R. W., van Schooten, F. J., and Barjesteh van Waalwijk van Doorn-Khosrovani, S. (2011) Epigenetics: prenatal exposure to genistein leaves a permanent signature on the hematopoietic lineage. FASEBJ 25, 797-807 
22. Dolinoy, D. C., Weidman, J. R., Waterland, R. A., and Jirtle, R. L. (2006) Maternal genistein alters coat color and protects Avy mouse offspring from obesity by modifying the fetal epigenome. Environ Health Perspect 114, 567-572

23. Abbott, B. D., Birnbaum, L. S., and Perdew, G. H. (1995) Developmental expression of two members of a new class of transcription factors: I. Expression of aryl hydrocarbon receptor in the C57BL/6N mouse embryo. Dev Dyn 204, 133-143

24. Pogribny, I. P., Ross, S. A., Tryndyak, V. P., Pogribna, M., Poirier, L. A., and Karpinets, T. V. (2006) Histone H3 lysine 9 and $\mathrm{H} 4$ lysine 20 trimethylation and the expression of Suv4-20h2 and Suv-39h1 histone methyltransferases in hepatocarcinogenesis induced by methyl deficiency in rats. Carcinogenesis 27, 1180-1186

25. Reddy, M. V., and Randerath, K. (1986) Nuclease P1-mediated enhancement of sensitivity of 32Ppostlabeling test for structurally diverse DNA adducts. Carcinogenesis 7, 1543-1551

26. Godschalk, R. W., Maas, L. M., Van Zandwijk, N., van 't Veer, L. J., Breedijk, A., Borm, P. J., Verhaert, J., Kleinjans, J. C., and van Schooten, F. J. (1998) Differences in aromatic-DNA adduct levels between alveolar macrophages and subpopulations of white blood cells from smokers. Carcinogenesis 19, 819-825

27. Kramerov, D. A., and Vassetzky, N. S. (2005) Short retroposons in eukaryotic genomes. Int Rev Cytol 247, $165-221$

28. Stribinskis, V., and Ramos, K. S. (2006) Activation of human long interspersed nuclear element 1 retrotransposition by benzo(a)pyrene, an ubiquitous environmental carcinogen. Cancer Res 66, 2616-2620

29. Santini, S. E., Basini, G., Bussolati, S., and Grasselli, F. (2009) The phytoestrogen quercetin impairs steroidogenesis and angiogenesis in swine granulosa cells in vitro. J Biomed Biotechnol 2009, 419891

30. Hanna, I. H., Dawling, S., Roodi, N., Guengerich, F. P., and Parl, F. F. (2000) Cytochrome P450 1B1 (CYP1B1) pharmacogenetics: association of polymorphisms with functional differences in estrogen hydroxylation activity. Cancer Res 60, 3440-3444

31. Delbes, G., Levacher, C., and Habert, R. (2006) Estrogen effects on fetal and neonatal testicular development. Reproduction 132, 527-538

32. Nelson, D. R., Koymans, L., Kamataki, T., Stegeman, J. J., Feyereisen, R., Waxman, D. J., Waterman, M. R., Gotoh, O., Coon, M. J., Estabrook, R. W., Gunsalus, I. C., and Nebert, D. W. (1996) P450 superfamily: update on new sequences, gene mapping, accession numbers and nomenclature. Pharmacogenetics 6, 1-42

33. Ten Have-Opbroek, A. A. (1991) Lung development in the mouse embryo. Exp Lung Res 17, 111-130

34. Zaret, K. S. (2002) Regulatory phases of early liver development: paradigms of organogenesis. Nat Rev Genet 3, 499-512

35. Boots, A. W., Li, H., Schins, R. P., Duffin, R., Heemskerk, J. W., Bast, A., and Haenen, G. R. (2007) The quercetin paradox. Toxicol Appl Pharmacol 222, 89-96

36. Choi, E. J., Chee, K. M., and Lee, B. H. (2003) Anti- and prooxidant effects of chronic quercetin administration in rats. Eur J Pharmacol 482, 281-285

37. Delaunois, A., Florquin, S., Segura, P., Montano, L. M., Vargas, M. H., and Gustin, P. (1999) Interactions between cytochrome P-450 activities and ozone-induced modulatory effects on endothelial permeability in rabbit lungs: influence of gender. Inhal Toxicol 11, 999-1014

38. Scandlyn, M. J., Stuart, E. C., and Rosengren, R. J. (2008) Sex-specific differences in CYP450 isoforms in humans. Expert Opin Drug Metab Toxicol 4, 413-424

39. Timofeeva, M. N., Kropp, S., Sauter, W., Beckmann, L., Rosenberger, A., Illig, T., Jager, B., Mittelstrass, K., Dienemann, H., Bartsch, H., Bickeboller, H., Chang-Claude, J. C., Risch, A., and Wichmann, H. E. (2009) CYP450 polymorphisms as risk factors for early-onset lung cancer: gender-specific differences. Carcinogenesis 30, 1161-1169

40. Lofgren, S., Hagbjork, A. L., Ekman, S., Fransson-Steen, R., and Terelius, Y. (2004) Metabolism of human cytochrome P450 marker substrates in mouse: a strain and gender comparison. Xenobiotica 34, 811-834

41. Waterland, R. A., Kellermayer, R., Rached, M. T., Tatevian, N., Gomes, M. V., Zhang, J., Zhang, L., Chakravarty, A., Zhu, W., Laritsky, E., Zhang, W., Wang, X., and Shen, L. (2009) Epigenomic profiling indicates a role for DNA methylation in early postnatal liver development. Hum M ol Genet 18, 3026-3038

42. Uppstad, H., Ovrebo, S., Haugen, A., and Mollerup, S. (2010) Importance of CYP1A1 and CYP1B1 in bioactivation of benzo[a]pyrene in human lung cell lines. Toxicol Lett 192, 221-228 



\section{Chapter 7}

Summary \& General discussion 
Adult chronic illnesses, such as cancer, cardiovascular and respiratory diseases are a major burden on human health worldwide (1). Exposure to genotoxins and mutagens are thought to play an important role in the etiology of these diseases (2-6). On the other hand, a healthy diet is though to protect against genotoxins and mutagens and would therefore also protect against these chronic diseases to maintain health. One major dietary group receiving a lot of attention regarding the treatment and prevention of adult chronic diseases are the flavonoids, because of their potent antioxidant capacity (7-10). They comprise a large group of polyphenolic compounds widely distributed in the human diet (9), resulting in an average intake from 65 to $250 \mathrm{mg}$ of mixed flavonoids a day (11). The most predominant flavonoid in the human diet is quercetin, which is present in for instance onions, apples, tea and red wine $(9,12-14)$. Besides being a potent free radical scavenger, it also chelates iron $(15,16)$. Genistein is another important flavonoid, with antioxidant properties and is mainly found in soybeans. However, it also has estrogen-like properties due to its structural similarities to $17 \beta$-estradiol. Whether it works as an estrogen agonist or antagonist depends on the situation $(17,18)$.

Due to the health benefits they are presumed to provide, flavonoids are freely available as high dose supplements, with a recommended daily dose ranging between 1-2 gram (19, 20). Additionally, disturbingly is the increase in supplement consumption of woman during pregnancy. In the US $78 \%$ of the pregnant woman take dietary supplements (21), which includes the intake of folic acid. However, folic acid supplementation in adults has been shown to increase the risk on cancer (22). Yet little is known about the biological actions of flavonoids in pregnancy and the short-term and/ or long-term effects they exert on the offspring's health. It is known that flavonoids can cross the placenta and may accumulate in the fetus $(23,24)$. Therefore research is needed to assess the safety of intake of flavonoid supplements during pregnancy.

\section{Flavonoids during pregnancy: Infant leukemia}

Excessive intake of flavonoids could play a role in the onset of infant leukemia as they are efficient topoisomerase II inhibitors $(25,26)$. Flavonoids could therefore induce DNA double-strand breaks (DSB) and rearrangements in the mixed-lineage leukemia (MLL) gene, which is frequently observed in childhood leukemia $(26,27)$. In Chapter 2 we mated Atm- $\Delta$ SRI heterozygote mice to obtain pups with a different genetic capacity for the DNA repair of DSBs, namely Atm wild-type, Atm- $\Delta$ SRI heterozygote and Atm- $\Delta$ SRI mutant offspring mice and found that prenatal exposure to flavonoids indeed induced $M I I$ translocations in the bone marrow of both wild-type and Atm- $\Delta$ SRI mutant mice. Moreover, Atm- $\Delta$ SRI mutant mice did show a higher susceptibility to develop these chromosomal aberrations. We also showed that mice with an impaired DNA repair had an increased risk on developing other malignancies when prenatally exposed to genistein besides an increased risk on infant leukemia, which indicates that the DSB DNA repair pathway is relevant for maintaining genomic integrity in the developing fetus.

The Atm- $\Delta$ SRI mutation corresponds to one of the most common Atm mutations found to date in humans and these mice have a phenotype which is distinct from Atm knockout mice. It is known that Atm- $\Delta$ SRI mutant mice have a $50 \%$ chance of developing leukemia and lymphoma without additional exposures (28). The age of tumor onset was 
decreased dramatically by prenatal exposure to genistein and quercetin from an average of 18.6 months $(28,29)$ to only 3 months in our study.

Although the number of animals in which leukemia could actually be identified was low in our study, analysis of MII translocations established in offspring mice prenatally exposed to both flavonoids, suggested that the risk of developing cancer later in life for these animals was elevated.

\section{Flavonoids during pregnancy: Fetal programming}

Besides directly increasing cancer susceptibility, flavonoids are also thought to be involved in so-called 'fetal programming'. This concept defines an attempt of the fetus to adapt to adverse conditions encountered in utero, which results in adaptations that will be detrimental when these conditions will not prevail later in life (30). A clear example of fetal programming by genistein was given by Dolinoy et al. (31), as they showed that prenatal exposure of agouti mice to genistein resulted in a change in coat color, but it also protected the mouse from obesity later in life, which is distinctive for these mice. These effects were caused by epigenetic changes, namely hypermethylation of a repetitive element upstream of the transcription start site of the Agouti gene and the Agouti gene was silenced as a result of this hypermethylation. Formation of altered DNA methylation patterns in cells during fetal development by flavonoid intake may thus have long-lasting effects, because patterns can be transmitted to daughter cells after cell division

\section{Persistent changes in gene expression}

In Chapter 3, the effect of prenatal exposure to genistein on gene expression and global methylation of bone marrow cells of 12 week old male mice was investigated. Prenatal exposure to genistein resulted in a pronounced down-regulation of estrogen responsive genes and of genes involved in inhibiting hematopoiesis, consequently up-regulating erythropoiesis and granulopoiesis in these mice. The effect of genistein on estrogen responsive genes was to some extent expected as genistein has structural similarities with $17 \beta$-estradiol, exerting its effect through the estrogen receptor (18). In addition, the effect of genistein on hematopoiesis was also found by Zhou et al. (32) who pretreated mice with genistein for 7 days prior to whole-body irradiation, protecting them from death due to enhanced regeneration of hematopoietic stem cells. We hypothesize that the changes in gene expression were a result of epigenetic mechanisms, because hypermethylation of repetitive elements could be distinguished in the bone marrow cells of these animals.

\section{Oxidative stress related processes}

Since flavonoids are well known for their antioxidant properties (9) and they can cross the placenta to reach the developing fetus, we investigated whether prenatal exposure to genistein and quercetin could also have long-lasting effects on systems that contribute to the resistance to oxidative stress, which is involved in the onset of cancer (33). To this end, 
the antioxidant capacity of liver and lung tissue of adult male mice prenatally exposed to genistein or quercetin was assessed in Chapter 4. Quercetin exposure during pregnancy resulted in the up-regulation of genes involved in the enzymatic antioxidant defense system of the liver of fetuses at day 14.5 of gestation. Especially Nrf2, which functions as an important transcription factor responding to oxidative stress, showed increased gene expression levels during quercetin exposure. This indicated that despite quercetin's antioxidant property, it probably exerted pro-oxidant effects during in utero exposure. Prooxidant effects have previously also been ascribed to quercetin $(34,35)$. Genistein exposure on the contrary, had no effect on the enzymatic antioxidant defense system at this time point in gestation. This could be the result of a less pro-oxidant or even antioxidant effect of genistein. However, it has also been reported for genistein that in case of Nrf2 genistein impedes its nuclear export and degradation (36), making the up-regulation in gene expression unnecessary.

However, at adult age, mice prenatally exposed to either genistein or quercetin still had a differential expression of genes involved in the enzymatic antioxidant defense in their liver. This suggests that the adaptations made by the fetus in response to the in utero conditions by the increased supply of genistein or quercetin to the mother are maintained throughout life. We also investigated the effect of prenatal exposure to genistein or quercetin on the non-enzymatic antioxidant defense system and could only find an effect of prenatal exposure to genistein in the lung compared to control animals. Oxidative stress induced DNA damage, namely direct oxidizing of the DNA (8-0x0-dG levels) or indirect DNA damage induced by the lipid peroxidation product MDA $\left(\mathrm{M}_{1} \mathrm{dG}\right)$, was also assessed in the liver and lung of adult male mice prenatally exposed to quercetin or genistein. Prenatal exposure to genistein but especially to quercetin resulted in lower levels of oxidative stress induced DNA damage, however, only in the liver of these animals. As we mainly found changes in the gene expression of enzymatic antioxidants in the liver, it seems that the pre-emptive trigger of the enzymatic antioxidant defense system appeared to be beneficial and protective against oxidative DNA damage in the liver of adult mice prenatally exposed to genistein but especially to quercetin.

This effect was tissue specific as in the lung only modest effects of maternal flavonoid supplementation on gene expression of enzymatic antioxidants were observed and the non-enzymatic antioxidant defense system was only increased due to prenatal genistein exposure. Therefore the minor statistically non significant decrease in 8-oxo$d G$ levels and $M_{1} d G$ in the lung of male mice prenatally exposed to either genistein or quercetin was as expected.

This study showed that although genistein and quercetin are mainly known for their antioxidant properties, they probably functioned as pro-oxidants during gestation, as has been reported previously $(35,37-40)$, probably due to their accumulation in the fetus $(23$, 24), because antioxidant properties mainly occur at lower concentrations. This study also showed that genistein and quercetin did not exerted the same effects, with regard to longlasting changes in the enzymatic antioxidant defense system; quercetin was more effective than genistein. Though it had already been shown that exposure to genistein and quercetin during adult life protects against oxidative stress $(41,42)$, we have now shown that in utero exposure also results in protection at adulthood, but it remains to be established whether this beneficial effect outweighs the oxidative stress that is induced in utero. 
Iron chelating properties of quercetin as programming trigger

Quercetin is known to be a very potent iron chelator $(15,16)$. Therefore, the effect of prenatal quercetin exposure on iron homeostasis was assessed during fetal development and at adult age in Chapter 5. First, we investigated whether quercetin exposure in utero indeed resulted in iron chelation. However, at day 14.5 of gestation, no differences in the total amount of iron measured in amniotic fluid could be detected. Next, since the largest amount of iron is used for the production of hemoglobin $(43,44)$, gene expression of globin genes was assessed. At day 14.5 of gestation, fetuses are undergoing a switch from the embryonic hemoglobin, solely produced by primitive erythrocytes, to the adult hemoglobin, produced by primitive and definitive erythrocytes $(45,46)$. The main difference between both forms of hemoglobin is their affinity for oxygen. During early development, oxygen levels are low due to limited vascularisation to ensure proper organogenesis, because at this time point the fetus is the most vulnerable for oxidative stress, which could lead to damage or disruption of the fetus $(47,48)$. Nevertheless, the fetus needs to subtract oxygen from the maternal blood. Therefore, in the early phase of pregnancy the fetus produces embryonic hemoglobin as it has a higher affinity for oxygen compared to adult hemoglobin present in the maternal blood $(49,50)$. However, once the utero-placental circulation is well established (between day 9.5 and 11 of gestation) (47) a switch to the adult hemoglobin occurs due to the increase in oxygen concentration (45, $46,48)$. In addition, embryonic hemoglobin is less stable compared to adult hemoglobin (48) making it more prone to oxidation, resulting in the formation of methemoglobin, which is incapable of binding oxygen. Hence, embryonic hemoglobin also releases iron more easily from heme (51). As it has been shown that quercetin exposure results in the formation of methemoglobin by entering red blood cells (RBCs) and oxidizing the iron ion $(15,16)$, we expected to see an accelerated switch from the fetal to the adult hemoglobin in fetuses exposed to quercetin. Though the results were not significant, we did observe a trend in globin gene expression, namely the decrease in gene expression of embryonic globins in fetuses exposed to quercetin. However, the gene expression of adult globins remained unaltered while the switch from the primitive erythroid lineage towards the definitive erythroid lineage was accelerated due to increased quercetin intake by the mothers. This could indicate that, thought iron levels were not significantly lower quercetin did chelate the iron delivered by the mother, making the amount of iron available for hemoglobin production limited. Moreover, these data also suggested that quercetin chelated the iron from embryonic hemoglobin, which is less stable, accelerating the switch from embryonic to adult hemoglobin. However, the level of adult hemoglobin was not elevated as the globin production is dependent on iron availability (52), which we suspected to be low. However, the accelerated switch in hemoglobin production seems reasonable as the switch in erythroid lineage was also accelerated in these mice, and RBCs from the definitive lineage mainly produce adult hemoglobin.

The amount of iron stored in the liver of adult offspring was much higher in mice prenatally exposed to quercetin compared to control animals. We assume that exposure to quercetin resulted in lower levels of available iron in utero, to which the fetus adapted. Once born, fetuses were exposed to normal levels of iron, because the chelating activity of quercetin ceased. However, due to this fetal programming towards a life with lower levels of iron, these levels exceeded the levels they perceived as normal. Therefore, pathways 
were activated to cope with this "iron overload". Hence, we found an increased gene expression of several interleukins and hepcidin, all involved in iron storage normally seen with anemia of chronic disease also known as 'anemia of inflammation'. Interestingly, anemia is seen more frequently at advanced age and in people with cancer, where 'anemia of inflammation' accounts for $77 \%$ of the underlying causes of anemia (53). In addition, a decreased gene expression of Steap4, involved in the iron uptake by cells (54), was found in bone marrow cells of mice prenatally exposed to quercetin. We assumed that this measure was taken to protect the bone marrow from excess iron and subsequent DNA damage.

These data suggested that although mice were adapted to an in utero situation, with scarcity of iron due to quercetin chelation, they did cope with the increased iron availability later in life. M oreover, they even decreased the risk on iron induced ROS formation, as a decrease in 8-oxo-dG levels was found for the liver of these mice. However, as gene expression of inflammation related pathways were induced in the absence of an inflammatory trigger, one could expect that these mice could react differently if inflammation would be triggered. As inflammation is involved in many chronic diseases, including cancer (33), one can hypothesize that although these animals seemed to be protected against oxidative stress induced diseases, an inflammatory stressor could alter this protective mechanism towards a harmful one, but this needs confirmation.

\section{Quercetin as AhR agonist modifies xenobiotic metabolism}

AhR-signaling in the liver is of major importance in determining the capacity to metabolize certain well known carcinogens. It therefore determines an individual's risk to develop cancer after exposure to genotoxic compounds. We further elucidated the potential of quercetin exposure on carcinogen metabolism, more precisely on the metabolism of B[a]P (Chapter 6). B[a]P is know to be a potent mutagen and carcinogen when metabolically activated. This activation is performed by CYP1A1 and CYP1B1 (55, $56)$, which both have been shown to be modulated by quercetin. Moreover, quercetin can also modulate phase II enzymes (57-59). However, no straightforward effect of quercetin on phase I and II expression has been reported (56, 57, 60-62). Here, we showed that exposure to quercetin induced Cyplal and Cyplb1 gene expression in mice fetuses at day 14.5 of gestation. This increase could be due to the fact that CYPs are hemoproteins, containing heme-iron (63), which could be chelated by quercetin resulting in less CYP activity that needs to be compensated by an increase in gene expression. Another explanation is the fact that quercetin can increase the $17 \beta$-estradiol level, which is a known substrate for Cyp1b1 and Cypla1 (64). Moreover, AhR gene expression was not induced in these fetuses. However, as in the liver of developing mice the AhR mRNA and protein expression peaks between gestational day 14 and 16 (65), it may be that the effect of quercetin on AhR gene expression may not be visible at that time point. Furthermore, gene expression of Nqo1, Ugtla6 and Gstp1 was also induced in fetuses exposed to quercetin. We suspect that this is the result of the activation of the Nrf2-pathway as all three genes are target genes of the transcription factor Nrf2 (66, 67). Indeed, Nrf2 gene expression was up-regulated in these fetuses (Chapter 4).

At 12 weeks of age, mice prenatally exposed to quercetin still had an up-regulation in the expression of Cyp1b1 in their liver, while the up-regulation of the other genes was not maintained throughout life. Interesting to see was that in adult mice, AhR gene 
expression was increased, which could at least partly explain the increase in Cyp1b1 expression. We compared male and female littermates and found that female mice prenatally exposed to quercetin developed a more masculine profile regarding the phase I and II enzymes compared to control female mice. In rats it has also been shown that prenatal exposure to quercetin resulted in long-term alterations of CYP activity, predominantly in the female offspring. Here, the CYP profile of the female offspring also showed to be more masculine compared to control females. It was suggested that quercetin exerted these effects by regulating constitutive androstene receptor or Ah receptor (58). Indeed, AhR gene expression was slightly increased in female mice prenatally exposed to quercetin.

Gene expression of phase I and II enzymes demonstrated a different profile in the lung of 12 week old mice prenatally exposed to quercetin. Here phase II enzymes (Gstp1, $\mathrm{NqO1}$ and Ugt1a6) were mainly induced. The difference in tissue response to prenatal quercetin exposure could be due to the fact that the lung develops mainly in the final stages of pregnancy and even continues to develop after birth (68), while the liver is largely differentiated before birth (69). Hence, less gender effects were noticeable in the lung, which is in line with the fact that lung is not a main organ involved in estrogen metabolism. However, in fetuses at gestational day 14.5, increased gene expression of Nqol and Ugtla6 was detected and was suggested to be the result of the activation of the Nrf2-pathway, as quercetin can also function as pro-oxidant (Chapter 4). As the lung is directly exposed to oxygen concentrations higher than in most tissues (33), a preemptive oxidative stress trigger in utero could result in the up-regulation of the Nrf2pathway and therefore of phase II enzymes. However, as mentioned above, Nrf2pathway was probably only modestly induced in the lung of these mice (Chapter 4).

Although prenatal exposure to quercetin resulted in an increased expression of phase I and $I I$ enzymes in liver and lung, differences in ex vivo B[a]P metabolism were only found in the lung of mice prenatally exposed to quercetin as they showed a decrease in the amount of B[a]P-9,10-dihydrodiol and B[a]P-7,8-dihydrodiol. Moreover, mice prenatally exposed to quercetin showed an increase in $\mathrm{B}[\mathrm{a}] \mathrm{P}$ metabolism. However, due to the high detoxification of B[a]P towards 3-hydroxy-B[a]P in all diet groups, no BPDEinduced DNA-adducts could be detected. However, as the lung is the primary target organ for airborne $\mathrm{B}[\mathrm{a}] \mathrm{P}$ the increased $\mathrm{B}[\mathrm{a}] \mathrm{P}$ metabolism and phase II gene expression suggests that prenatal exposure to quercetin could decrease the susceptibility to develop lung cancer in vivo.

Surprisingly, in case of the liver the ex vivo induction of BPDE DNA-adducts was decreased for mice prenatally exposed to quercetin, although they did not show a change in the rate of $B[a] P$ metabolism or a changed profile of the 3 major $B[a] P$ metabolites, including the 7,8-dihydrodiol of $B[a] P$ which is thought to be the precursor of the ultimate genotoxic metabolite, BPDE. This suggests that prenatal exposure to quercetin results in the protection from $B[a] P$ induced DNA damage in the liver, we suspect due to up-regulation of phase I enzymes. Although CYP1A1 and CYP1B1 are mainly thought to be important for metabolic activation of $\mathrm{B}[\mathrm{a}] \mathrm{P}$, we suspect that they also contributed to the detoxification of $\mathrm{B}[\mathrm{a}] \mathrm{P}$, as previously also has been suggested by Uno et al. (70). 


\section{Fetal programming is regulated via epigenetics}

The changes in gene expression discussed in Chapter 3-6, as a result of in utero exposure to genistein or quercetin, are maintained throughout life. We therefore expected epigenetic mechanisms to be involved. Therefore, the induction of changes in methylation status of repetitive elements due to prenatal exposure to genistein or quercetin was investigated, as the mouse genome constitutes almost for $37.5 \%$ out of these repetitive elements (71). Results showed that that both flavonoids did not induce changes in global methylation (namely, methylation of SINEB1, SINEB2, LINE1, IAP, Major and Minor satellites) in the liver of fetuses at gestational day 14.5 (Chapter 3, 5, 6). However, when investigating methylation patterns in the bone marrow of 12 week old mice, an overall increase in methylation could be distinguished and this especially for SINEB1 and SINEB2 (Chapter 3, 5). Moreover, in liver and lung tissue of 12 week old mice prenatally exposed to genistein or quercetin mild hypomethylation of the repetitive elements SINEB1, SINEB2, and LINE1 occurred (Chapter 6). The fact that no changes in methylation could be distinguished in fetuses at day 14.5 of gestation could suggest that de novo methylation induced by flavonoids took place at a later time point in gestation or even after birth. This is plausible as during the late gestational and early postnatal period, tissue maturation can result in epigenetic modifications. Moreover, it has been suggested that transcriptional inactivity attracts de novo methylation while transcriptional activity can override DNA methylation, inducing developmental hypomethylation (72). Besides, the level of exposure to genistein and quercetin only increases throughout gestation, enhancing their effects.

Prenatal exposure to genistein has previously been shown to alter gene expression by affecting methylation patterns, namely prenatal exposure of yellow agouti mice altered coat color and body weight of agouti mice by inducing hypermethylation of transposable repetitive elements upstream of the transcription start site of the Agouti gene (31). Hence, both genistein and quercetin have been shown to inhibit DNA methyltransferases, inducing hypomethylation, namely of hypermethylated tumor suppressor genes, to which their anticancer effects are ascribed $(73,74)$. However, prenatal exposure to flavonoids resulted in a tissue dependent effect on methylation, namely hypermethylation in case of the bone marrow and hypomethylation in case of liver and lung tissue, especially of SINE transcripts. During early embryogenesis SINE and LINE repetitive elements are normally expressed, after which their expression rapidly decreases with development. Therefore, SINEB1, SINEB2 and LINE1 expression later in life is associated with cell stress, for instance induced by DNA-damaging agents $(75,76)$, which we have shown in Chapter 2 quercetin and genistein are capable of due to their topoll inhibiting properties. As SINE and LINE expression are also associated with cancer $(75,76)$, this could suggest that an in utero flavonoid trigger can result in an increased silencing of SINEB1, SINEB2 and LINE1 to protect the genome from any future genomic instability. 


\section{Implications and future research}

As this is only the beginning of understanding how maternal intake of genistein and quercetin can affect offspring's risk on developing cancer later in life, further elaborate studies need to be performed:

- Concerning the epigenetic mechanisms behind the genistein and quercetin induced fetal programming. Moreover, the critical window of exposure should be assessed.

- Although genistein and quercetin both are flavonoids, they exert different effects. Therefore their specific actions should be further elucidated.

- At 12 weeks of age it seemed that prenatal exposure to genistein and quercetin overall had beneficial effects regarding cancer susceptibility. However, as these mice are relatively young, the true contribution of the adaptations made by the fetus regarding genistein and quercetin exposure in utero will not be visible at this age and additional studies should thus include aging mice. Moreover, the effects of fetal programming should also be investigated at a later time point in life, when these mice normally are subjected to adult chronic diseases. These chronic diseases could also be induced by for instance pro-inflammatory triggers.

- It would also be interesting to investigate what the effects of life-long exposure to both flavonoids would be regarding the cancer susceptibility.

- It would also be valuable to study the effects of prenatal exposure to genistein or quercetin on following generations. However, to examine the true transgenerational inheritance, the third generation, the first unexposed generation, needs to be examined, as the first generation is directly exposed to genistein or quercetin and the second generation results from gametes that are exposed to genistein or quercetin (Figure 1).

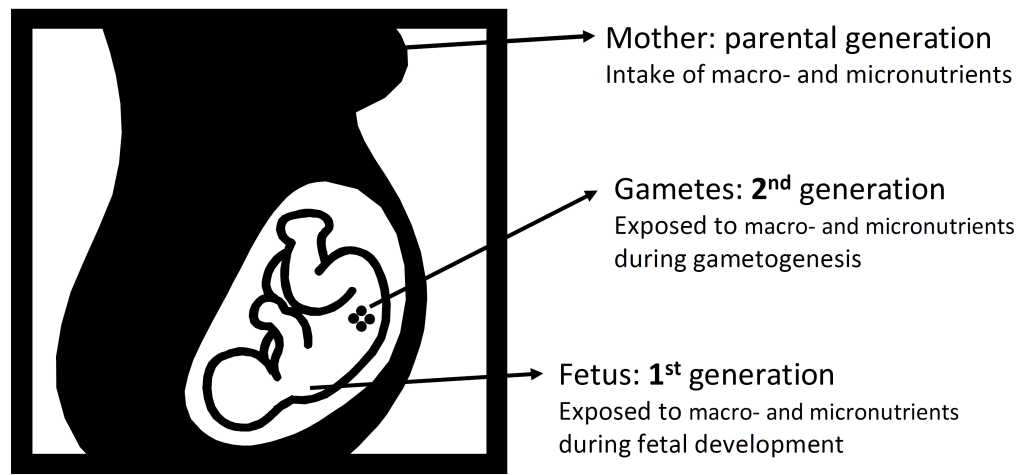

Figure 1. Overview of transgenerational inheritance of effects induced by genistein or quercetin exposure.

When summarizing the results as described in this thesis it can be concluded that prenatal exposure to quercetin and genistein resulted in altered fetal programming as compared to a non-supplemented diet during pregnancy. During gestation, when fetuses are directly exposed to both flavonoids, changes in expression of genes involved in antioxidant defense and carcinogen metabolism occurred, suggesting that these fetuses adapted to 
the in utero environment. However, once born genistein and quercetin exposure ceased, but some changes in gene expression were maintained until adult life, while others were gained throughout life, showing that the offspring was trying to cope with its new 'unexpected' environment.

At the age of 12 weeks, prenatal exposure to genistein and quercetin seemed to be beneficial as these mice showed to have less oxidative stress induced DNA damage as a result of increased enzymatic antioxidant defense system and more efficient iron storage. It also seemed that they could better cope with B[a]P induced DNA-damage due to the upregulation of phase I and II enzymes. Moreover, the increased methylation in certain repetitive elements suggested that these animals were more protected from genomic instability, overall suggesting they were less susceptible to develop cancer. On the other hand, prenatal exposure to genistein and quercetin induced $M$ II translocations, increasing the risk on leukemia especially in mice with an impaired DNA repair. Additionally, some inflammatory cytokines were increased in their basal expression, which could affect the inflammatory response.

A general overview of the effects of prenatal genistein and quercetin exposure on the offspring's risk to develop cancer is depicted in Figure 2.

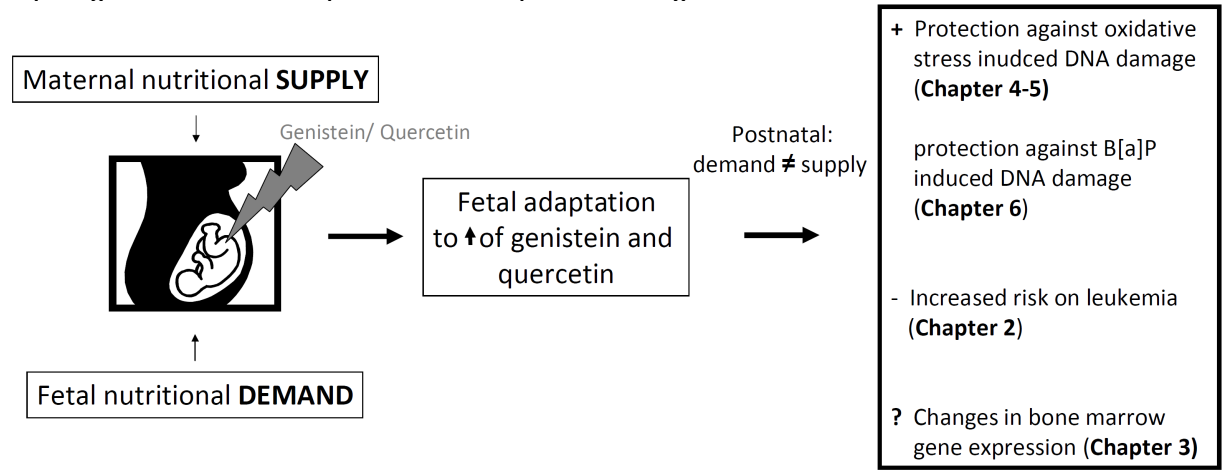

Figure 2. General overview of the effects of prenatal exposure to genistein or quercetin on the offspring's cancer risk discussed in this thesis 


\section{References}

1. Darnton-Hill, I., Nishida, C., and James, W. P. (2004) A life course approach to diet, nutrition and the prevention of chronic diseases. Public Health Nutr 7, 101-121

2. Khan, T. H., Jahangir, T., Prasad, L., and Sultana, S. (2006) Inhibitory effect of apigenin on benzo(a)pyrenemediated genotoxicity in Swiss albino mice.J Pharm Pharmacol 58, 1655-1660

3. Muhammad, S., Bierhaus, A., and Schwaninger, M. (2009) Reactive oxygen species in diabetes-induced vascular damage, stroke, and Alzheimer's disease. J Alzheimers Dis 16, 775-785

4. Tabner, B. J., Turnbull, S., El-Agnaf, O., and Allsop, D. (2001) Production of reactive oxygen species from aggregating proteins implicated in Alzheimer's disease, Parkinson's disease and other neurodegenerative diseases. Curr Top M ed Chem 1, 507-517

5. Touyz, R. M. (2004) Reactive oxygen species and angiotensin II signaling in vascular cells -- implications in cardiovascular disease. Braz J Med Biol Res 37, 1263-1273

6. Weinberg, F., and Chandel, N. S. (2009) Reactive oxygen species-dependent signaling regulates cancer. Cell Mol Life Sci 66, 3663-3673

7. Arts, I. C., and Hollman, P. C. (2005) Polyphenols and disease risk in epidemiologic studies. Am J Clin Nutr 81, 317S-325S

8. Hollman, P. C., and Katan, M. B. (1999) Dietary flavonoids: intake, health effects and bioavailability. Food Chem Toxicol 37, 937-942

9. Ross, J. A., and Kasum, C. M. (2002) Dietary flavonoids: bioavailability, metabolic effects, and safety. Annu Rev Nutr 22, 19-34

10. Yao, L. H., Jiang, Y. M., Shi, J., Tomas-Barberan, F. A., Datta, N., Singanusong, R., and Chen, S. S. (2004) Flavonoids in food and their health benefits. Plant Foods Hum Nutr 59, 113-122

11. Erdman, J. W., Jr., Balentine, D., Arab, L., Beecher, G., Dwyer, J. T., Folts, J., Harnly, J., Hollman, P., Keen, C. L., M azza, G., M essina, M., Scalbert, A., Vita, J., Williamson, G., and Burrowes, J. (2007) Flavonoids and heart health: proceedings of the ILSI North America Flavonoids Workshop, May 31-June 1, 2005, Washington, DC.J Nutr 137, 718S-737S

12. Aherne, S. A., and O'Brien, N. M. (2002) Dietary flavonols: chemistry, food content, and metabolism. Nutrition 18, 75-81

13. Diplock, A. T., Charleux, J. L., Crozier-Willi, G., Kok, F. J., Rice-Evans, C., Roberfroid, M., Stahl, W., and VinaRibes, J. (1998) Functional food science and defence against reactive oxidative species. Br J Nutr 80 Suppl 1, S77-112

14. Skibola, C. F., and Smith, M. T. (2000) Potential health impacts of excessive flavonoid intake. Free Radic Biol Med 29, 375-383

15. Ferrali, M., Signorini, C., Caciotti, B., Sugherini, L., Ciccoli, L., Giachetti, D., and Comporti, M. (1997) Protection against oxidative damage of erythrocyte membrane by the flavonoid quercetin and its relation to iron chelating activity. FEBS Lett 416, 123-129

16. Kitagawa, S., Sakamoto, H., and Tano, H. (2004) Inhibitory effects of flavonoids on free radical-induced hemolysis and their oxidative effects on hemoglobin. Chem Pharm Bull (Tokyo) 52, 999-1001

17. Marik, R., Allu, M., Anchoori, R., Stearns, V., Umbricht, C. B., and Khan, S. (2011) Potent genistein derivatives as inhibitors of estrogen receptor alpha-positive breast cancer. Cancer Biol Ther $\mathbf{1 1}$

18. Miodini, P., Fioravanti, L., Di Fronzo, G., and Cappelletti, V. (1999) The two phyto-oestrogens genistein and quercetin exert different effects on oestrogen receptor function. Br J Cancer 80, 1150-1155

19. Espin, J. C., Garcia-Conesa, M. T., and Tomas-Barberan, F. A. (2007) Nutraceuticals: facts and fiction. Phytochemistry 68, 2986-3008

20. Harwood, M., Danielewska-Nikiel, B., Borzelleca, J. F., Flamm, G. W., Williams, G. M., and Lines, T. C. (2007) A critical review of the data related to the safety of quercetin and lack of evidence of in vivo toxicity, including lack of genotoxic/carcinogenic properties. Food Chem Toxicol 45, 2179-2205

21. Sullivan, K. M., Ford, E. S., Azrak, M. F., and Mokdad, A. H. (2009) Multivitamin use in pregnant and nonpregnant women: results from the Behavioral Risk Factor Surveillance System. Public Health Rep 124, 384-390

22. Baggott, J. E., Oster, R. A., and Tamura, T. (2011) M eta-analysis of cancer risk in folic acid supplementation trials. Cancer Epidemiol

23. Bonacasa, B., Siow, R. C., and Mann, G. E. (2011) Impact of dietary soy isoflavones in pregnancy on fetal programming of endothelial function in offspring. Microcirculation 18, 270-285

24. Schroder-van der Elst, J. P., van der Heide, D., Rokos, H., Morreale de Escobar, G., and Kohrle, J. (1998) Synthetic flavonoids cross the placenta in the rat and are found in fetal brain. Am J Physiol 274, E253-256 
25. Ross, J. A., Potter, J. D., Reaman, G. H., Pendergrass, T. W., and Robison, L. L. (1996) Maternal exposure to potential inhibitors of DNA topoisomerase II and infant leukemia (United States): a report from the Children's Cancer Group. Cancer Causes Control 7, 581-590

26. Spector, L. G., Xie, Y., Robison, L. L., Heerema, N. A., Hilden, J. M., Lange, B., Felix, C. A., Davies, S. M., Slavin, J., Potter, J. D., Blair, C. K., Reaman, G. H., and Ross, J. A. (2005) Maternal diet and infant leukemia: the DNA topoisomerase II inhibitor hypothesis: a report from the children's oncology group. Cancer Epidemiol Biomarkers Prev 14, 651-655

27. Barjesteh van Waalwijk van Doorn-Khosrovani, S., Janssen, J., M aas, L. M., Godschalk, R. W., Nijhuis, J. G., and van Schooten, F. J. (2007) Dietary flavonoids induce M LL translocations in primary human CD34+cells. Carcinogenesis 28, 1703-1709

28. Spring, K., Cross, S., Li, C., Watters, D., Ben-Senior, L., Waring, P., Ahangari, F., Lu, S. L., Chen, P., Misko, I., Paterson, C., Kay, G., Smorodinsky, N. I., Shiloh, Y., and Lavin, M. F. (2001) Atm knock-in mice harboring an in-frame deletion corresponding to the human ATM 7636del9 common mutation exhibit a variant phenotype. Cancer Res 61, 4561-4568

29. Spring, K., Ahangari, F., Scott, S. P., Waring, P., Purdie, D. M., Chen, P. C., Hourigan, K., Ramsay, J., McKinnon, P. J., Swift, M., and Lavin, M. F. (2002) Mice heterozygous for mutation in Atm, the gene involved in ataxia-telangiectasia, have heightened susceptibility to cancer. Nat Genet 32, 185-190

30. Barker, D. J., and Clark, P. M . (1997) Fetal undernutrition and disease in later life. Rev Reprod 2, 105-112

31. Dolinoy, D. C., Weidman, J. R., Waterland, R. A., and Jirtle, R. L. (2006) Maternal genistein alters coat color and protects Avy mouse offspring from obesity by modifying the fetal epigenome. Environ Health Perspect $114,567-572$

32. Zhou, Y., and Mi, M. T. (2005) Genistein stimulates hematopoiesis and increases survival in irradiated mice. J Radiat Res (Tokyo) 46, 425-433

33. Reuter, S., Gupta, S. C., Chaturvedi, M. M., and Aggarwal, B. B. (2010) Oxidative stress, inflammation, and cancer: how are they linked? Free Radic Biol Med 49, 1603-1616

34. Boots, A. W., Li, H., Schins, R. P., Duffin, R., Heemskerk, J. W., Bast, A., and Haenen, G. R. (2007) The quercetin paradox. Toxicol Appl Pharmacol 222, 89-96

35. Choi, E. J., Chee, K. M., and Lee, B. H. (2003) Anti- and prooxidant effects of chronic quercetin administration in rats. Eur J Pharmacol 482, 281-285

36. Kaspar, J. W., and Jaiswal, A. K. (2011) Tyrosine phosphorylation controls nuclear export of Fyn, allowing Nrf2 activation of cytoprotective gene expression. FASEB J 25, 1076-1087

37. Cao, G., Sofic, E., and Prior, R. L. (1997) Antioxidant and prooxidant behavior of flavonoids: structure-activity relationships. Free Radic Biol Med 22, 749-760

38. Galati, G., Sabzevari, O., Wilson, J. X., and O'Brien, P. J. (2002) Prooxidant activity and cellular effects of the phenoxyl radicals of dietary flavonoids and other polyphenolics. Toxicology 177, 91-104

39. Ullah, M. F., Shamim, U., Hanif, S., Azmi, A. S., and Hadi, S. M. (2009) Cellular DNA breakage by soy isoflavone genistein and its methylated structural analogue biochanin A. M ol Nutr Food Res 53, 1376-1385

40. Vargas, A. J., and Burd, R. (2010) Hormesis and synergy: pathways and mechanisms of quercetin in cancer prevention and management. Nutr Rev 68, 418-428

41. Boots, A. W., Drent, M., de Boer, V. C., Bast, A., and Haenen, G. R. (2011) Quercetin reduces markers of oxidative stress and inflammation in sarcoidosis. Clin Nutr 30, 506-512

42. Siow, R. C., and Mann, G. E. (2010) Dietary isoflavones and vascular protection: activation of cellular antioxidant defenses by SERM s or hormesis? M ol Aspects M ed 31, 468-477

43. Munoz, M., Villar, I., and Garcia-Erce, J. A. (2009) An update on iron physiology. World J Gastroenterol 15, 4617-4626

44. Zhang, A. S., and Enns, C. A. (2009) Molecular mechanisms of normal iron homeostasis. Hematology Am Soc Hematol Educ Program, 207-214

45. Kingsley, P. D., Malik, J., Emerson, R. L., Bushnell, T. P., M cGrath, K. E., Bloedorn, L. A., Bulger, M., and Palis, J. (2006) "M aturational" globin switching in primary primitive erythroid cells. Blood 107, 1665-1672

46. Palis, J. (2008) Ontogeny of erythropoiesis. Curr Opin Hematol 15, 155-161

47. Dennery, P. A. (2007) Effects of oxidative stress on embryonic development. Birth Defects Res C Embryo Today 81, 155-162

48. Jauniaux, E., Gulbis, B., and Burton, G. J. (2003) The human first trimester gestational sac limits rather than facilitates oxygen transfer to the foetus--a review. Placenta $\mathbf{2 4}$ Suppl A, S86-93

49. Amoyal, I., and Fibach, E. (2007) Hemoglobin switch in the newborn: a flow cytometry analysis. Neonatology 91, 61-68

50. Purdie, A., Wells, R. M., and Brittain, T. (1983) Molecular aspects of embryonic mouse haemoglobin ontogeny. Biochem J 215, 377-383 
51. Comporti, M., Signorini, C., Buonocore, G., and Ciccoli, L. (2002) Iron release, oxidative stress and erythrocyte ageing. Free Radic Biol Med 32, 568-576

52. Koury, M. J., and Ponka, P. (2004) New insights into erythropoiesis: the roles of folate, vitamin B12, and iron. Annu Rev Nutr 24, 105-131

53. Weiss, G. (2009) Iron metabolism in the anemia of chronic disease. Biochim Biophys Acta 1790, 682-693

54. Ohgami, R. S., Campagna, D. R., McDonald, A., and Fleming, M. D. (2006) The Steap proteins are metalloreductases. Blood 108, 1388-1394

55. Alexandrov, K., Rojas, M., and Satarug, S. (2010) The critical DNA damage by benzo(a)pyrene in lung tissues of smokers and approaches to preventing its formation. Toxicol Lett 198, 63-68

56. Delgado, M. E., Haza, A. I., Arranz, N., Garcia, A., and Morales, P. (2008) Dietary polyphenols protect against $\mathrm{N}$-nitrosamines and benzo(a)pyrene-induced DNA damage (strand breaks and oxidized purines/ pyrimidines) in HepG2 human hepatoma cells. Eur J Nutr 47, 479-490

57. Ciolino, H. P., Daschner, P. J., and Yeh, G. C. (1999) Dietary flavonols quercetin and kaempferol are ligands of the aryl hydrocarbon receptor that affect CYP1A1 transcription differentially. Biochem J 340 ( Pt 3), 715722

58. Makaji, E., Ho, S. H., Holloway, A. C., and Crankshaw, D. J. (2011) Effects in rats of maternal exposure to raspberry leaf and its constituents on the activity of cytochrome p450 enzymes in the offspring. Int J Toxicol 30, 216-224

59. Moon, Y. J., Wang, X., and Morris, M. E. (2006) Dietary flavonoids: effects on xenobiotic and carcinogen metabolism. Toxicol In Vitro 20, 187-210

60. Kang, Z. C., Tsai, S. J., and Lee, H. (1999) Quercetin inhibits benzo[a]pyrene-induced DNA adducts in human Hep G2 cells by altering cytochrome P-450 1A1 gene expression. Nutr Cancer 35, 175-179

61. Sergent, T., Dupont, I., Van der Heiden, E., Scippo, M. L., Pussemier, L., Larondelle, Y., and Schneider, Y. J. (2009) CYP1A1 and CYP3A4 modulation by dietary flavonoids in human intestinal Caco-2 cells. Toxicol Lett $191,216-222$

62. Walle, T., and Walle, U. K. (2007) Novel methoxylated flavone inhibitors of cytochrome P450 1B1 in SCC-9 human oral cancer cells. J Pharm Pharmacol 59, 857-862

63. Nelson, D. R., Koymans, L., Kamataki, T., Stegeman, J. J., Feyereisen, R., Waxman, D. J., Waterman, M. R., Gotoh, O., Coon, M. J., Estabrook, R. W., Gunsalus, I. C., and Nebert, D. W. (1996) P450 superfamily: update on new sequences, gene mapping, accession numbers and nomenclature. Pharmacogenetics 6, 1-42

64. Santini, S. E., Basini, G., Bussolati, S., and Grasselli, F. (2009) The phytoestrogen quercetin impairs steroidogenesis and angiogenesis in swine granulosa cells in vitro. J Biomed Biotechnol 2009, 419891

65. Abbott, B. D., Birnbaum, L. S., and Perdew, G. H. (1995) Developmental expression of two members of a new class of transcription factors: I. Expression of aryl hydrocarbon receptor in the C57BL/6N mouse embryo. Dev Dyn 204, 133-143

66. Kohle, C., and Bock, K. W. (2007) Coordinate regulation of Phase I and II xenobiotic metabolisms by the Ah receptor and Nrf2. Biochem Pharmacol 73, 1853-1862

67. Niestroy, J., Barbara, A., Herbst, K., Rode, S., van Liempt, M., and Roos, P. H. (2011) Single and concerted effects of benzo[a]pyrene and flavonoids on the AhR and Nrf2-pathway in the human colon carcinoma cell line Caco-2. Toxicol In Vitro 25, 671-683

68. Ten Have-Opbroek, A. A. (1991) Lung development in the mouse embryo. Exp Lung Res 17, 111-130

69. Zaret, K. S. (2002) Regulatory phases of early liver development: paradigms of organogenesis. Nat Rev Genet 3, 499-512

70. Uno, S., Dalton, T. P., Dragin, N., Curran, C. P., Derkenne, S., Miller, M. L., Shertzer, H. G., Gonzalez, F. J., and Nebert, D. W. (2006) Oral benzo[a]pyrene in Cyp1 knockout mouse lines: CYP1A1 important in detoxication, CYP1B1 metabolism required for immune damage independent of total-body burden and clearance rate. Mol Pharmacol 69, 1103-1114

71. Waterston, R. H., Lindblad-Toh, K., Birney, E., Rogers, J., Abril, J. F., Agarwal, P., Agarwala, R., Ainscough, R., Alexandersson, M., An, P., Antonarakis, S. E., Attwood, J., Baertsch, R., Bailey, J., Barlow, K., Beck, S., Berry, E., Birren, B., Bloom, T., Bork, P., Botcherby, M., Bray, N., Brent, M. R., Brown, D. G., Brown, S. D., Bult, C., Burton, J., Butler, J., Campbell, R. D., Carninci, P., Cawley, S., Chiaromonte, F., Chinwalla, A. T., Church, D. M., Clamp, M., Clee, C., Collins, F. S., Cook, L. L., Copley, R. R., Coulson, A., Couronne, O., Cuff, J., Curwen, V., Cutts, T., Daly, M., David, R., Davies, J., Delehaunty, K. D., Deri, J., Dermitzakis, E. T., Dewey, C., Dickens, N. J., Diekhans, M., Dodge, S., Dubchak, I., Dunn, D. M., Eddy, S. R., Elnitski, L., Emes, R. D., Eswara, P., Eyras, E., Felsenfeld, A., Fewell, G. A., Flicek, P., Foley, K., Frankel, W. N., Fulton, L. A., Fulton, R. S., Furey, T. S., Gage, D., Gibbs, R. A., Glusman, G., Gnerre, S., Goldman, N., Goodstadt, L., Grafham, D., Graves, T. A., Green, E. D., Gregory, S., Guigo, R., Guyer, M., Hardison, R. C., Haussler, D., Hayashizaki, Y., Hillier, L. W., Hinrichs, A., Hlavina, W., Holzer, T., Hsu, F., Hua, A., Hubbard, T., Hunt, A., Jackson, I., Jaffe, D. B., Johnson, 
L. S., Jones, M., Jones, T. A., Joy, A., Kamal, M., Karlsson, E. K., Karolchik, D., Kasprzyk, A., Kawai, J., Keibler, E., Kells, C., Kent, W. J., Kirby, A., Kolbe, D. L., Korf, I., Kucherlapati, R. S., Kulbokas, E. J., Kulp, D., Landers, T., Leger, J. P., Leonard, S., Letunic, I., Levine, R., Li, J., Li, M., Lloyd, C., Lucas, S., Ma, B., Maglott, D. R., Mardis, E. R., Matthews, L., Mauceli, E., Mayer, J. H., McCarthy, M., McCombie, W. R., M LLaren, S., M cLay, K., McPherson, J. D., Meldrim, J., Meredith, B., Mesirov, J. P., Miller, W., Miner, T. L., M ongin, E., Montgomery, K. T., M organ, M., M ott, R., Mullikin, J. C., M uzny, D. M., Nash, W. E., Nelson, J. O., Nhan, M. N., Nicol, R., Ning, Z, Nusbaum, C., O'Connor, M. J., Okazaki, Y., Oliver, K., Overton-Larty, E., Pachter, L., Parra, G., Pepin, K. H., Peterson, J., Pevzner, P., Plumb, R., Pohl, C. S., Poliakov, A., Ponce, T. C., Ponting, C. P., Potter, S., Quail, M., Reymond, A., Roe, B. A., Roskin, K. M., Rubin, E. M., Rust, A. G., Santos, R., Sapojnikov, V., Schultz, B., Schultz, J., Schwartz, M. S., Schwartz, S., Scott, C., Seaman, S., Searle, S., Sharpe, T., Sheridan, A., Shownkeen, R., Sims, S., Singer, J. B., Slater, G., Smit, A., Smith, D. R., Spencer, B., Stabenau, A., Stange-Thomann, N., Sugnet, C., Suyama, M., Tesler, G., Thompson, J., Torrents, D., Trevaskis, E., Tromp, J., Ucla, C., Ureta-Vidal, A., Vinson, J. P., Von Niederhausern, A. C., Wade, C. M., Wall, M., Weber, R. J., Weiss, R. B., Wendl, M. C., West, A. P., Wetterstrand, K., Wheeler, R., Whelan, S., Wierzbowski, J., Willey, D., Williams, S., Wilson, R. K., Winter, E., Worley, K. C., Wyman, D., Yang, S., Yang, S. P., Zdobnov, E. M., Zody, M. C., and Lander, E. S. (2002) Initial sequencing and comparative analysis of the mouse genome. Nature 420, 520-562

72. Waterland, R. A., Kellermayer, R., Rached, M. T., Tatevian, N., Gomes, M. V., Zhang, J., Zhang, L., Chakravarty, A., Zhu, W., Laritsky, E., Zhang, W., Wang, X., and Shen, L. (2009) Epigenomic profiling indicates a role for DNA methylation in early postnatal liver development. Hum M ol Genet 18, 3026-3038

73. Duthie, S. J. (2011) Epigenetic modifications and human pathologies: cancer and CVD. Proc Nutr Soc 70, 4756

74. Li, Y., and Tollefsbol, T. O. (2010) Impact on DNA methylation in cancer prevention and therapy by bioactive dietary components. Curr M ed Chem 17, 2141-2151

75. Kramerov, D. A., and Vassetzky, N. S. (2005) Short retroposons in eukaryotic genomes. Int Rev Cytol 247, $165-221$

76. Stribinskis, V., and Ramos, K. S. (2006) Activation of human long interspersed nuclear element 1 retrotransposition by benzo(a)pyrene, an ubiquitous environmental carcinogen. Cancer Res 66, 2616-2620 
Nederlandse samenvatting 
Chronische ziektes die op volwassen leeftijd optreden, zoals kanker, cardiovasculaire en respiratoire aandoeningen zijn een grote last voor de gezondheid van de mens wereldwijd (1). Blootstelling aan genotoxische en mutagene stoffen lijkt een belangrijke rol te spelen in de ontwikkeling van dit soort ziektes (2-6). Van gezonde voeding wordt vermoed dat ze beschermen tegen deze genotoxische en mutagene stoffen en zo ook bescherming bieden tegen chronische ziektes en de gezondheid te bevorderen. Een voedingscomponent dat veel aandacht krijgt in verband met de behandeling en preventie van chronische ziektes zijn de flavonoïden (7-10). Flavonoïden bestaan uit een grote groep polyfenolen die wijdverspreid voorkomen in onze voeding (9), waardoor de gemiddelde inname varieert tussen 65 en $250 \mathrm{mg}$ flavonoïden per dag (11). Quercetine is de meest voorkomende flavonoïd in ons dieet en wordt teruggevonden in uien, appels, thee en rode wijn $(9,12-14)$. Het is een zeer krachtige radicaalvanger en kan ook ijzer cheleren $(15,16)$. Genisteïne is ook een belangrijk flavonoïd dat voornamelijk wordt teruggevonden in sojabonen. Naast een antioxidant werking heeft het ook oestrogeen agonistische/ antagonistische werkingen, afhankelijk van de situatie, als gevolg van structurele overeenkomsten met $17 \beta$-oestradiol $(17,18)$.

Aangezien flavonoïden momenteel geacht worden voordeling te zijn voor de gezondheid, zijn ze vrij verkrijgbaar als voedingssupplementen en dit in hoge dosissen, met een aangeraden dagelijkse dosis tussen 1-2 gram $(19,20)$. Zorgwekkend is de toename in supplement inname door zwangere vrouwen. In de VS nemen $78 \%$ van de zwangere vrouwen voedingssupplementen (21), waaronder foliumzuur. Nochtans verhoogt de inname van foliumzuur het risico op kanker bij volwassenen (22). Er is echter weinig bekend over de biologische werking van flavonoïden tijdens de zwangerschap en over de kort en/ of lange termijn effecten die ze kunnen hebben op de gezondheid van het kind. Aangezien flavonoïden de placenta kunnen doorkruisen om zo te accumuleren in de foetus $(23,24)$, is het nodig onderzoek te verrichten naar de veiligheid van verhoogde flavonoïd inname tijdens de zwangerschap.

\section{Flavonoïden tijdens de zwangerschap: Kinderleukemie}

Een verhoogde flavonoïd inname wordt ook in verband gebracht met het ontstaan van kinderleukemie, omdat ze topoïsomerase II kunnen remmen $(25,26)$ en zo dubbelstrengsbreuken in DNA en herschikkingen van het mixed-lineage leukemia (MLL) gen kunnen induceren, wat veel voorkomt bij kinderleukemie $(26,27)$. In Hoofdstuk 2 werden Atm- $\Delta$ SRI heterozygote muizen gepaard om nakomelingen te verkrijgen met een verschillende genetische mogelijkheid om DNA schade te herstellen, namelijk Atm wildtype, Atm- $\Delta$ SRI heterozygote en Atm- $\Delta$ SRI mutante nakomelingen. Wij konden vaststellen dat prenatale blootstelling aan flavonoïden inderdaad $\mathrm{M} \| \mathrm{I}$ translocaties in het beenmerg van zowel wild-type als Atm- $\Delta$ SRI mutante muizen veroorzaakte. Bovendien waren Atm$\Delta$ SRI mutante muizen gevoeliger voor het ontwikkelen van deze chromosomale afwijkingen. Ook werd aangetoond dat muizen met een slecht werkend DNA herstelmechanisme een verhoogd risico hadden op het ontwikkelen van andere aandoeningen buiten kinderleukemie, wanneer ze prenataal blootgesteld waren aan genisteïne. Dit geeft aan dat het DNA dubbelstrengsbreuk herstelmechanisme van belang is voor het behoud van de integriteit van het genoom in de ontwikkelende foetus. 
De Atm- $\Delta$ SRI mutatie komt overeen met een van de meest voorkomende Atm mutaties teruggevonden in de mens. Atm- $\Delta$ SRI muizen hebben ook een fenotype dat verschilt van Atm knock-out muizen. Atm- $\Delta$ SRI mutant muizen hebben $50 \%$ kans op het ontwikkelen van leukemie en lymfoma, zonder bijkomende blootstellingen (28). In onze studie lag de leeftijd waarop deze muizen tumoren ontwikkelden dramatisch lager wanneer ze prenataal blootgesteld waren aan genisteïne en quercetine, namelijk van een gemiddelde leeftijd van 18,6 maanden $(28,29)$ naar slechts 3 maanden.

Ondanks dat het aantal dieren waarin leukemie vastgesteld kon worden tamelijk laag was in onze studie, toonden de MII translocatie analyse wel aan dat muizen die prenataal blootgesteld waren aan een van beide flavonoïden een verhoogd risico liepen op het krijgen van kanker op latere leeftijd.

\section{Flavonoïden tijdens de zwangerschap: Foetale programmering}

Naast het direct verhogen van de gevoeligheid voor het ontwikkelen van kanker wordt van flavonoïden ook vermoed dat ze betrokken zijn bij 'foetale programmering'. Dit concept houdt in dat de foetus zich tracht aan te passen aan ongunstige omstandigheden dat het tegenkomt in utero, wat kan resulteren in aanpassingen die schadelijk zijn wanneer deze omstandigheden niet overheersen tijdens het verdere leven (30). Dolinoy et al. (31) geeft een duidelijk voorbeeld van foetale programmering door aan te tonen dat agouti muizen die prenataal blootgesteld werden aan genisteïne een andere vachtkleur hadden, terwijl ze ook beschermd waren tegen obesitas op latere leeftijd, wat kenmerkend is voor agouti muizen. Deze effecten werden veroorzaakt door epigenetische veranderingen, namelijk door hypermethylatie van een repetitief element stroomopwaarts van de transcriptie start site van het Agouti gen dat resulteerde in de verminderde expressie van dit gen. De verandering in het DNA methylatie patroon tijdens de foetale ontwikkeling door blootstelling aan flavonoïden kan dus langdurige effecten hebben, omdat dit patroon doorgegeven wordt aan dochtercellen tijdens de celdeling.

\section{Aanhoudende veranderingen in gen expressie}

In Hoofdstuk 3 werd het effect van prenatale blootstelling aan genisteïne op gen expressie en globale methylatie van beenmerg cellen van 12 weken oude, mannelijke muizen onderzocht. Prenatale blootstelling aan genisteïne resulteerde overduidelijk in een verminderde expressie van oestrogeengevoelige genen en genen betrokken bij het remmen van de hematopoëse. Dit had als gevolg dat de erythropoëse en granulopoëse toenam in deze muizen. Het effect dat genisteïne uitoefende op de oestrogeengevoelige genen was min of meer verwacht, aangezien genisteïne structurele gelijkenissen heeft met 17ß-oestradiol, waardoor het via de oestrogeenreceptor zijn effect kan uitoefenen (18). Daarnaast werd het effect van genisteïne op de hematopoëse ook teruggevonden door Zhou et al. (32), waar muizen voorbehandeld werden met genisteïne alvorens ze 7 dagen later aan een gehele lichaamsbestraling blootgesteld werden. De voorbehandeling met genisteïne had een beschermend effect op deze muizen doordat het de regeneratie van hematopoëtische stamcellen verbeterde. We vermoeden dat de 
verandering in gen expressie in onze studie het resultaat is van epigenetische mechanismen, aangezien de repetitieve elementen een toename in methylatie vertoonden in het beenmerg van deze dieren.

\section{Oxidatieve stress gerelateerde processen}

Flavonoïden zijn voornamelijk gekend omwille van hun werking als antioxidant (9) en ze kunnen de placenta doorkruisen om zo de ontwikkelende foetus te bereiken. Daarom hebben wij onderzocht of prenatale blootstelling aan genisteïne of quercetine ook lange termijn effecten kon hebben op systemen die bijdragen aan de bescherming tegen oxidatieve stress, aangezien dit betrokken is bij het ontstaan van kanker (33). Hiervoor hebben we de antioxidant capaciteit van lever en long weefsel van volwassen, mannelijke muizen die prenataal blootgesteld werden aan genisteïne en quercetine, onderzocht in Hoofdstuk 4. Quercetine blootstelling tijdens de dracht resulteerde in een verhoogde expressie van genen die betrokken zijn bij het enzymatische antioxidant verdedigingssysteem van de lever van foetussen op dag 14,5 van de dracht. Vooral Nrf2, een belangrijke transcriptie factor die reageert op oxidatieve stress, toonde een verhoogde expressie bij blootstelling aan quercetine. Dit toont aan dat, ondanks quercetine's eigenschappen als antioxidant, het waarschijnlijk een pro-oxidante werking uitoefende tijdens de in utero blootstelling. Pro-oxidante effecten zijn reeds eerder aangetoond voor quercetine $(34,35)$. Blootstelling aan genisteïne daarentegen had op dit moment van de dracht geen effect op het enzymatische antioxidant $e$ verdedigingssysteem. Dit zou kunnen zijn doordat genisteïne een minder sterke prooxidant is of zelfs eerder een antioxidant werking had. Het is echter wel reeds aangetoond dat genisteïne het nucleaire transport en de degradatie van Nrf2 verhinderd (36), waardoor de verhoogde gen expressie overbodig is.

Op volwassen leeftijd vertoonde de muizen die prenataal blootgesteld werden aan genisteïne of quercetine nog altijd een verandering in de expressie van genen die betrokken zijn bij de enzymatische antioxidante verdediging van de lever. Dit suggereert dat de foetus zich aanpast aan de in utero omgeving, gecreëerd door de verhoogde aanlevering van genisteïne en quercetine door de moeder, en dat deze aanpassingen behouden blijven tijdens het leven. We onderzochten ook het effect van prenatale blootstelling aan genisteïne en quercetine op de non-enzymatische antioxidant e verdediging. Enkel prenatale blootstelling aan genisteïne had een effect op de nonenzymatische antioxidante capaciteit van de long. Oxidatieve stress-geïnduceerde DNA schade, namelijk directe oxidatie van het DNA (8-oxo-dG levels) of indirecte DNA schade geïnduceerd door het lipidenperoxidatie product MDA $\left(M_{1} \mathrm{dG}\right)$ werd ook gemeten in de lever en longen van volwassen muizen die prenataal blootgesteld werden aan quercetine of genisteïne. Zowel prenatale blootstelling aan genisteïne, maar vooral aan quercetine, resulteerde in minder oxidatieve stress geïnduceerd DNA schade, maar dit enkel in de lever van de dieren. Aangezien we in de lever voornamelijk veranderingen in gen expressie van de enzymatische antioxidanten vonden, lijkt het erop dat het preventief stimuleren van het enzymatische antioxidant verdedigingssysteem voordelig en beschermend werkt tegen oxidatieve DNA schade in de lever van volwassen muizen die prenataal blootgesteld waren aan genisteïne, maar vooral aan quercetine. 
Dit effect was weefselspecifiek, aangezien in de long enkel bescheiden effecten in gen expressie van de enzymatische antioxidanten terug te vinden waren ten gevolge van toevoeging van flavonoïden aan het dieet van de moeder en de non-enzymatische antioxidanten verdedigingssysteem enkel toegenomen was ten gevolge van blootstelling aan genisteïne, in vergelijking met de lever. Daarom dat de beperkte, niet statistisch significante, daling in 8-oxo-dG en $M_{1} d G$ in de long van volwassen muizen die prenataal blootgesteld werden aan genisteïne of quercetine te verwachten was.

Deze studie toonde aan dat, ondanks het feit dat genisteïne en quercetine voornamelijk gekend zijn omwille van hun antioxidante eigenschappen, ze waarschijnlijk als pro-oxidanten fungeerden tijdens de dracht, zoals ook al eerder gemeld werd $(35,37-40)$. Dit is aannemelijk aangezien ze accumuleren in de foetus $(23,24)$ terwijl een antioxidante werking optreed bij lagere concentraties. Deze studie toonde ook aan dat genisteïne en quercetine niet hetzelfde effect uitoefenden als we kijken naar de lange termijn veranderingen in het enzymatische antioxidante verdedigingssysteem. Het effect van quercetine was meer uitgesproken dan dat van genisteïne. Hoewel het al eerder was aangetoond dat blootstelling aan genisteïne en quercetine op volwassen leeftijd beschermt tegen oxidatieve stress (41, 42), hebben wij nu aangetoond dat in utero blootstelling ook voor bescherming zorgt op volwassen leeftijd. Het moet echter nog vastgesteld worden of dit voordelige effect kan opwegen tegen de oxidatieve stress veroorzaakt in utero.

\section{De ijzer chelerende eigenschap van quercetine als programmeringsstimulus}

Quercetine is een gekende, zeer krachtige ijzer chelator $(15,16)$. Dit is de rede dat het effect van prenatale blootstelling aan quercetine op de ijzerhuishouding onderzocht werd tijdens de foetale ontwikkeling en op volwassen leeftijd in Hoofdstuk 5. Eerst werd onderzocht of in utero blootstelling aan quercetine wel degelijk resulteerde in ijzer chelatie, maar op dag 14,5 van de dracht was er echter geen verschil in de totale hoeveelheid ijzer meetbaar in het vruchtwater. Aangezien het merendeel van het ijzer gebruikt wordt voor hemoglobine vorming $(43,44)$ werd de gen expressie van globine genen bepaald. Op dag 14,5 van de dracht ondergaan foetusen een omschakeling van de embryonische vorm van hemoglobine, dat enkel gevormd wordt door primitieve rode bloedcellen (RBCs), naar de volwassen vorm van hemoglobine, dat gevormd wordt door zowel de primitieve als de definitieve RBCs $(45,46)$. Het belangrijkste verschil tussen beide vormen van hemoglobine is hun affiniteit voor zuurstof. Tijdens de vroege ontwikkeling zijn de zuurstof niveaus laag door de beperkte doorbloeding, om een optimale orgaanontwikkeling te garanderen. Dit is de periode waarin de foetus het meest kwetsbaar is voor oxidatieve stress, wat kan leiden tot beschadiging van de foetus en vroegtijdig beëindigen van de zwangerschap $(47,48)$. Niettemin moet de foetus ook zuurstof krijgen via het bloed van de moeder. Daarom vormt de foetus in de eerste fase van de zwangerschap embryonische hemoglobine, welke een hogere affiniteit voor zuurstof heeft in vergelijking met de adulte hemoglobine, wat gevormd wordt door de moeder $(49,50)$. Eens de utero-placentale circulatie gevormd is (tussen dag 9,5 en 11 van de dracht) (47), komt er een overschakeling naar de adulte hemoglobine, als gevolg van de toename in zuurstof concentratie $(45,46,48)$. M aar de embryonische hemoglobine is ook minder stabiel in vergelijking met de adulte hemoglobine (48), waardoor het gevoeliger is voor oxidatie, wat resulteert in de 
vorming van methemoglobine dat niet in staat is zuurstof te binden. Daarbij laat embryonische hemoglobine ook makkelijker ijzer vrij van zijn heem groep (51). Aangezien het aangetoond is dat blootstelling aan quercetine leidt tot de vorming van methemoglobine, doordat quercetine de RBCs ingaat en het ijzer ion oxideert $(15,16)$, verwachtten wij ook een versnelde overgang van embryonische naar adulte hemoglobine waar te nemen bij blootstelling aan quercetine. Ondanks dat de resultaten niet significant waren, zagen we toch een trend in de expressie van de globine genen, namelijk een vermindering in gen expressie van de embryonische globines in foetussen die blootgesteld waren aan quercetine. De gen expressie van de adulte globines was echter onveranderd, terwijl de overgang van de primitieve RBC lijn naar de definitieve RBC lijn versneld was ten gevolg van de verhoogde inname van quercetine door de moeders. Dit kan betekenen dat ondanks dat de ijzer niveaus niet significant afgenomen waren, quercetine toch het ijzer dat geleverd werd door de moeder cheleerde, waardoor er minder ijzer beschikbaar was voor de vorming van hemoglobine. Daarbij doet deze data ook vermoeden dat quercetine het ijzer van de embryonische hemoglobine cheleerde, omdat deze minder stabiel is, waardoor de overgang van embryonische naar adult hemogelobine versneld werd. Er was echter geen verandering in de hoeveelheid adulte hemoglobine detecteerbaar. Dit kan verklaard worden doordat de globine productie afhankelijk is van de hoeveelheid beschikbaar ijzer (52), waarvan wij vermoeden dat er minder beschikbaar was. Desondanks lijkt de versnelde overgang van embryonisch naar adult hemoglobine aannemelijk aangezien de overgang in RBC lijn ook versneld was in deze muizen en RBCs van de definitieve lijn voornamelijk adult hemoglobine produceren.

De hoeveelheid ijzer dat opgeslagen was in de lever van volwassen nakomelingen lag veel hoger in muizen die prenataal blootgesteld waren aan quercetine in vergelijking met controle dieren. Wij vermoeden dat de foetus zich aangepast heeft aan de lagere hoeveelheden bruikbaar ijzer waaraan het in utero blootgesteld was door de chelatie van quercetine. Eens geboren worden de foetussen blootgesteld aan een normaal ijzer niveau, aangezien de chelerende werking van quercetine wegvalt. Doordat deze foetussen echter geprogrammeerd werden voor een leven met een laag ijzer niveau voelden deze niveaus aan alsof ze de normale waarden overschreden. Hierdoor werden pathways geactiveerd om deze 'ijzer overlast' te verwerken. We vonden ook een verhoogde gen expressie terug voor verschillende interleukines en hepcidin die allemaal betrokken zijn bij de opslag van ijzer wanneer 'anemie van chronische ziekten', ook wel 'inflammatoire anemie' genoemd, optreed. Interessant om te weten is dat anemie vaker voorkomt op oudere leeftijd en bij personen die lijden aan kanker, waarvan 'inflammatoire anemie' meetelt voor $77 \%$ van de onderliggende oorzaken van de anemie (53). In beenmerg cellen van muizen die prenataal blootgesteld werden aan quercetine werd ook een daling teruggevonden in de gen expressie van Steap4, wat normaal betrokken is bij de opname van ijzer door cellen (54). Wij vermoeden dat deze maatregel genomen was om het beenmerg te beschermen tegen een overmaat aan ijzer en de DNA schade die hierdoor veroorzaakt kan worden.

Deze data doet vermoeden dat de nakomelingen konden omgaan met de toename in beschikbaar ijzer tijdens hun leven, ondanks dat ze zich hadden aangepast aan de in utero omstandigheden, waar ijzer schaars was door de chelatie door quercetine. Sterker nog, er werden minder reactieve zuurstof soorten (ROS) gevormd door ijzer aangezien 
lagere 8-oxo-dG levels teruggevonden werden in de lever van deze muizen. Maar omdat de expressie van genen betrokken bij inflammatie ook verhoogd was in afwezigheid van een inflammatoire stimulus, zou het kunnen dat deze muizen anders zullen reageren als inflammatie zou plaats vinden. Aangezien inflammatie betrokken is bij vele chronische ziektes, waaronder kanker (33), lijkt het erop dat, ondanks dat deze dieren beschermd zijn tegen oxidatieve stress gerelateerde ziektes, een inflammatoire stimulus dit beschermend mechanisme misschien kan veranderen in een schadelijk mechanisme. Dit moet echter nog bevestigd worden.

\section{Quercetine als AhR agonist wijzigt het xenobiotisch metabolisme}

AhR-signalering in de lever speelt een belangrijke rol in het metabolisme van bepaalde, gekende carcinogenen. Zo bepaalt het het risico van een individu op het ontwikkelen van kanker na blootstelling aan genotoxische stoffen. Daarom hebben wij uitgezocht of blootstelling aan quercetine het carcinogeen metabolisme kon beïnvloeden, meer bepaald het metabolisme van B[a]P (Hoofdstuk 6). B[a]P is een gekend, krachtig mutageen en carcinogeen dat metabolisch geactiveerd moet worden. Deze activatie wordt uitgevoerd door CYP1A1 en CYP1B1 $(55,56)$, die beiden gereguleerd kunnen worden door quercetine. Quercetine kan zelfs fase II enzymen reguleren (57-59). Desondanks is er geen eenduidig effect van quercetine op fase I en II enzyme expressie gemeld $(56,57,60-62)$. In deze studie toonden we aan dat blootstelling aan quercetine Cypla1 en Cyp1b1 gen expressie verhoogde in foetussen op dag 14,5 van de dracht. Aangezien CYPs hemoproteïnes zijn, die ijzer bevatten in hun heemgroep (63), kan het zijn dat de toename in gen expressie het resultaat is van de chelerende werking van quercetine. Dit kan namelijk resulteren in een mindere CYP activiteit wat gecompenseerd wordt door een toename in gen expressie. Een andere verklaring kan zijn dat quercetine het $17 \beta$-oestradiol niveau verhoogt, wat ook een substraat is voor Cyp1b1 en Cypla1 (64). AhR gen expressie was bovendien niet verhoogd in foetussen. Dit kan zijn omdat in de lever van ontwikkelende muizen foetussen de AhR mRNA en proteïne expressie een piek kent tussen dag 14 en 16 van de dracht (65), waardoor het effect van quercetine op de AhR gen expressie misschien nog niet zichtbaar is op dit tijdstip. Daarbuiten was de gen expressie van Nqo1, Ugtla6 and Gstp1 wel verhoogd in foetussen die blootgesteld waren aan quercetine. Wij vermoeden dat dit het resultaat is van de activatie van het Nrf2-pathway, aangezien deze 3 genen doelgenen zijn van de transcriptie factor Nrf2 $(66,67)$. Nrf2 gen expressie was inderdaad verhoogd in foetussen blootgesteld aan quercetine (Hoofdstuk 4).

Op 12 weken vertoonde de muizen die prenataal blootgesteld waren aan quercetine nog altijd een verhoogde expressie van Cyp1b1 in hun lever, terwijl de verhoogde expressie van de overige genen niet behouden bleef over tijd. Interessant om te zien was dat in volwassen dieren de gen expressie van AhR verhoogd was, wat de toename in Cyp1b1 gen expressie kan verklaren. Wanneer mannelijke en vrouwelijke muizen van eenzelfde nest met elkaar vergeleken werden, vonden we dat vrouwelijke muizen die prenataal blootgesteld waren aan quercetine een mannelijker fase I en II enzyme profiel ontwikkelden in vergelijking met vrouwelijke controle muizen. In ratten werd ook aangetoond dat prenatale blootstelling aan quercetine lange termijn veranderingen in CYP activiteit veroorzaakte, voornamelijk in de vrouwelijke nakomelingen. Het CYP 
profiel van de vrouwelijke nakomelingen toonde ook in dit geval een mannelijker profiel in vergelijking met controle vrouwen. Er werd vermoed dat quercetine zijn effecten uitoefende via de regulatie van de androstene of Ah receptor (58). Inderdaad, AhR gen expressie was licht verhoogd in vrouwelijke muizen die prenataal blootgesteld waren aan quercetine.

Gen expressie van fase I en II enzymen toonde een ander profiel in de longen van 12 weken oude muizen die prenataal blootgesteld waren aan quercetine. In dit geval was de gen expressie van de fase II enzymen (Gstpl, Nqol and Ugtla6) verhoogd. Het feit dat beide weefsels anders reageren op prenatale blootstelling aan quercetine kan verklaard worden doordat de longen zich voornamelijk ontwikkelen tijdens de laatste fase van de zwangerschap en zelfs nog verder ontwikkelen na de geboorte (68), terwijl de lever grotendeels gevormd is voor de geboorte (69). De minder aanwezige geslachtseffecten in de long kunnen ook het gevolg zijn van de minder belangrijke rol die de long speelt in het metabolisme van oestrogeen. Desondanks vertoonden de foetussen op dag 14,5 van de dracht wel een toename in Nqol en Ugtla6 gen expressie, waarvan wij vermoeden dat dit het resultaat was van de activering van het Nrf2pathway, aangezien quercetine ook als pro-oxidant kan werken (Hoofdstuk 4). Aangezien de long blootgesteld wordt aan hogere zuurstof concentraties in vergelijking met andere weefsels (33) kan een preventieve oxidatieve stress stimulus in utero resulteren in de verhoogde expressie van de Nrf2-pathway en zo ook van de fase II enzymen. Maar, zoals hierboven aangegeven, was het Nrf2-pathway slechts matig geïnduceerd in de longen van muizen die prenataal blootgesteld waren aan quercetine (Hoofdstuk 4).

Hoewel prenatale blootstelling aan quercetine resulteerde in een verhoogde expressie van fase I en II enzymen in lever en longen, werden er slechts enkele veranderingen teruggevonden in het ex vivo $\mathrm{B}[\mathrm{a}] \mathrm{P}$ metabolisme van de longen van muizen die prenataal blootgesteld werden aan quercetine. Dit was zichtbaar als een afname in B[a]P-9,10dihydrodiol en B[a]P-7,8-dihydrodiol. Bovendien hadden muizen die prenataal blootgesteld waren aan quercetine een verhoogd $\mathrm{B}[\mathrm{a}] \mathrm{P}$ metabolisme. Omwille van de hoge detoxificatie van B[a]P tot 3-hydroxy-B[a]P konden er echter geen BPDEgeinduceerde DNA-adducten gedetecteerd worden in geval van alle 3 de dieetgroepen. Aangezien de long het doelorgaan is voor vluchtig B[a]P zou de toename in $\mathrm{B}[\mathrm{a}] \mathrm{P}$ metabolisme en fase II gen expressie erop kunnen wijzen dat prenatale blootstelling aan quercetine de gevoeligheid voor het ontwikkelen van longkanker in vivo kan verminderen. In de lever was verrassend genoeg te zien dat ex vivo inductie van BPDE DNA-adducten verminderd was wanneer muizen prenataal blootgesteld waren aan quercetine. Desondanks was er geen verandering in de snelheid waarmee B[a]P gemetaboliseerd werd of in het profiel van de 3 belangrijkste B[a]P metabolieten, waaronder de 7,8dihydrodiol van $\mathrm{B}[\mathrm{a}] \mathrm{P}$ wat een voorloper is van de uiteindelijke genotoxische metaboliet BPDE. Dit wijst erop dat prenatale blootstelling aan quercetine resulteert in de bescherming tegen $\mathrm{B}[\mathrm{a}] \mathrm{P}$ geïnduceerde DNA schade in de lever, waarschijnlijk door een verhoogde expressie van fase I enzymen. Ondanks dat CYP1A1 en CYP1B1 belangrijk zijn voor de activering van $\mathrm{B}[\mathrm{a}] \mathrm{P}$, vermoeden wij dat ze ook bijdragen aan $\mathrm{B}[\mathrm{a}] \mathrm{P}$ detoxificatie, wat voorheen ook voorgesteld werd door Uno et al. (70). 


\section{Foetale programmering wordt gereguleerd via epigenetica}

De verandering in gen expressie ten gevolge van in utero blootstelling aan genisteïne of quercetine, besproken in Hoofdstuk 3-6, werd behouden doorheen het leven van de muis. Wij vermoeden dus dat epigenetische mechanismen betrokken zijn. Daarom werden in dit onderzoek de veranderingen in methylatie status van repetitieve elementen ten gevolge van prenatale blootstelling aan genisteïne en quercetine nagegaan, aangezien het muizen genoom voor $37,5 \%$ uit repetitieve elementen bestaat (71). De resultaten toonden aan dat beide flavonoïden geen veranderingen in globale methylatie (namelijk methylatie van SINEB1, SINEB2, LINE1, IAP, major en minor satellieten) veroorzaakten in de lever van foetussen op dag 14,5 van de dracht (Hoofdstuk 3, 5, 6). Wanneer echter het methylatie patroon van het beenmerg van 12 weken oude muizen onderzocht werd, was een algemene toename in methylatie zichtbaar, vooral in geval van SINEB1 en SINEB2, wanneer muizen prenataal blootgesteld waren aan genisteïne of quercetine (Hoofdstuk $\mathbf{3}, \mathbf{5}$ ). In lever en long weefsel van 12 weken oude muizen die prenataal blootgesteld waren aan genisteïne of quercetine bleken de repetitieve elementen SINEB1, SINEB2 en LINE1 licht gehypomethyleerd te zijn (Hoofdstuk 6). Het feit dat er nog geen verandering in methylatie vastgesteld kon worden in foetussen op dag 14,5 van de dracht kan betekenen dat de novo methylatie veroorzaakt door flavonoïden op een later tijdstip in de dracht of zelfs na de geboorte pas plaatsvindt. Dit is aannemelijk aangezien tijdens de laatste fase van de dracht en tijdens de vroege postnatale periode weefsel maturatie plaatsvindt, waardoor epigenetische modificaties plaatsvinden. Bovendien wordt beweerd dat transcriptionele inactivatie de novo methylatie aantrekt, terwijl transcriptionele activitie de novo methylatie kan uitschakelen, met het laatste resulterend in hypomethylatie tijdens de foetale ontwikkeling (72). Daarbij neemt het niveau van blootstelling aan genisteïne en quercetine ook enkel toe doorheen de dracht, waardoor hun effect enkel versterkt wordt. Eerder is al aangetoond dat prenatale blootstelling aan genisteine de gen expressie kan veranderen door het methylatie patroon te beïnvloeden. Meer bepaald gele agouti muizen die prenataal blootgesteld waren aan genisteine vertoonden een verandering in vachtkleur en lichaamsgewicht doordat een repetitief element stroomopwaarts van de transcriptie start site van het Agouti gen gehypermethyleerd was (31). Daarbij is voor zowel genisteïne als quercetine aangetoond dat ze in staat zijn DNA methyltransferases te remmen om zo hypomethylatie te veroorzaken, meer bepaald van gehypermethyleerde tumor suppressor genen, waaraan hun beschermend effect tegen kanker ook wordt toegeschreven $(73,74)$. Er is echter ook een weefsel effect zichtbaar wat de methylatie betreft. Hypermethylatie komt voor in het geval van het beenmerg terwijl de lever en long hypomethylatie ondergaan, met name de SINE transcripten. In het begin van de embryogenese worden SINE en LINE repetitieve elementen normaal uitgedrukt, waarna hun expressie snel afneemt. Naderhand wordt de expressie van SINEB1, SINEB2 en LINE1 geassocieerd met cellulaire stress. Dit kan veroorzaakt worden door DNA beschadigende stoffen $(75,76)$ zoals genisteine en quercetine, aangezien zij een topoïsomerase II remmende werking hebben, wat aangetoond werd in Hoofdstuk 2. Aangezien SINE en LINE expressie geassocieerd is met kanker $(75,76)$ kan dit betekenen dat een flavonoïden stimulus in utero SINEB1, SINEB2 en LINE1 expressie kan onderdrukken om zo te beschermen tegen genoom instabiliteit op latere leeftijd. 


\section{Implicaties en verder onderzoek}

Omdat dit slechts het begin is van inzicht te verkrijgen in hoe genisteïne en quercetine inname door de moeder een effect kan hebben op het risico van de nakomelingen om kanker te ontwikkelen op latere leeftijd, moeten verdere studies uitgevoerd worden:

- Betreffende het epigenetische mechanisme dat betrokken is bij de genisteïne en quercetine veroorzaakte foetale programmering. De 'critical window' van de blootstelling moet achterhaald worden.

- Ondanks dat genisteïne en quercetine beide flavonoïden zijn, oefenen ze toch verschillende effecten uit. Daarom moet hun specifieke werking verder onderzocht worden.

- Als de muizen 12 weken oud zijn, lijkt het alsof prenatale blootstelling aan genisteïne en quercetine over het algemeen voordelige effecten heeft veroorzaakt ten opzichte van de gevoeligheid voor kanker. Deze muizen zijn echter nog relatief jong, waardoor de werkelijke bijdrage van de aanpassingen gemaakt door de foetus als reactie op de in utero blootstelling aan genisteïne en quercetine misschien nog niet zichtbaar zijn op deze leeftijd. Daarom dat toekomstige studies op oudere muizen uitgevoerd moeten worden. Onderzoek naar het effect van foetale programmering zou ook op latere leeftijd moeten gebeuren, wanneer deze muizen te maken krijgen met chronische ziektes. Deze chronische ziektes zouden ook geïnduceerd kunnen worden aan de hand van pro-inflammatoire stimuli.

- Het zou ook interessant zijn te kijken naar het effect van levenslange blootstelling aan genisteïne en quercetine met betrekking tot de gevoeligheid voor het ontwikkelen van kanker.

- Het zou ook waardevol zijn te kijken naar het effect van prenatale blootstelling aan genisteïne en quercetine in volgende generaties. Echter, om de werkelijke erfelijkheid te bepalen, zou de derde generatie, de eerste niet blootgestelde generatie, onderzocht moeten worden. De eerste generatie is namelijk direct blootgesteld geweest aan genisteïne of quercetine, terwijl de tweede generatie ontstaat uit voortplantingscellen die blootgesteld zijn aan genisteïne of quercetine (Figuur 1).

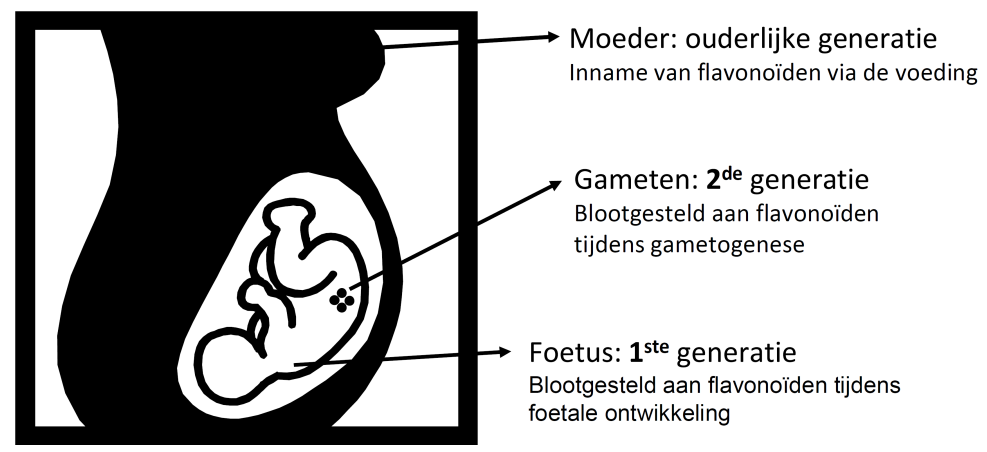

Figuur 1. Overzicht van hoe de effecten geinduceerd door genisteïne of quercetine blootstelling overgeërfd kan worden door volgende generaties. 
Wanneer alle resultaten beschreven in deze thesis opgesomd worden, kan geconcludeerd worden dat prenatale blootstelling aan quercetine en genisteïne de foetale programmering veranderd in vergelijking met een niet-gesupplementeerd dieet tijdens de zwangerschap.

Tijdens de dracht, wanneer de foetussen direct blootgesteld zijn aan flavonoïden, treden veranderingen op in de gen expressie van genen die betrokken zijn bij het antioxidante verdedigingssysteem en bij het carcinogeen metabolisme. Dit doet vermoeden dat foetussen zich aanpasten aan de in utero omgeving. Eens geboren viel de blootstelling aan genisteïne en quercetine weg. Sommige veranderingen in gen expressie bleven echter behouden tot op volwassen leeftijd, terwijl andere verkregen werden doorheen het leven, wat erop wijst dat de nakomelingen zich probeerden aan te passen aan de nieuwe 'onverwachte' omgeving.

Op de leeftijd van 12 weken lijkt het dat prenatale blootstelling aan genisteïne en quercetine voordelig blijkt te zijn, aangezien de muizen minder oxidatieve stress geïnduceerde DNA schade hadden ten gevolge van een verhoogde enzymatische antioxidante verdedigingssysteem en omdat ze op een meer efficiëntere manier ijzer opsloegen. Het lijkt ook dat ze onder deze condities beter overweg konden met B[a]P geïnduceerde DNA schade door de verhoogde expressie van fase I en II enzymen. Daarbij vertoonden deze muizen ook een verhoogde methylatie van bepaalde repetitieve elementen dat erop wijst dat deze dieren meer beschermd waren tegen genoom instabiliteit, waardoor ze minder gevoelig leken voor het ontwikkelen van kanker. Aan de andere kant veroorzaakte prenatale blootstelling aan genisteïne en quercetine ook M II translocaties waardoor het risico op leukemie verhoogd was, zeker voor muizen met een beperkt DNA herstel. Daarbij was ook de basale expressie van een aantal inflammatoire cytokines verhoogd, wat de inflammatoire respons kan beïnvloeden.

Een algemeen overzicht van het effect van prenatale blootstelling aan genisteïne en quercetine op het risico voor de nakomeling om kanker te ontwikkelen, wordt weergegeven in Figuur 2.

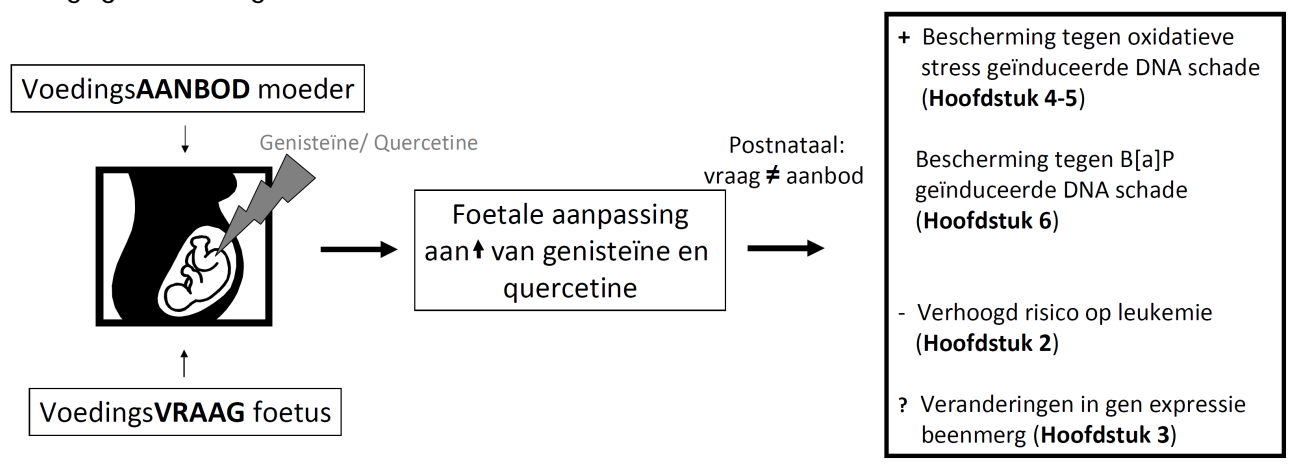

Figuur 2. Algemeen overzicht van het effect van prenatale blootstelling aan genisteïne en quercetine op het risico voor de nakomelingen om kanker te ontwikkelen beschreven in deze thesis. 


\section{Referenties}

1. Darnton-Hill, I., Nishida, C., and James, W. P. (2004) A life course approach to diet, nutrition and the prevention of chronic diseases. Public Health Nutr 7, 101-121

2. Khan, T. H., Jahangir, T., Prasad, L., and Sultana, S. (2006) Inhibitory effect of apigenin on benzo(a)pyrenemediated genotoxicity in Swiss albino mice.J Pharm Pharmacol 58, 1655-1660

3. Muhammad, S., Bierhaus, A., and Schwaninger, M. (2009) Reactive oxygen species in diabetes-induced vascular damage, stroke, and Alzheimer's disease. J Alzheimers Dis 16, 775-785

4. Tabner, B. J., Turnbull, S., El-Agnaf, O., and Allsop, D. (2001) Production of reactive oxygen species from aggregating proteins implicated in Alzheimer's disease, Parkinson's disease and other neurodegenerative diseases. Curr Top M ed Chem 1, 507-517

5. Touyz, R. M. (2004) Reactive oxygen species and angiotensin II signaling in vascular cells -- implications in cardiovascular disease. Braz J Med Biol Res 37, 1263-1273

6. Weinberg, F., and Chandel, N. S. (2009) Reactive oxygen species-dependent signaling regulates cancer. Cell Mol Life Sci 66, 3663-3673

7. Arts, I. C., and Hollman, P. C. (2005) Polyphenols and disease risk in epidemiologic studies. Am J Clin Nutr 81, 317S-325S

8. Hollman, P. C., and Katan, M. B. (1999) Dietary flavonoids: intake, health effects and bioavailability. Food Chem Toxicol 37, 937-942

9. Ross, J. A., and Kasum, C. M. (2002) Dietary flavonoids: bioavailability, metabolic effects, and safety. Annu Rev Nutr 22, 19-34

10. Yao, L. H., Jiang, Y. M., Shi, J., Tomas-Barberan, F. A., Datta, N., Singanusong, R., and Chen, S. S. (2004) Flavonoids in food and their health benefits. Plant Foods Hum Nutr 59, 113-122

11. Erdman, J. W., Jr., Balentine, D., Arab, L., Beecher, G., Dwyer, J. T., Folts, J., Harnly, J., Hollman, P., Keen, C. L., Mazza, G., Messina, M., Scalbert, A., Vita, J., Williamson, G., and Burrowes, J. (2007) Flavonoids and heart health: proceedings of the ILSI North America Flavonoids Workshop, May 31-June 1, 2005, Washington, DC. J Nutr 137, 718S-737S

12. Aherne, S. A., and O'Brien, N. M. (2002) Dietary flavonols: chemistry, food content, and metabolism. Nutrition 18, 75-81

13. Diplock, A. T., Charleux, J. L., Crozier-Willi, G., Kok, F. J., Rice-Evans, C., Roberfroid, M., Stahl, W., and Vina-Ribes, J. (1998) Functional food science and defence against reactive oxidative species. Br J Nutr 80 Suppl 1, S77-112

14. Skibola, C. F., and Smith, M. T. (2000) Potential health impacts of excessive flavonoid intake. Free Radic Biol Med 29, 375-383

15. Ferrali, M., Signorini, C., Caciotti, B., Sugherini, L., Ciccoli, L., Giachetti, D., and Comporti, M. (1997) Protection against oxidative damage of erythrocyte membrane by the flavonoid quercetin and its relation to iron chelating activity. FEBS Lett 416, 123-129

16. Kitagawa, S., Sakamoto, H., and Tano, H. (2004) Inhibitory effects of flavonoids on free radical-induced hemolysis and their oxidative effects on hemoglobin. Chem Pharm Bull (Tokyo) 52, 999-1001

17. Marik, R., Allu, M., Anchoori, R., Stearns, V., Umbricht, C. B., and Khan, S. (2011) Potent genistein derivatives as inhibitors of estrogen receptor alpha-positive breast cancer. Cancer Biol Ther 11, 883-892

18. Miodini, P., Fioravanti, L., Di Fronzo, G., and Cappelletti, V. (1999) The two phyto-oestrogens genistein and quercetin exert different effects on oestrogen receptor function. Br J Cancer 80, 1150-1155

19. Espin, J. C., Garcia-Conesa, M. T., and Tomas-Barberan, F. A. (2007) Nutraceuticals: facts and fiction. Phytochemistry 68, 2986-3008

20. Harwood, M., Danielewska-Nikiel, B., Borzelleca, J. F., Flamm, G. W., Williams, G. M ., and Lines, T. C. (2007) A critical review of the data related to the safety of quercetin and lack of evidence of in vivo toxicity, including lack of genotoxic/ carcinogenic properties. Food Chem Toxicol 45, 2179-2205

21. Sullivan, K. M., Ford, E. S., Azrak, M. F., and M okdad, A. H. (2009) Multivitamin use in pregnant and nonpregnant women: results from the Behavioral Risk Factor Surveillance System. Public Health Rep 124, 384-390

22. Baggott, J. E., Oster, R. A., and Tamura, T. (2011) Meta-analysis of cancer risk in folic acid supplementation trials. Cancer Epidemiol

23. Bonacasa, B., Siow, R. C., and Mann, G. E. (2011) Impact of dietary soy isoflavones in pregnancy on fetal programming of endothelial function in offspring. Microcirculation 18, 270-285

24. Schroder-van der Elst, J. P., van der Heide, D., Rokos, H., Morreale de Escobar, G., and Kohrle, J. (1998) Synthetic flavonoids cross the placenta in the rat and are found in fetal brain. Am J Physiol 274, E253-256 
25. Ross, J. A., Potter, J. D., Reaman, G. H., Pendergrass, T. W., and Robison, L. L. (1996) Maternal exposure to potential inhibitors of DNA topoisomerase II and infant leukemia (United States): a report from the Children's Cancer Group. Cancer Causes Control 7, 581-590

26. Spector, L. G., Xie, Y., Robison, L. L., Heerema, N. A., Hilden, J. M ., Lange, B., Felix, C. A., Davies, S. M., Slavin, J., Potter, J. D., Blair, C. K., Reaman, G. H., and Ross, J. A. (2005) Maternal diet and infant leukemia: the DNA topoisomerase II inhibitor hypothesis: a report from the children's oncology group. Cancer Epidemiol Biomarkers Prev 14, 651-655

27. Barjesteh van Waalwijk van Doorn-Khosrovani, S., Janssen, J., Maas, L. M., Godschalk, R. W., Nijhuis, J. G., and van Schooten, F. J. (2007) Dietary flavonoids induce MLL translocations in primary human CD34+cells. Carcinogenesis 28, 1703-1709

28. Spring, K., Cross, S., Li, C., Watters, D., Ben-Senior, L., Waring, P., Ahangari, F., Lu, S. L., Chen, P., Misko, I., Paterson, C., Kay, G., Smorodinsky, N. I., Shiloh, Y., and Lavin, M. F. (2001) Atm knock-in mice harboring an in-frame deletion corresponding to the human ATM 7636del9 common mutation exhibit a variant phenotype. Cancer Res 61, 4561-4568

29. Spring, K., Ahangari, F., Scott, S. P., Waring, P., Purdie, D. M., Chen, P. C., Hourigan, K., Ramsay, J., M cKinnon, P. J., Swift, M., and Lavin, M. F. (2002) Mice heterozygous for mutation in Atm, the gene involved in ataxiatelangiectasia, have heightened susceptibility to cancer. Nat Genet 32, 185-190

30. Barker, D. J., and Clark, P. M. (1997) Fetal undernutrition and disease in later life. Rev Reprod 2, 105-112

31. Dolinoy, D. C., Weidman, J. R., Waterland, R. A., and Jirtle, R. L. (2006) Maternal genistein alters coat color and protects Avy mouse offspring from obesity by modifying the fetal epigenome. Environ Health Perspect 114, 567-572

32. Zhou, Y., and Mi, M. T. (2005) Genistein stimulates hematopoiesis and increases survival in irradiated mice. J Radiat Res (Tokyo) 46, 425-433

33. Reuter, S., Gupta, S. C., Chaturvedi, M. M., and Aggarwal, B. B. (2010) Oxidative stress, inflammation, and cancer: how are they linked? Free Radic Biol M ed 49, 1603-1616

34. Boots, A. W., Li, H., Schins, R. P., Duffin, R., Heemskerk, J. W., Bast, A., and Haenen, G. R. (2007) The quercetin paradox. Toxicol Appl Pharmacol 222, 89-96

35. Choi, E. J., Chee, K. M., and Lee, B. H. (2003) Anti- and prooxidant effects of chronic quercetin administration in rats. Eur J Pharmacol 482, 281-285

36. Kaspar, J. W., and Jaiswal, A. K. (2011) Tyrosine phosphorylation controls nuclear export of Fyn, allowing Nrf2 activation of cytoprotective gene expression. FASEB J 25, 1076-1087

37. Cao, G., Sofic, E., and Prior, R. L. (1997) Antioxidant and prooxidant behavior of flavonoids: structure-activity relationships. Free Radic Biol Med 22, 749-760

38. Galati, G., Sabzevari, O., Wilson, J. X., and O'Brien, P. J. (2002) Prooxidant activity and cellular effects of the phenoxyl radicals of dietary flavonoids and other polyphenolics. Toxicology 177, 91-104

39. Ullah, M. F., Shamim, U., Hanif, S., Azmi, A. S., and Hadi, S. M. (2009) Cellular DNA breakage by soy isoflavone genistein and its methylated structural analogue biochanin A. M ol Nutr Food Res 53, 1376-1385

40. Vargas, A. J., and Burd, R. (2010) Hormesis and synergy: pathways and mechanisms of quercetin in cancer prevention and management. Nutr Rev $68,418-428$

41. Boots, A. W., Drent, M., de Boer, V. C., Bast, A., and Haenen, G. R. (2011) Quercetin reduces markers of oxidative stress and inflammation in sarcoidosis. Clin Nutr 30, 506-512

42. Siow, R. C., and Mann, G. E. (2010) Dietary isoflavones and vascular protection: activation of cellular antioxidant defenses by SERM s or hormesis? Mol Aspects M ed 31, 468-477

43. Munoz, M., Villar, I., and Garcia-Erce, J. A. (2009) An update on iron physiology. World J Gastroenterol 15, 4617-4626

44. Zhang, A. S., and Enns, C. A. (2009) Molecular mechanisms of normal iron homeostasis. Hematology Am Soc Hematol Educ Program, 207-214

45. Kingsley, P. D., Malik, J., Emerson, R. L., Bushnell, T. P., M cGrath, K. E., Bloedorn, L. A., Bulger, M., and Palis, J. (2006) "Maturational" globin switching in primary primitive erythroid cells. Blood 107, 1665-1672

46. Palis, J. (2008) Ontogeny of erythropoiesis. Curr Opin Hematol 15, 155-161

47. Dennery, P. A. (2007) Effects of oxidative stress on embryonic development. Birth Defects Res C Embryo Today 81, 155-162

48. Jauniaux, E., Gulbis, B., and Burton, G. J. (2003) The human first trimester gestational sac limits rather than facilitates oxygen transfer to the foetus--a review. Placenta 24 Suppl A, S86-93

49. Amoyal, I., and Fibach, E. (2007) Hemoglobin switch in the newborn: a flow cytometry analysis. Neonatology 91, 61-68

50. Purdie, A., Wells, R. M., and Brittain, T. (1983) Molecular aspects of embryonic mouse haemoglobin ontogeny. Biochem J 215, 377-383 
51. Comporti, M., Signorini, C., Buonocore, G., and Ciccoli, L. (2002) Iron release, oxidative stress and erythrocyte ageing. Free Radic Biol Med 32, 568-576

52. Koury, M. J., and Ponka, P. (2004) New insights into erythropoiesis: the roles of folate, vitamin B12, and iron. Annu Rev Nutr 24, 105-131

53. Weiss, G. (2009) Iron metabolism in the anemia of chronic disease. Biochim Biophys Acta 1790, 682-693

54. Ohgami, R. S., Campagna, D. R., McDonald, A., and Fleming, M. D. (2006) The Steap proteins are metalloreductases. Blood 108, 1388-1394

55. Alexandrov, K., Rojas, M., and Satarug, S. (2010) The critical DNA damage by benzo(a)pyrene in lung tissues of smokers and approaches to preventing its formation. Toxicol Lett 198, 63-68

56. Delgado, M. E., Haza, A. I., Arranz, N., Garcia, A., and M orales, P. (2008) Dietary polyphenols protect against $\mathrm{N}$-nitrosamines and benzo(a)pyrene-induced DNA damage (strand breaks and oxidized purines/pyrimidines) in HepG2 human hepatoma cells. Eur J Nutr 47, 479-490

57. Ciolino, H. P., Daschner, P. J., and Yeh, G. C. (1999) Dietary flavonols quercetin and kaempferol are ligands of the aryl hydrocarbon receptor that affect CYP1A1 transcription differentially. Biochem J 340 ( Pt 3), 715-722

58. Makaji, E., Ho, S. H., Holloway, A. C., and Crankshaw, D. J. (2011) Effects in rats of maternal exposure to raspberry leaf and its constituents on the activity of cytochrome p450 enzymes in the offspring. Int J Toxicol 30, 216-224

59. Moon, Y. J., Wang, X., and Morris, M. E. (2006) Dietary flavonoids: effects on xenobiotic and carcinogen metabolism. Toxicol In Vitro 20, 187-210

60. Kang, Z C., Tsai, S. J., and Lee, H. (1999) Quercetin inhibits benzo[a]pyrene-induced DNA adducts in human Hep G2 cells by altering cytochrome P-450 1A1 gene expression. Nutr Cancer 35, 175-179

61. Sergent, T., Dupont, I., Van der Heiden, E., Scippo, M. L., Pussemier, L., Larondelle, Y., and Schneider, Y. J. (2009) CYP1A1 and CYP3A4 modulation by dietary flavonoids in human intestinal Caco-2 cells. Toxicol Lett $191,216-222$

62. Walle, T., and Walle, U. K. (2007) Novel methoxylated flavone inhibitors of cytochrome P450 1B1 in SCC-9 human oral cancer cells. J Pharm Pharmacol 59, 857-862

63. Nelson, D. R., Koymans, L., Kamataki, T., Stegeman, J. J., Feyereisen, R., Waxman, D. J., Waterman, M. R., Gotoh, O., Coon, M. J., Estabrook, R. W., Gunsalus, I. C., and Nebert, D. W. (1996) P450 superfamily: update on new sequences, gene mapping, accession numbers and nomenclature. Pharmacogenetics 6, 1-42

64. Santini, S. E., Basini, G., Bussolati, S., and Grasselli, F. (2009) The phytoestrogen quercetin impairs steroidogenesis and angiogenesis in swine granulosa cells in vitro. J Biomed Biotechnol 2009, 419891

65. Abbott, B. D., Birnbaum, L. S., and Perdew, G. H. (1995) Developmental expression of two members of a new class of transcription factors: I. Expression of aryl hydrocarbon receptor in the C57BL/6N mouse embryo. Dev Dyn 204, 133-143

66. Kohle, C., and Bock, K. W. (2007) Coordinate regulation of Phase I and II xenobiotic metabolisms by the Ah receptor and Nrf2. Biochem Pharmacol 73, 1853-1862

67. Niestroy, J., Barbara, A., Herbst, K., Rode, S., van Liempt, M., and Roos, P. H. (2011) Single and concerted effects of benzo[a]pyrene and flavonoids on the AhR and Nrf2-pathway in the human colon carcinoma cell line Caco-2. Toxicol In Vitro 25, 671-683

68. Ten Have-Opbroek, A. A. (1991) Lung development in the mouse embryo. Exp Lung Res 17, 111-130

69. Zaret, K. S. (2002) Regulatory phases of early liver development: paradigms of organogenesis. Nat Rev Genet $3,499-512$

70. Uno, S., Dalton, T. P., Dragin, N., Curran, C. P., Derkenne, S., Miller, M. L., Shertzer, H. G., Gonzalez, F. J., and Nebert, D. W. (2006) Oral benzo[a]pyrene in Cyp1 knockout mouse lines: CYP1A1 important in detoxication, CYP1B1 metabolism required for immune damage independent of total-body burden and clearance rate. Mol Pharmacol 69, 1103-1114

71. Waterston, R. H., Lindblad-Toh, K., Birney, E., Rogers, J., Abril, J. F., Agarwal, P., Agarwala, R., Ainscough, R., Alexandersson, M., An, P., Antonarakis, S. E., Attwood, J., Baertsch, R., Bailey, J., Barlow, K., Beck, S., Berry, E., Birren, B., Bloom, T., Bork, P., Botcherby, M., Bray, N., Brent, M. R., Brown, D. G., Brown, S. D., Bult, C., Burton, J., Butler, J., Campbell, R. D., Carninci, P., Cawley, S., Chiaromonte, F., Chinwalla, A. T., Church, D. M., Clamp, M., Clee, C., Collins, F. S., Cook, L. L., Copley, R. R., Coulson, A., Couronne, O., Cuff, J., Curwen, V., Cutts, T., Daly, M., David, R., Davies, J., Delehaunty, K. D., Deri, J., Dermitzakis, E. T., Dewey, C., Dickens, N. J., Diekhans, M., Dodge, S., Dubchak, I., Dunn, D. M., Eddy, S. R., Elnitski, L., Emes, R. D., Eswara, P., Eyras, E., Felsenfeld, A., Fewell, G. A., Flicek, P., Foley, K., Frankel, W. N., Fulton, L. A., Fulton, R. S., Furey, T. S., Gage, D., Gibbs, R. A., Glusman, G., Gnerre, S., Goldman, N., Goodstadt, L., Grafham, D., Graves, T. A., Green, E. D., Gregory, S., Guigo, R., Guyer, M., Hardison, R. C., Haussler, D., Hayashizaki, Y., Hillier, L. W., Hinrichs, A., Hlavina, W., Holzer, T., Hsu, F., Hua, A., Hubbard, T., Hunt, A., Jackson, I., Jaffe, D. B., Johnson, L. S., Jones, M., Jones, T. A., Joy, A., Kamal, M., Karlsson, E. K., Karolchik, D., Kasprzyk, A., Kawai, J., Keibler, E., Kells, C., 
Kent, W. J., Kirby, A., Kolbe, D. L., Korf, I., Kucherlapati, R. S., Kulbokas, E. J., Kulp, D., Landers, T., Leger, J. P., Leonard, S., Letunic, I., Levine, R., Li, J., Li, M., Lloyd, C., Lucas, S., Ma, B., Maglott, D. R., Mardis, E. R., Matthews, L., Mauceli, E., Mayer, J. H., McCarthy, M., McCombie, W. R., M cLaren, S., M cLay, K., McPherson, J. D., Meldrim, J., Meredith, B., Mesirov, J. P., Miller, W., Miner, T. L., Mongin, E., Montgomery, K. T., Morgan, M., M ott, R., M ullikin, J. C., M uzny, D. M., Nash, W. E., Nelson, J. O., Nhan, M. N., Nicol, R., Ning, Z., Nusbaum, C., O'Connor, M. J., Okazaki, Y., Oliver, K., Overton-Larty, E., Pachter, L., Parra, G., Pepin, K. H., Peterson, J., Pevzner, P., Plumb, R., Pohl, C. S., Poliakov, A., Ponce, T. C., Ponting, C. P., Potter, S., Quail, M., Reymond, A., Roe, B. A., Roskin, K. M., Rubin, E. M., Rust, A. G., Santos, R., Sapojnikov, V., Schultz, B., Schultz, J., Schwartz, M. S., Schwartz, S., Scott, C., Seaman, S., Searle, S., Sharpe, T., Sheridan, A., Shownkeen, R., Sims, S., Singer, J. B., Slater, G., Smit, A., Smith, D. R., Spencer, B., Stabenau, A., Stange-Thomann, N., Sugnet, C., Suyama, M., Tesler, G., Thompson, J., Torrents, D., Trevaskis, E., Tromp, J., Ucla, C., Ureta-Vidal, A., Vinson, J. P., Von Niederhausern, A. C., Wade, C. M., Wall, M., Weber, R. J., Weiss, R. B., Wendl, M. C., West, A. P., Wetterstrand, K., Wheeler, R., Whelan, S., Wierzbowski, J., Willey, D., Williams, S., Wilson, R. K., Winter, E., Worley, K. C., Wyman, D., Yang, S., Yang, S. P., Zdobnov, E. M., Zody, M. C., and Lander, E. S. (2002) Initial sequencing and comparative analysis of the mouse genome. Nature 420, 520-562

72. Waterland, R. A., Kellermayer, R., Rached, M. T., Tatevian, N., Gomes, M. V., Zhang, J., Zhang, L., Chakravarty, A., Zhu, W., Laritsky, E., Zhang, W., Wang, X., and Shen, L. (2009) Epigenomic profiling indicates a role for DNA methylation in early postnatal liver development. Hum M ol Genet 18, 3026-3038

73. Duthie, S. J. (2011) Epigenetic modifications and human pathologies: cancer and CVD. Proc Nutr Soc 70, 47-56

74. Li, Y., and Tollefsbol, T. O. (2010) Impact on DNA methylation in cancer prevention and therapy by bioactive dietary components. Curr Med Chem 17, 2141-2151

75. Kramerov, D. A., and Vassetzky, N. S. (2005) Short retroposons in eukaryotic genomes. Int Rev Cytol 247, $165-221$

76. Stribinskis, V., and Ramos, K. S. (2006) Activation of human long interspersed nuclear element 1 retrotransposition by benzo(a)pyrene, an ubiquitous environmental carcinogen. Cancer Res 66, 2616-2620 

